\author{
UNIVERSIDADE DE SÃO PAULO \\ FACULDADE DE CIÊNCIAS FARMACÊUTICAS \\ Programa de Pós-Graduação em Fármacos e Medicamentos \\ Área de Produção e Controle
}

\begin{abstract}
Abordagem Farmacocinética e Farmacodinâmica no
Monitoramento Terapêutico de Antimicrobianos em

Pacientes Queimados da Unidade de Terapia

Intensiva
\end{abstract}

CRISTINA SANCHES GIRAUD 


\author{
UNIVERSIDADE DE SÃO PAULO \\ FACULDADE DE CIÊNCIAS FARMACÊUTICAS \\ Programa de Pós-Graduação em Fármacos e Medicamentos \\ Área: Produção e Controle
}

\title{
Abordagem Farmacocinética e Farmacodinâmica no Monitoramento Terapêutico de Antimicrobianos em Pacientes Queimados da Unidade de Terapia Intensiva
}

CRISTINA SANCHES GIRAUD

Tese para obtenção do grau de DOUTOR

Orientadora:

Prof $^{\mathrm{a}}$. Dr ${ }^{\mathrm{a}}$. Silvia R. C. J. Santos

São Paulo

2011 


\section{CRISTINA SANCHES GIRAUD}

Abordagem Farmacocinética e Farmacodinâmica no Monitoramento Terapêutico de Antimicrobianos em Pacientes Queimados da Unidade de Terapia Intensiva

Comissão Julgadora

da

Tese para obtenção do grau de Doutor

Profa. Dra. Silvia Regina Cavani Jorge Santos orientador/presidente

\begin{tabular}{c}
\hline $1^{\circ}$. examinador \\
\hline $2^{\circ}$. examinador \\
\hline $3^{\circ}$. examinador \\
\hline $4^{\circ}$. examinador
\end{tabular}

São Paulo, de 
"A premência do tempo ajeita muitas coisas a seus desígnios, decidindo, por vezes, no momento mais grave, o que um processo interminável não pudera fazê-lo" Willian Shakespeare 


\section{DEDICATÓRIA}

À Dudu Princesa, filha amada, fonte inesgotável de amor e força,

nasceu junto com esta tese e me ensina diariamente

o verdadeiro sentido da vida.

Ao Reginaldo, companheiro desta jornada, nossas batalhas nem sempre são fáceis, mas sei que diariamente somos vencedores.

TE AMO.

À Família Sanches (Pedro, Marlene, Rafael e Silvia), pelo apoio, amor e dedicação incondicionais em todos os momentos de minha vida. 


\section{AGRADECIMENTOS}

À Deus, pelas graças concedidas. Talvez ainda seja cedo para entender seus desígnios, mas confio!

À Professora Silvia Regina Cavani Jorge Santos, pelo apoio durante esta caminhada, pelos ensinamentos e conselhos que levarei pela vida. Obrigada por entender!

Á Diretoria da Divisão de Cirurgia Plástica e Queimaduras do HC FMUSP. Em especial, ao Dr. David Souza Gomez, por acreditar e apoiar este trabalho desde o princípio.

Aos intensivistas do Serviço de Queimaduras do HC FMUSP (Dr. Edvaldo Vieira Campos e Dr. Rodrigo Azevedo) pela valiosa parceria na realização deste trabalho.

Ao Dr. Edvaldo, pelos momentos de discussão e aprendizado tão importantes.

Aos amigos do laboratório (Adriana e Carlindo) pelos momentos inesquecíveis que compartilhamos.

À Equipe de Enfermagem e de Residentes (R1) da UTI de Queimados HCFMUSP. A dedicação de vocês são exemplos que levarei pela vida.

Aos pacientes que aceitaram participar deste projeto acadêmico. Espero que de alguma forma, tenhamos contribuído para a melhora da farmacoterapia em queimados.

À Pós-graduação da Faculdade de Ciências Farmacêuticas pela oportunidade de realizar o Doutorado.

À CAPES e à FAPESP, por acreditar e incentivar a pós-graduação e a pesquisa no país.

Aos amigos queridos que torceram por mim durante a realização deste trabalho. 


\section{RESUMO}

Introdução: A sepse é a maior causa de morbidade e mortalidade em pacientes queimados, uma vez que profundas alterações ocorrem na farmacocinética de agentes antimicrobianos prescritos para o controle das infecções. Além disso, pacientes queimados podem apresentar quadro de infecção por germes da comunidade, numa fase precoce de internação na UTI, e devem receber antimicrobianos que diferem daqueles indicados na sepse. Na vigência de infecção fúngica, o quadro se torna ainda mais grave para os pacientes queimados de prolongada internação e imunocomprometidos.

Objetivo: Realizar o monitoramento plasmático de oito antimicrobianos largamente prescritos na UTI, a investigação da farmacocinética e a modelagem PK-PD para o ajuste do regime de dose e controle das infecções em pacientes queimados.

Casuística: Investigaram-se 32 pacientes queimados internados na UTI/Unidade de Queimados - Divisão de Cirurgia Plástica do HC FMUSP, portadores de infecção recebendo pela via sistêmica sete antimicrobianos e um antifúngico.

Métodos- Etapa Clinica: Os pacientes receberam os antimicrobianos geralmente em associação para o controle das infecções seguindo as recomendações da CCIH do hospital relativas ao regime de dose empírica inicial do controle de infecção na UTI de Queimados, na fase precoce e tardia da internação. Realizou-se o monitoramento plasmático do fluconazol, para a infecção fúngica, e dos sete antimicrobianos mais prescritos na UTI para os germes da comunidade e hospitalares (cefepime, ciprofloxacino, imipenem, oxacilina, piperacilina, sulfametoxazol e vancomicina) através das coletas de amostras sanguíneas de pico (termino da infusão) e vale (imediatamente antes da dose subseqüente). Complementarmente, a critério Clínico, foram colhidas amostras seriadas de sangue (pico, $1^{\mathrm{a}}, 2^{\mathrm{a}}, 4^{\mathrm{a}}, 6^{\mathrm{a}}$ e vale), totalizando seis coletas, para investigação da farmacocinética do agente que requereu ajuste de dose e individualização de terapia no paciente queimado. As coletas de sangue foram realizadas através de cateter venoso ( $2 \mathrm{~mL} /$ coleta em tubos contendo EDTA sódico) pelo médico intensivista de plantão na UTI; o plasma foi obtido pela centrifugação para análise do fármaco de interesse ou então armazenado no congelador $\left(-80^{\circ} \mathrm{C}\right)$ até o ensaio.

Métodos - Etapa Analítica: Previamente à realização da Etapa Clínica, foi realizado no Laboratório o desenvolvimento, validação e otimização de método bioanalítico para quantificação dos oito antimicrobianos no plasma. Preferencialmente, as análises foram realizadas no dia da coleta de sangue do paciente, e o "Laudo de Exame" contendo os resultados foi expedido no mesmo dia ou na manhã do dia subseqüente possibilitando a intervenção precoce da Equipe Clínica e se necessária a substituição do regime empírico pela terapia individualizada dose ajustada.

Métodos- Etapa estatística: A estatística propriamente dita foi realizada pelo tratamento estatístico com utilização do software GraphPad Instat 4.0., GraphPad Prism 4.0, pela utilização de testes paramétricos e não paramétricos. A modelagem farmacocinética foi realizada através da aplicação do software NonCompartmental Analysis, PK Solutions 2.0, aos pares de dados (C vs T) para cada antimicrobiano. Adicionalmente, aplicou-se o software GraphPad Prism 4.0 para a modelagem PK-PD, ferramenta importante na tomada de decisão relativa à alteração do regime empírico dos antimicrobianos.

Resultados: Os pacientes queimados incluídos no protocolo eram adultos de ambos os sexos 23F/9M, 39,6 anos, 69,5 kg, 33,9\% SCQ, e os agentes da queimadura foram para 27 pacientes/ térmico-fogo e para três pacientes/trauma elétrico; a lesão inalatória foi registrada em 11/32 pacientes. Foram realizados 303 seguimentos farmacoterapêuticos com a emissão de laudos de exame para os antimicrobianos prescritos aos pacientes nas fases precoce e tardia da internação. O ajuste de dose foi requerido para a vancomicina em $88 \%$ das solicitações de exame, cefepime (65\%), sulfametozaxol (52\%), fluconazol (74\%) e imipenem (19\%). Registrou-se alta variabilidade na farmacocinética para todos os antimicrobianos investigados. Adicionalmente, registrou-se alteração significativa dos parâmetros farmacocinéticos do imipenem, fluconazol, sulfametoxazol e vancomicina nos seguimentos de pacientes queimados com disfunção renal dialítica relativamente aqueles em que se registrou função renal preservada. A modelagem PK-PD para os diversos antimicrobianos se baseou nos parâmetros de predição de eficácia recomendados tais como o intervalo de tempo em que a concentração plasmática permaneceu acima da concentração inibitória mínima (\% $\%$ T> CIM) para o cefepime, imipenem, oxacilina e piperacilina, $A S^{s S}{ }_{0-24} / C I M+C^{s S} \max / C I M$ para 0 ciprofloxacino, $\mathrm{ASC}_{0-24}^{\mathrm{sS}} / \mathrm{CIM}$ para o fluconazol e para a vancomicina e $\mathrm{ASC}_{0-24}^{\mathrm{sS}} / \mathrm{CIM}+\% \Delta \mathrm{T}>$ CIM para a sulfametoxazol. 
Conclusões: Registrou-se alta variabilidade na farmacocinética dos agentes investigados e a modelagem PK-PD justificou plenamente a substituição da terapia empírica inicial pela dose ajustada para a cobertura dos germes sensíveis, daqueles apresentando sensibilidade dose dependente ao antimicrobiano, além daqueles com alto CIM, pouco sensíveis as doses usuais. Finalmente, a modelagem PK-PD mostrou-se definitiva e ferramenta indispensável na manutenção desses agentes no arsenal terapêutico, garantindo terapia eficaz ao paciente queimado, evitando a emergência bacteriana e o desenvolvimento de resistência.

Palavras-chave: queimados, controle das infecções, terapia dose ajustada, monitoramento plasmático, modelagem farmacocinética, PK-PD. 


\section{ABSTRACT}

Introduction: Sepsis is a main cause of morbidity and mortality in burn patients, once pharmacokinetics of antimicrobials prescribed for the control of infections are significantly altered in those patients. In addition, burn patients in the ICU, initially can present infections by community microbial and must receive different antimicrobials than those prescribed for sepsis. On the other hand, burn immunocompromized patients with prolonged staying in the ICU, reincidence of sepsis and fungal infection requires an effective antifungal agent that must be associated to the antimicrobials prescription

Objective: Therapeutic plasma monitoring of eight antimicrobials largely prescribed to burn patients from the ICU, Pharmacokinetic and PK-PD modeling for dose adjustment and for the control of infections.

Study design: Thirty two burn inpatients with infections from the ICU Burns- Division of Plastic Surgery of Clinics Hospital Medical School University of Sao Paulo received systemically antimicrobials/ antifungal agents.

Methods - Clinical Procedures: In general burn patients received several antimicrobial agents as recommended by the Control of Hospital Infection Committee as empirical dose at the beginning of therapy and also afterwards in the ICU. The control of infections by community microbials or yet by hospital microbials, and also for fungal infection, was performed by drug plasma monitoring of cefepime, ciprofloxacin, imipenem, oxacillin, piperacillin, sulphamethoxazole, vancomycin and fluconazole after blood sample collection at the peak and at the trough. Complementary, usually by clinical criteria, six blood sample collections were performed at time dose interval (end of drug infusion, $1^{\text {st }}, 2^{\text {nd }}, 4^{\text {th }}, 6^{\text {th }}$ and at the trough) for pharmacokinetic purposes, dose adjustment and individualization of drug therapy for burn patients. Blood sample collection was done by the physician from the ICU by venous catheter $(2 \mathrm{~mL} /$ each into blood collection tubes sodium EDTA); plasma obtained by centrifugation of blood tubes were analyzed in the same day or in a deep freezer to storage $\left(-80^{\circ} \mathrm{C}\right)$ until assay.

Methods - Analytical Procedures: Previously to the clinical study, in the Laboratory School of Pharmaceutical Sciences was performed the development, validation and optimization of bioanalytical methods for drug plasma monitoring of eight antimicrobial/antifungal agents by HPLC-UV. Drug measurements were performed on the day of blood collection and data were preferentially informed to the physician at the same day or at the early morning of the following day to facilitate the therapeutic intervention and changes on the morning prescription to guarantee drug efficacy.

Methods - Statistics Procedures: Descriptive statistics was performed by applying the software GraphPad Instat v 4.0., GraphPad Prism v.4.0 by parametric and non parametric tests. Pharmacokinetics was estimated by applying the software NonCompartmental Analysis, PK Solutions 2.0, to data (C vs T) for each antimicrobial agent. Additionally, the software GraphPad Prism v 4.0 was applied to PK-PD modeling, an important tool related to dilemma decision about changes on empirical dose of an antimicrobial agent and obviously helps the physician in the rationalization of drug therapy in severe burns.

Results: Burn patients included in the protocol were of both genders 23F/9M, $39.6 \mathrm{yrs}, 69.5 \mathrm{~kg}$, $33.9 \%$ TBSA; agents of the accident were fire/ alcohol for 27 patients and electrical trauma for three patients; inhalation injury were described for 11/32 patients. Approximately 1500 drug plasma measurements for all antimicrobials prescribed to burn patients for the control of infection in the ICU were performed totalizing 303 follow up for pharmacokinetic purposes during the period in the ICU for 32 burn patients. Dose adjustment was required in $88 \%$ of vancomycin prescription, $65 \%$ for cefepime, $52 \%$ for sulphamethoxazole, $74 \%$ for fluconazole e $19 \%$ for imipenem. High pharmacokinetic variability was registered for all agents investigated. In addition, significant changes on pharmacokinetic parameters were described for imipenem, fluconazole, sulphamethoxazole and vancomycin for burn patients with dialytic renal dysfunction compared to those with renal function preserved. PK-PD modeling applied to antimicrobials investigated in the present study was based on predictive parameters recommended like time interval to maintain drug plasma concentration higher than the minimum effective concentration

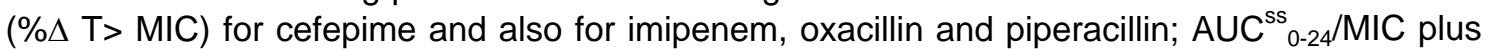
$\mathrm{C}_{\max }^{\mathrm{ss}} / \mathrm{MIC}$ for ciprofloxacin, $\mathrm{AUC}^{\mathrm{ss}}{ }_{0-24} / \mathrm{MIC}$ for fluconazole and vancomycin, and finally, $\mathrm{AUC}^{\mathrm{ss}}{ }_{0}$ ${ }_{24} / \mathrm{MIC}$ plus $\% \Delta \mathrm{T}>\mathrm{MIC}$ for sulphamethoxazole.

Conclusions: High pharmacokinetic variability was obtained for all investigated agents. PK-PD modeling applied could justify definitively the antimicrobial therapy dose adjustment instead the empirical dose regimen. Then, drug efficacy was guaranteed against susceptible microbial, 
spreading to susceptible to antimicrobial dose dependent and also those presenting high value for MIC related to microbial resistance to empiric dose regimen. In conclusion, it was demonstrated that PK-PD modeling of antimicrobials with basis on predictive drug efficacy parameter is definitively an important tool to preserve and safeguard these agents for the control of severe infection in burn patients, to avoid the bacterial emergency and microbial resistance.

Key-words: burns, control of infections, dose adjusted therapy, drug plasma monitoring, pharmacokinetics, PK-PD modeling. 


\section{LISTA DE ILUSTRAÇÕES}

Figura 1 -

Figura 2 -

Estrutura da pele íntegra

Alterações morfológicas apresentadas na lesão de primeiro, segundo e terceiro graus

Figura 3 -

A Regra dos Nove: determinação da superfície corpórea queimada ........ 7

Figura 4 - Ajuste de dose requerido no paciente queimado durante o seguimento (painel à esquerda) Terapia dose ajustada requerida para os pacientes queimados (\%); (painel à direita) Indicação de controle terapêutico para antimicrobianos nos pacientes queimados, expressos em percentagem do total relativamente ao antimicrobiano plasmático monitorado.

Figura 5 - Dose diária de cefepime $(\mathrm{g})$ versus Vale $(\mu \mathrm{g} / \mathrm{mL})$ : Ajuste de dose em pacientes queimados internados na UTI do HCFMUSP total de 10 seguimentos. CIM: concentração inibitória mínima $(1,2$, 4 e $8 \mu \mathrm{g} / \mathrm{mL})$............ 39

Figura 6 - Dados individuais para as constantes farmacocinéticas do cefepime. Faixa de referência: Meia Vida (2hs); Depuração Plasmática (1,7-2,0 $\mathrm{mL} / \mathrm{min} . \mathrm{kg})$; Volume de Distribuição $(0,2-0,3 \mathrm{~L} / \mathrm{kg})$

Figura 7 - Modelagem PK-PD para o cefepime ( $\% \Delta T>C I M)$ em pacientes queimados, dados expressos através das médias

Figura 8 - Concentração plasmática de vale para o ciprofloxacino (acima de $0,5 \mu \mathrm{g} / \mathrm{mL}$ ): Monitoramento plasmático de ciprofloxacino em pacientes queimados internados na UTI do HCFMUSP.

Figura 9 - Dados individuais para as constantes farmacocinéticas do ciprofloxacino Faixa de referência: Meia Vida (3-6hs); Depuração Plasmática (4,3 $\mathrm{mL} / \mathrm{min} . \mathrm{kg})$; Volume de Distribuição $(1,2-2,7 \mathrm{~L} / \mathrm{kg})$........................................ 44

Figura 10 - Modelagem PK-PD para o ciprofloxacino ( $C_{\max }^{s s}$ e ASC ${ }_{0-24 \mathrm{hs}}^{\text {sobre } C I M) ~ e m ~}$ pacientes queimados.

Figura 11 - Alteração do regime de dose empírica de Fluconazol, 400mg ao dia no total de 31 seguimentos realizados em 12 pacientes. ......................................... 46

Figura 12 - Vale de concentração plasmática de fluconazol. Monitoramento das concentrações plasmáticas em sete pacientes queimados internados na UTI do HCFMUSP com função renal normal.

Concentração plasmática de fluconazol no vale $(\mu \mathrm{g} / \mathrm{mL})$ : Ajuste de dose em seis pacientes queimados internados na UTI do HCFMUSP com insuficiência renal dialítica. ................................................................. 48

Figura 14 - Comparação dos parâmetros farmacocinéticos do Fluconazol para os pacientes com função renal normal e pacientes dialíticos (mediana/+ IC95\%) $\mathbf{5 1}$

Figura 15 - Modelagem PK-PD para o fluconazol (ASC ${ }_{24 \mathrm{hs}}^{\mathrm{ss}} / \mathrm{CIM}$ ) em pacientes queimados. ................................................................................... 52

Figura 16 - Indicação de terapia dose ajustada com alteração do regime de dose empírica de Imipenem. ................................................................................. 53

Figura 17 - Alteração do regime de dose empírica de Imipenem no seguimento de pacientes queimados (A) com função renal normal, $n=47$ seguimentos; (B) pacientes que evoluíram para insuficiência renal dialítica, $n=28$ seguimentos. 54

Figura 18 - Farmacocinética do imipenem nos seguimentos de pacientes com FRN e em diálise, resultados expressos através da mediana e a dispersão IC95\% intervalo de confiança.

Figura 19 - Modelagem PK-PD para o imipenem (\% $\Delta \mathrm{T}>\mathrm{CIM})$ em pacientes queimados... 58

Figura 20 - Concentração plasmática de oxacilina no vale $(\mu \mathrm{g} / \mathrm{mL})$ : Ajuste de dose em dois pacientes queimados internados na UTI do HCFMUSP. Dose diária para o \#12 de $6000 \mathrm{mg}$ e de 4000mg para \#20. CIM: concentração inibitória mínima, valor de referência $2 \mathrm{mg} / \mathrm{L}$.

Figura 21 - Dados individuais para as constantes farmacocinéticas da oxacilina. Faixa de referência: Meia Vida (0,38-0,75hs); Depuração Plasmática $(5,4 \mathrm{~mL} / \mathrm{min} . \mathrm{kg})$; Volume de Distribuição $(0,39-0,43 \mathrm{~L} / \mathrm{kg})$

Figura 22 - Modelagem PK-PD para a oxacilina (\% $\% \mathrm{~T}>\mathrm{CIM})$ em pacientes queimados, dados individuais $(n=5)$.........................................................................

Figura 23 - Concentração plasmática de piperacilina no vale $(\mu \mathrm{g} / \mathrm{mL})$ : Ajuste de dose em 07 pacientes queimados internados na UTI do HCFMUSP. Dose diária de 
$12000 \mathrm{mg} / \mathrm{dia}$.

Figura 24 - Dados individuais para as constantes farmacocinéticas da piperacilina. Faixa de referência: Meia Vida (0,7-1,2hs); Depuração Plasmática (1,9 mL/min.kg); Volume de Distribuição $(0,14-0,22 \mathrm{~L} / \mathrm{kg})$

Figura 25 - Modelagem PK-PD para a piperacilina $(\% \Delta T>C I M)$ em pacientes queimados, dados expressos através das médias.

Figura 26 - Concentração plasmática de sulfametoxazol no vale $(\mu \mathrm{g} / \mathrm{mL})$ : Ajuste de dose em 05 pacientes queimados internados na UTI do HCFMUSP com função renal normal.

Figura 27 - Concentração plasmática de sulfametoxazol no vale $(\mu \mathrm{g} / \mathrm{mL})$ : Ajuste de dose em pacientes queimados internados na UTI do HCFMUSP com insuficiência renal dialítica.

Figura 28 - Comparação dos parâmetros farmacocinéticos do Sulfametoxazol para os pacientes com função renal normal e pacientes dialíticos (mediana; IC95\%) .. $\mathbf{7 0}$

Figura 29 - Modelagem PK-PD para o sulfametoxazol - (A)ASC ${ }_{24 h s}^{\text {ss }} / \mathrm{CIM}$ e (B) \%T>CIM em pacientes queimados.

Figura 30 - Necessidade de alteração do regime de dose empírica da Vancomicina para terapia dose ajustada num total de 147 seguimentos de 31 pacientes queimados com FRN e IR

Figura 31 - Alteração do regime de dose para individualização de terapia da Vancomicina num total de 147 seguimentos de 31 pacientes queimados

Figura 32 - Alteração do regime de dose de Vancomicina em pacientes queimados, com função renal normal $(A)$ e insuficiência renal dialítica (B). ACM: a critério médico e administração com base no vale.

Figura 33 - Comparação dos parâmetros farmacocinéticos da Vancomicina para os pacientes com função renal normal e pacientes dialíticos (mediana; IC95\%) $\quad 77$

Figura 34 - Modelagem PK-PD para a vancomicina (ASC ${ }_{0-24 h s}^{s s} / \mathrm{CIM}$ ) em pacientes queimados.

Fluxograma 1 Terapia antimicrobiana empírica para pacientes grandes queimados HCFMUSP. Fonte: Guia de Utilização de Antimicrobianos e recomendações para a prevenção de infecções hospitalares, HCFMUSP, 2007-2008

Ilustração 1 Curva de concentração plasmática versus tempo: parâmetros PK/PD...... 


\section{LISTA DE QUADROS E DIAGRAMAS}

Quadro 01 - Farmacocinética de antimicrobianos em pacientes

Quadro 02 - $\quad$ Farmacodinâmica e correlação com a eficácia de antimicrobianos................. 23

Quadro 03 - $\quad$ Características dos pacientes investigados, dados individuais........................ 27

Quadro 4- Protocolo empírico de administração de antimicrobianos ao paciente, HCFMUSP, 2008............................................................................ 30

Quadro 5 Parâmetros farmacocinéticos após infusão múltipla no estado de equilíbrio.......................................................................... 32

Diagrama 01 - Alterações Farmacocinéticas registradas na sepse....................................... 20

Diagrama 02 - Critérios para Terapêutica Empírica Sistêmica em pacientes grande queimados. 


\section{LISTA DE TABELAS}

Tabela 1 -

Tabela 2 -

Tabela 3 -

Tabela 4 -

Tabela 5 Tabela 6 -

Tabela 7 -

Tabela 8 -

Tabela 9 -

Tabela 10 .

Tabela 11 -

Tabela 12 -

Tabela 13 -

Tabela 14 -

Tabela 15 -

Tabela 16 -

Tabela 17 -

Tabela 18 -

Tabela 19 -

Tabela 20 -

Tabela 21 -

Tabela 22 -

Tabela 23 -

Tabela 24 -

Tabela 25 -
Caracterização da população de pacientes queimados investigados

Paciente queimado tratado com antimicrobiano e antifúngico

Parâmetros farmacocinéticos registrados para o cefepime

Modelagem PK/PD expressa através do período de tempo $(\% \Delta T)$ requerido para manutenção da concentração plasmática do cefepime acima da concentração inibitória mínima obtida in vitro $(\% \Delta T>C I M), n=10$ seguimentos em três pacientes

Parâmetros farmacocinéticos registrados para o ciprofloxacino

Modelagem PK/PD expressa através da relação entre $C_{\text {max }}^{s s}$ e $A S C_{0-24 h s}^{s S}$ versus a CIM, $n=6$ seguimentos em três pacientes, regime $200 \mathrm{mg} 12 / 12 \mathrm{hs} . .$.

Meia vida biológica do fluconazol, $\mathrm{n}=31$

Depuração plasmática do fluconazol $n=31$

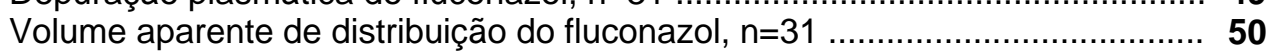

Farmacocinética do fluconazol em queimados com infecção fúngica, $n=31$ seguimentos

Meia vida biológica de Imipenem, $\mathrm{n}=75$.

Depuração plasmática de Imipenem, $\mathrm{n}=75$

Volume aparente de distribuição de Imipenem, $n=75$

Farmacocinética do imipenem em queimados com sepse, $\mathrm{n}=75 \ldots \ldots \ldots \ldots \ldots \ldots \ldots . .56$

Parâmetros farmacocinéticos registrados para a oxacilina ( $n=5$ seguimentos em dois pacientes)

Disposição cinética de piperacilina $(n=10)$ para manutenção da concentração plasmática da piperacilina acima da concentração inibitória mínima obtida in vitro (\% $\% \mathrm{~T}>\mathrm{CIM}), \mathrm{n}=10$ seguimentos em sete pacientes

Meia vida biológica de Sulfametoxazol, $\mathrm{n}=19$

Depuração plasmática de Sulfametoxazol, $n=19$

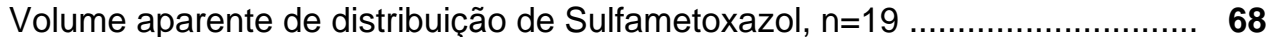

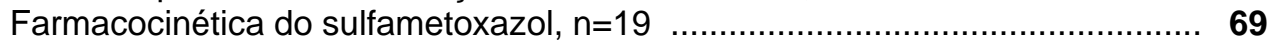

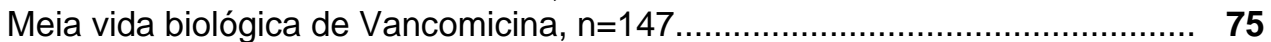

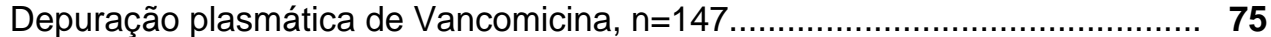

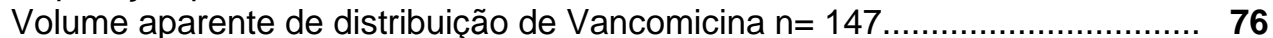

Farmacocinética vancomicina em queimados com sepse, $n=147$ seguimentos 76 


\section{LISTA DE SIGLAS E ABREVIATURAS}

$\% \Delta \mathrm{T}>\mathrm{CIM}$ Porcentagem do tempo em que as concentrações plasmáticas do antimicrobiano encontram-se acima do CIM

\begin{tabular}{|c|c|}
\hline$\mu \mathrm{L}$ & Microlitros \\
\hline $\mathrm{ASC}_{0-24}^{\mathrm{SS}}$ & Área sobre a curva no intervalo $0-24 \mathrm{hs}$ \\
\hline CEP & Comitê de ética em pesquisa \\
\hline CIM & Concentração inibitória mínima \\
\hline CLAE & Cromatografia líquida de alta eficiência \\
\hline CLAE-UV & Cromatografia Líquida de Alta Eficiência - Ultravioleta \\
\hline $\mathrm{CL}_{\mathrm{CR}}$ & Clearance de creatinina \\
\hline $\mathrm{CL}_{\mathrm{T}}$ & Depuração total do fármaco \\
\hline CQ & Controle de Qualidade \\
\hline CQA & Controle de qualidade alto \\
\hline CQB & Controle de qualidade baixo \\
\hline CQM & Controle de qualidade médio \\
\hline $\mathrm{Cr}$ & Creatinina \\
\hline $\mathrm{C}^{\mathrm{ss}}{ }_{\operatorname{Max}}$ & Concentração máxima no estado de equilíbrio \\
\hline CV\% & Coeficiente de Variação \\
\hline DP & Desvio padrão \\
\hline EDTA & Etilenodiaminotetracético sal sódico \\
\hline G & Grama \\
\hline $\mathrm{H}$ & Hora \\
\hline IC95\% & Intervalo de Confiança 95\% \\
\hline IMC & Índice de Massa Corpórea \\
\hline $\mathrm{Kg}$ & Quilograma \\
\hline $\mathrm{L}$ & Litros \\
\hline LD & Limite de detecção \\
\hline LI IC95\% & Limite inferior do intervalo de confiança 95\% \\
\hline LQ & Limite de quantificação \\
\hline LS IC95\% & Limite superior do intervalo de confiança 95\% \\
\hline M & Metro \\
\hline M & Molar \\
\hline $\mathrm{m}^{2}$ & Metro quadrado \\
\hline $\mathrm{Mg}$ & Miligrama \\
\hline Min & Minutos \\
\hline $\mathrm{Ml}$ & Mililitro \\
\hline $\mathrm{Mm}$ & Milímetro \\
\hline MOPS & Ácido 3-(N-morfolino)-propano-sulfônico \\
\hline $\mathrm{N}_{2}$ & Nitrogênio \\
\hline NAP & Não aplicável \\
\hline ND & Não detectado \\
\hline $\mathrm{Nm}$ & Nanômetro \\
\hline $\mathrm{P}$ & Significância estatística \\
\hline $\mathrm{Pi}$ & Padrão Interno \\
\hline$r^{2}$ & Coeficiente de correlação linear \\
\hline RA & Razão da área \\
\hline Rpm & Rotações por minuto \\
\hline SCQ & Superfície corpórea queimada \\
\hline
\end{tabular}


Scr

$\mathrm{T}_{1 / 2 \beta}$

TCLE

UTI

UV

$\mathrm{v} / \mathrm{v}$

$\mathrm{Vd}$

Vmax

Vmin
Creatinina sérica

Meia-vida biológica

Termo de consentimento livre e esclarecido

Unidade de Terapia Intensiva

Ultravioleta

Volume por volume

Volume aparente de distribuição

Valor máximo

Valor mínimo 


\section{SUMÁRIO}

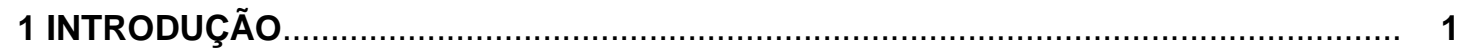

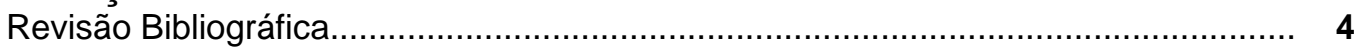

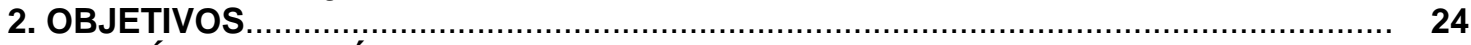

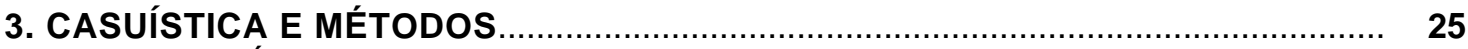

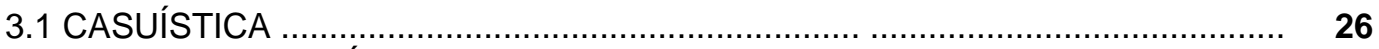

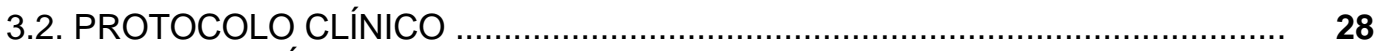

3.3. ETAPA ANALÍTICA …...................................................................... 30

3.4 ETAPA ESTATÍSTICA ……....................................................... 34

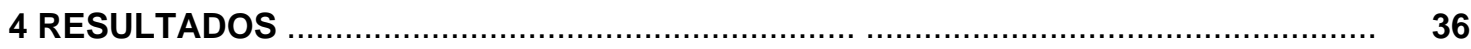

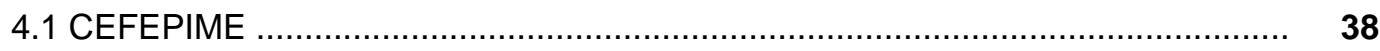

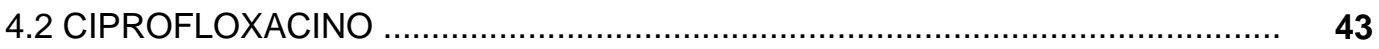

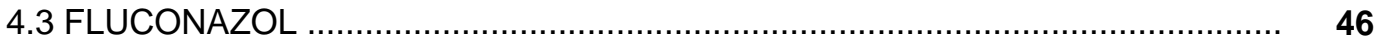

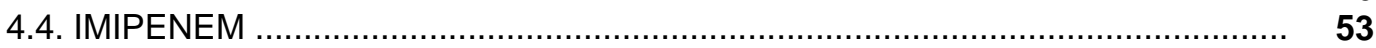

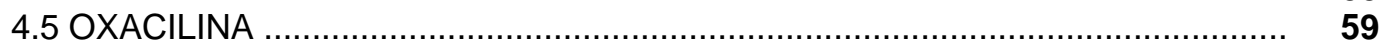

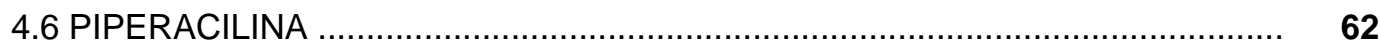

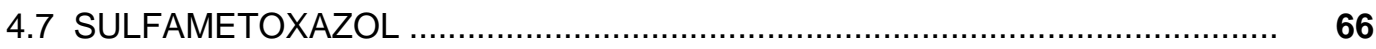

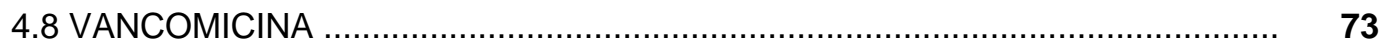

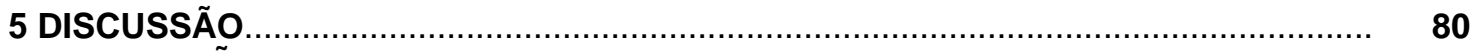

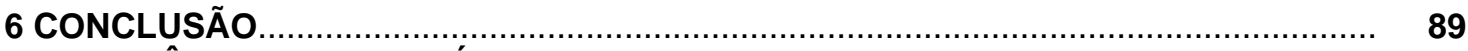

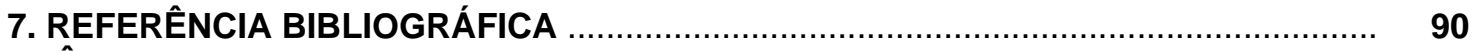

APÊNDICE I ANEXOS.

Apêndice I - Desenvolvimento e Validação de Metodologia analítica.

Anexo I - Propriedades Moleculares e Farmacocinéticos dos Antimicrobianos

Anexo II - Aprovação do Comitê de Ética em Pesquisa FCF/USP

Anexo III - Aprovação CAPEPesq HCFMUSP

Anexo IV - Termo de Consentimento Livre e Esclarecido (TCLE) 


\section{INTRODUÇÃO}

As concentrações sub-terapêuticas de um antimicrobiano podem levar à ineficácia no tratamento do paciente e ao surgimento da resistência bacteriana (HIRAMATSU et al, 1998). Pacientes em estado crítico, sob situação de "stress", estado hiperdinâmico, ou em sepse, apresentam alterações na farmacocinética de antimicrobianos, de forma geral, com aumento do volume de distribuição e redução da meia vida biológica (FRY et al, 1996). Por outro lado, naqueles em estado crítico, incluem-se os pacientes seriamente queimados. Garrelts \& Peterie, (1988) investigaram grupo de pacientes recebendo infusão intermitente que requereu dose mais elevada de vancomicina para manter as concentrações plasmáticas efetivas. Dessa forma, em vista da alteração na farmacocinética, esses autores consideram importante a realização do controle terapêutico da vancomicina para o ajuste do regime posológico e garantia da eficácia.

Adicionalmente, após uma lesão térmica, todos os órgãos e sistemas, entre eles, o cardiovascular, rins e o fígado, sofrem mudanças fisiopatológicas dinâmicas, devendo-se esperar então uma alteração profunda na farmacocinética de todos os antimicrobianos de administração sistêmica no paciente grande queimado (BOUCHER et al, 1992).

Após a ocorrência da queimadura existe uma maior incidência de sepse quando comparada a outros tipos de trauma. Dentre os motivos da susceptibilidade às infecções nos queimados destacam-se a perda da primeira linha de defesa contra a invasão microbiana causada pelo rompimento da barreira da pele, a presença de tecido desvitalizado (escara do queimado) que proporciona um ambiente favorável para o crescimento bacteriano e de fungos, as alterações nos componentes específicos e não específicos do sistema imune, seguido da lesão térmica, e as alterações na resposta imune celular e humoral (BOUCHER et al, 1992; BANG et al, 1998). Todos estes fatores contribuem para o aparecimento de resistência, associada à necessidade de antimicrobianos muitas vezes em dose inadequada, uma vez que o regime empírico de dosagem baseado na 
idade, peso e função renal dentre outros, não é seguro nem efetivo no paciente queimado.

Relativamente ao monitoramento plasmático e à farmacocinética de antimicrobianos nestes pacientes, a literatura disponível é muito escassa. Recentemente, López e colaboradores (2007) reportaram o monitoramento plasmático de três antimicrobianos prescritos no controle da sepse de pacientes grandes queimados. Os autores desenvolveram e validaram método analítico robusto e de alta sensibilidade utilizando a cromatografia líquida de alta eficiência (CLAE-UV) para determinação simultânea do cefepime, imipenem e da vancomicina no plasma; a aplicação do método possibilitou o monitoramento terapêutico de dois pacientes queimados portadores de sepse recebendo vancomicina e cefepime ou vancomicina e imipenem sugerindo falha terapêutica nos dois pacientes para a vancomicina e para ao cefepime. Considera-se, desta forma, que a literatura não dispõe de resultados consistentes até o momento relativamente à farmacocinética dos antimicrobianos utilizados nos pacientes grandes queimados.

O protocolo de terapia antimicrobiana para o controle de infecções recomendado, no Hospital das Clínicas da Faculdade de Medicina da Universidade de São Paulo, para pacientes queimados até $72 \mathrm{hs}$ de internação e sem uso prévio de antimicrobiano é constituído por oxacilina e ciprofloxacino. Por outro lado, após $72 \mathrm{hs}$ de internação ou uso prévio de antimicrobiano propõe-se para o controle dos germes hospitalares a utilização de vancomicina e ciprofloxacina. A conduta após 48hs na reavaliação ou presença de piora importante é prescrever imipenem e vancomicina. Subsequentemente, na reavaliação após 48hs ou piora importante do quadro infeccioso do paciente, a conduta é associar anfotericina B ou fluconazol (HCFMUSP, 2009-2011).

Em alguns casos o cefepime vem sendo utilizado em associação à vancomicina ao invés do imipenem. Por outro lado, visando aumentar o espectro de ação antimicrobiana, e para os pacientes que apresentaram convulsões, recomenda-se substituir o cefepime pela piperacilina/tazobactam. Nos casos de reinfecções e/ou fungemia utiliza-se adicionalmente a 
linezolida, polimixina B ou E, caspofungina dependendo da cepa isolada e/ou das condições clínicas do paciente (HCFMUSP, 2009-2011).

Os pacientes grandes queimados envolvem um grupo bastante heterogêneo em função do tipo da queimadura e extensão da lesão. Por outro lado, esperam-se variações interpacientes significativas nas concentrações plasmáticas desses antimicrobianos em função da variabilidade imprevisível da farmacocinética. Em adição, deve-se considerar ainda a variabilidade intrapaciente para o grande queimado nos diferentes seguimentos do tratamento, em função da profundidade e extensão da lesão ativa, da alteração de compartimentos fluidos, do grau de integridade das barreiras e da maior ou menor perda de líquidos através das lesões. Todos esses fatores levam a uma imprevisibilidade da dose requerida pelo paciente para se manter concentrações adequadas de cada antimicrobiano prescrito (GARRELTS \& PETERIE, 1988; WEINBREN, 1999).

Desta forma, utilizou-se no presente estudo a modelagem farmacocinética e farmacodinâmica a partir do monitoramento das concentrações plasmáticas dos antimicrobianos utilizados na unidade de terapia intensiva para adequação do regime de dose e garantia da terapia efetiva nos pacientes queimados. 


\subsection{Revisão Bibliográfica}

A pele é um órgão essencial para a sobrevivência que apresenta a função principal de proteção (DE SANTI, 2005; KECK et al, 2009).

A camada superior da epiderme é constituída por células mortas e queratina formando uma barreira contra bactérias e toxinas do ambiente. As células basais são fonte de novas células epidérmicas. A superfície ondulada da epiderme conhecida como invaginação, aumenta a aderência da epiderme à derme através da membrana basal. A camada dérmica possui inúmeras funções essenciais, incluindo a restauração contínua da epiderme; encontra-se classificada em papilar e reticular. A primeira apresenta-se mais bioativa que a segunda, o que leva à conseqüente diferença no tempo de reabilitação de acordo com a profundidade da queimadura, pois os componentes papilares são perdidos em queimaduras mais profundas (DE SANTI, 2005; KECK et al, 2009), figura 1.

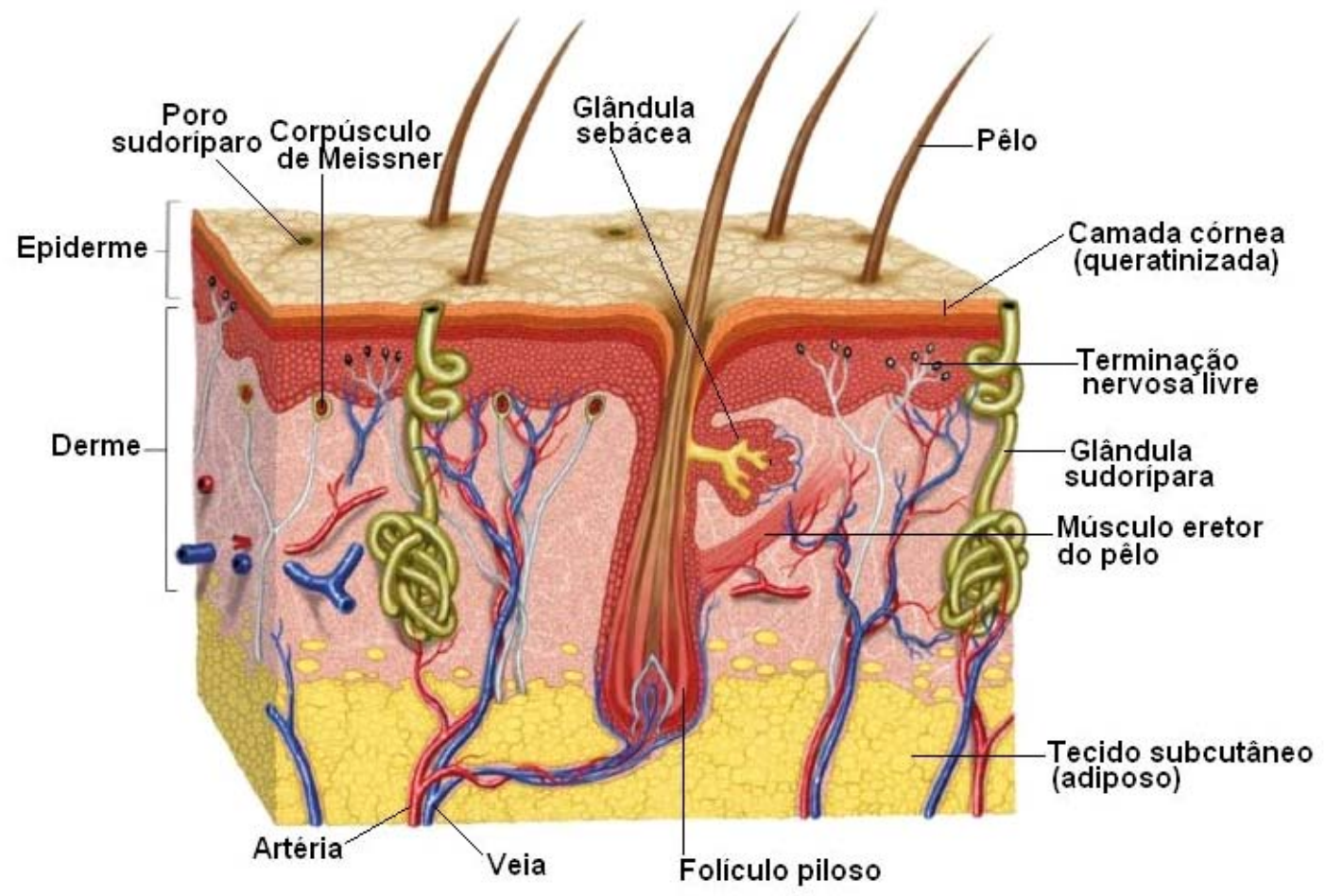

Figura 1. Estrutura da pele íntegra 
Através do Projeto Diretrizes da Associação Médica Brasileira e do Conselho Federal de Medicina (AMB, 2008), a Sociedade Brasileira de Cirurgia Plástica (SBCP) define as queimaduras como

"Lesões dos tecidos orgânicos em decorrência de trauma de origem térmica resultante da exposição a chamas, líquidos quentes, superfícies quentes, frio, substâncias químicas, radiação, atrito ou fricção".

Devemos salientar que nesta definição não se consideraram as queimaduras resultantes do trauma elétrico.

A história natural do paciente com queimadura é sombria, pois o principal agravante é o choque em decorrência da queimadura (burn shock) durante os primeiros dias pós-lesão térmica. Subseqüentemente, durante as primeiras semanas segue-se uma fase de risco aumentado de sepse, e finalmente em decorrência de contrações e epitelização do tecido resultam as deformidades pós-queimaduras (SHERIDAN, 2002).

De acordo com a Sociedade Americana de Queimaduras, 500.000 pessoas receberam tratamento em 2007 para queimaduras nos Estados Unidos, gerando 40.000 hospitalizações e 4.000 mortes por fogo. Entre 1995 e 2005 observou-se taxa de sobrevida destes pacientes de 94,4\%, sendo estes $70 \%$ do sexo masculino, $10 \%$ com superfície corpórea queimada (SCQ) maior que $30 \%$, sendo as principais causas da queimadura: fogo $(46 \%)$, escaldo $(32 \%)$, objetos quentes $(8 \%)$, elétrico (4\%), químico (3\%) entre outros (6\%) (ABA, 2009).

Felizmente, nos últimos 20 anos observou-se uma redução de $50 \%$ nas mortes e hospitalizações relacionadas à queimadura. Tal fato se deve principalmente à prevenção e avanços na terapia. Este último, por sua vez, deve-se ao melhor entendimento da resposta fisiopatológica desenvolvida após uma queimadura o que leva à maior eficácia na ressuscitação, tratamento cirúrgico agressivo, melhor cobertura da ferida, melhor suporte à resposta hipermetobólica, controle mais apropriado da dor e infecção e melhora do tratamento da lesão inalatória (KECK et al, 2009; DE SANTI, 2005). 
A gravidade da lesão pode ser determinada a partir da profundidade, tamanho, localização e idade do paciente. Sendo a última o fator de maior determinação de prognóstico: lactentes e idosos apresentam maior taxa de mortalidade do que as demais faixas etárias (DE SANTI, 2005).

\section{Classificação}

A Sociedade Brasileira de Cirurgia Plástica divide o diagnóstico das queimaduras quanto (AMB, 2008):

1 - Agente Etiológico:

- Queimaduras térmicas;

- Queimaduras químicas;

- Queimaduras elétricas;

- Queimaduras por radiação;

- Queimaduras por atrito;

- Outras.

2 - Profundidade (Figura 2):

- Primeiro grau: Lesões da epiderme apenas, espessura parcial superficial.

- Segundo grau: Lesões da epiderme e parte da derme, espessura parcial profunda. Registra-se o aparecimento de bolhas.

- Terceiro grau: Lesões da epiderme e da derme, espessura total.

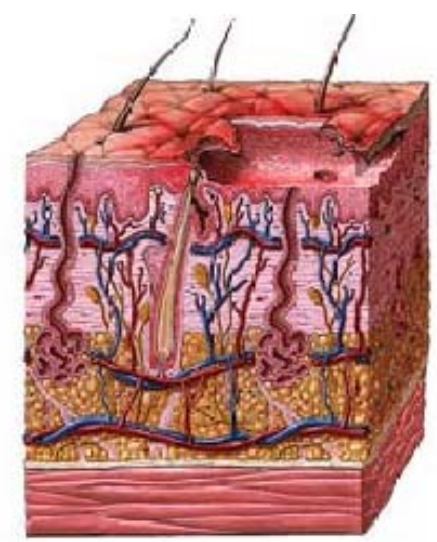

$1^{\circ}$ Grau

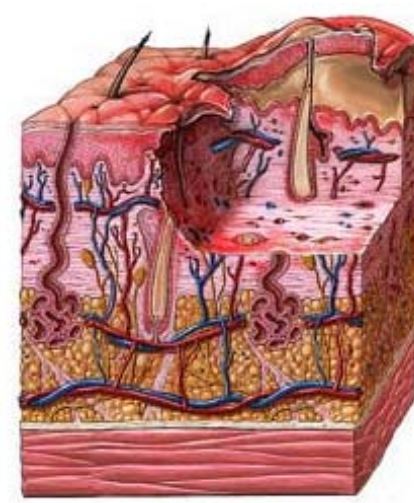

$2^{\circ}$ Grau

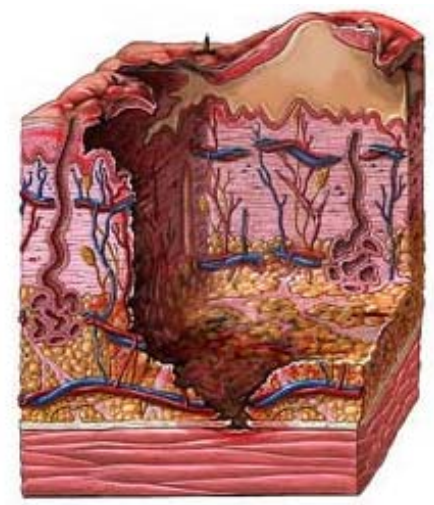

$3^{\circ}$ Grau

Figura 2. Alterações morfológicas apresentadas na lesão de primeiro, segundo e terceiro graus. 
3 - Quanto à superfície corpórea queimada que deve ser estimada de acordo com a extensão da queimadura e as regiões afetadas (Figura 3).

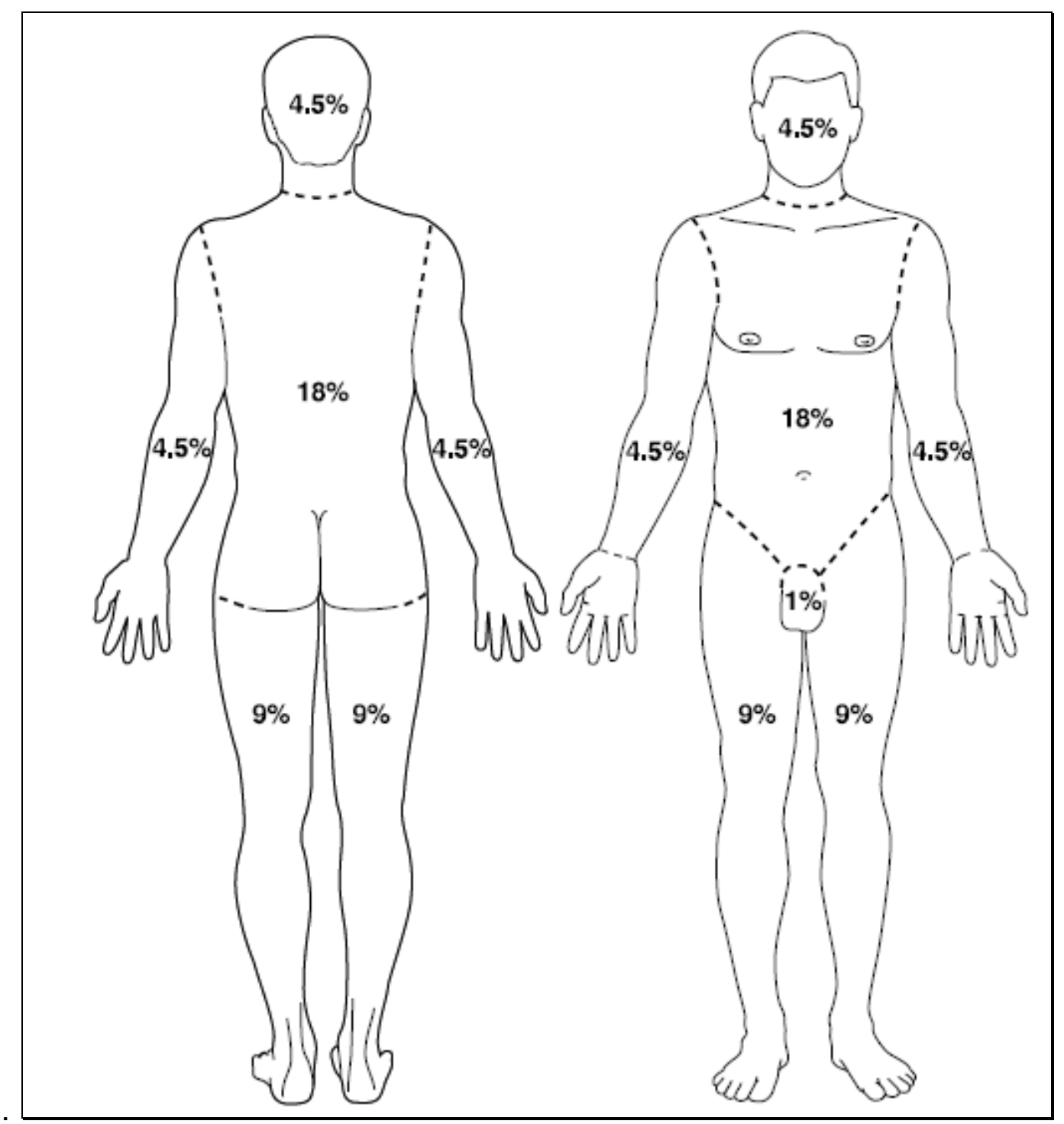

Figura 3: A Regra dos Nove: determinação da superfície corpórea queimada. Fonte: De Santi, 2005.

4 - Quanto à complexidade da queimadura deve ser estimada com base na superfície corporal queimada e na profundidade da lesão. As porcentagens utilizadas para caracterizar cada classe quanto à complexidade são controversas de acordo com a literatura utilizada, porém, de acordo com a Diretriz, esses percentuais determinam e diferenciam o pequeno, médio e grande queimado, conforme abaixo referido.

- Pequeno queimado 
o queimaduras de primeiro grau em qualquer extensão, e/ou,

o queimaduras de segundo grau com área corporal atingida até $5 \%$ em crianças menores de 12 anos e $10 \%$ em maiores de 12 anos.

- Médio queimado

- queimaduras de segundo grau com área corporal atingida entre $5 \%$ a $15 \%$ em menores de 12 anos e $10 \%$ e $20 \%$ em maiores de 12 anos, ou

o queimaduras de terceiro grau com até $10 \%$ da área corporal atingida em adultos, quando não envolver face ou mão ou períneo ou pé, e menor que $5 \%$ nos menores de 12 anos, ou

o qualquer queimadura de segundo grau envolvendo mão ou pé ou face ou pescoço ou axila.

- Grande queimado

o queimaduras de segundo grau com área corporal atingida maior do que $15 \%$ em menores de 12 anos ou maior de $20 \%$ em maiores de 12 anos, ou

o queimaduras de terceiro grau com mais de $10 \%$ da área corporal atingida no adulto e maior que 5\% nos menores de 12 anos, ou

o queimaduras de períneo, ou

o queimaduras por corrente elétrica, ou

o queimaduras de mão ou pé ou face ou pescoço ou axila que tenha terceiro grau, ou

o lesão inalatória, politrauma, trauma craniano, choque de qualquer origem, insuficiência renal, insuficiência cardíaca, insuficiência hepática, diabetes, distúrbios da coagulação hemostasia, embolia pulmonar, infarto agudo do miocárdio, quadros infecciosos graves decorrentes ou não da queimadura, síndrome compartimental, doenças consuptivas ou qualquer outra 
afecção que possa ser fator de complicação à queimadura.

\section{Fisiopatologia}

A resposta local à queimadura envolve tanto a coagulação do tecido quanto reações microvasculares da derme (SHERIDAN, 2002).

A perda da função de barreira da pele leva às complicações mais comuns da queimadura com destaque para as infecções, perda de calor, aumento da perda de água e mudança nas funções de interação sociais como aparência e toque (SHERIDAN, 2002; KECK et al, 2009).

A perda primária de tecido ocorre como resultado da desnaturação protéica. Este processo é rapidamente acompanhado pela ativação dos mediadores inflamatórios; agentes oxidantes e proteases causam danos adicionais à pele e às células endoteliais capilares, potencializando a necrose tecidual isquêmica. O rompimento da ligação do colágeno leva à desregulação do gradiente de pressão osmótico e hidrostático, resultando em edema local e grande perda de fluidos. Ao nível molecular, tanto a ativação do complemento quanto a estimulação dos neutrófilos intravasculares resultam na produção de radicais livres. O aumento da atividade histamínica, somado às propriedades catalíticas da xantina oxidase, levam ao aumento progressivo da permeabilidade vascular. Além disto, os subprodutos tóxicos da xantina oxidase, incluindo o peróxido de hidrogênio e radical hidroxila, promovem dano direto nas estruturas dérmicas (KECK et al, 2009).

A resposta sistêmica é uma conseqüência das alterações descritas acima. Quando o tamanho da queimadura excede $20-30 \%$ da superfície corpórea, ocorre o aparecimento do edema intersticial em órgãos e tecidos moles, secundário à liberação de mediadores e hipoproteinemia (SHERIDAN, 2002). Este edema é aumentado pelo procedimento de ressuscitação, tornando-se uma complicação séria, pois reduz a difusão de oxigênio no tecido levando à isquemia em células já comprometidas, com fluxo sanguíneo reduzido e, conseqüentemente, aumenta o risco de infecções (KECK et al, 2009). 
Além disto, lesões cutâneas que representem mais de $1 / 3$ da superfície corpórea do paciente resultam invariavelmente em burn shock, devido tanto à hipovolemia quanto aos mediadores da inflamação, com efeitos na microcirculação e no funcionamento do coração, veias de grande calibre e pulmões. Mesmo que a hipovolemia seja corrigida, ocorre um aumento na resistência pulmonar e vascular sistêmica e a depressão do miocárdio independentemente do aumento de volume. Tal disfunção cardiovascular pode acentuar ainda mais a resposta inflamatória permanecendo desta forma num circulo vicioso e acelerando a disfunção orgânica (KECK et al, 2009).

Após a fase de ressuscitação, ocorre uma resposta hipermetabólica com duplicação do débito cardíaco e do gasto de energia, aumento da gliconeogenese, de resistência à insulina e do catabolismo protéico. Estas reações ainda não são bem conhecidas, mas acredita-se que se deve a uma combinação de fatores incluindo as mudanças na função hipotalâmica, aumento na secreção do glucagon, de cortisol e das catecolaminas, disfunção na barreira gastrointestinal e translocação, crescimento bacteriano no tecido queimado e perda de calor através da lesão (SHERIDAN, 2002).

\section{Tratamento}

O tratamento do paciente é realizado em duas etapas (AMB, 2008):

- Tratamento sintomático (medicamentoso): reposição hidroeletrolítica, transfusão sanguínea, antibioticoterapia, analgesia.

- Tratamento da lesão (cirúrgico):

o Desbridamento cirúrgico é indicado praticamente em todos os casos de queimaduras de segundo e terceiro graus. Deve ser realizado no centro cirúrgico, sob anestesia. Envolve a retirada mecânica de todo o tecido necrótico (epiderme/derme) além da remoção de contaminantes como restos de roupa, medicamentos caseiros, etc, bem como a limpeza cuidadosa da lesão queimada. O desbridamento é seguido por curativos com ou sem anestesia, em intervalos de 12 até 24-36 horas, dependendo da extensão e da gravidade da lesão. 
o Enxerto é realizado para se obter o fechamento da ferida de terceiro grau. Pode ser realizado imediatamente após a excisão, ou mais tardiamente, em feridas que evoluíram com tecido de granulação.

o Reconstrução da área lesionada.

É importante destacar os substitutos de pele (Skin substitutes), com grande valor no tratamento e recuperação do paciente; a alta efetividade, melhora da qualidade e redução no tempo de internação foram amplamente discutidas na literatura (DE SANTI, 2005). Porém, no Brasil, e principalmente na rede pública que concentra a maioria dos pacientes vítimas de queimaduras, este tratamento ainda não se encontra acessível, com exceção da pele de cadáver. Tal fato faz com que o perfil do paciente queimado no Brasil seja diferente daquele reportado até o momento na literatura.

\section{Farmacocinética Clínica}

A Farmacocinética Clínica é definida pela ASHP (American Society of Health System Pharmacist) como um processo para determinar o esquema de dose de um fármaco para um paciente específico, aplicando os princípios farmacocinéticos. Visa obter efeito farmacoterapêutico máximo e adverso mínimo. Apresenta como vantagens a redução da mortalidade, morbidade, tempo de tratamento, tempo de hospitalização e efeitos adversos (DASGUPTA, 2008; SANTOS, 2008; ASHP, 1998).

A aplicação dos princípios farmacocinéticos requer o entendimento das características de absorção, distribuição, metabolismo e excreção de cada fármaco estudado, de cada doença e das populações de pacientes. Além disto, a influência de fatores como a idade, sexo, genética, dieta, condições fisiopatológicas e o uso concomitante de outros medicamentos também deve ser levado em conta (ASHP, 1998; DASGUPTA, 2008; SANTOS, 2008; KANG \& LEE, 2009).

Em 2007, a Sociedade Brasileira de Farmacêuticos Hospitalares (SBRAFH) em conjunto com o Conselho Federal de Farmácia (CFF), 
lançou cartilha intitulada "Padrões mínimos para farmácia hospitalar e serviços de saúde". Nesta cartilha, ao discorrer sobre parâmetros mínimos para ambiente e recursos humanos observa-se a necessidade de um serviço de farmacocinética clínica. No Brasil são raros os hospitais que possuem este serviço em funcionamento, sendo a primeira vez que se inclui tal serviço dentro dos requisitos mínimos para a Farmácia Hospitalar. Nos hospitais americanos, por outro lado, na década de $80,35 \%$ dos hospitais apresentavam este serviço em funcionamento (MURPHY et al, 1990).

O monitoramento terapêutico segundo Santos (2008) é indicado:

- Boa correlação entre resposta farmacológica e concentração plasmática;

- Alta variabilidade inter-indivíduos para as concentrações plasmáticas do fármaco após a mesma dose ou regime de dose;

- Ocorrência de produtos de biotransformação de relevância clinica que devem ser monitorados juntamente com o fármaco inalterado;

- Baixa margem de segurança (ou índice terapêutico) associado à estreita faixa terapêutica do fármaco, isto é, as concentrações terapêuticas estão muito próximas das concentrações tóxicas;

- Dificuldade na medida dos efeitos farmacológicos desejados que não possa ser obtidos rápida e facilmente;

- Difícil avaliação da resposta clínica;

- Sinais semelhantes para a toxicidade e para a doença;

- Rapidez na obtenção dos resultados;

- Custo aceitável ou viabilidade farmacoeconômica.

Os fatores de erro mais comuns que ocorrem no seguimento farmacoterapêutico de um paciente com relação ao monitoramento das concentrações plasmáticas, estão relacionados à:

- Coleta das amostras: período/ horário real da coleta, horário real da medicação administrada, tipo de tubo de coleta/anticoagulante, conservante, acondicionamento e transporte, armazenamento; 
- Erros de medicação: não conformidades quanto à administração do medicamento (dose, intervalo de dose e horário de administração);

- Cronofarmacocinética prevê alteração dos parâmetros cinéticos, portanto a coleta sangue deve preferencialmente ser realizada no período diurno;

- Método analítico não validado ou convenientemente otimizado;

- Armazenamento inadequado de matrizes biológicas;

- Variáveis relacionadas ao paciente (fatores fisiopatológicos);

- Variáveis relacionadas à formulação (fatores biofarmacêuticos p.ex. diferente biodisponibilidade de formulações orais).

Desta forma, a aplicação da Farmacocinética Clínica, aliada à utilização de método bioanalítico seletivo e específico, possibilita a individualização da farmacoterapia, a melhoria da aderência do paciente ao tratamento, a diferenciação entre ineficácia e toxicidade, bem como o estabelecimento de esquema terapêutico não-convencional para pacientes de risco, garantindo terapia dose ajustada, com a maximização dos efeitos terapêuticos e minimização dos efeitos adversos e tóxicos. 


\section{Infecção e terapia antimicrobiana em pacientes queimados}

Nos últimos 50 anos, a resistência bacteriana tem sido debatida (BRISKIER, 2005). No Brasil, a partir de 1968 e principalmente durante os anos 70, juntamente com a implantação de um modelo altamente tecnológico de atendimento, surgiram as primeiras comissões de controle de infecção hospitalar do país (ANVISA, 2000).

A prevalência de infecções adquiridas em ambiente hospitalar varia entre 5 a 15\% (AMB, 2001). Sendo a UTI um ambiente importante para o surgimento de resistência e também para a transmissão inter paciente (BRISKIER, 2005). No Brasil em 1994, o Ministério da Saúde avaliou a magnitude das infecções hospitalares e a qualidade das ações de controle em 99 hospitais terciários localizados nas capitais brasileiras vinculados ao Sistema Único de Saúde (SUS). A porcentagem de pacientes com infecção hospitalar foi $13,0 \%$, sendo que os maiores índices foram obtidos nas unidades de terapia intensiva e de queimados (ANVISA, 2000).

O paciente com queimadura representa, comparado a outros grupos de pacientes internados, um dos de maior risco para adquirir infecção hospitalar. Principalmente infecção da queimadura, que se desenvolve a partir de condições próprias comuns a este tipo de pacientes: perda do tegumento (quebra da barreira física à invasão de microrganismos), presença de tecido necrótico na escara queimada, presença de proteínas séricas e imunossupressão ocasionada pela lesão térmica. A colonização da queimadura é definida como a presença de microrganismos na superfície e na espessura do tecido queimado inviável, antes da limpeza cirúrgica. Ela se inicia logo após ocorrer a queimadura e poderá se manter até o fechamento de todas as lesões (mesmo após a limpeza cirúrgica). Nos primeiros dois dias, predominam os cocos Gram positivos (Staphylococcus aureus, Streptococcus spp.), enquanto entre o $3^{\circ}$ e $21^{\circ}$ dias são mais freqüentes os bacilos Gram negativos (Pseudomonas aeruginosa, Enterobacter sp, E. coli, Serratia marcescens, Klebsiella pneumoniae). Por outro lado, a infecção da queimadura ocorre quando microrganismos colonizantes, inicialmente presentes em tecidos inviáveis, invadem os tecidos viáveis (subjacentes à escara da queimadura). Ela 
pode se iniciar nos primeiros dias após a queimadura e ocorre apenas até a limpeza cirúrgica da escara (ANVISA, 2000).

As principais fontes ou reservatórios de microorganismos que ocasionam a colonização e infecção da queimadura são a pele e o trato digestivo do próprio paciente; a pele dos profissionais da saúde que cuidam diretamente dos pacientes; os outros pacientes e os dispositivos de uso exclusivo no cuidado individual do paciente tais como sondas ou máscaras e cateteres contaminados; as superfícies do mobiliário do quarto do paciente. São considerados fatores de risco para a infecção da queimadura: tamanho e profundidade da queimadura; tempo de internação; freqüência na transfusão de sangue ou recebimento de hemoderivados; presença de germes resistentes aos antimicrobianos utilizados por via tópica e sistêmica. Dentre os sinais e sintomas mais freqüentes da infecção da queimadura destacam-se (ANVISA, 2000):

- Características da ferida: marrom escura, enegrecida e violácea.

- Descolamento rápido da escara (crosta);

- Coloração hemorrágica do tecido abaixo da escara e edema;

- Coloração violácea da pele não queimada na margem da ferida;

- Hipotermia ( $<35,5^{\circ} \mathrm{C}$ ) é mais freqüente nas infecções por bacilos Gramnegativos;

- Hipertermia (> 37,8 C) é mais freqüente nas infecções por Grampositivos;

- Hipotensão (PS < 90 mm Hg);

- Leucocitose é mais freqüente nas infecções por Gram-positivos;

- Leucopenia é mais freqüente nas infecções por bacilos Gram-negativos;

- Oligúria (<20 ml/hora);

- Íleo paralítico;

- Intolerância a glicose e hiperglicemia é mais comum nas infecções por Gram negativos;

- Alteração do estado mental é mais comum em infecções por Grampositivos;

- Bacteremia, como complicação mais freqüente das infecções de ferida.

O aprofundamento da queimadura é considerado uma complicação da infecção. A suspeita inicial de infecção é principalmente clínica, pois o 
diagnóstico de certeza de infecção é muito difícil e o resultado de hemoculturas é indicativo de infecção, porém esta já se encontra num estágio muito avançado e a cultura de superfície não tem valor diagnóstico. O tratamento desta geralmente exige $O$ uso de antimicrobianos administrados por via sistêmica. Na suspeita clínica, dever-se-á obter hemoculturas e instituir tratamento empírico inicial. Este poderá ser ratificado ou alterado com a disponibilidade dos resultados das culturas. No tratamento da infecção, não se utiliza antimicrobianos via tópica, os quais podem ser usados com função profilática (ANVISA, 2000).

A escolha da terapia antimicrobiana empírica segue as normas estabelecidas pela Comissão de Controle de Infecções Hospitalares do HCFMUSP conforme esquematizado no fluxograma abaixo: 


\section{Grande Queimado}

\section{Esquema Terapêutico Empírico para Infecções}

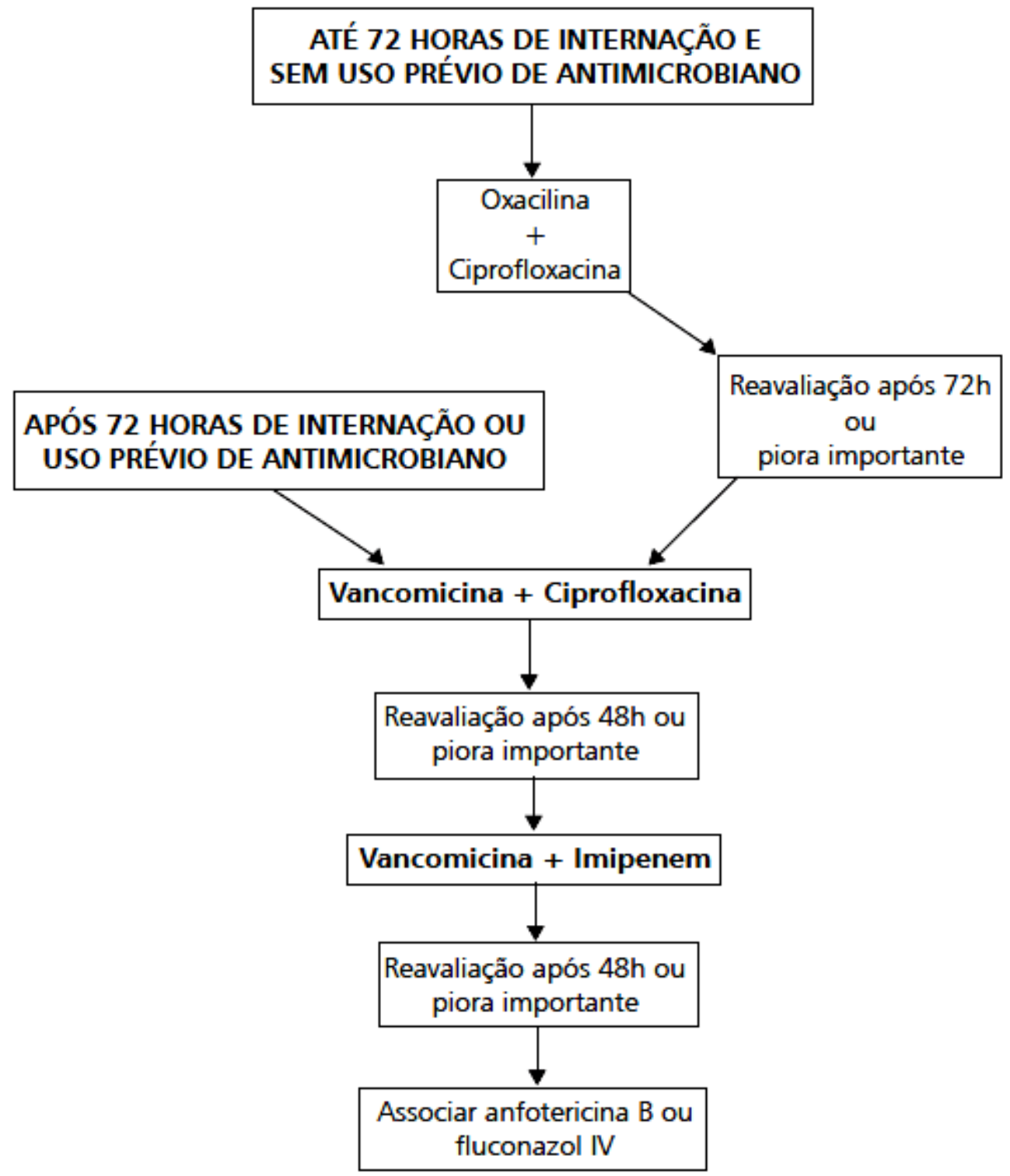

Fluxograma 1 - Terapia antimicrobiana empírica para pacientes grandes queimados HCFMUSP. Fonte: Guia de Utilização de Antimicrobianos e recomendações para a prevenção de infecções hospitalares, HCFMUSP, 20092010 


\section{Alterações na Farmacocinética de Pacientes Queimados com Sepse}

A farmacocinética dos medicamentos encontra-se alterada em pacientes queimados. As alterações observadas nestes pacientes podem ser explicadas, em grande parte, pelas alterações fisiológicas reportadas anteriormente por Garrelts e Peterie (1988), Weinbrer (1999), Blanchet e colaboradores (2008), Rong-Hua e colaboradores (2009) abaixo descritas:

- Nas primeiras 48 horas (fase aguda): perda de fluido protéico do sistema vascular através de alterações na permeabilidade vascular. Como resultado observa-se hipovolemia com conseqüente redução do débito cardíaco e hipoperfusão tecidual (redução do fluxo renal e da taxa de filtração glomerular)

- Após as primeiras 48 horas (fase hipermetabólica): as características do paciente se modificam uma vez que ocorre reposição adequada de fluidos, além do aumento no débito cardíaco, com concomitante aumento no fluxo sangüíneo de rins e fígado. Ocorre aumento da filtração glomerular. A função tubular, porém pode estar deprimida apesar do aumento da perfusão renal. O fluxo sanguíneo no fígado também está significantemente aumentado durante esta fase. $O$ efeito no metabolismo de fármacos é diverso: existe uma depressão aguda na atividade microssomal, porém a atividade de conjugação não está alterada. Durante esta fase, a queimadura ainda causa alterações significativas nos níveis de proteínas plasmáticas. Geralmente, os pacientes apresentam uma redução na albumina e aumento nos níveis de a1-glicoproteina ácida. Estas alterações podem influenciar a necessidade de dose de ataque para fármacos de alta ligação, mas é geralmente de menor importância durante as doses de manutenção, principalmente para os agentes antimicrobianos.

Além destes, muitos outros fatores podem influenciar a depuração renal de fármacos: doenças renais ou cardiovasculares pré-existentes, perfusão renal inadequada durante a ressuscitação, sepse e a administração de agentes potencialmente nefrotóxicos. O que resulta em uma grande variabilidade inter-paciente em relação à função renal, o que pode ser estendido à farmacocinética destes fármacos. Encontra-se 
aumentada a depuração renal; adicionalmente a depuração não renal também está aumentada pelo extravasamento do exsudato nas áreas queimadas. A fase hipermetabólica, dependendo do processo inflamatório, pode durar várias semanas alterando os parâmetros farmacocinéticos (GARRELTS \& PETERIE, 1988, WEINBRER, 1999; BLANCHET et al, 2008 RONG-HUA et al., 2009)

Adicionalmente, nos queimados surge um novo compartimento fluido no tecido abaixo da escara. O acúmulo desse fluido ocorre devido à vasodilatação e aumento da permeabilidade microvascular, aumento da pressão extra vascular e da pressão osmótica. O conteúdo deste fluido é semelhante ao do plasma, com relação inclusive aos fármacos contidos nos medicamentos administrados (RONG-HUA et al, 2009)

Além das alterações provenientes da queimadura, conforme descrito acima, alterações provenientes da sepse também estão envolvidas na modificação da farmacocinética dos antimicrobianos administrados a estes pacientes críticos. De maneira simplificada considera-se que a sepse altera a farmacocinética dos antimicrobianos de acordo com as características moleculares de cada fármaco e de acordo com as alterações sistêmicas, conforme resumido no quadro e diagrama abaixo (ROBERTS \& LIPMAN, 2009). 


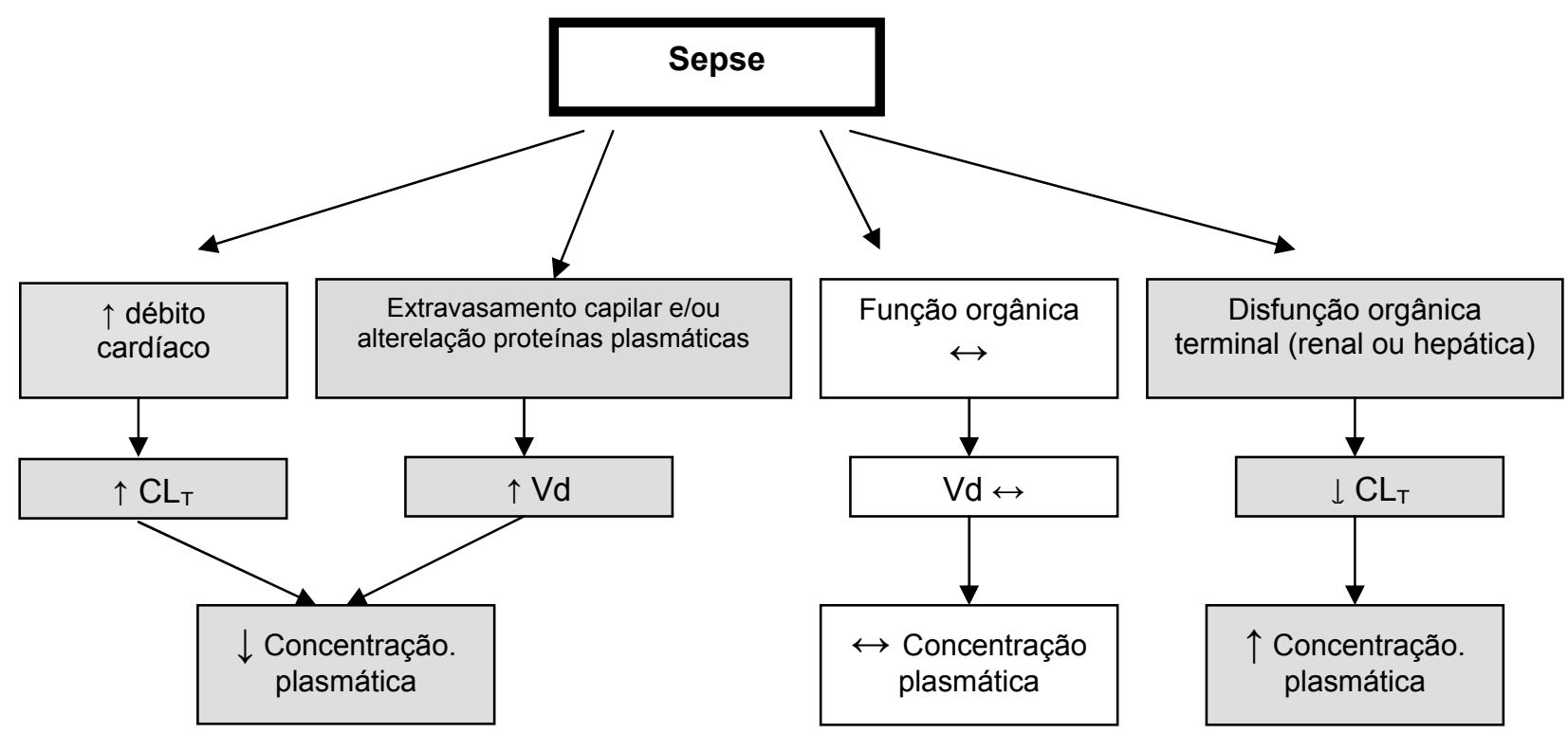

Diagrama 01 - Alterações Farmacocinéticas registradas na sepse.

Fonte: Roberts \& Lipman(2009).

Abreviaturas: Depuração plasmática: $\mathrm{CL}_{T}$; Volume aparente de distribuição: Vd.

Símbolos: $(\uparrow)$ aumento; $(\downarrow)$ redução; $(\leftrightarrow)$ inalterado

Quadro 01 - Farmacocinética de antimicrobianos em pacientes

\begin{tabular}{|lll|}
\hline Farmacocinética & \multicolumn{1}{c|}{$\begin{array}{c}\text { Antimicrobianos } \\
\text { hidrofílicos }\end{array}$} & \multicolumn{1}{c|}{$\begin{array}{c}\text { Antimicrobianos } \\
\text { lipofílicos }\end{array}$} \\
\hline Ausência de sepse & Vd baixo & Vd alto \\
& $\mathrm{CL}_{T}$ predominantemente renal \\
& Baixa penetrelação intracelular & $\begin{array}{l}\mathrm{CL}_{T} \text { predominantemente } \\
\text { hepático } \\
\text { Boa penetrelação intracelular }\end{array}$ \\
\hline Presença de sepse & $\mathrm{Vd} \uparrow$ & $\mathrm{Vd} \leftrightarrow$ \\
& $\uparrow$ ou $\downarrow C L_{T}$ dependente da $\uparrow$ ou $\downarrow C L_{T}$ dependendo da \\
& função renal & função hepática \\
\hline Ex. Antimicrobianos & -beta lactâmicos & -fluoroquinolonas \\
& -aminoglicosídeos & -macrolídeos \\
& -glicopeptídeos & -lincosamidas \\
& -linezolida & -tigeciclina \\
& -colistina & \\
\hline
\end{tabular}

Fonte: Roberts \& Lipman, 2009. Abreviaturas: Depuração plasmática: $\mathrm{CL}_{T}$; Volume aparente de distribuição: Vd. Símbolos $(\uparrow)$ aumento; $(\downarrow)$ redução; $(\leftrightarrow)$ inalterado 


\section{ALTERAÇÕES NO VOLUME DE DISTRIBUIÇÃO}

As endotoxinas liberadas por bactérias ou fungos estimulam a produção de vários mediadores endógenos que afetam 0 endotélio, resultando em vasodilatação ou constrição com alteração do fluxo sanguíneo, dano endotelial e aumento da permeabilidade capilar. Este processo resulta em perda de fluidos do compartimento intravascular para o espaço intersticial, o que aumenta o volume aparente de distribuição de fármacos hidrofílicos, reduzindo a concentração plasmática do mesmo. Estas alterações também podem ocorrera com a presença de ventilação mecânica, hipoalbuminemia por aumento do extravasamento capilar, circulação extracorpórea, drenos pós-cirúrgicos, ou em pacientes queimados. Para fármacos lipofílicos, devido ao elevado volume aparente de distribuição, (distribuição para o tecido adiposo) as alterações que ocorrem no terceiro espaço não alteram significantemente seu valores (ROBERTS \& LIPMAN, 2009).

\section{ALTERAÇÕES NA DEPURAÇÃO PLASMÁTICA}

$\mathrm{Na}$ ausência de disfunção renal importante, o aumento na perfusão renal é acompanhado pelo aumento do clearance de creatinina e na eliminação dos antimicrobianos hidrofílicos, como é o caso da utilização de fármacos vasoativos. Desta forma, o ajuste de dose para antimicrobianos hidrofílicos pode ser guiado através da medida do marcador de filtração renal (PEA et al, 2000; ROBERTS \& LIPMAN, 2009).

\section{ALTERAÇÕES NA MEIA-VIDA BIOLÓGICA}

Sabe-se que o parâmetro meia vida biológica (t1/2 $\beta)$ é diretamente proporcional à depuração plasmática e ao volume aparente de distribuição; desta forma, alteração num desses parâmetros ou em ambos em diferentes proporções contribuam em maior ou menor proporção nos valores estimados para a meia-vida biológica (ROBERTS \& LIPMAN, 2009). 


\section{DISFUNÇÃO/ FALÊNCIA DE ÓRGÃOS}

Com a evolução do paciente para deterioração do estado geral, ocorre a depressão do miocárdio que leva a uma redução na perfusão dos órgãos e à falência da circulação microvascular, o que pode progredir para a falência de múltiplos órgãos, incluindo rim e fígado. Nesta situação, o antimicrobiano mostrará redução na depuração, prolongamento na meia vida e potencial toxicidade para o paciente (ROBERTS \& LIPMAN, 2009).

\section{Correlação Farmacocinética-Farmacodinâmica e Modelagem PK-PD de Antimicrobianos}

A utilização de doses adequadas de antimicrobianos é a chave para evitar o surgimento e proliferação de resistência bacteriana e fúngica. Tal fato é dependente do conhecimento da atividade microbiológica do antimicrobiano, sensibilidade do microorganismo ao fármaco e à farmacocinética. Esta última pode estar afetada por fatores relacionados ao paciente. Desta forma, ao correlacionar o perfil farmacocinético do antimicrobiano com a susceptibilidade do microorganismo ao agente verifica-se a habilidade do fármaco em alcançar e permanecer no local de ação juntamente com a atividade microbiológica deste fármaco (RYBAK, 2006).

O parâmetro utilizado para medir a atividade microbiológica do antimicrobiano é a concentração inibitória mínima (CIM). Trata-se de uma medida in vitro do efeito do fármaco sobre o microorganismo (FRIMODTMOLLER, 2002).

Os parâmetros importantes obtidos pela modelagem PK-PD para se predizer a eficácia antimicrobiana são: a) razão entre a concentração plasmática máxima e a concentração inibitória mínima $\left(\mathrm{C}^{\mathrm{ss}}{ }_{\mathrm{max}} / \mathrm{CIM}\right)$ é aplicada para os aminoglicosídeos, metronidazol, fluoroquinolonas, telitromicina, daptomicina, b) relação entre a área sobre a curva e a concentração inibitória mínima (ASC/CIM) é aplicada para as fluoroquinolonas, aminoglicosídeos, azitromicina, glicopeptídeos, tigeciclina e linezolida; c) tempo durante o intervalo de dose em que a concentração plasmática encontra-se acima da concentração inibitória mínima $(\% \mathrm{~T}>\mathrm{CIM})$ é aplicada aos $\beta$-lactâmicos, 
carbapenêmicos, linezolida, eritromicina, claritromicina e lincosamida (RYBAK, 2006; ROBERTS \& LIPMAN, 2009).

Desta forma, pode-se resumir que a farmacodinâmica de um agente pode ser tempo dependente, concentração dependente e concentração/tempo dependentes, conforme referido no quadro 2.

Quadro 2 - Farmacodinâmica e correlação com a eficácia de antimicrobianos

\begin{tabular}{|c|c|c|c|}
\hline Parâmetro PK-PD & $\% \Delta \mathrm{T}>\mathrm{CIM}$ & $\begin{array}{l}\text { Concentração } \\
\text { dependente } \\
\mathrm{C}_{\text {max }}^{\text {ss }} \text { CIM }\end{array}$ & $\begin{array}{l}\text { Concentração } \\
\text { tempo dependente } \\
\mathrm{AUC}^{\mathrm{ss}}{ }_{0-24} / \mathrm{CIM}\end{array}$ \\
\hline Antimicrobianos & $\begin{array}{l}\beta \text {-lactâmicos } \\
\text { Carbapenêmicos } \\
\text { Linezolida } \\
\text { Eritromicina } \\
\text { Claritromicina } \\
\text { Lincosamida }\end{array}$ & $\begin{array}{l}\text { Fluoroquinolonas } \\
\text { Aminoglicosídeos } \\
\text { Metronidazol } \\
\text { Telitromicina } \\
\text { Daptomicina }\end{array}$ & $\begin{array}{l}\text { Fluoroquinolonas } \\
\text { Aminoglicosídeos } \\
\text { Azitromicina } \\
\text { Tetraciclina } \\
\text { Glicopeptídeos } \\
\text { Tigeciclina } \\
\text { Linezolida }\end{array}$ \\
\hline
\end{tabular}

Fonte: Roberts \& Lipman, 2009.

Abreviaturas: $\% \Delta \mathrm{T}>\mathrm{CIM}$ : período de tempo em que a concentração plasmática (medida in vivo) permanece acima da concentração inibitória mínima (medida in vitro); $\mathrm{C}^{\mathrm{ss}}{ }_{\max } / \mathrm{CIM}$ : razão concentração plasmática máxima (medida in vivo) e concentração inibitória mínima (medida in vitro); $\mathrm{AUC}^{\mathrm{ss}}{ }_{0-24} / \mathrm{CIM}$ : razão Área sob a Curva de concentração plasmática integrada no período 0-24 horas (medida in vivo) e a e concentração inibitória mínima (medida in vitro). 


\section{OBJETIVOS}

Realizar o monitoramento plasmático de sete antimicrobianos e um antifúngico (cefepime, ciprofloxacino, fluconazol, imipenem, oxacilina, piperacilina, sulfametoxazol e vancomicina) prescritos na UTI de queimados, para o ajuste do regime de dose e controle das infecções a partir da abordagem farmacocinética e modelagem farmacocinéticafarmacodinâmica. 


\section{3 - CASUÍSTICA E MÉTODOS}

A Etapa Clínica do estudo foi desenvolvida na Unidade de Terapia Intensiva da Divisão de Cirurgia Plástica e Queimaduras do Hospital das Clínicas da Faculdade de Medicina da Universidade de São Paulo. A UTI de Queimaduras obedece a um protocolo de uso de antimicrobianos instituído pela $\mathrm{CClH}$ (Comissão de Controle de Infecção Hospitalar). As etapas analítica e estatística foram desenvolvidas no Laboratório de Farmacologia Terapêutica, Faculdade de Ciências Farmacêuticas da Universidade de São Paulo

O protocolo foi aprovado pelos Comitês de Ética em Pesquisa do HCFMUSP e da FCF-USP (Anexos II e III).

O termo de Consentimento Livre e Esclarecido foi previamente aprovado pelos Comitês de Ética em Pesquisa das Instituições envolvidas no presente estudo (Anexo IV). Os pacientes que preencheram os critérios de inclusão foram incluídos no estudo. O termo de consentimento assinado pelo paciente/ou seu representante legal, e pelo clínico responsável foi arquivado, ficando sob a guarda desse último.

Foram incluídos todos os pacientes internados na Unidade de Queimaduras do hospital no período de maio de 2009 a abril de 2010 que preencheram os critérios de inclusão e exclusão, perfazendo um total de 32 pacientes. Os mesmos foram monitorados durante o tratamento realizado na UTI de Queimaduras. O controle terapêutico foi efetuado em todos os pacientes investigados e a modelagem farmacocinética foi aplicada para suporte ao ajuste de dose.

\section{Critérios de inclusão}

1. Pacientes de ambos os sexos, com idade superior a 18 anos

2. Sinais e sintomas clínicos compatíveis com infecção nas queimaduras, impondo a necessidade de introdução de um ou mais antimicrobianos sistêmicos; paciente apresentando no mínimo dois dos seguintes sinais e sintomas constantes do "Guia de Utilização de Antimicrobianos e 
Recomendações para a Prevenção de Infecções Hospitalares, HCFMUSP”, 2009-2011, apresentado no diagrama abaixo.

\section{Grande Queimado}

\section{Critérios para Terapêutica Empírica Sistêmica}

Iniciar antimicrobiano sistêmico quando se observarem dois dos critérios abaixo:

1. Leucopenia $\left(<2500 / \mathrm{mm}^{3}\right)$

2. Aprofundamento do grau da queimadura (exceto em queimadura elétrica) ou febre $\left(>38,5^{\circ} \mathrm{C}\right)$ ou hipotermia $\left(<36^{\circ} \mathrm{C}\right)$

3. Instabilidade hemodinâmica após correçăo hidroeletrolítica

4. Celulite

5. Confusåo mental (sem outra causa) ou hiperglicemia ( $>150 \mathrm{mg} / \mathrm{dl}$ sem diabetes prévia)

Diagrama 02. Critérios para Terapêutica Empírica Sistêmica em pacientes grandes queimados (HCFMUSP 2009-2011).

\section{Critérios de exclusão}

1. Paciente gravemente neutropênico (contagem absoluta de neutrófilos < $500 / \mathrm{mm} 3$ ) no período de estudo devido à quimioterapia prévia ou planejada ou ainda no paciente com HIV apresentando contagem de CD4 < 200 nos últimos 6 meses,

2. Mulheres grávidas ou amamentando,

3. Hipersensibilidade conhecida ou intolerância aos medicamentos em estudo ou aos excipientes de sua formulação.

\subsection{CASUÍSTICA}

O estudo realizado refere-se ao monitoramento terapêutico de 32 pacientes queimados com sepse que receberam infusão intermitente de antimicrobianos sistêmicos.

Os pacientes foram alocados de acordo com a ordem de inclusão no estudo (seqüencial crescente) e de acordo com o antimicrobiano utilizado 
durante o tratamento. Vale lembrar que um mesmo paciente pode encontrar-se em mais de um grupo, pelo fato de ter utilizado mais de um antimicrobiano durante o tratamento. As características individuais dos pacientes investigados são descritas no Quadro 03.

Quadro 03 - Características dos pacientes investigados, dados individuais $(n=32)$.

\begin{tabular}{|c|c|c|c|c|c|c|}
\hline $\begin{array}{l}\text { Número de } \\
\text { alocação } \\
\# 1 \text { a \#32 }\end{array}$ & Sexo & $\begin{array}{l}\text { Idade } \\
\text { (anos) }\end{array}$ & $\begin{array}{l}\text { Peso } \\
(\mathrm{kg})\end{array}$ & $\begin{array}{c}\text { SCQ } \\
(\%)\end{array}$ & Agente & $\begin{array}{c}\text { Lesão } \\
\text { Inalatória }\end{array}$ \\
\hline 1 & $\mathrm{~F}$ & 28 & 60 & 70 & $\mathrm{~T}$ & - \\
\hline 2 & $\mathrm{M}$ & 33 & 70 & 93 & $\mathrm{~T}$ & + \\
\hline 3 & $\mathrm{~F}$ & 18 & 60 & 39 & $\mathrm{~T}$ & - \\
\hline 4 & $M$ & 43 & 102 & 18 & E & - \\
\hline 5 & $\mathrm{~F}$ & 55 & 70 & 10 & $\mathrm{~T}$ & - \\
\hline 6 & $M$ & 32 & 76 & 37 & $\mathrm{~T}$ & - \\
\hline 7 & M & 41 & 58 & 10,5 & $\mathrm{~T}$ & - \\
\hline 8 & M & 53 & 70 & 28,5 & E & - \\
\hline 9 & M & 45 & 85 & 58 & $\mathrm{~T}$ & + \\
\hline 10 & M & 22 & 70 & 75 & $\mathrm{~T}$ & - \\
\hline 11 & $M$ & 62 & 70 & 29,5 & $E$ & - \\
\hline 12 & $\mathrm{~F}$ & 26 & 50 & 39 & $T$ & - \\
\hline 13 & $M$ & 24 & 70 & 33 & $\mathrm{~T}$ & - \\
\hline 14 & $M$ & 18 & 70 & 17,5 & $T$ & - \\
\hline 15 & $\mathrm{~F}$ & 35 & 60 & 52,5 & $T$ & + \\
\hline 16 & M & 36 & 70 & 8 & $T$ & - \\
\hline 17 & M & 26 & 70 & 62 & $\mathrm{~T}$ & + \\
\hline 18 & M & 67 & 70 & 36 & $\mathrm{~T}$ & - \\
\hline 19 & M & 48 & 70 & 29 & $T$ & - \\
\hline 20 & $\mathrm{~F}$ & 32 & 70 & 28 & $T$ & + \\
\hline 21 & M & 47 & 70 & 28 & $\mathrm{~T}$ & + \\
\hline 22 & M & 32 & 70 & 33,5 & E & - \\
\hline 23 & M & 28 & 70 & 33,5 & $\mathrm{~T}$ & + \\
\hline 24 & M & 90 & 63,5 & 8,5 & $\mathrm{~T}$ & - \\
\hline 25 & $\mathrm{~F}$ & 18 & 52 & 20,25 & $\mathrm{~T}$ & - \\
\hline 26 & $M$ & 49 & 83 & 16,5 & $\mathrm{~T}$ & - \\
\hline 27 & $M$ & 43 & 80 & 22 & $\mathrm{~T}$ & - \\
\hline 28 & $M$ & 34 & 70 & 15 & $T$ & + \\
\hline 29 & $\mathrm{~F}$ & 38 & 70 & 31 & $\mathrm{~T}$ & + \\
\hline 30 & $\mathrm{~F}$ & 70 & 70 & 45 & $\mathrm{~T}$ & + \\
\hline 31 & $M$ & 55 & 70 & 35 & $\mathrm{~T}$ & + \\
\hline 32 & $M$ & 19 & 65 & 23 & $\mathrm{E}$ & - \\
\hline
\end{tabular}

Abreviaturas: M: masculino; F: feminino; T: térmico; E: elétrico; SCQ: superfície corpórea queimada; lesão inalatória (+) presença, (-) ausência

A função renal foi avaliada através da creatinina sérica (SCr: 0,6 e 1,4 $\mathrm{mg} / \mathrm{dL}$ valor de referência, faixa de normalidade); o clearance de creatinina 
REGIME INICIAL - EVOLUÇÃO CLINICA(mL/min) foi estimado a partir da creatinina sérica, equação abaixo referida, utilizando o nomograma de Cockcroft e Gault (COCKCROFT \& GAULT, 1976) e calculado através de programa disponibilizado pelo Micromedex (Clearance calculator; MICROMEDEX, 2010).

$$
\text { Clearance creatinina }=\frac{(140-\text { idade }) \times \text { Peso }(\mathrm{kg})}{72 \times \operatorname{Cr}(\mathrm{mg} / \mathrm{dL})}
$$

No caso de mulheres, empregou-se a mesma equação com fator de correção de 0,85 , em função de uma menor produção de creatinina decorrente da massa muscular reduzida.

Como estes pacientes permanecem habitualmente hospitalizados por longo período, e considerando-se a variabilidade na função renal, a creatinina sérica e o clearance de creatinina foram monitorados em cada coleta seriada de amostras de sangue durante todo seguimento farmacoterapêutico relativo aos antimicrobianos em estudo.

No caso específico do paciente queimado, uma vez que ocorre aumento do catabolismo e perda de massa muscular, a creatinina sérica e o clearance de creatinina não refletem a verdadeira função renal do paciente; desta forma, a falência renal deve ser considerada para o paciente queimado na vigência de diálise.

\subsection{PROTOCOLO CLÍNICO}

Investigaram-se os pacientes queimados portadores de sepse, que receberam doses iniciais de antimicrobianos por via intravenosa, segundo o protocolo recomendado pela CCIH e apresentado no Quadro 4 (HCFMUSP, 2009-2011). Estas doses foram ajustadas "em tempo real" de acordo com o resultado do monitoramento terapêutico realizado através do decaimento das concentrações plasmáticas e modelagem farmacocinética. 
Durante o seguimento farmacoterapêutico do paciente na UTI, a critério médico realizaram-se em cada período cerca de cinco coletas seriadas de sangue (2 $\mathrm{mL}$ cada) através de cateter venoso para quantificação das concentrações plasmáticas de cada antimicrobiano no intervalo de dose, Quadro 04. As amostras de sangue foram coletadas em tubos de hemograma contendo EDTA sódico, estado de equilíbrio na fase de eliminação (5 meiasvidas de tratamento). As amostras de sangue foram identificadas com etiquetas com código de barra (serviço/registro hospitalar/convenio/leito e nome do paciente/data de nascimento); incluíram-se nessas etiquetas as informações de data e horário da coleta realizada. As coletas foram realizadas exclusivamente pela equipe médica da UTI de Queimaduras. O volume de sangue coletado na seringa foi transferido para tubos contendo EDTA sódico (BD, São Paulo, SP, Brasil), seguido de homogeneização, três vezes por inversão. Durante as coletas as amostras foram mantidas em geladeira e, ao término, os tubos e a prescrição informatizada foram encaminhados para a FCF USP para a realização das etapas analítica e estatística.

Ali o sangue foi centrifugado a $2800 \mathrm{~g}$ por 30 minutos, o plasma separado e as amostras foram acondicionadas, devidamente identificadas com etiquetas em código de barras, em estante identificada por paciente (número de alocação \#1 a \#32) e analisadas. Especificamente, para os antimicrobianos cefepime, imipenem e vancomicina, volumes de $400 \mu \mathrm{L}$ de plasma foram transferidos para tubos de Eppendorf (2 mL) contendo $200 \mu \mathrm{L}$ de solução estabilizante ácido $3 \mathrm{~N}$-morfolinopropano sulfônico a 10\% (MOPS). 
Quadro 04 - Protocolo empírico de administração de antimicrobianos ao paciente, HCFMUSP, 2009-2011.

\begin{tabular}{|ccc|}
\hline Antimicrobiano & Dose diária & Intervalo entre doses \\
\hline Cefepime & $2-4 \mathrm{~g}$ & $8 / 8$ horas \\
& & $12 / 12$ horas \\
Ciprofloxacino & $400-800 \mathrm{mg}$ & $12 / 12$ horas \\
Fluconazol & $100-400 \mathrm{mg}$ & $24 / 24$ horas \\
Imipenem & $2-3 \mathrm{~g}$ & $6 / 6$ horas \\
& & $8 / 8$ horas \\
Oxacilina & $6-12 \mathrm{~g}$ & $4 / 4$ horas \\
Piperacilina & $12 \mathrm{~g}$ & $6 / 6$ horas \\
Sulfametoxazol & $400-800 \mathrm{mg}$ & $6 / 6 \mathrm{hs}$ \\
Vancomicina & $2 \mathrm{~g}$ & $12 / 12 \mathrm{hs}$ \\
& & $6 / 6$ horas \\
& & $12 / 12$ horas \\
\hline
\end{tabular}

(*):Regime posológico inicial proposto para pacientes com função renal normal no Guia de utilização de antimicrobianos HCFMUSP,2009-2011.

\subsection{ETAPA ANALÍTICA}

A quantificação dos antimicrobianos nas amostras de plasma coletadas foi realizada através dos métodos analíticos de quantificação em Cromatografia Líquida de Alta Eficiência (CLAE-UV), desenvolvidos e validados no Laboratório de Farmacocinética Clínica, do Departamento de Farmácia da Faculdade de Ciências Farmacêuticas da USP.

Com referência aos procedimentos cromatográficos de quantificação e da validação do método bioanalítico todo o detalhamento encontra-se descrito no Apêndice I.

\subsubsection{Controle Terapêutico}

No monitoramento das concentrações plasmáticas através de CLAEUV, o resultado de vale (concentração mínima obtida pela coleta de sangue imediatamente antes da dose subseqüente) é proporcional ao acúmulo de infusões múltiplas no platô. Portanto se pela primeira infusão de curta duração o estado de equilíbrio não é atingido, através de múltiplas infusões o platô é atingido, podendo se proceder à coleta de sangue antes 
da dose subseqüente para o monitoramento terapêutico com base no vale. O suporte adicional fornecido pela modelagem farmacocinética dá informações referentes aos processos de distribuição e eliminação a partir da coleta de amostras seriadas; portanto fornece ao médico embasamento para alteração da posologia empírica para a terapia segura e efetiva doseajustada.

\subsubsection{Farmacocinética}

Aplicou-se o modelo aberto de um compartimento, considerando-se a transformação logarítmica das concentrações plasmáticas (C) obtidas em função do tempo $(T)$ após administração intravenosa do fármaco em regime de doses múltiplas, através da utilização do software $P K$ Solutions versão 2.0 Noncompartmental Pharmacokinetics Data Analysis, Ashland, OH, USA. Estimaram-se as constantes farmacocinéticas modelo-dependentes (constante de velocidade de eliminação e meia-vida biológica) e modeloindependentes (depuração plasmática e volume aparente de distribuição) a partir da área sob a curva integrada no intervalo de dose, conforme descrito no Quadro 05.

A distribuição foi estimada a partir do volume aparente que expressa a extensão da distribuição, uma vez que no modelo utilizado a velocidade do processo alfa não foi determinada. A meia-vida biológica $t_{(1 / 2 \beta)}$, estimada na fase terminal da curva de decaimento, é o tempo necessário para a redução da concentração plasmática em $50 \%$ na fase de eliminação. A constante da velocidade de eliminação (Kel) é definida a partir da inclinação da reta de eliminação, e a equação abaixo que permite correlacionar esses dois parâmetros do processo de eliminação. Após administração intravascular de cada antimicrobiano investigado, a depuração plasmática $\left(\mathrm{CL}_{T}\right)$ foi estimada a partir da razão entre a dose infundida e a área sobre a curva integrada no intervalo de dose $\left(\mathrm{ASC}_{\tau}^{\mathrm{SS}}\right)$ considerando-se as concentrações plasmáticas obtidas no estado de equilíbrio. O volume aparente de distribuição ( $\mathrm{Vd}$ ) foi estimado através da razão entre a depuração plasmática e a constante de velocidade de eliminação (Kel). 
Quadro 05- Parâmetros farmacocinéticos após infusão múltipla no estado de equilíbrio.

\begin{tabular}{|c|c|c|}
\hline Descrição do Parâmetro & Parâmetro/unidade & Equação \\
\hline Constante de infusão & Ko (mg/hora) & Dose/ Tinfusão \\
\hline Constante de eliminação & $\mathrm{Kel}\left(\mathrm{h}^{-1}\right)$ & $\left(\mathrm{LnC}_{1}-\mathrm{LnC}_{2}\right) / \mathrm{T}_{2}-\mathrm{T}_{1}$ \\
\hline Meia-vida de beta & $\mathrm{t}(1 / 2) \beta(h)$ & $0,693 / \mathrm{Kel}$ \\
\hline $\begin{array}{l}\text { Área sob a curva no steady } \\
\text { state }\end{array}$ & $\mathrm{ASC}_{\tau}^{\mathrm{SS}}$ & $\begin{array}{l}\text { Trapezóides (integração ponto } \\
\text { a ponto do intervalo de dose) }\end{array}$ \\
\hline Depuração plasmática & $\mathrm{CL}_{\mathrm{T}}(\mathrm{mL} / \mathrm{min} / \mathrm{kg})$ & Dose/ $\mathrm{ASC}^{\mathrm{SS}} \tau$ \\
\hline $\begin{array}{l}\text { Volume aparente de } \\
\text { distribuição no steady state }\end{array}$ & $\mathrm{Vd}^{S S}(\mathrm{~L} / \mathrm{kg})$ & Dose/Kel . ASC $^{S S} \tau$ \\
\hline
\end{tabular}

Fontes: DiPiro, 2002; PK Solutions 2.0 Non Compartimental Analysis, Summit, USA

\subsubsection{Modelagem PK-PD de Antimicrobianos e do Antifúngico}

O surgimento da resistência bacteriana e/ou fúngica devido à dose inadequada dos antimicrobianos e antifúngicos é decorrente da alteração da farmacocinética desses agentes; sabe-se ainda que esse fato é dependente do conhecimento da atividade do antimicrobiano, sensibilidade do microorganismo ao agente. A modelagem PK-PD permite estabelecer correlação entre o perfil farmacocinético do antimicrobiano com a susceptibilidade do microorganismo ao agente obtida pela medida in vitro (CIM) (RYBAK, 2006).

O parâmetro utilizado para medir a atividade in vitro do antimicrobiano é a concentração inibitória mínima (FRIMODT-MOLLER, 2002). Adicionalmente, consideram-se os parâmetros de relevância da predição da eficácia antimicrobiana na modelagem PK-PD para os diferentes agentes investigados no presente estudo:

- A razão entre a concentração plasmática máxima e a concentração inibitória mínima $\left(\mathrm{C}_{\max }^{\mathrm{ss}} / \mathrm{CIM}\right)$;

- A relação entre a área sobre a curva e a concentração inibitória mínima $\left(\mathrm{ASC}^{\mathrm{sS}}{ }_{0-24} / \mathrm{CIM}\right)$, e 
- O período de tempo em que a concentração plasmática encontra-se acima da concentração inibitória mínima (\% $\%$ T >CIM), (RYBAK, 2006; ROBERTS \& LIPMAN, 2009).

Desta forma, a predição de eficácia foi realizada para cada antimicrobiano investigado com base em um ou mais parâmetros PK-PD, conforme ilustrado abaixo.

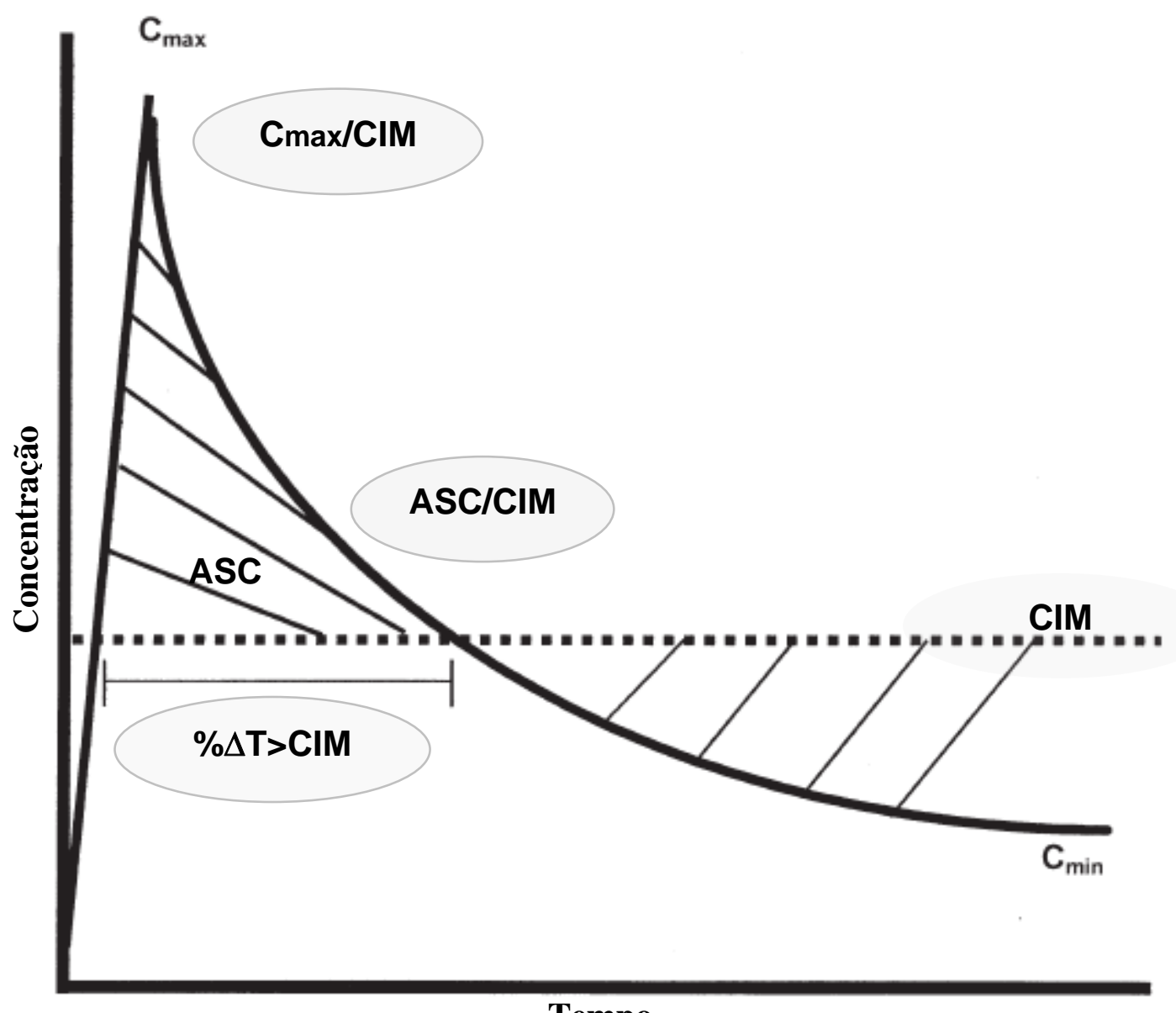

\section{Tempo}

Ilustração 1 - Curva de concentração plasmática versus tempo: parâmetros PK/PD. (Adaptado de RYBAK. 2006)

Abreviaturas: \% $\Delta \mathrm{T}>\mathrm{CIM}$ : período de tempo em que a concentração plasmática (medida in vivo) permanece acima da concentração inibitória mínima (medida in vitro); $\mathrm{C}^{\mathrm{ss}}{ }_{\max } / \mathrm{CIM}$ : razão concentração plasmática máxima (medida in vivo) e concentração inibitória mínima (medida in vitro); $\mathrm{ASC}^{\text {ss }}{ }_{0-24} / \mathrm{CIM}$ : razão Área sob a Curva de concentração plasmática integrada no período 0-24 horas (medida in vivo) e a e concentração inibitória mínima (medida in vitro). 


\subsection{ETAPA ESTATÍSTICA}

\section{Modelagem Farmacocinética}

A modelagem farmacocinética foi realizada através da aplicação do software Noncompartmental Analysis PK Solutions 2.0 (Summit, USA) aos pares de dados concentração versus tempo para estimativa dos parâmetros cinéticos modelo dependentes e modelo independentes.

\section{Modelagem Farmacocinética- Farmacodinâmica}

A modelagem farmacocinética-farmacodinâmica foi realizada através da aplicação do software GraphPad Prism for Windows versão 4.0 (GraphPad Software Inc., San Diego, CA, USA) aos pares de dados medidos in vivo e in vitro considerando-se os parâmetros de interesse específicos para cada antimicrobiano investigado: a) (\% \% >CIM): período de tempo em que a concentração plasmática (medida in vivo) permanece acima da concentração inibitória mínima (medida in vitro); b) $\mathrm{C}_{\max }^{\text {ss }} / \mathrm{CIM}$ : razão concentração plasmática máxima (medida in vivo) e concentração inibitória mínima (medida in vitro); c) $\mathrm{ASC}^{\text {ss }}{ }_{0-24} / \mathrm{CIM}$ : razão Área sob a Curva de concentração plasmática integrada no período 0-24 horas (medida in vivo) e a e concentração inibitória mínima (medida in vitro). 


\section{Tratamento Estatístico}

O tratamento estatístico dos resultados obtidos experimentalmente ou estimados a partir de aplicação de softwares foi realizado através da aplicação de softwares Microsoft Excel 2007 (Microsoft Corporation, USA) e GraphPad Instat for Windows versão 3.0 (GraphPad Software Inc., San Diego, CA, USA) GraphPad Prism for Windows versão 4.0 (GraphPad Software Inc., San Diego, CA, USA). Na estatística descritiva, os dados foram expressos através das médias, desvio padrão, faixa de variação IC95\% (intervalo de confiança 95\% delimitada pelos limites inferior e superior) bem como o valor mínimo e máximo obtidos para todos os parâmetros estudados na população de pacientes de acordo com antimicrobiano utilizado. A expressão dos resultados através das medianas foi escolhida para os parâmetros estimados através da modelagem farmacocinética. Utilizaram-se testes paramétricos (ANOVA e Teste T) e não paramétricos (Wilcoxon e Mann Whitney) para dados pareados e não pareados.

Realizaram-se ainda estudo de correlação (linear e não linear) entre os parâmetros farmacocinéticos e dados laboratoriais ou do paciente pela aplicação do software GraphPad Prism for Windows versão 4.0 (GraphPad Software Inc., San Diego, CA, USA)

$\mathrm{Na}$ modelagem PK-PD plotou-se em eixos cartesianos $\mathrm{Y}: \mathrm{X}$, cada parâmetro importante na predição da farmacodinâmica do agente antimicrobiano versus as concentrações inibitórias mínimas para diferentes agentes antimicrobianos: a) período de tempo em que a concentração plasmática (medida in vivo) permanece acima da concentração inibitória mínima (medida in vitro); b) $\mathrm{C}_{\max }^{\text {ss }} / \mathrm{CIM}$ : razão concentração plasmática máxima (medida in vivo) e concentração inibitória mínima (medida in vitro); c) $\mathrm{ASC}^{\text {ss }}{ }_{0-24} / \mathrm{CIM}$ : razão Área sob a Curva de concentração plasmática integrada no período 0-24 horas (medida in vivo) e a e concentração inibitória mínima (medida in vitro). 


\section{4- RESULTADOS}

Foram incluídos pacientes de ambos os sexos (23M/9F), com idade media +/- DP de 39,6+/-17,0 anos, peso de 69,5 +/-9,5 kg e \%SCQ de 33,9 +/$20,2 \%$. Observou-se maior incidência de lesão de origem térmica 27/32 (84\%) contra 5/32 (16\%) de lesão de origem elétrica. Além disso, registrou-se a incidência de lesão inalatória em 11/32 (34\%) dos pacientes.

A caracterização da população de pacientes queimados encontra-se descrita na tabela 1 através de dados antropométricos (sexo, idade, peso) e a superfície corporal queimada, agente da queimadura e lesão inalatória.

Tabela 1- Caracterização da população de pacientes queimados investigados

\begin{tabular}{ccccccc}
\hline Parâmetro & $\begin{array}{c}\text { Sexo } \\
\text { M/F }\end{array}$ & $\begin{array}{c}\text { Idade } \\
\text { (anos) }\end{array}$ & $\begin{array}{c}\text { Peso } \\
(\mathbf{k g})\end{array}$ & $\begin{array}{c}\text { SCQ } \\
\mathbf{( \% )}\end{array}$ & $\begin{array}{c}\text { Agente } \\
\text { T/E }\end{array}$ & $\begin{array}{c}\text { Lesão } \\
\text { Inalatória } \\
+/-\end{array}$ \\
\hline Média & $23 / 9$ & 39,6 & 69,5 & 33,9 & $27 / 5$ & $11 / 21$ \\
DP & NAP & 17 & 9,5 & 20,2 & NAP & NAP \\
Vmín & NAP & 18 & 52 & 8 & NAP & NAP \\
Vmáx & NAP & 90 & 102 & 93 & NAP & NAP \\
LI IC 95\% & NAP & 33,7 & 66,2 & 26,9 & NAP & NAP \\
LS IC 95\% & NAP & 45,5 & 72,8 & 40,9 & NAP & NAP \\
\hline
\end{tabular}

Estatística: GraphPad Prism 4 para estatística descritiva.

Abreviaturas: NAP: Não Aplicável; M: masculino; F: feminino; SCQ: superfície corporal queimada; T: térmico; E: elétrico; DP: desvio padrão da média; LI IC95\%: limite inferior do intervalo de confiança 95\%; LS IC95\%: limite superior do intervalo de confiança 95\%; Vmín: valor mínimo; Vmáx: valor máximo ; Lesão inalatória: (+) presença, (-) ausência.

Durante o período, realizou-se o seguimento de 32 pacientes, no atendimento a 84 solicitações de exame totalizando 303 laudos emitidos. Em cada laudo de exame registrou-se a concentração plasmática de vale, bem como os parâmetros farmacocinéticos mais relevantes, e os respectivos valores de referência para apoio ao Clinico na interpretação dos resultados do paciente em cada seguimento. O número de solicitações e o número de laudos de exame expedidos por antimicrobiano encontram-se reunidos na tabela 2. 
Tabela 2 - Paciente queimado tratado com antimicrobiano e antifúngico

\begin{tabular}{lcc} 
Parâmetro & $\begin{array}{c}{ }^{\mathrm{a}} \mathbf{N}^{\mathbf{0}} \text { pacientes } \\
\text { atendidos }\end{array}$ & $\begin{array}{c}\mathbf{N}^{\mathbf{0}} \text { Laudos de } \\
\text { Exame nos } \\
\text { seguimentos }\end{array}$ \\
\hline Cefepime & 03 & 10 \\
Ciprofloxacino & 03 & 06 \\
Fluconazol & 12 & 31 \\
Imipenem & 18 & 75 \\
Oxacilina & 02 & 05 \\
Piperacilina & 07 & 10 \\
Sulfametoxazol & 08 & 19 \\
Vancomicina & 31 & 147 \\
\hline TOTAL & 84 & 303 \\
\hline
\end{tabular}

Os resultados indicam que em média cada solicitação de seguimento farmacoterapêutico com suporte laboratorial gerou o monitoramento das concentrações plasmáticas de três antimicrobianos em média por paciente queimado da UTI, tabela 2.

Registrou-se a necessidade de ajuste da dose para a garantia da eficácia e baixo risco da terapia antimicrobiana, decorrente da alteração na farmacocinética em aproximadamente $80 \%$ dos pacientes queimados recebendo os antimicrobianos sistêmicos principalmente para cefepime, fluconazol, imipenem, sulfametoxazol e vancomicina. Relativamente aos demais antimicrobianos prescritos (ciprofloxacino, oxacilina e piperacilina), a concentração eficaz mínima (CEM) foi alcançada através da prescrição da dose usual empírica recomendada na população de queimados, figura 4.

Por outro lado, a indicação do controle terapêutico para os antimicrobianos variou em função do agente infeccioso e da margem de segurança do antimicrobiano de escolha: vancomicina (88\%), cefepime (64\%), sulfametoxazol (52\%), fluconazol (74\%) e em menor proporção para o imipenem (19\%), figura 4. 

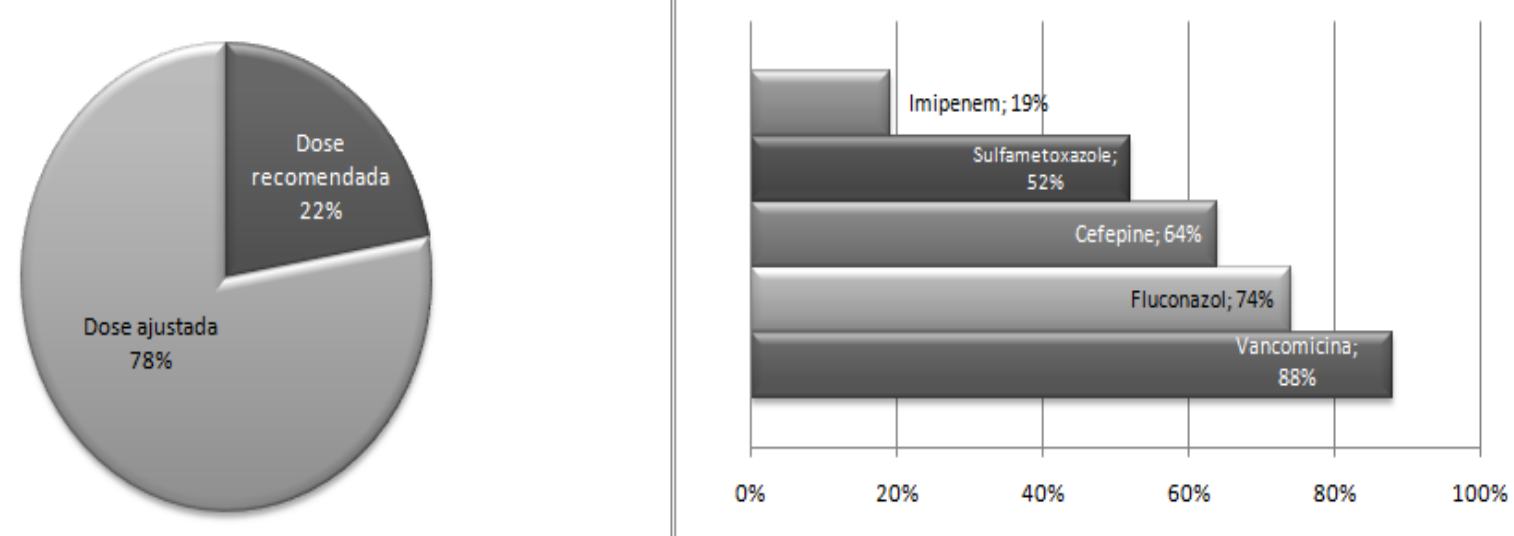

Figura 4 - Ajuste de dose requerido no paciente queimado durante o seguimento (painel à esquerda) Terapia dose ajustada requerida para os pacientes queimados (\%); (painel à direita) Indicação de controle terapêutico para antimicrobianos nos pacientes queimados, expressos em percentagem do total relativamente ao antimicrobiano plasmático monitorado.

\section{-TERAPIA DOSE AJUSTADA COM BASE NA FARMACOCINÉTICA}

\subsection{CEFEPIME}

Durante o período de realização do projeto realizou-se o seguimento farmacoterapêutico de três pacientes recebendo o cefepime: \#3, \#5 e \#6. No período do seguimento, todos apresentavam função renal normal durante todos os seguimentos. As concentrações plasmáticas apresentadas no vale e as doses diárias empíricas e ajustadas estão ilustradas na figura 5. A dose foi ajustada em $63,6 \%$ dos seguimentos. 


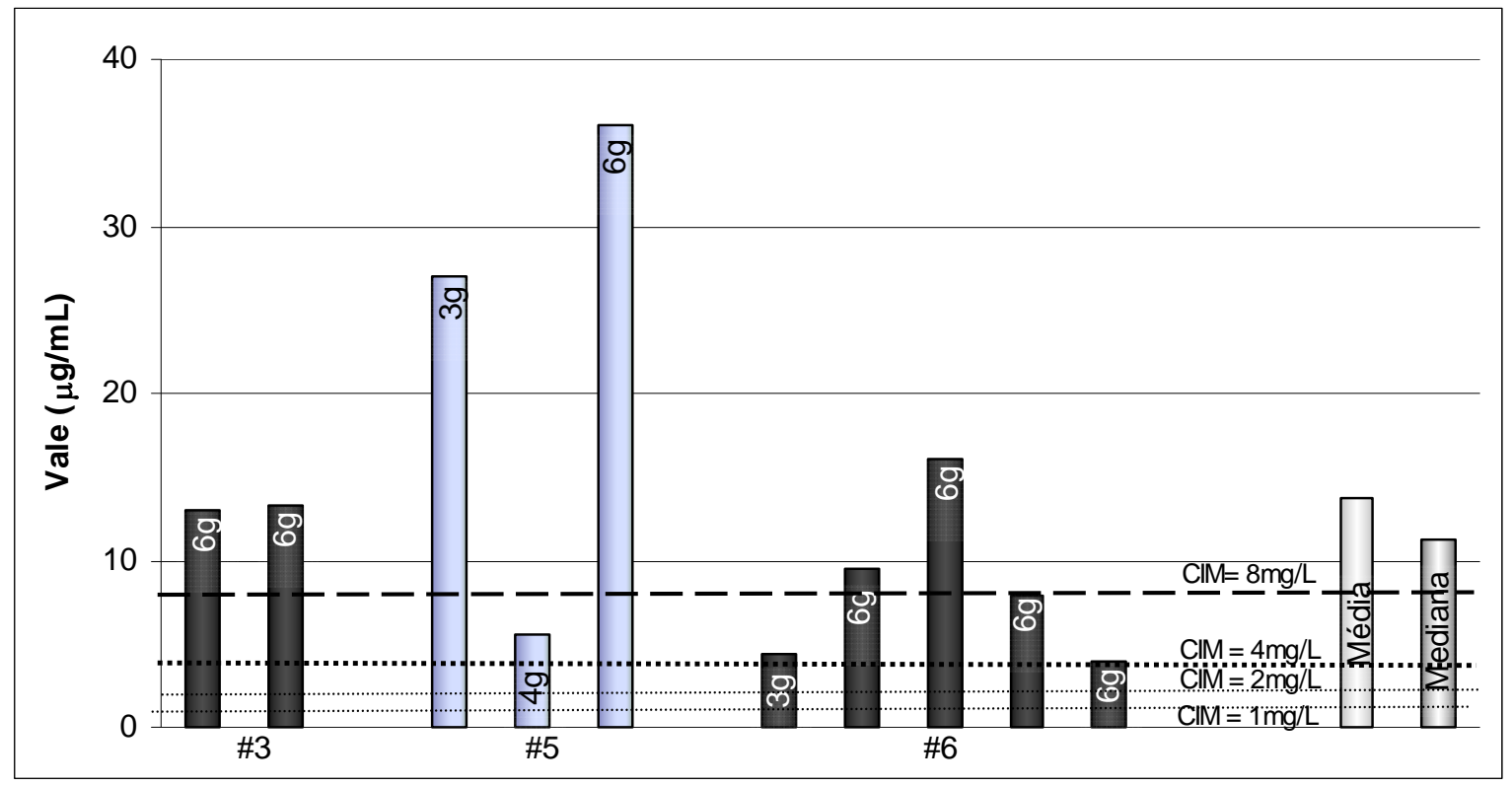

Figura 5 - Dose diária de cefepime (g) versus Vale $(\mu \mathrm{g} / \mathrm{mL})$ : Ajuste de dose em pacientes queimados internados na UTI do HCFMUSP total de 10 seguimentos. Valor de Referência: CIM de 8mg/L (Pseudômonas aeruginosa e Staphylococcus aureus), $2 \mathrm{mg} / \mathrm{L}$ (Enterobacter ssp) e <1mg/L (Escherichia coli, Klebsiella pneumoniae, Serratia marcescens, Citrobacter ssp). Abreviaturas: CIM: concentração inibitória mínima obtida in vitro (mg/L).. Fonte: Cheatham et al, 2011; Chapuis et al., 2010; Micromedex, 2010

Os parâmetros farmacocinéticos observados para os pacientes em uso de cefepime encontram-se descritos na tabela 3 e figura 6 , abaixo. 
Tabela 3 - Parâmetros farmacocinéticos registrados para o cefepime $(n=10$ seguimentos em três pacientes)

\begin{tabular}{cccc}
\hline Parâmetro & $\begin{array}{c}\mathrm{t}_{(1 / 2) \beta} \\
(\mathrm{h})\end{array}$ & $\begin{array}{c}\mathbf{C L}_{\mathbf{T}} \\
(\mathrm{mL} / \mathrm{min} . \mathrm{kg})\end{array}$ & $\begin{array}{c}\mathrm{Vd} \\
(\mathrm{L} / \mathrm{kg})\end{array}$ \\
\hline $\begin{array}{c}\text { Valor de } \\
\text { Referência }\end{array}$ & 2,0 & $1,7-2,0$ & $0,2-0,3$ \\
\hline Mediana & 3,1 & 1,5 & 0,4 \\
Média (DP) & $3,2(1,4)$ & $1,6(0,8)$ & $0,4(0,2)$ \\
Variabilidade (\%) & 44,9 & 48,8 & 53,9 \\
\hline Vmín & 1,0 & 0,5 & 0,2 \\
Vmáx & 6,4 & 3,0 & 0,8 \\
LI IC 95\% & 2,3 & 1,1 & 0,3 \\
LS IC 95\% & 4,1 & 2,1 & 0,6 \\
\hline
\end{tabular}

Fonte Micromedex, 2010.

Estatística: GraphPad Instat 3.0 e GraphPad Prism 4 para estatística descritiva. Abreviaturas: FRN: função renal normal; DP: desvio padrão da média; LI IC95\%: limite inferior do intervalo de confiança 95\%; LS IC95\%: limite superior do intervalo de confiança 95\%; Vmín: valor mínimo; Vmáx: valor máximo; CV\%: coeficiente de variação; $\mathrm{t}_{(1 / 2) \beta}$ meia vida biológica; $\mathrm{CL}_{T}$ depuração plasmática; $\mathrm{Vd}$ : volume aparente de distribuição
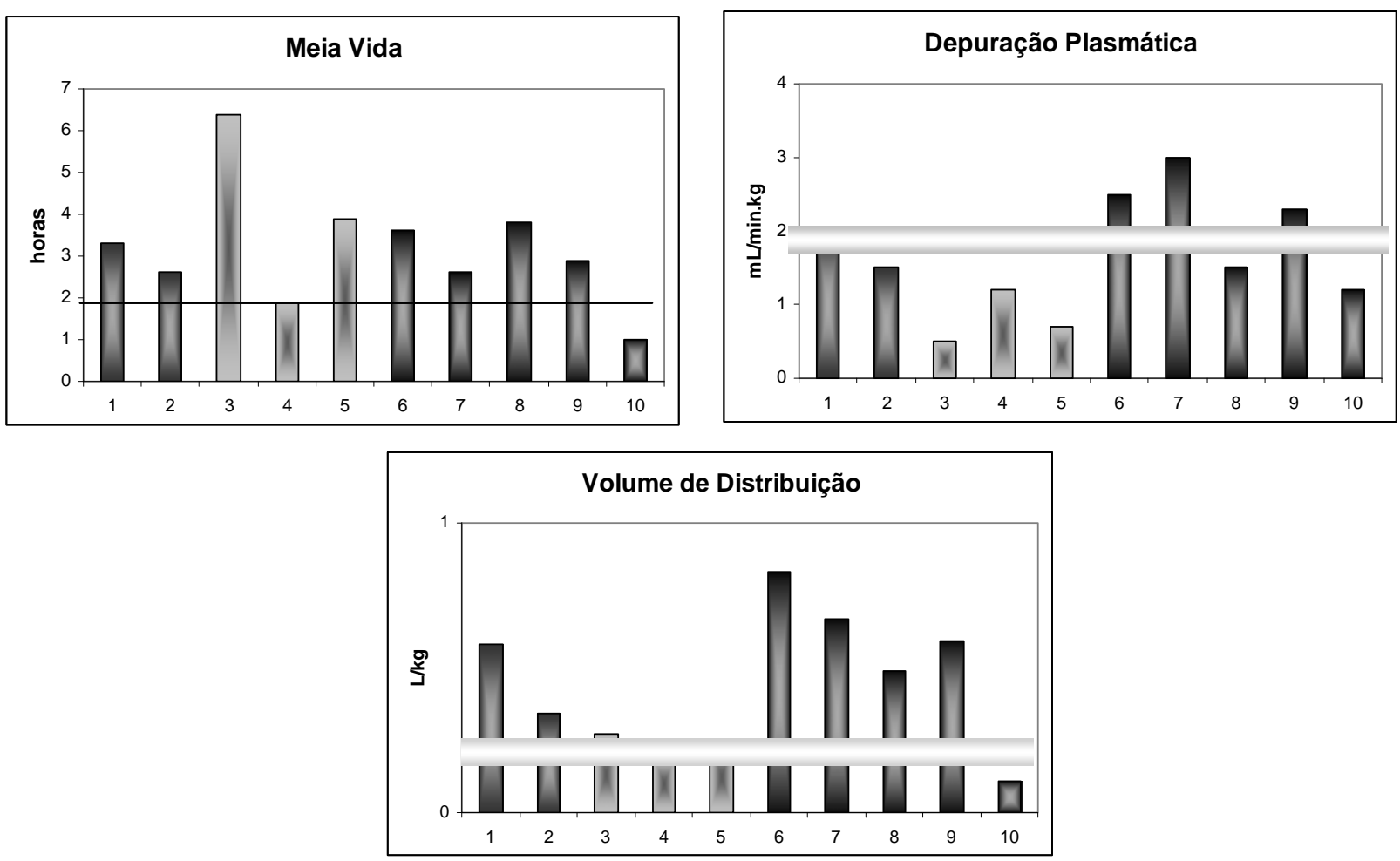

Figura 6. Dados individuais para as constantes farmacocinéticas do cefepime. Faixa de referência: Meia Vida (2hs); Depuração Plasmática (1,7-2,0 mL/min.kg); Volume de Distribuição (0,2-0,3L/kg) Fonte: Micromedex, 2010. 
A atividade antibacteriana tempo-dependente do cefepime é observada através da razão \% \%T>CIM. A modelagem PK-PD foi aplicada no presente estudo para o cefepime conforme apresentado abaixo, com base na curva de decaimento plasmático no decurso do tempo, considerando-se a porcentagem de tempo $(\% \Delta \mathrm{T})$ em que a concentração do fármaco encontra-se acima do CIM (Tabela 4, Figura 7).

Tabela 4. Modelagem PK/PD expressa através do período de tempo (\% $\% \mathrm{~T})$ requerido para manutenção da concentração plasmática do cefepime acima da concentração inibitória mínima obtida in vitro $(\% \Delta \mathrm{T}>\mathrm{CIM}), \mathrm{n}=10$ seguimentos em três pacientes

\begin{tabular}{c|c|cccc}
\hline Paciente & $\begin{array}{c}\text { Regime } \\
(\mathrm{TPQ})\end{array}$ & $1 \mathrm{mg} / \mathrm{L}$ & $2 \mathrm{mg} / \mathrm{L}$ & $4 \mathrm{mg} / \mathrm{L}$ & $8 \mathrm{mg} / \mathrm{L}$ \\
\hline$\# 3$ & $2 \mathrm{~g} 8 / 8 \mathrm{~h}\left(8^{\circ} \mathrm{d}\right)$ & 100 & 100 & 100 & 100 \\
& $2 \mathrm{~g} 8 / 8 \mathrm{~h}\left(13^{\circ} \mathrm{d}\right)$ & 100 & 100 & 100 & 100 \\
\hline$\# 5$ & $1 \mathrm{~g} 8 / 8 \mathrm{~h}\left(11^{\circ} \mathrm{d}\right)$ & 100 & 100 & 100 & 100 \\
& $2 \mathrm{~g} 12 / 12 \mathrm{~h}\left(18^{\circ} \mathrm{d}\right)$ & 100 & 100 & 100 & 89 \\
& $2 \mathrm{~g} 8 / 8 \mathrm{~h}\left(21^{\circ} \mathrm{d}\right)$ & 100 & 100 & 100 & 100 \\
\hline$\# 6$ & $1 \mathrm{~g} 8 / 8 \mathrm{~h}\left(6^{\circ} \mathrm{d}\right)$ & 100 & 100 & 100 & 61 \\
& $2 \mathrm{~g} 8 / 8 \mathrm{~h}\left(9^{\circ} \mathrm{d}\right)$ & 100 & 100 & 100 & 100 \\
& $2 \mathrm{~g} 8 / 8 \mathrm{~h}\left(11^{\circ} \mathrm{d}\right)$ & 100 & 100 & 100 & 100 \\
& $2 \mathrm{~g} 8 / 8 \mathrm{~h}\left(13^{\circ} \mathrm{d}\right)$ & 100 & 100 & 100 & 100 \\
& $2 \mathrm{~g} 8 / 8 \mathrm{~h}\left(17^{\circ} \mathrm{d}\right)$ & 100 & 100 & 100 & 65 \\
\hline
\end{tabular}

Valor de Referência: 60-70\%>CIM Enterobacteriaceae; 40-50\%>CIM Staphylococcus aureus (Chapuis et al., 2010) Abreviaturas: CIM: concentração inibitória mínima obtida in vitro (mg/L); TPQ: tempo pós queimadura (dias) 


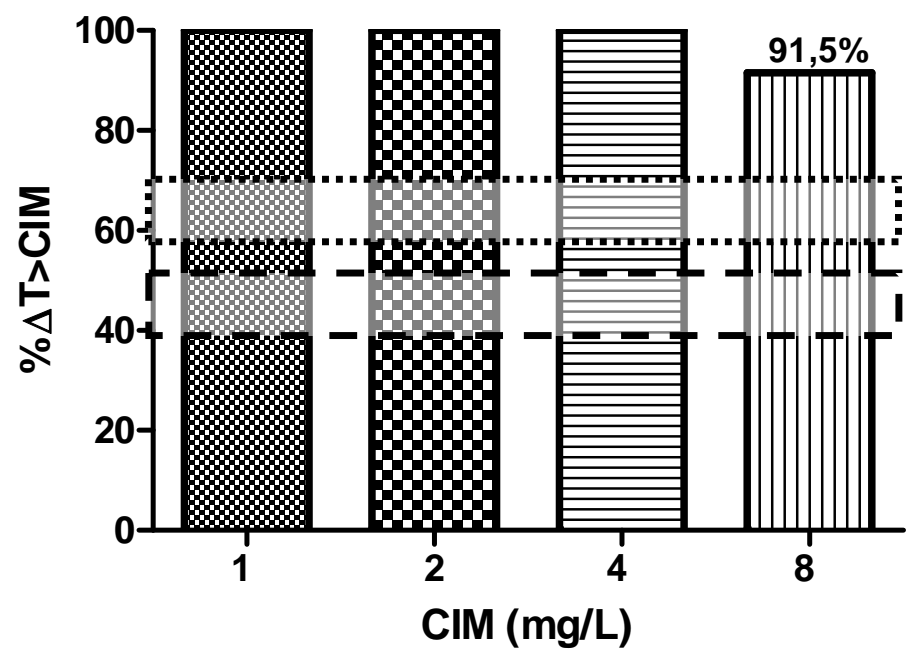

Figura 7 - Modelagem PK-PD para o cefepime $(\% \Delta T>C I M)$ em pacientes queimados, dados expressos através das médias. Abreviaturas: CIM: concentração inibitória mínima obtida in vitro (mg/L). CIM de 8mg/L (Pseudômonas aeruginosa e Staphylococcus aureus),2mg/L (Enterobacter ssp) e $<1 \mathrm{mg} / \mathrm{L}$ (Escherichia coli, Klebsiella pneumoniae, Serratia marcescens, Citrobacter ssp)..Valor de Referência: 60-70\%T>CIM Enterobacteriaceae; 4050\%T>CIM Staphylococcus aureus (CHEATHAM et al, 2011; CHAPUIS et al., 2010). Estatística: GraphPad Prism 4, n=10 seguimentos em três pacientes.

Adicionalmente, a aplicação da modelagem PK-PD indicou que o parâmetro de predição de eficácia $(\% \Delta \mathrm{T}>\mathrm{CIM})$ para o cefepime se mostrou acima da concentração inibitória mínima obtida na medida in vitro (CIM variando de 1 a $8 \mathrm{mg} / \mathrm{L}$ ), figura 7, para a família Enterobacteriaceae (60$70 \% \mathrm{~T}>\mathrm{CIM}$ ) e para o Staphylococcus aureus (40-50\% $>\mathrm{CIM}$ ) garantindo-se portanto a eficácia desse agente nos pacientes queimados durante os seguimentos realizados na UTI. 


\subsection{CIPROFLOXACINO}

Durante o período, realizaram-se seis seguimentos farmacoterapêuticos de três pacientes \#12, \#20 e \#32 em uso sistêmico de ciprofloxacino nas doses usuais recomendadas de 400mg ao dia, no regime posológico de 200mg 12/12 horas, figura 8.

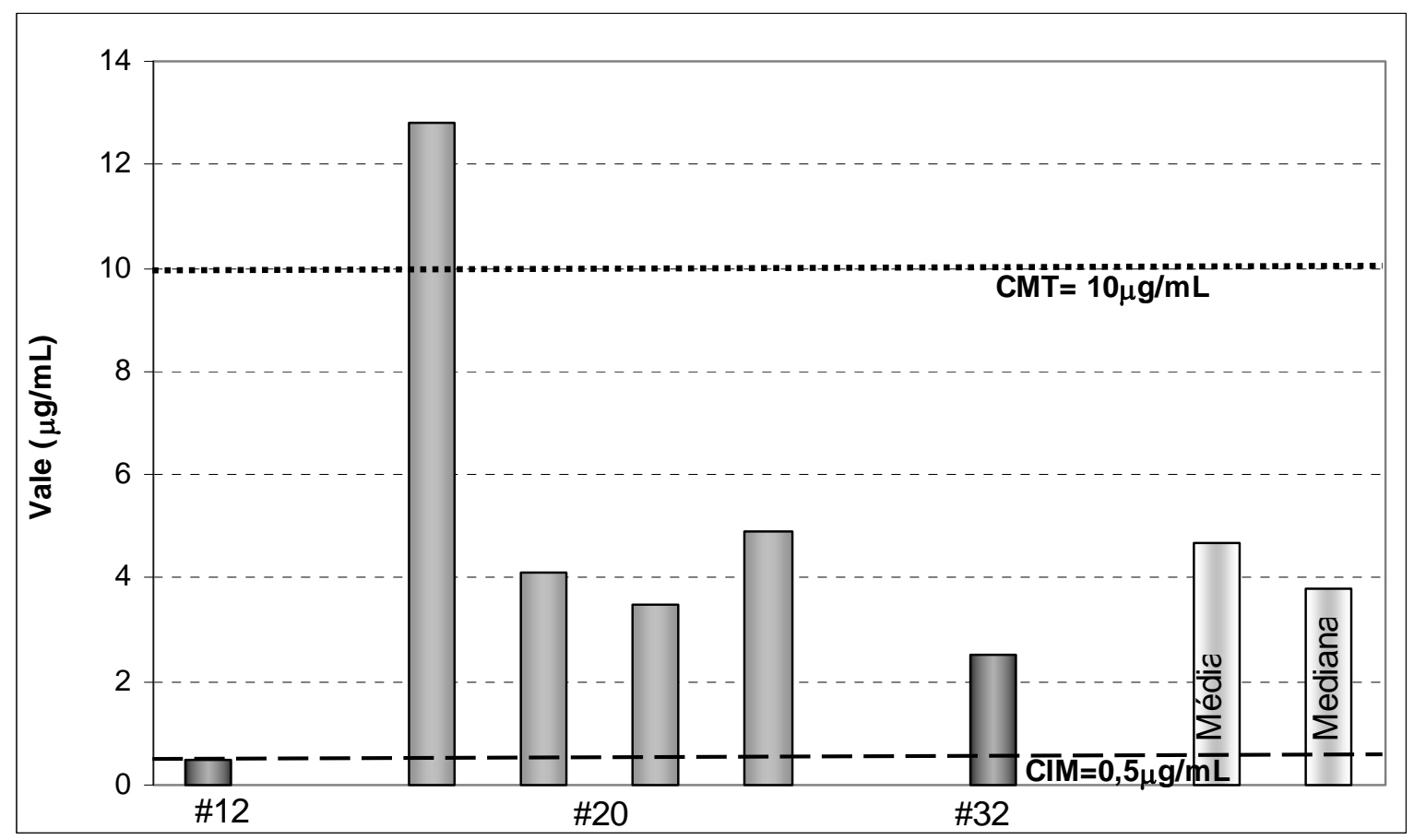

Figura 8 - Concentração plasmática de vale para o ciprofloxacino (acima de 0,5 $\mu \mathrm{g} / \mathrm{mL}$ ): Monitoramento plasmático de ciprofloxacino em pacientes queimados internados na UTI do HCFMUSP. Abreviaturas: CV\%: variabilidade, CIM: Concentração inibitória mínima (valor de referência $0,5 \mu \mathrm{g} / \mathrm{mL}$ ); $\mathrm{CMT}$ : concentração plasmática máxima tolerada, (valor de referência 10 $\mathrm{gg} / \mathrm{mL}$ ). Fonte: Micromedex, 2010.

A variabilidade da farmacocinética do ciprofloxacino foi registrada para os parâmetros meia-vida biológica (CV: 68,1\%), depuração plasmática (CV: 106,4\%) e volume aparente de distribuição (CV: 67,6\%), tabela 5. 
Tabela 5 - Parâmetros farmacocinéticos registrados para o ciprofloxacino ( $\mathrm{n}=6$ seguimentos em três pacientes)

\begin{tabular}{cccc}
\hline Parâmetro & $\mathbf{t}_{(1 / 2) \beta}(\mathrm{h})$ & $\begin{array}{c}\mathbf{C L}_{\mathbf{T}} \\
(\mathrm{mL} / \mathrm{min} . \mathrm{kg})\end{array}$ & $\mathbf{V d}(\mathrm{L} / \mathrm{kg})$ \\
\hline $\begin{array}{c}\text { Valor de } \\
\text { Referência }\end{array}$ & $3,0-6,0$ & 4,3 & $1,2-2,7$ \\
\hline Mediana & 7,5 & 1,5 & 1,9 \\
Média (DP) & $8,8(6,0)$ & $2,8(3,0)$ & $1,5(1,0)$ \\
Variabilidade (\%) & 68,1 & 106,4 & 67,6 \\
\hline Vmín & 3,0 & 0,3 & 0,1 \\
Vmáx & 18,4 & 6,6 & 2,3 \\
LI IC 95\% & 4,0 & 0,4 & 0,7 \\
LS IC 95\% & 13,6 & 5,2 & 2,3 \\
\hline
\end{tabular}

Fonte Micromedex, 2010.

Estatística: GraphPad Prism 4 para estatística descritiva.

Abreviaturas: FRN: função renal normal; DP: desvio padrão da média; LI IC95\%: limite inferior do intervalo de confiança 95\%; LS IC95\%: limite superior do intervalo de confiança 95\%; Vmín: valor mínimo; Vmáx: valor máximo; CV\%: coeficiente de variação; $\mathrm{t}_{(1 / 2) \beta}$ meia vida biológica; $\mathrm{CL}_{T}$ depuração plasmática; $V \mathrm{~d}$ : volume aparente de distribuição
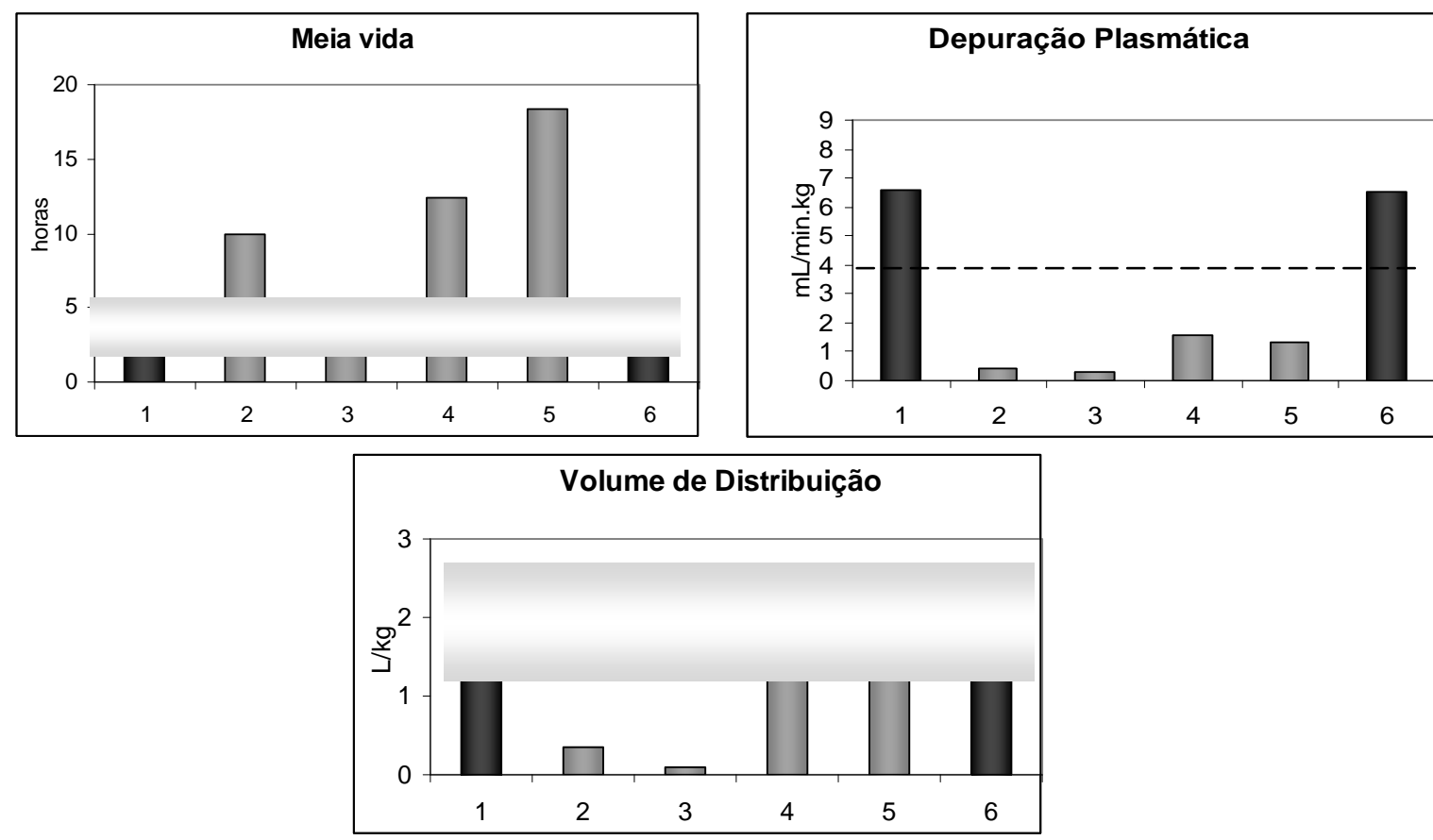

Figura 9. Dados individuais para as constantes farmacocinéticas do ciprofloxacino Faixa de referência: Meia Vida (3-6hs); Depuração Plasmática (4,3 mL/min.kg); Volume de Distribuição $(1,2-2,7 \mathrm{~L} / \mathrm{kg})$ Fonte: Micromedex, 2010

A atividade antibacteriana do ciprofloxacino é concentração-dependente, desta forma a predição de eficácia se realiza através das razões $C_{\text {max }}^{\text {ss }} / \mathrm{CIM}$ e $\mathrm{ASC}^{\mathrm{SS}}{ }_{0-24} / \mathrm{CIM}$ pela modelagem PK-PD conforme ilustrado na tabela 6 e figura 
10. Com base na curva de decaimento plasmático no decurso do tempo, considera-se a concentração máxima $\left(\mathrm{C}^{\mathrm{sS}}{ }_{\max }\right)$ e a área sobre a curva $\left(\mathrm{ASC}^{\mathrm{ss}}{ }_{0}\right.$ 24).

Tabela 6. Modelagem PK/PD expressa através da relação entre $C_{\max }^{s s} \mathrm{e}$ $\mathrm{ASC}^{\mathrm{ss}}{ }_{0-24 \mathrm{hs}}$ versus a CIM, $\mathrm{n}=6$ seguimentos em três pacientes, regime $200 \mathrm{mg}$ $12 / 12 \mathrm{hs}$

\begin{tabular}{r|c|cc}
\hline Paciente & TPQ (dias) & $\mathrm{ASC}^{\text {sS }}{ }_{0-24 h s} / \mathrm{CIM}^{\mathrm{S}}$ & $\mathrm{C}_{\max }^{\mathrm{SS}} / \mathrm{CIM}$ \\
\hline$\# 12$ & 3 & 80,8 & 58 \\
\hline \multirow{3}{*}{$\# 20$} & 5 & 967,2 & 134 \\
& 8 & 1101,2 & 13,6 \\
& 12 & 240 & 15,2 \\
& 15 & 296 & 55,2 \\
\hline$\# 32$ & 7 & 492 & 48,8 \\
\hline
\end{tabular}

Valor de Referência: $\mathrm{C}^{\mathrm{SS}}{ }_{\max } / \mathrm{CIM}>12 ; \mathrm{ASC}_{0-24}^{\mathrm{SS}} / \mathrm{CIM}>125$. CIM para bactérias gram negativas susceptíveis: 0,25-0,50 mg/L.(PEA et al., 2006) Abreviaturas: CIM: concentração inibitória mínima obtida in vitro (mg/L); TPQ: tempo pós queimadura (dias)
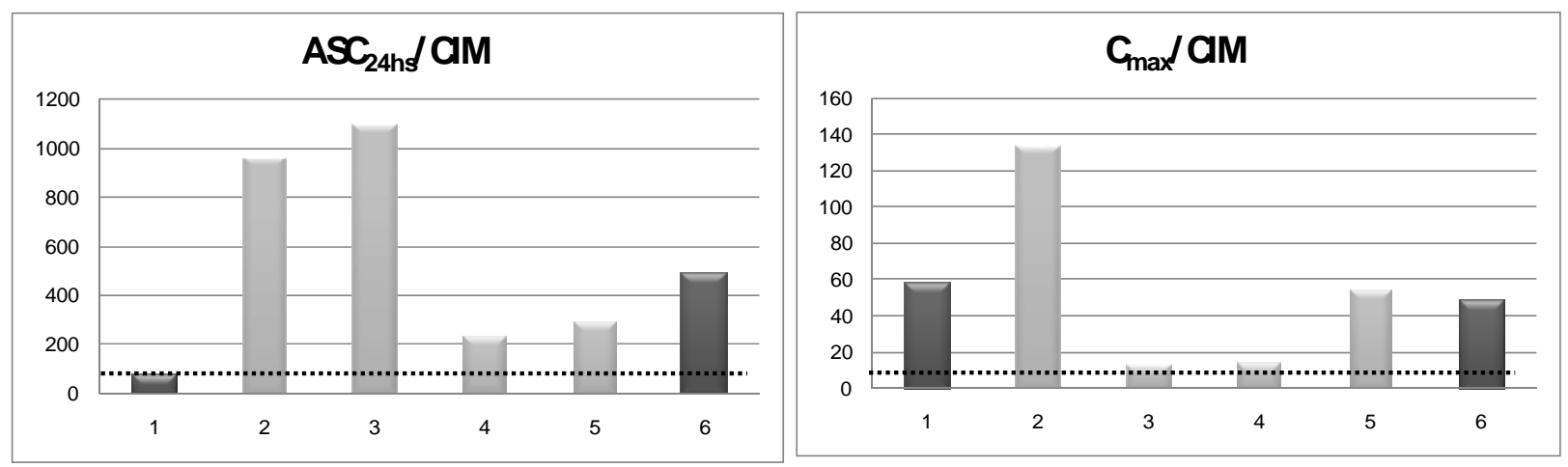

Figura 10: Modelagem PK-PD para o ciprofloxacino ( $\mathrm{C}_{\text {max }}^{\mathrm{SS}}$ e $A S C^{\mathrm{sS}}{ }_{0-24 \mathrm{hs}}$ sobre $\mathrm{CIM}$ ) em pacientes queimados. Valor de Referência: $\mathrm{ASC}_{24}^{\mathrm{sS}} / \mathrm{CIM}>125 ; \mathrm{C}^{\mathrm{SS}} \max / \mathrm{CIM}>10$. CIM para bactérias gram negativas susceptíveis: 0,5mg/L.(PEA et al., 2006), Abreviaturas: ASC: área sobre a curva; $\mathrm{C}_{\text {max: }}^{\text {sS }}$ Concentração máxima; CIM: concentração inibitória mínima obtida in vitro $(\mathrm{mg} / \mathrm{L})$

A aplicação da modelagem PK-PD indicou que os valores de referência para os parâmetros de predição de eficácia do ciprofloxacino (ASC ${ }_{0-24}^{\mathrm{ss}} / \mathrm{CIM}$ $>125$ e $\mathrm{C}_{\text {max }}^{\text {ss }} / \mathrm{CIM}>10$ ) não foram atingidos em todos os seguimentos realizados considerando-se as bactérias gram negativas susceptíveis, CIM 0,5 $\mathrm{mg} / \mathrm{L}$ indicando que a eficácia agente não foi garantida em 100\%. 


\subsection{FLUCONAZOL}

Em decorrência da infecção fúngica na fase tardia de internação do paciente queimado na UTI, realizou-se o seguimento farmacoterapêutico para o fluconazol em 12 pacientes recebendo esse agente sistêmico.

A alteração do regime posológico do fluconazol prescrito inicialmente (dose empírica) foi requerida em 58\% das prescrições 26\% redução e 32\% de aumento para garantir baixo risco no paciente, figura 11.

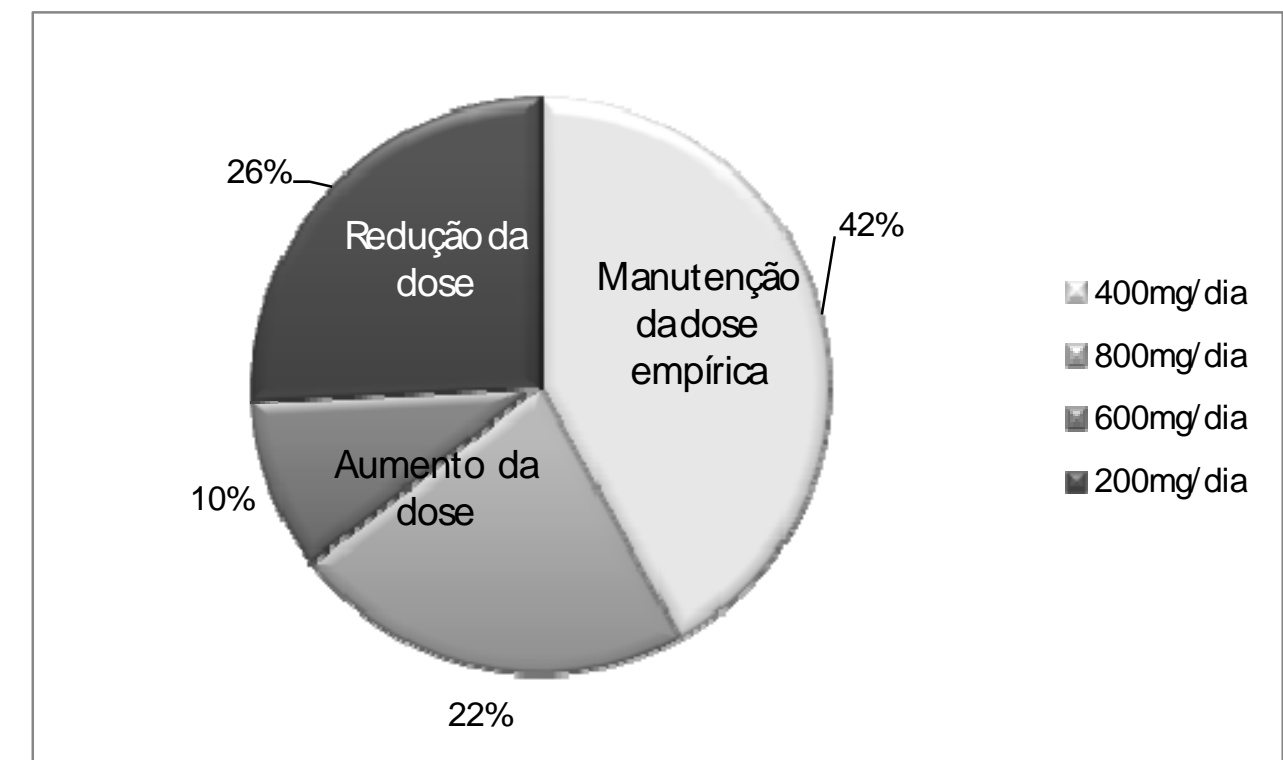

Figura 11 - Alteração do regime de dose empírica de Fluconazol, 400mg ao dia no total de 31 seguimentos realizados em 12 pacientes.

A terapia dose ajustada foi requerida para o controle da infecção fungica nos queimados pelo aumento da dose diária do fluconazol e alteração do regime de dose recomendado inicialmente (400mg/dia, 200mg de 12/12hs) em $58 \%$ dos seguimentos realizados nos 12 pacientes. Registrou-se aumento da dose diária para 600mg/dia (200mg 8/8hs) e para 800mg/dia (200mg 6/6hs), respectivamente em $10 \%$ e $22 \%$ dos seguimentos realizados. Entretanto, a dose diária requerida foi reduzida para 200mg, 1x ao dia nos casos de falência renal em 26\% dos seguimentos realizados, figura 11.

O ajuste de dose realizado com base no vale e estudo farmacocinético em cada período do seguimento é ilustrado nas figuras 12 e 13 para 12 pacientes recebendo 0 agente antifúngico. Durante 0 seguimento 
farmacoterapêutico sete pacientes apresentaram função renal normal (Figura 12), cinco iniciaram o tratamento já com o procedimento de diálise instalada e apenas o paciente \#15 da população portadora de função renal normal evoluiu para insuficiência renal dialítica, figura 13.

Desta forma, considerou-se a função renal dos pacientes com base na presença ou não de procedimento de diálise para fins de distribuição em grupos no tratamento estatístico dos resultados obtidos.

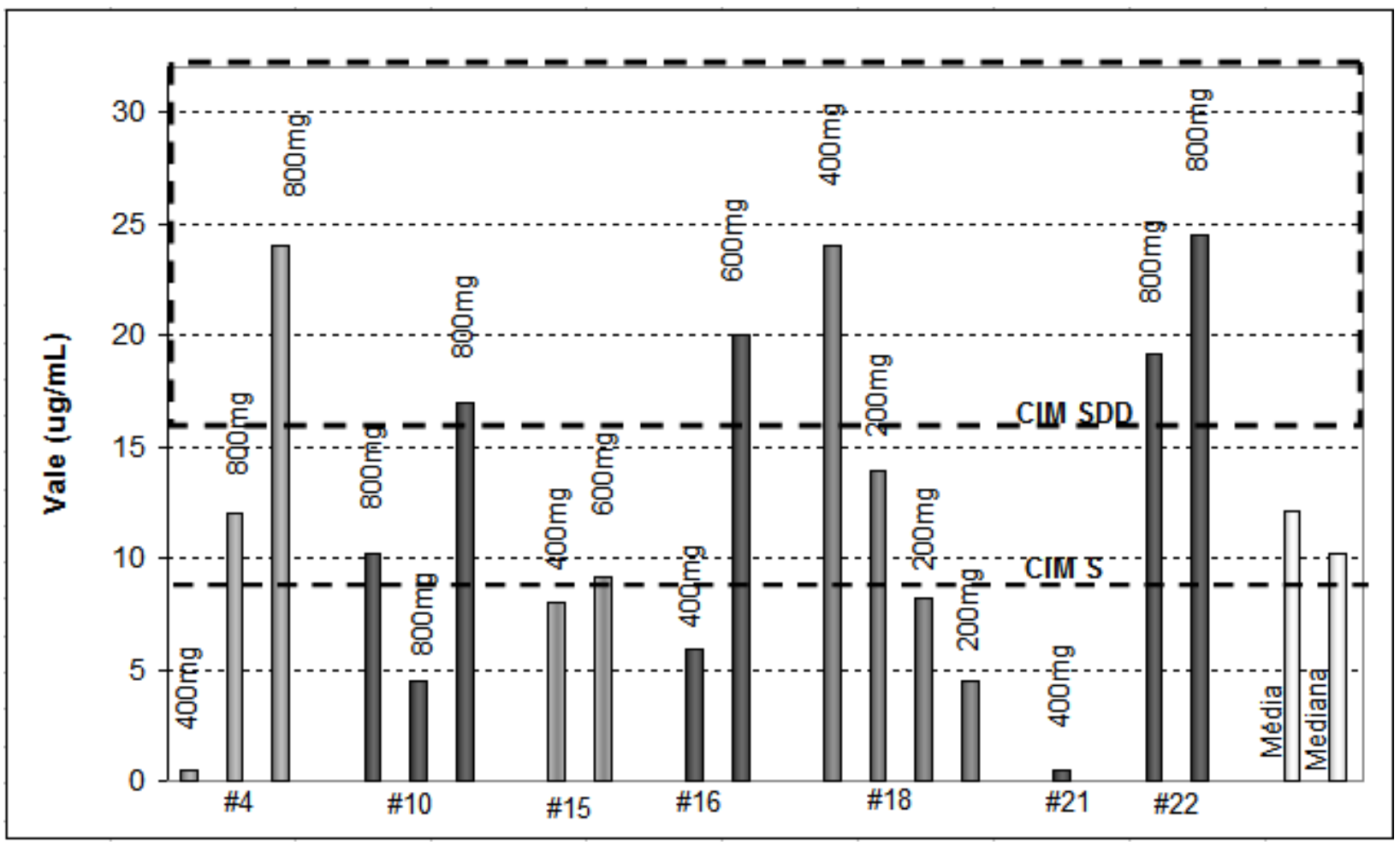

Figura 12 - Vale de concentração plasmática de fluconazol. Monitoramento das concentrações plasmáticas em sete pacientes queimados internados na UTI do HCFMUSP com função renal normal. Valor de Referência: CIM para Candida sensível:<8mg/L; sensibilidade dosedependente:16-32mg/L e resistente>64mg/L (PFALLER et al., 2006) Abreviaturas: CIM: concentração inibitória mínima obtida in vitro (mg/L). 


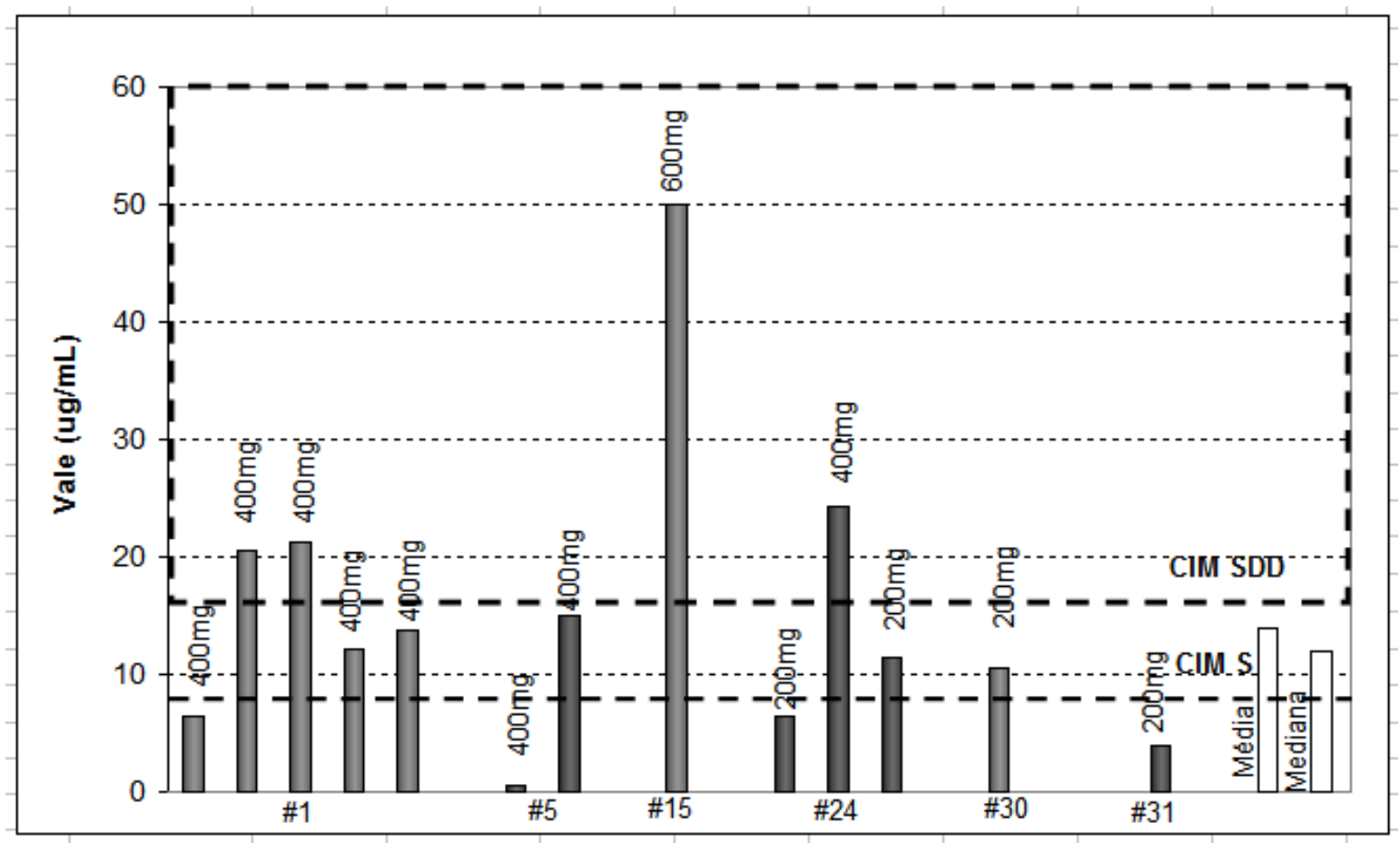

Figura 13 - Concentração plasmática de fluconazol no vale $(\mu \mathrm{g} / \mathrm{mL})$ : Ajuste de dose em seis pacientes queimados internados na UTI do HCFMUSP com insuficiência renal dialítica. Abreviaturas: CIM: concentração inibitória mínima obtida in vitro (mg/L).Valor de Referência: CIM para Candida sensível:<8mg/L; sensibilidade dose-dependente:16-32mg/L e resistente>64mg/L (PFALLER et al., 2006)

A estatística descritiva relativa à farmacocinética do fluconazol nas populações de pacientes com função renal normal e com insuficiência renal dialítica encontra-se nas tabelas 7, 8, 9 e 10.

A meia vida biológica frente aos valores de referência se mostrou reduzida nos dois grupos de pacientes queimados (Tabela 7). Enquanto que, na tabela 8, a depuração plasmática se mostrou dentro dos valores de referência nos dois grupos de pacientes queimados. 
Tabela 7 - Meia vida biológica do fluconazol, $\mathrm{n}=31$

\begin{tabular}{ccc}
\hline Parâmetro & $\begin{array}{c}\text { FRN } \\
(\mathbf{n = 1 7})\end{array}$ & $\begin{array}{c}\text { Diálise } \\
(\mathbf{n = 1 4 )}\end{array}$ \\
\hline Mediana & 8,1 & 8,3 \\
Média/DP & $9,1+/-5,8$ & $10,6+/-8,6$ \\
Vmín & 1,5 & 0,7 \\
Vmáx & 21,1 & 25 \\
LI IC 95\% & 6,3 & 6,1 \\
LS IC 95\% & 11,8 & 15,1 \\
CV\% & 63,5 & 80,5
\end{tabular}

Valor de referência: 27 a 37 horas Fonte: Micromedex, 2010. Estatística: GraphPad Instat 3.0 e GraphPad Prism 4 para estatística descritiva. Abreviaturas: FRN: função renal normal; DP: desvio padrão da média; LI IC95\%: limite inferior do intervalo de confiança 95\%; LS IC95\%: limite superior do intervalo de confiança 95\%; Vmín: valor mínimo; Vmáx: valor máximo; CV\%: coeficiente de variação

Tabela 8 - Depuração plasmática do fluconazol, $n=31$

\begin{tabular}{ccc}
\hline Parâmetro & $\begin{array}{c}\text { FR normal } \\
(\mathbf{n}=\mathbf{1 7})\end{array}$ & $\begin{array}{c}\text { Diálise } \\
(\mathbf{n}=\mathbf{1 4})\end{array}$ \\
\hline Mediana & 0,3 & 0,3 \\
Média & 0,3 & 0,6 \\
DP & 0,1 & 0,8 \\
Vmín & 0,1 & 0,1 \\
Vmáx & 0,6 & 2,6 \\
LI IC 95\% & 0,2 & 0,1 \\
LS IC 95\% & 0,3 & 1,0 \\
CV\% & 50,6 & 144,7
\end{tabular}

Valor de referência: $\overline{0,27 \text { a } 0,63 \mathrm{~mL} / \mathrm{min} . \mathrm{kg} \text { Fonte: Micromedex, } 2010}$ Estatística: GraphPad Prism 4 para estatística descritiva. Abreviaturas: FR: função renal; DP: desvio padrão da média; LI IC95\%: limite inferior do intervalo de confiança 95\%; LS IC95\%: limite superior do intervalo de confiança 95\%; Vmín: valor mínimo; Vmáx: valor máximo; CV: coeficiente de variação.

Conforme referido na tabela 9, o volume aparente de distribuição frente aos valores de referência se mostrou muito reduzido nos dois grupos de pacientes queimados. 
Tabela 9 - Volume aparente de distribuição do fluconazol, n=31

\begin{tabular}{ccc}
\hline Parâmetro & $\begin{array}{c}\text { FR normal } \\
(\mathbf{n = 1 7})\end{array}$ & $\begin{array}{c}\text { Diálise } \\
(\mathbf{n}=\mathbf{1 4})\end{array}$ \\
\hline Mediana & 0,13 & 0,15 \\
Média & 0,23 & 0,23 \\
DP & 0,24 & 0,18 \\
Vmín & 0,02 & 0,05 \\
Vmáx & 0,76 & 0,45 \\
LI IC 95\% & 0,12 & 0,14 \\
LS IC 95\% & 0,35 & 0,32 \\
CV\% & 103,7 & 77,5
\end{tabular}

Valor de referência: 0,56 a 0,82 L/kg Fonte: Micromedex, 2010 Estatística: GraphPad Prism 4 para estatística descritiva. Abreviaturas: FR: função renal; DP: desvio padrão da média; LI IC95\%: limite inferior do intervalo de confiança 95\%; LS IC95\%: limite superior do intervalo de confiança 95\%; Vmín: valor mínimo; Vmáx: valor máximo; CV: coeficiente de variação

Comparou-se a farmacocinética do antifúngico em 31 seguimentos realizados para os pacientes distribuídos em dois grupos com base na função renal normal versus insuficiência renal dialítica, tabela 10. Não se evidenciou diferença significativa entre os dois grupos para todos os parâmetros investigados, figura 14.

Tabela 10 - Farmacocinética do fluconazol em queimados com infecção fúngica, $\mathrm{n}=31$ seguimentos

\begin{tabular}{ccccc}
\hline Parâmetro & Unidade & $\begin{array}{c}\text { FRN } \\
(\mathbf{n = 1 7})\end{array}$ & $\begin{array}{c}\text { Diálise } \\
(\mathbf{n = 1 4 )}\end{array}$ & $\mathbf{P}$ \\
\hline $\mathrm{t}_{(1 / 2) \beta}$ & $($ hora $)$ & 8,1 & 8,3 & 0,7554 \\
$\mathrm{CL}_{T}$ & $(\mathrm{~mL} / \mathrm{min} . \mathrm{kg})$ & 0,3 & 0,3 & 0,9771 \\
$\mathrm{Vd}$ & $(\mathrm{L} / \mathrm{kg})$ & 0,13 & 0,15 & 0,7985 \\
\hline
\end{tabular}

Estatística: Teste de Mann Whitney não paramétrico, dados não pareados,medianas, $\mathrm{n}=31$ Abreviaturas: FRN: função renal normal; $P$ : probabilidade, nível de significância $p<0,05 ; t_{(1 / 2) \beta}$ meia vida biológica; $\mathrm{CL}_{\mathrm{T}}$ depuração plasmática; $\mathrm{Vd}$ : volume aparente de distribuição 

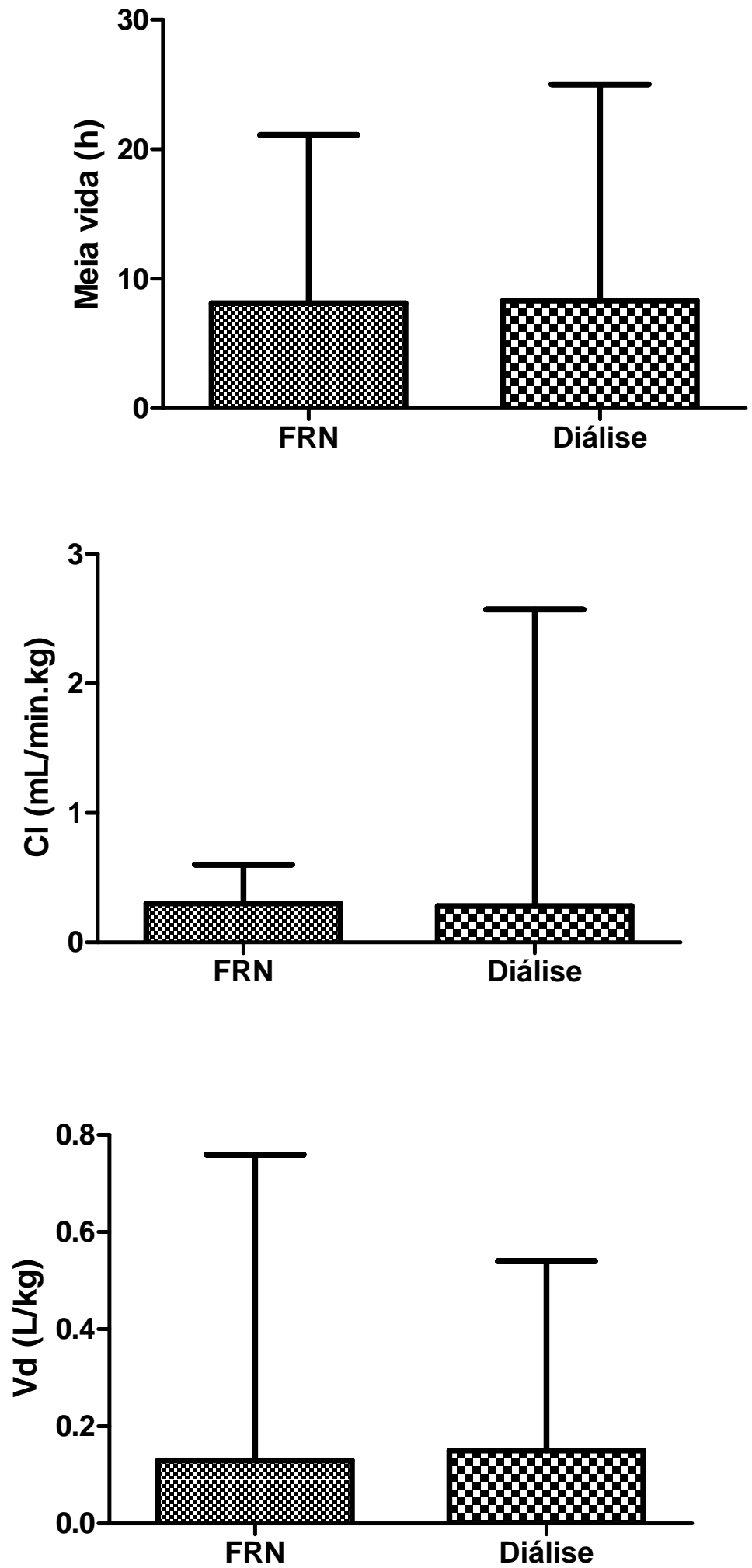

Figura 14: Comparação dos parâmetros farmacocinéticos do Fluconazol para os pacientes com função renal normal e pacientes dialíticos (mediana/+ IC95\%). Abreviaturas: $F R N$ : função renal normal; $\mathrm{t}_{(1 / 2) \beta}$ meia vida biológica; $\mathrm{CL}_{\mathrm{T}}$ depuração plasmática; Vd: volume aparente de distribuição. Estatística: Teste de Mann Whitney não paramétrico, dados não pareados, medianas * $p<0,05$ 
Evidenciou-se alta variabilidade na farmacocinética do agente antifúngico considerando-se os 31 seguimentos realizados nos pacientes queimados, independentemente da função renal preservada $(n=17)$ ou não $(n=14)$, fato que indicou a necessidade da terapia dose ajustada. A eficácia foi garantida pelo aumento da dose diária em 32\% dos seguimentos. Adicionalmente, nos seguimentos de pacientes queimados com função renal reduzida (26\%) realizou-se a redução da dose diária de 400mg para 200mg 1x ao dia.

A atividade fungistática do fluconazol depende do intervalo de tempo para manter a concentração que forneça área sob a curva integrada acima do valor recomendado, mas não da concentração em si isoladamente; e a medida preditiva de eficácia é realizada através da razão $\mathrm{ASC}_{0-24}^{\mathrm{SS}} / \mathrm{CIM}$ para o efeito pós-fluconazol contra a Candida ssp.. A modelagem PK-PD foi aplicada considerando-se a área sobre a curva $\left(\mathrm{ASC}^{\mathrm{SS}}{ }_{0-24}\right)$ em sua relação com o CIM (Figura 15).

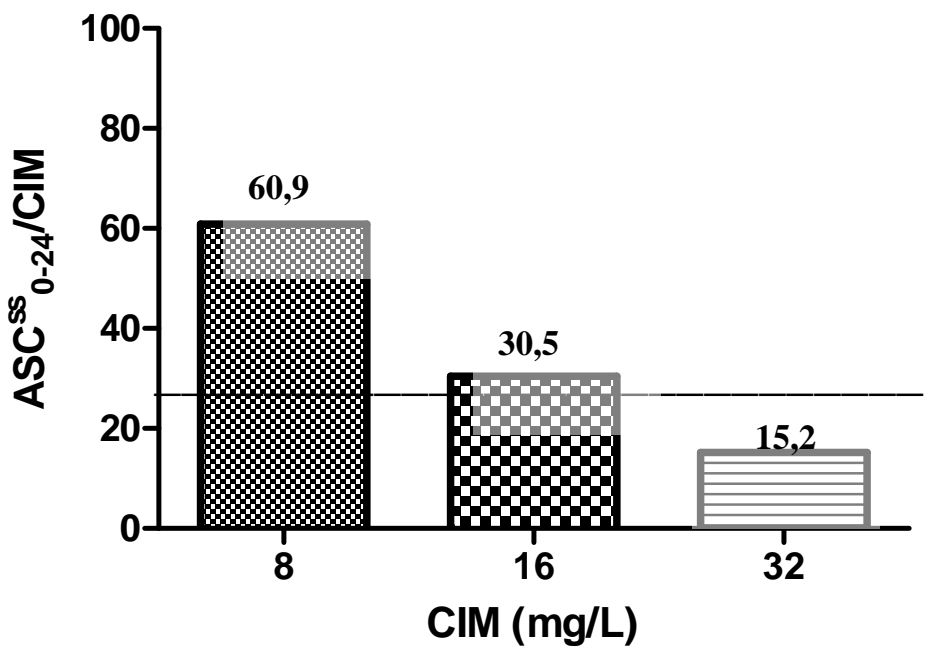

Figura 15: Modelagem PK-PD para o fluconazol (ASC ${ }_{0-24 h s}^{\text {ss }} / \mathrm{CIM}$ ) em pacientes queimados. Valor de Referência: $\mathrm{ASC}^{\mathrm{SS}}{ }_{0-24} / \mathrm{CIM}>25$. CIM para Candida sensível: $<8 \mathrm{mg} / \mathrm{L}$; sensibilidade dose-dependente:16-32mg/L e resistente>64mg/L (PFALLER et al., 2006) Abreviaturas: ASC: área sobre a curva; CIM: concentração inibitória mínima obtida in vitro $(\mathrm{mg} / \mathrm{L})$

Observou-se que os valores de referência para a predição de eficácia do fluconazol $\mathrm{ASC}^{\mathrm{sS}}{ }_{0-24} / \mathrm{CIM}>25$ foram atingidos somente em parte dos seguimentos realizados considerando-se Candida ssp, cepas sensíveis CIM 8 $\mathrm{mg} / \mathrm{L}$, estendendo-se ainda para os casos de Candida ssp. apresentando sensibilidade dose dependente para valores de CIM 8 e 16 mg/L, mas não para cepas apresentando CIM $32 \mathrm{mg} / \mathrm{L}$. 


\subsection{IMIPENEM}

Durante o período foram acompanhados num total de 75 seguimentos, 18 pacientes (\#2, \#5, \#9, \#10, \#11, \#13, \#14, \#15, \#17, \#18, \#20, \#21, \#22, \#23, \#24, \#25, \#28, \#31), inicialmente todos com função renal normal recebendo imipenem sistêmico. No decorrer do seguimento na UTI, cinco pacientes \#5, \#18, \#24, \#25, \#31 (27,8\%) evoluíram para insuficiência renal dialítica.

Nos pacientes com função renal normal, o regime posológico recomendado para o imipenem (dose empírica, $2 \mathrm{~g}$ diárias, 500mg 6/6 horas) foi alterado em $41 \%$ dos seguimentos, sendo mantido nos demais períodos investigados conforme ilustrado na figura 16.

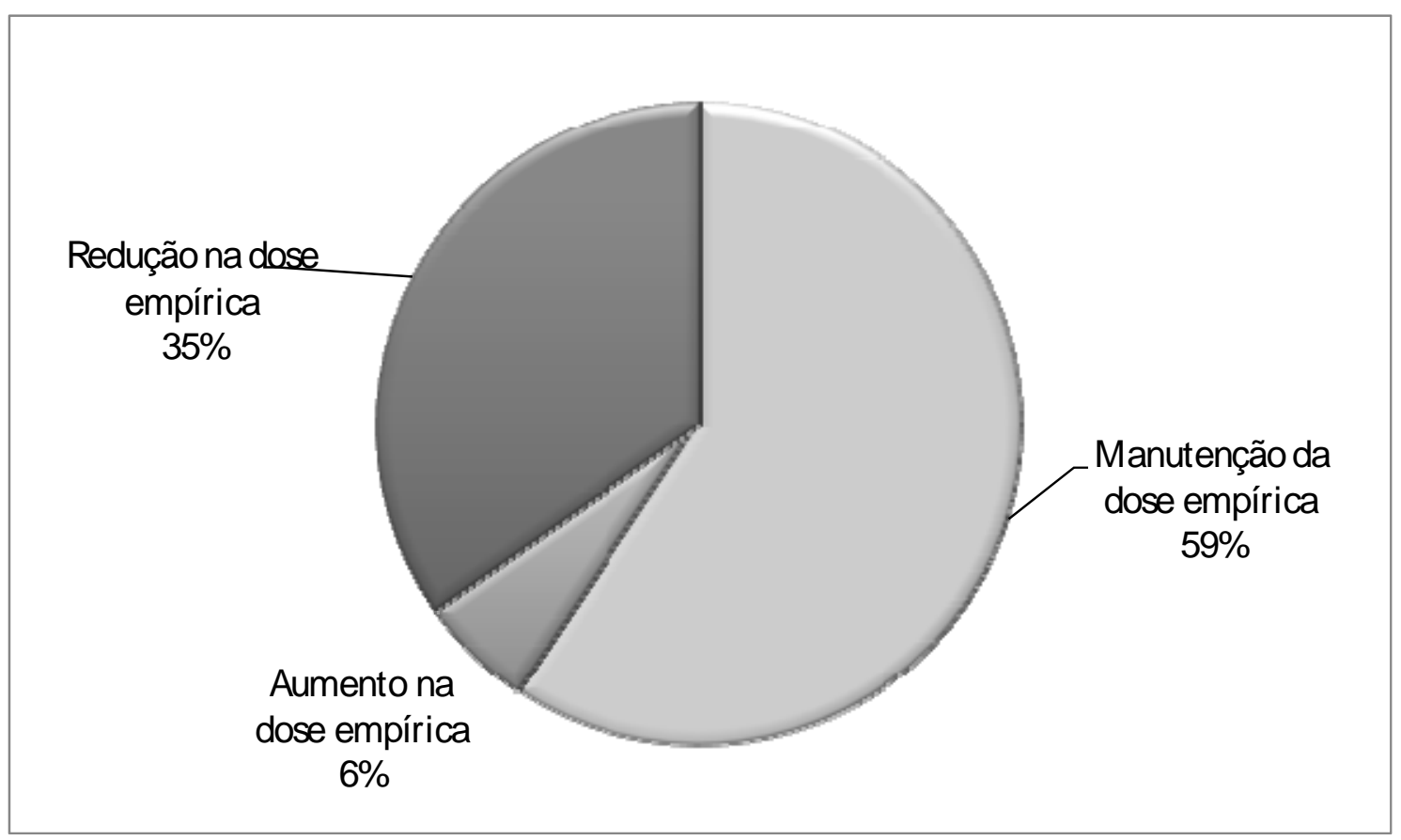

Figura 16. Indicação de terapia dose ajustada com alteração do regime de dose empírica de Imipenem. 
O regime posológico recomendado para o imipenem (dose empírica, $500 \mathrm{mg}$ 6/6 horas) foi alterado em 19\% dos seguimentos, sendo mantido em $81 \%$ dos demais períodos investigados para os pacientes com função renal normal, conforme ilustrado na figura 17A.

A figura 17B ilustra a alteração o regime posológico para $68 \%$ dos pacientes com insuficiência renal dialítica considerando-se a necessidade de redução da dose diária pela terapia dose ajustada.

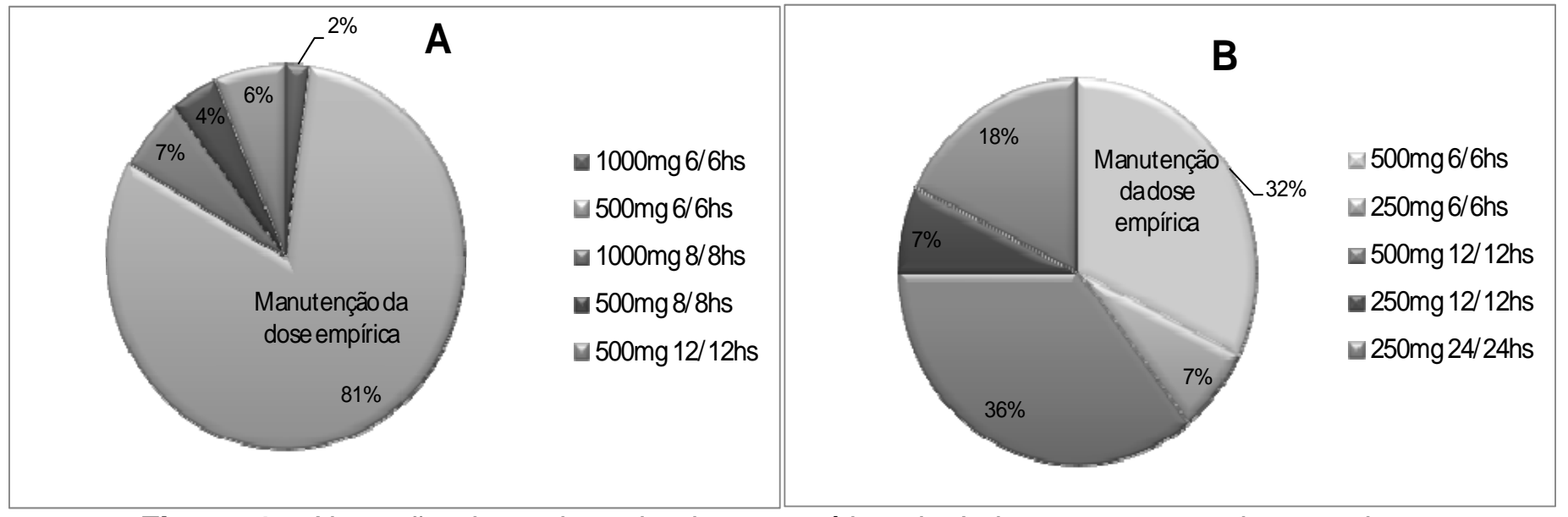

Figura 17 Alteração do regime de dose empírica de Imipenem no seguimento de pacientes queimados (A) com função renal normal, $n=47$ seguimentos; (B) pacientes que evoluíram para insuficiência renal dialítica, $n=28$ seguimentos.

A farmacocinética do imipenem foi investigada com base na função renal (normal e insuficiência renal dialítica) dos pacientes investigados, tabelas 11, 12,13 e 14.

A meia vida biológica, frente aos valores de referência se mostrou prolongada nos pacientes queimados dialíticos $(p<0,05)$, tabela 11 e 14 . 


\begin{tabular}{|c|c|c|}
\hline Parâmetro & $\begin{array}{c}\text { FR normal } \\
(n=47)\end{array}$ & $\begin{array}{l}\text { Diálise } \\
(n=28)\end{array}$ \\
\hline Mediana & 3,4 & 8,4 \\
\hline Média & 4,8 & 14,5 \\
\hline DP & 4,3 & 19,1 \\
\hline Vmín & 0,4 & 1,6 \\
\hline Vmáx & 22,6 & 81,9 \\
\hline LI IC 95\% & 3,3 & 7,4 \\
\hline LS IC 95\% & 6,2 & 21,6 \\
\hline CV\% & 89,0 & 131,5 \\
\hline
\end{tabular}

Valor de referência: 1 hora, Fonte: Micromedex, 2010. Estatística: GraphPad Prism 4 para estatística descritiva. Abreviaturas: FRN: função renal normal; DP: desvio padrão da média; LI IC95\%: limite inferior do intervalo de confiança 95\%; LS IC95\%: limite superior do intervalo de confiança 95\%; Vmín: valor mínimo; Vmáx: valor máximo; CV\%: coeficiente de variação

A depuração plasmática se mostrou, frente aos valores de referência, acentuadamente reduzida nos queimados dialíticos $(p<0,05)$, tabela 12 e 14 . Por sua vez, o volume aparente de distribuição frente aos valores de referência se mostrou aumentado em pacientes queimados, tabela 13 e 14 .

\begin{tabular}{ccc} 
Tabela $\mathbf{1 2}$ - Depuração plasmática de Imipenem \\
\cline { 2 - 3 } Parâmetro & $\begin{array}{c}\text { FR normal } \\
(\mathbf{n = 4 7 )}\end{array}$ & $\begin{array}{c}\text { Diálise } \\
(\mathbf{n = 2 8})\end{array}$ \\
\hline Mediana & 2,5 & 0,6 \\
Média & 3,3 & 1,0 \\
DP & 2,6 & 1,0 \\
Vmín & 0,1 & 0,1 \\
Vmáx & 10,9 & 3,8 \\
LI IC 95\% & 2,4 & 0,6 \\
LS IC 95\% & 4,2 & 1,4 \\
CV\% & 80,8 & 103,8
\end{tabular}

Valor de referência: 2,6 a 3,1 mL/min.kg, Fonte:Micromedex 2010 Estatística: GraphPad Prism 4 para estatística descritiva. Abreviaturas: FRN: função renal normal; DP: desvio padrão da média; LI IC95\%: limite inferior do intervalo de confiança 95\%; LS IC95\%: limite superior do intervalo de confiança 95\%; Vmín: valor mínimo; Vmáx: valor máximo; CV\%: coeficiente de variação 
Tabela 13 - Volume aparente de distribuição de Imipenem, n=75

\begin{tabular}{ccc}
\hline Parâmetro & $\begin{array}{c}\text { FR normal } \\
(\mathbf{n}=33)\end{array}$ & $\begin{array}{c}\text { Diálise } \\
(\mathbf{n}=\mathbf{2 8})\end{array}$ \\
\hline Mediana & 0,7 & 0,4 \\
Média & 1,2 & 0,9 \\
DP & 1,8 & 1,3 \\
Vmín & 0,01 & 0,03 \\
Vmáx & 8,24 & 1,78 \\
LI IC 95\% & 0,6 & 0,4 \\
LS IC 95\% & 1,8 & 1,4 \\
CV\% & 140,6 & 142,7
\end{tabular}

Valor de referência: 0,14 a 0,23 L/kg, Fonte:Micromedex 2010 Estatística: GraphPad Instat 3.0 e GraphPad Prism 4 para estatística descritiva. Abreviaturas: FRN: função renal normal; DP: desvio padrão da média; LI IC95\%: limite inferior do intervalo de confiança 95\%; LS IC95\%: limite superior do intervalo de confiança 95\%; Vmín: valor mínimo; Vmáx: valor máximo; CV\%: coeficiente de variação

Tabela 14 - Farmacocinética do imipenem em queimados com sepse, n=75

\begin{tabular}{ccccc}
\hline Parâmetro & Unidade & $\begin{array}{c}\text { FRN } \\
(\mathbf{n = 4 7 )}\end{array}$ & $\begin{array}{c}\text { Diálise } \\
\mathbf{( n = 2 8 )}\end{array}$ & $\mathbf{P}$ \\
\hline $\mathrm{t}_{(1 / 2) \beta}$ & $($ hora $)$ & 3,4 & 8,4 & 0,0027 \\
$\mathrm{CL}_{T}$ & $(\mathrm{~mL} / \mathrm{min} . \mathrm{kg})$ & 2,5 & 0,6 & $<0,0001$ \\
$\mathrm{Vd}$ & $(\mathrm{L} / \mathrm{kg})$ & 0,74 & 0,43 & 0,1839 \\
\hline
\end{tabular}

Estatística: Teste de Mann Whitney, dados não pareados, medianas, $n=75$, significância $(p<0,05)$. Abreviaturas: FRN: função renal normal; $P$ : probabilidade; $t_{(1 / 2) \beta}$ meia vida biológica; $\mathrm{CL}_{\mathrm{T}}$ depuração plasmática; $\mathrm{Vd}$ : volume aparente de distribuição

Comparando-se os seguimentos de pacientes com insuficiência renal e com função renal preservada, a farmacocinética do imipenem mostrou na disfunção renal dialítica evidente prolongamento da meia vida biológica e grande redução da depuração plasmática. Como o volume de distribuição mostrou alta variabilidade tanto nos pacientes com FRN quanto na insuficiência renal dialítica, a aparente redução do parâmetro na IR não apresenta significância estatística.

Os parâmetros farmacocinéticos estimados para os pacientes queimados nos seguimentos realizados são ilustrados na figura 18. 

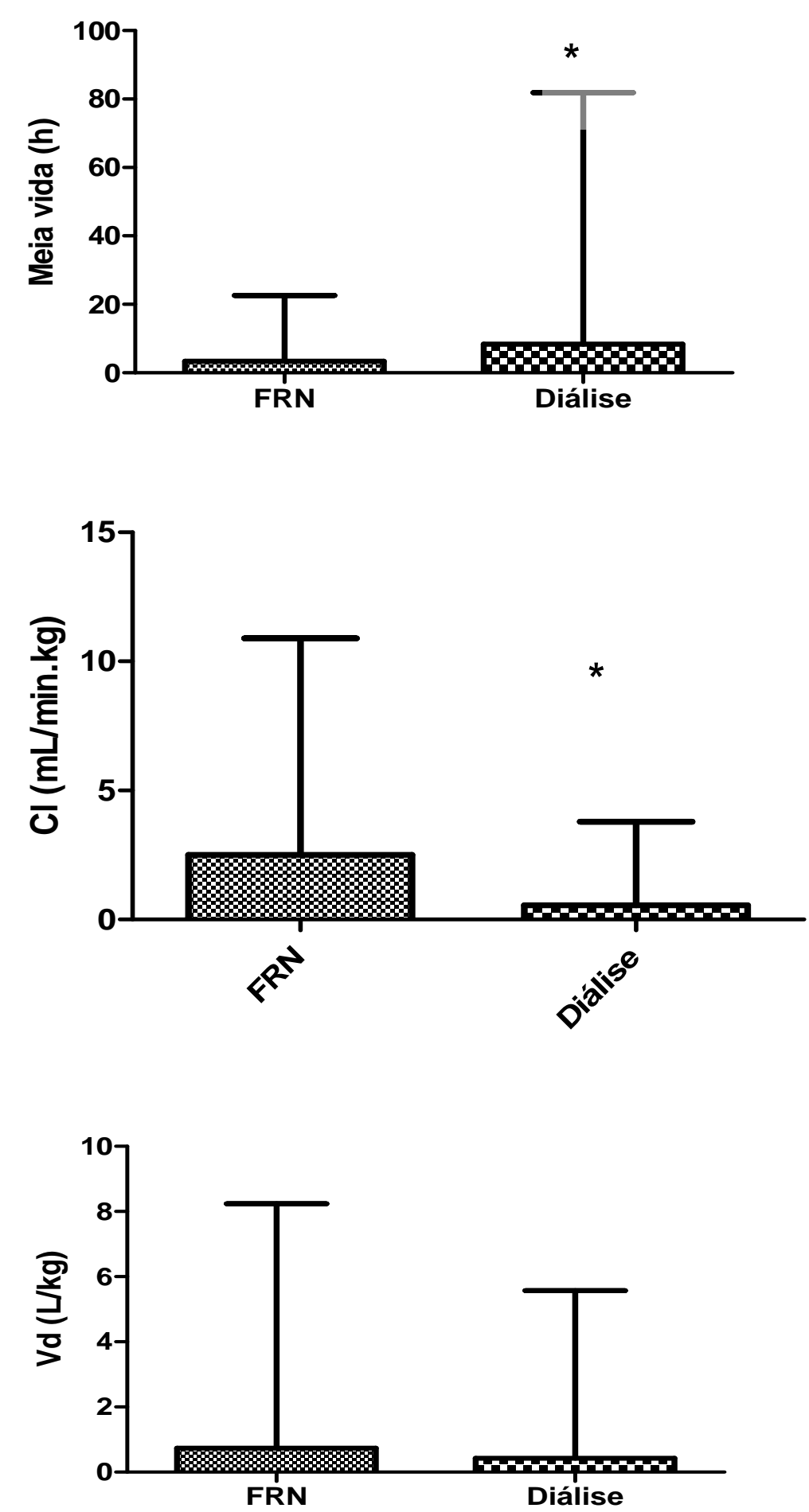

Figura 18: Farmacocinética do imipenem nos seguimentos de pacientes com FRN e em diálise, resultados expressos através da mediana e a dispersão IC95\% intervalo de confiança. Estatística: Teste de Mann Whitney não paramétrico, dados não pareados, medianas * $p<0,05$ Abreviaturas: $F R N$ : função renal normal; $t_{(1 / 2) \beta}$ meia vida biológica; $C_{T}$ depuração plasmática; Vd: volume aparente de distribuição 
A atividade antibacteriana tempo-dependente do imipenem é observada através da razão \% \%T>CIM. A modelagem PK-PD foi aplicada no presente estudo para o imipenem conforme ilustrado na figura 19 , com base na curva de decaimento plasmático no decurso do tempo, considerando-se a porcentagem de tempo $(\% \Delta T)$ em que a concentração do fármaco encontra-se acima do CIM.

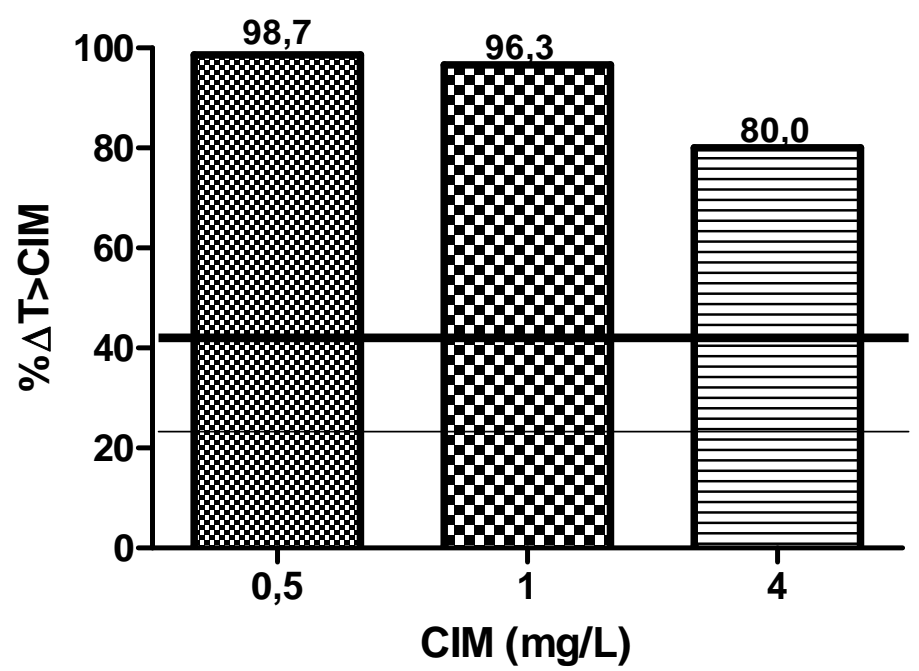

Figura 19: Modelagem PK-PD para o imipenem (\% $\% \mathrm{~T}>\mathrm{CIM})$ em pacientes queimados. Valor de Referência: atividade bacteriostática: acima de 20\%T>CIM; atividade bactericida: acima de 40\%T>CIM (IKAWA, 2008; BURGESS \& FREI, 2005; KAYS, 1999). Abreviaturas: CIM: concentração inibitória mínima, valor de referência 0,5mg/L (Escherichia coli), 1mg/L (Acinetobacter baumanni, Enterobacter aerogenes, Enterobacter cloacae, Klebsiella ssp) 4mg/L (Enterococcus faecalis, Enterococcus faecium, Morganella morganii). Fonte: Eucast 2010.

Registraram-se concentrações do imipenem acima do CIM para a grande maioria dos seguimentos realizados e para os diferentes microorganismos considerados. O parâmetro PK-PD (\% $\Delta \mathrm{T}>\mathrm{CIM})$ mostrou-se abaixo de 40\%, portanto sem efeito bactericida em apenas 6/75 seguimentos, e inferior a 20\%, sem efeito bacteriostático em apenas 2/75 seguimentos realizados. 


\subsection{OXACILINA}

Durante o período foram acompanhados dois pacientes com infecção da comunidade, recebendo oxacilina sistêmica: \#12 (01 seguimento) e \#20 (04 seguimentos), figura 20.

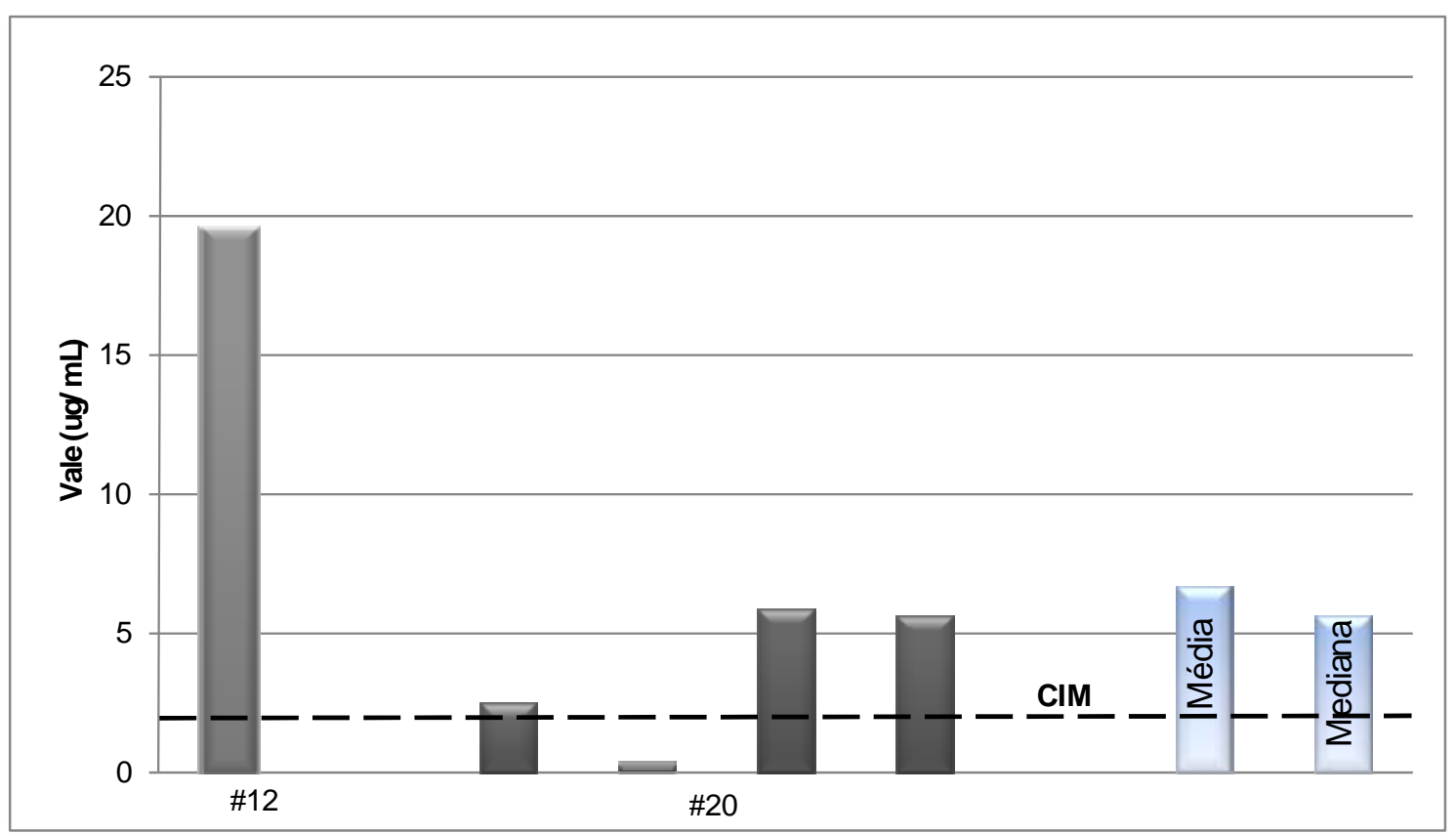

Figura 20 - Concentração plasmática de oxacilina no vale $(\mu \mathrm{g} / \mathrm{mL})$ : Ajuste de dose em dois pacientes queimados internados na UTI do HCFMUSP. Dose diária para o \#12 de $6000 \mathrm{mg}$ e de $4000 \mathrm{mg}$ para \#20. CIM: concentração inibitória mínima, valor de referência 2mg/L. Fonte: Micromedex, 2010; Eucast 2010.

Os parâmetros farmacocinéticos encontram-se descritos na tabela $15 \mathrm{e}$ ilustrados na figura 21, abaixo. A farmacocinética da oxacilina mostrou-se alterada com prolongamento da meia vida biológica como conseqüência do aumento do volume aparente de distribuição. 
Tabela 15 - Parâmetros farmacocinéticos registrados para a oxacilina ( $n=5$ seguimentos em dois pacientes)

\begin{tabular}{cccc}
\hline Parâmetro & $\mathbf{t}_{(1 / 2) \beta}(\mathrm{h})$ & $\begin{array}{c}\mathrm{CL}_{\mathbf{T}} \\
(\mathrm{mL} / \mathrm{min} . \mathrm{kg})\end{array}$ & $\mathbf{V d}(\mathrm{L} / \mathrm{kg})$ \\
\hline Valor de & $0,38-0,75$ & 5,4 & $0,39-0,43$ \\
Referência & 3,6 & 6,0 & 2,6 \\
\hline Mediana & $6,7(6,1)$ & $8,2(6,6)$ & $3,7(3,0)$ \\
Média (DP) & 91,9 & 80,9 & 80,3 \\
Variabilidade (\%) & 1,5 & 1,5 & 0,21 \\
\hline Vmín & 13,5 & 19,2 & 6,9 \\
Vmáx & 1,3 & 2,4 & 1,1 \\
LI IC 95\% & 12,0 & 14,0 & 6,3 \\
LS IC 95\% & . & &
\end{tabular}

Fonte Micromedex, 2010.Estatística: GraphPad Instat 3.0 e GraphPad Prism 4 para estatística descritiva.Abreviaturas: FRN: função renal normal; DP: desvio padrão da média; LI IC95\%: limite inferior do intervalo de confiança 95\%; LS IC95\%: limite superior do intervalo de confiança 95\%; Vmín: valor mínimo; Vmáx: valor máximo; CV\%: coeficiente de variação; $\mathrm{t}_{(1 / 2) \beta}$ meia vida biológica; $\mathrm{CL}_{\mathrm{T}}$ depuração plasmática; $\mathrm{Vd}$ : volume aparente de distribuição
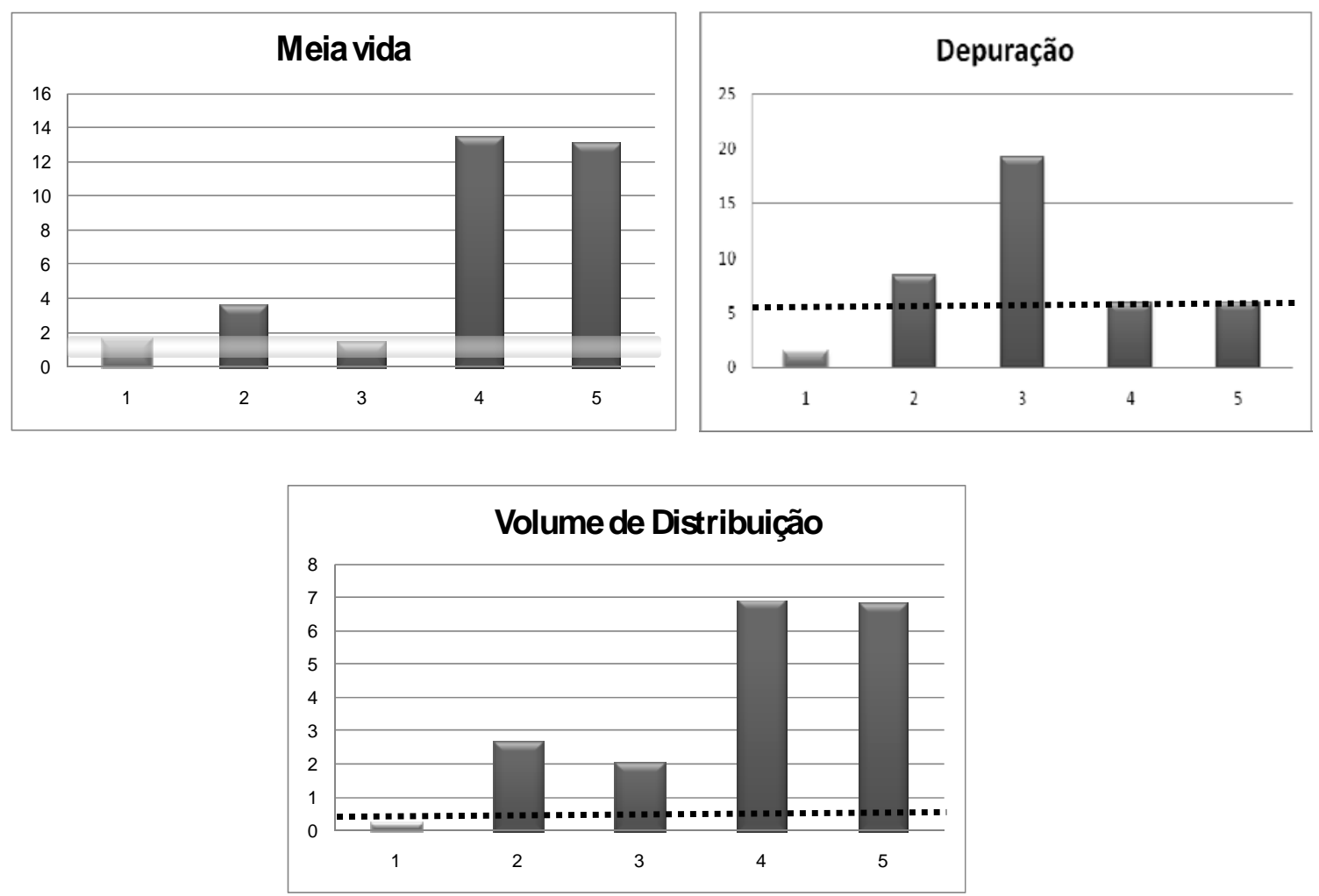

Figura 21. Dados individuais para as constantes farmacocinéticas da oxacilina. Faixa de referência: Meia Vida (0,38-0,75hs); Depuração Plasmática $(5,4 \mathrm{~mL} / \mathrm{min} . \mathrm{kg})$; Volume de Distribuição (0,39-0,43L/kg) Fonte Micromedex, 2010

Com relação à predição de eficácia desse agente, o intervalo de tempo em que a concentração plasmática do antimicrobiano permanece acima da 
concentração inibitória mínima $(\% \Delta \mathrm{T}>\mathrm{CIM})$ é o melhor parâmetro para os denominados antimicrobianos de ação tempo-dependente como a oxacilina, conforme ilustrado na figura 22, com base na curva de decaimento plasmático no decurso do tempo, considerando-se a porcentagem de tempo $(\% \Delta \mathrm{T})$ em que a concentração plasmática de oxacilina permanece acima do CIM.

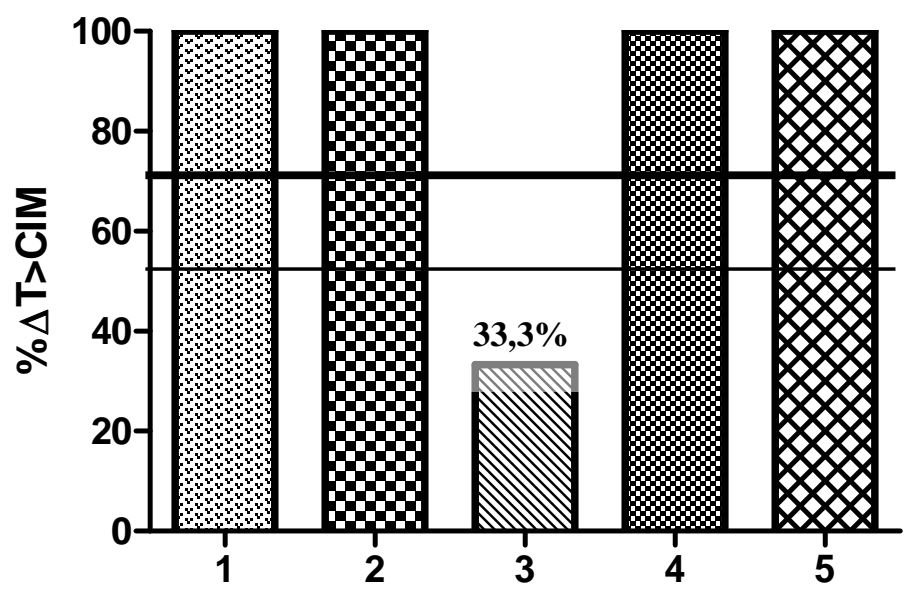

Figura 22: Modelagem PK-PD para a oxacilina $(\% \Delta T>C I M)$ em pacientes queimados, dados individuais $(n=5)$. Valor de Referência: $50 \%>$ CIM Staphylococcus aureus; $70 \%>C I M$ para a maioria dos organismos; CIM 2mg/L (KAYS et al., 1999) Abreviaturas: CIM: concentração inibitória mínima obtida in vitro $(\mathrm{mg} / \mathrm{L})$

Desta forma, os valores que se mostraram acima da concentração inibitória mínima obtida na medida in vitro (CIM $2 \mathrm{mg} / \mathrm{L}$ ), para todos os segmentos, exceto no $3^{\circ}$ segmento (\#20 amostra 2) onde a $\% \Delta \mathrm{T}>\mathrm{CIM}$ foi de $33,3 \%$, portanto ineficaz (Figura 22). 


\subsection{PIPERACILINA}

Durante o período foram acompanhados sete pacientes que fizeram uso de piperacilina: \#04, \#07, \#08, \#09, \#11, \#15, \#17 e receberam dose diária de $12 \mathrm{~g}$ (4g de 8/8 horas). Nenhum paciente evoluiu para insuficiência renal dialítica durante o tratamento com esse antimicrobiano, figura 23.

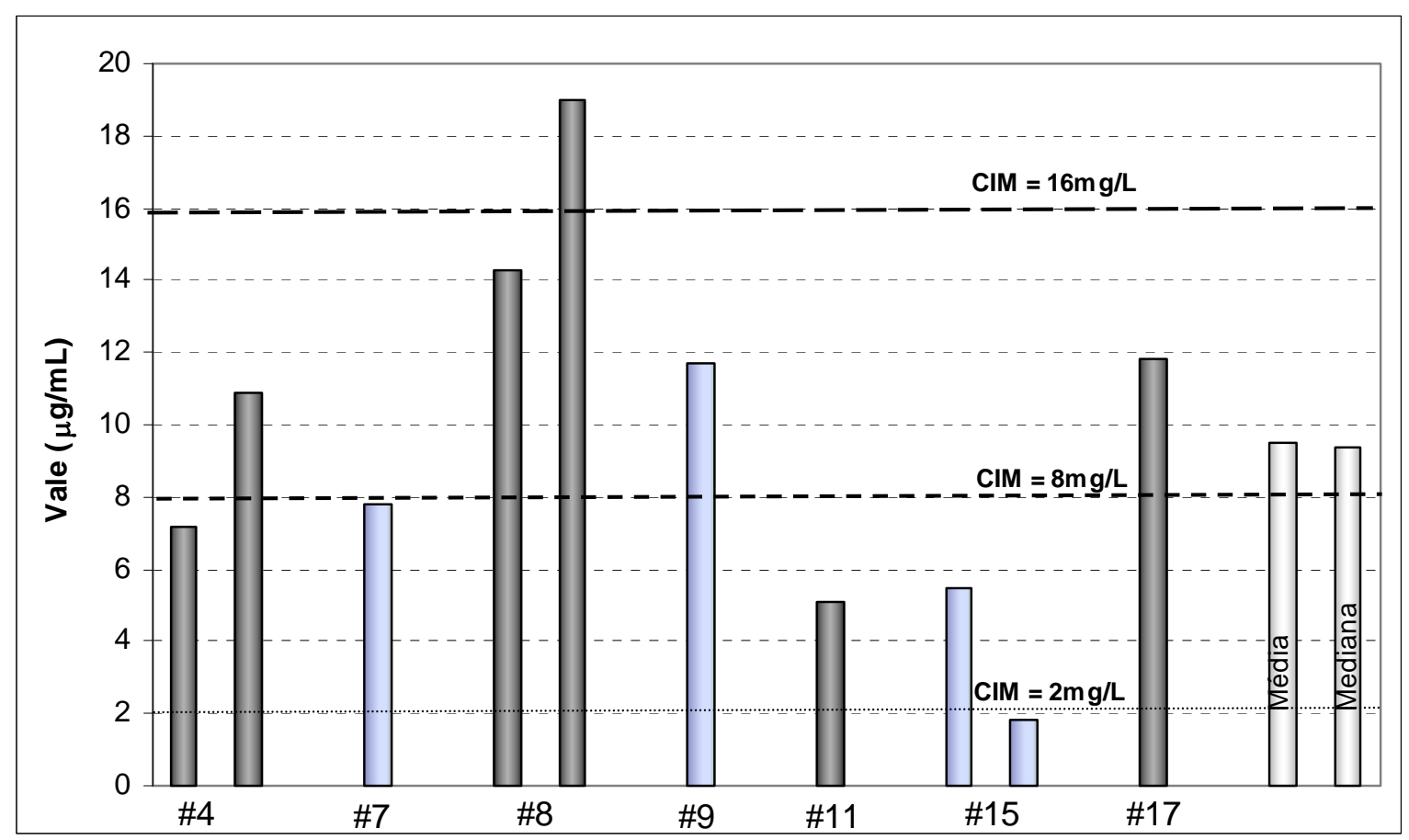

Figura 23 - Concentração plasmática de piperacilina no vale $(\mu \mathrm{g} / \mathrm{mL})$ : Ajuste de dose em 07 pacientes queimados internados na UTI do HCFMUSP. Dose diária de 12000mg/dia. Abreviaturas: CIM: concentração inibitória mínima, valor de referência $2 \mathrm{mg} / \mathrm{L}$ (Staphylococcus aureus), 8mg/L (E.coli, Klebsiella, Salmonella, Serratia) e 16mg/L (Pseudômonas aeruginos). Fonte: Micromedex, 2010; Eucast 2010.

A concentração de vale se mostrou abaixo dos valores recomendados em $50 \%$ dos seguimentos realizados nos sete pacientes.

A farmacocinética da piperacilina descrita na tabela 16 e figura 24 indica alta variabilidade principalmente com relação aos parâmetros meia vida biológica e volume aparente de distribuição. 
Tabela 16 - Disposição cinética de piperacilina $(n=10)$

\begin{tabular}{lcccc}
\hline Parâmetro & $\begin{array}{c}\text { Vale } \\
(\mu \mathrm{g} / \mathrm{mL})\end{array}$ & $\begin{array}{c}\mathrm{t}_{(1 / 2) \beta} \\
(\text { hora })\end{array}$ & $\begin{array}{c}\mathrm{CL}_{\top} \\
(\mathrm{mL} / \mathrm{min} . \mathrm{kg})\end{array}$ & $\begin{array}{c}\mathrm{Vd} \\
(\mathrm{L} / \mathrm{kg})\end{array}$ \\
\hline Mediana & 9,4 & 2,5 & 4,1 & 0,8 \\
Média & 9,5 & 3,9 & 4,4 & 1,9 \\
DP & 5,0 & 3,8 & 2,3 & 2,7 \\
Vmín & 1,8 & 1,4 & 1,0 & 0,14 \\
Vmáx & 14,3 & 13,6 & 7,6 & 8,9 \\
LI IC 95\% & 6,5 & 1,6 & 3,1 & 0,3 \\
LS IC 95\% & 12,5 & 6,2 & 5,8 & 3,5 \\
\hline Variabilidade (CV\%) & 53,0 & 98,3 & 52,1 & 144,0 \\
\hline Valor de Referência* & $>8$ & $0,7-1,2$ & 1,9 & $0,14-0,22$ \\
\hline
\end{tabular}

Fonte: Micromedex, 2010

Estatística: GraphPad Instat 3.0 e GraphPad Prism 4 para estatística descritiva.

Abreviaturas: FRN: função renal normal; DP: desvio padrão da média; LI IC95\%: limite inferior do intervalo de confiança 95\%; LS IC95\%: limite superior do intervalo de confiança 95\%; Vmín: valor mínimo; Vmáx: valor máximo; $C V \%$ : coeficiente de variação; $\mathrm{t}_{(1 / 2) \beta}$ meia vida biológica; $C L_{T}$ depuração plasmática; Vd: volume aparente de distribuição
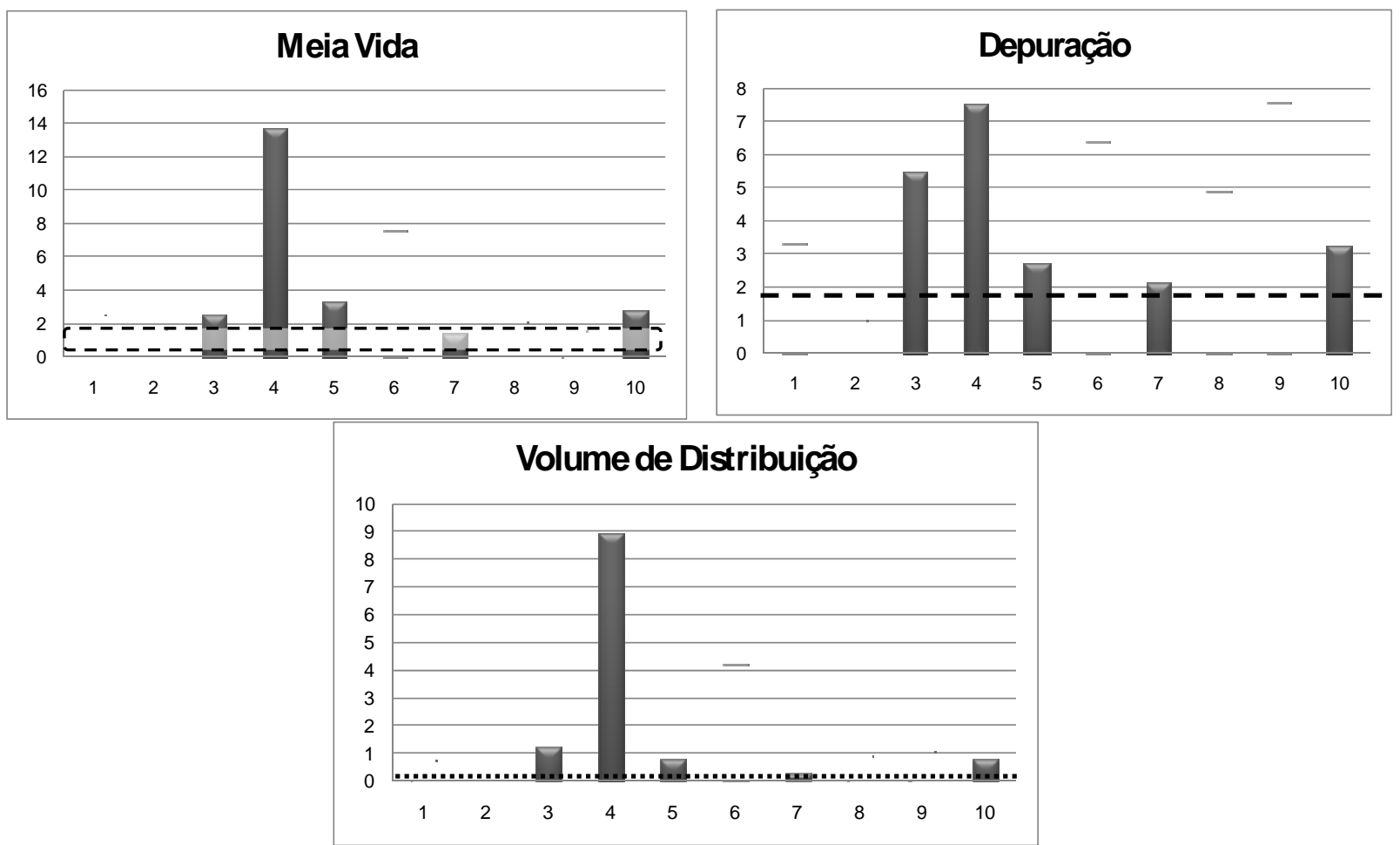

Figura 24. Dados individuais para as constantes farmacocinéticas da piperacilina. Faixa de referência: Meia Vida (0,7-1,2hs); Depuração Plasmática (1,9 mL/min.kg); Volume de Distribuição (0,14-0,22L/kg) Fonte: Micromedex, 2010. 
O intervalo de tempo em que a concentração plasmática do antimicrobiano permanece acima da concentração inibitória mínima (\% $\% \mathrm{~T}$ >CIM) é o melhor parâmetro para a predição da eficácia farmacodinâmica dos denominados antimicrobianos de ação tempo-dependente como a piperacilina. A modelagem PK-PD foi aplicada no presente estudo para a piperacilina conforme ilustrado na tabela 17 e figura 25, com base na curva de decaimento plasmático no decurso do tempo, considerando-se a porcentagem de tempo $(\% \Delta \mathrm{T})$ em que a concentração plasmática permanece acima do CIM.

Tabela 17. Modelagem PK/PD expressa através do período de tempo (\% $\% \mathrm{~T})$ requerido para manutenção da concentração plasmática da piperacilina acima da concentração inibitória mínima obtida in vitro $(\% \Delta T>C I M), \quad n=10$ seguimentos em sete pacientes

\begin{tabular}{c|c|ccc}
\hline Paciente & $\begin{array}{c}\text { TPQ } \\
\text { (dias) }\end{array}$ & $2 \mathrm{mg} / \mathrm{L}$ & $\begin{array}{c}\mathrm{CIM} \\
8 \mathrm{mg} / \mathrm{L}\end{array}$ & $16 \mathrm{mg} / \mathrm{L}$ \\
\hline$\# 4$ & 11 & 100 & 95 & 63 \\
& 13 & 100 & 100 & 88 \\
\hline$\# 7$ & 33 & 100 & 99 & 68 \\
\hline$\# 8$ & 8 & 100 & 100 & 72 \\
& 12 & 100 & 100 & 110 \\
\hline$\# 9$ & 6 & 100 & 100 & 57 \\
\hline$\# 11$ & 9 & 100 & 83 & 56 \\
\hline 15 & 5 & 100 & 86 & 60 \\
& 8 & 97 & 58 & 39 \\
\hline$\# 17$ & 9 & 100 & 100 & 85 \\
\hline
\end{tabular}

Valor de Referência: 50\%>CIM Staphylococcus aureus; 70\%>CIM para a maioria dos organismos (KAYS et al., 1999). CIM: 2mg/L (Staphylococcus aureus), 8mg/L (E.coli, Klebsiella, Salmonella, Serratia) e 16mg/L (Pseudomonas aeruginosa) Fonte: Micromedex, 2010; Eucast 2010.Abreviaturas: CIM: concentração inibitória mínima obtida in vitro (mg/L); TPQ: tempo pós queimadura (dias) 


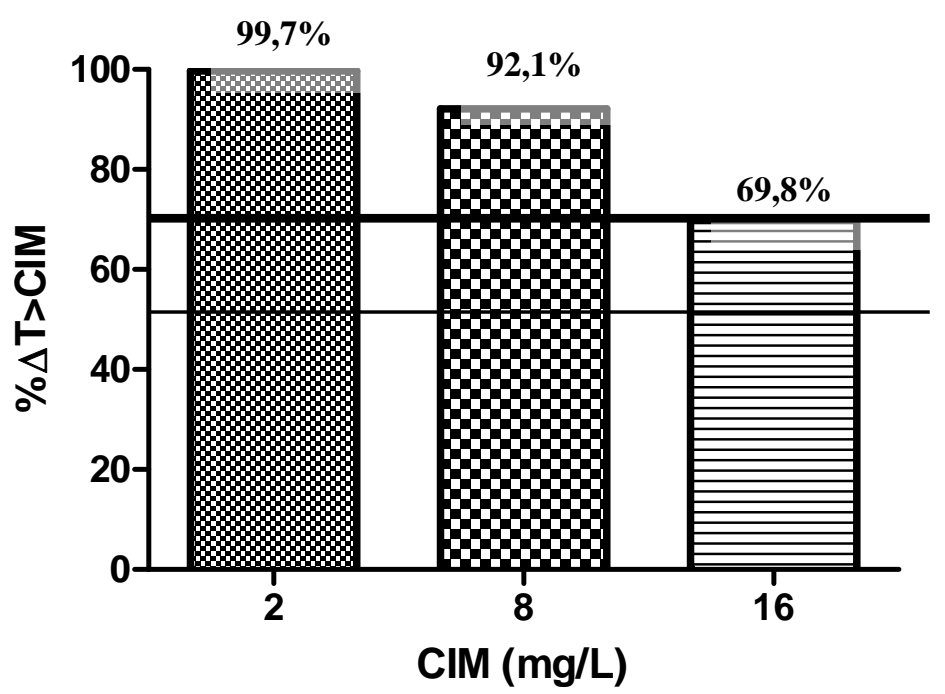

Figura 25: Modelagem PK-PD para a piperacilina $(\% \Delta T>C I M)$ em pacientes queimados, dados expressos através das médias. Valor de Referência: $50 \%>\mathrm{CIM}$ Staphylococcus aureus; $70 \%>$ CIM para a maioria dos organismos (KAYS et al., 1999) Abreviaturas: CIM: concentração inibitória mínima, valor de referência $2 \mathrm{mg} / \mathrm{L}$ (Staphylococcus aureus), 8mg/L (E.coli, Klebsiella ssp, Salmonella ssp, Serratia ssp) e 16mg/L (Pseudomonas aeruginosa) Fonte: Micromedex, 2010; Eucast 2010. Estatística: GraphPad Prism 4, n=10 seguimentos em sete pacientes.

A modelagem PK-PD foi aplicada para a piperacilina com base no parâmetro de predição de eficácia \% $\%$ T>CIM (50\% para Staphylococcus aureous; e 70\% para os outros microorganismos). Os valores que se mostraram acima da concentração inibitória mínima obtida na medida in vitro (CIM 2 e 8 mg/L), figura 25, para o Staphylococcus aureous, E.coli, Klebsiella ssp, Salmonella ssp, Serratia ssp. Por outro lado, os parâmetros de predição encontraram-se abaixo dos valores recomendados, permanecendo descoberto nas infecções por Pseudômonas aeruginosa (CIM: 64mg/L), em que se observou que o paciente se encontrava descoberto em 6/10 segmentos. 


\subsection{SULFAMETOXAZOL}

Durante o período foram acompanhados oito pacientes que fizeram uso de sulfametoxazol: \#04, \#10,\#15,\#16, \#22, \#24, \#25 e \#31, sendo que 5/8 (63\%) apresentaram função renal normal e 3/8 (37\%) se encontravam em tratamento dialítico. Em 46\% dos seguimentos a dose diária foi mantida em $6.4 \mathrm{~g}$ (Figuras 26 e 27).

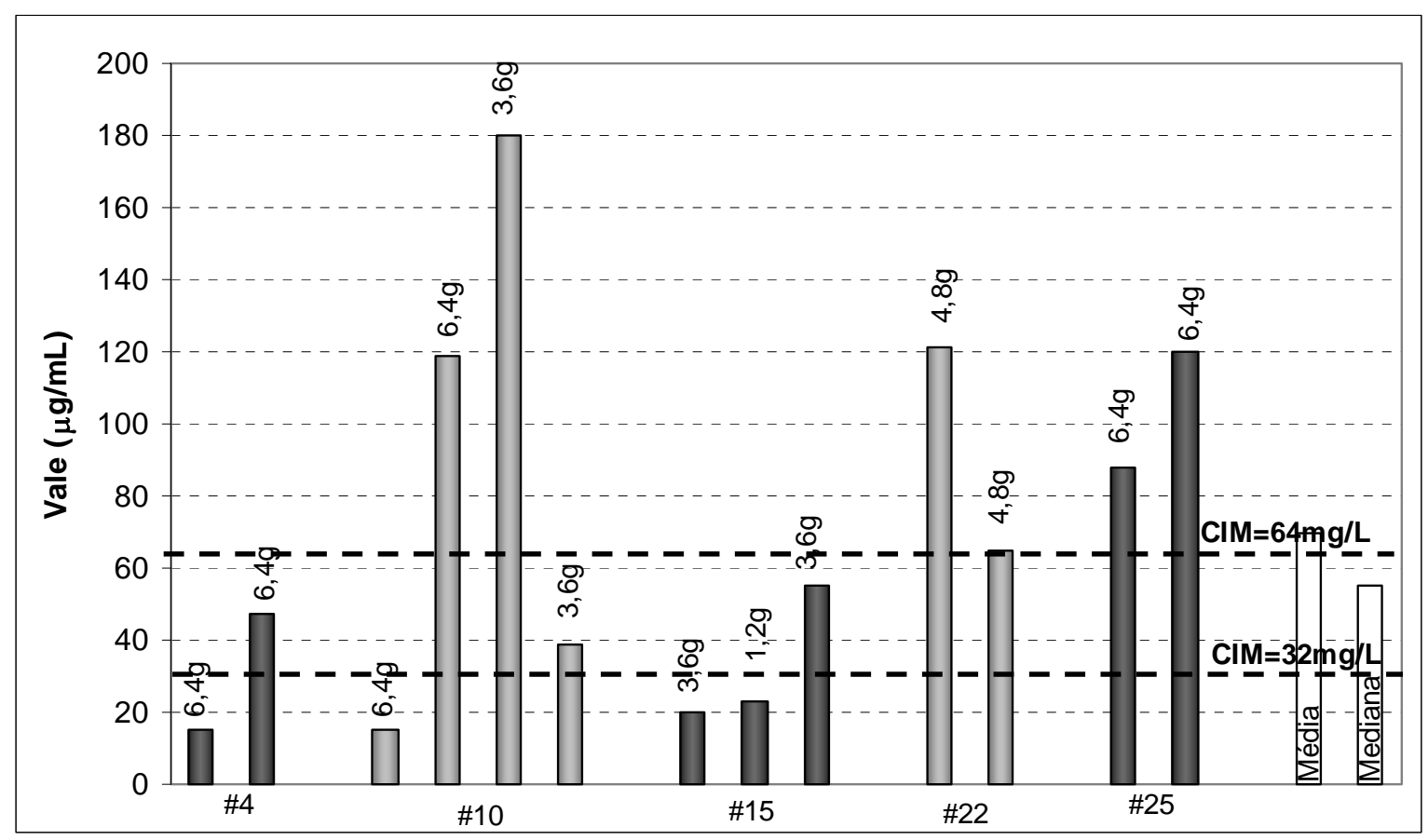

Figura 26 - Concentração plasmática de sulfametoxazol no vale $(\mu \mathrm{g} / \mathrm{mL})$ : Ajuste de dose em 05 pacientes queimados internados na UTI do HCFMUSP com função renal normal. Abreviaturas: CIM: concentração inibitória mínima, valor de referência 32mg/L (Staphylococcus aureus, Enterobacter ssp), $64 \mathrm{mg} / \mathrm{L}$ (Klebsiella pneumoniae, Listeria monocytogem). Fonte: Eucast 2010. 


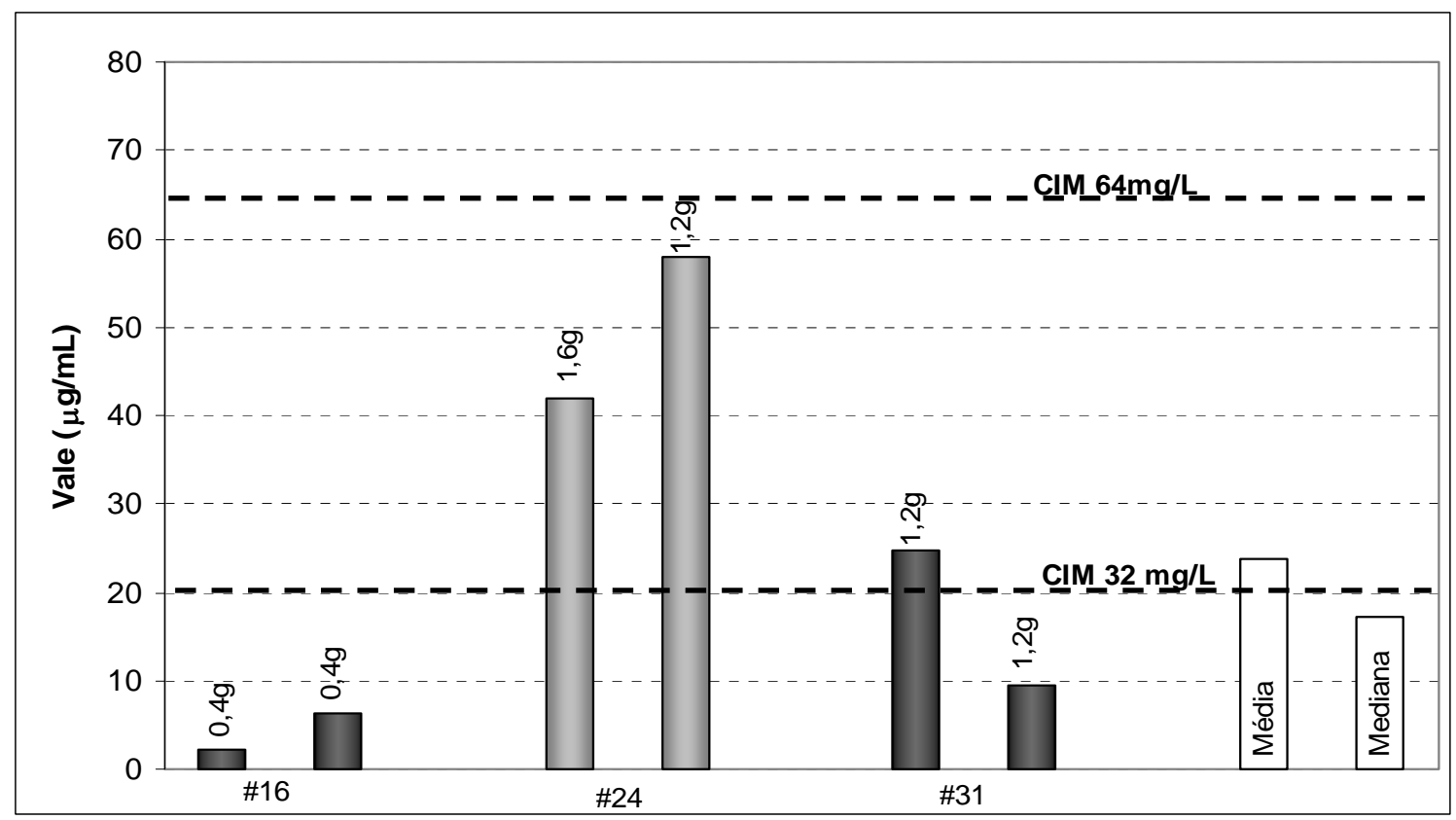

Figura 27 - Concentração plasmática de sulfametoxazol no vale $(\mu \mathrm{g} / \mathrm{mL})$ : Ajuste de dose em pacientes queimados internados na UTI do HCFMUSP com insuficiência renal dialítica. Abreviaturas: CIM: concentração inibitória mínima, valor de referência $32 \mathrm{mg} / \mathrm{L}$ (Staphylococcus aureus, Enterobacter ssp), 64mg/L (Klebsiella pneumoniae, Listeria monocytogem). Fonte: Eucast 2010.

A caracterização de cada parâmetro cinético investigado é apresentada nas tabelas 18 a 21 com base na função renal (normal e insuficiência renal dialítica). Conforme indicado na tabela 18, frente aos valores de referência, a meia vida biológica se mostrou prolongada nos pacientes queimados dialíticos.

Tabela 18 - Meia vida biológica de Sulfametoxazol, n=19

\begin{tabular}{lcc} 
Parâmetro & $\begin{array}{c}\text { FR normal } \\
(\mathbf{n}=13)\end{array}$ & $\begin{array}{c}\text { Diálise } \\
(\mathbf{n}=6)\end{array}$ \\
\hline Mediana & 8,5 & 24,8 \\
Média & 10,7 & 24,5 \\
DP & 8,4 & 11,1 \\
Vmín & 4,0 & 10,4 \\
Vmáx & 32,4 & 37,8 \\
LI IC 95\% & 6,2 & 15,6 \\
LS IC 95\% & 15,3 & 33,4 \\
CV\% & 78,4 & 45,4
\end{tabular}

Valor de referência: 8-11 horas. Fonte:Micromedex 2010. Estatística: GraphPad Instat 3.0 e GraphPad Prism 4 para estatística descritiva. Abreviaturas: FRN: função renal normal; DP: desvio padrão da média; LI IC95\%: limite inferior do intervalo de confiança 95\%; LS IC95\%: limite superior do intervalo de confiança 95\%; Vmín: valor mínimo; Vmáx: valor máximo; CV\%: coeficiente de variação 
Conforme indicado na tabela 19, frente aos valores de referência, a depuração plasmática se mostrou aumentada em pacientes queimados

Tabela 19 - Depuração plasmática de Sulfametoxazol, n=19

\begin{tabular}{lcc}
\hline Parâmetro & $\begin{array}{c}\text { FR normal } \\
(\mathbf{n}=13)\end{array}$ & $\begin{array}{c}\text { Diálise } \\
(\mathbf{n}=6)\end{array}$ \\
\hline Mediana & 0,5 & 0,4 \\
Média & 0,6 & 0,3 \\
DP & 0,4 & 0,2 \\
Vmín & 0,1 & 0,0 \\
Vmáx & 1,6 & 0,7 \\
LI IC 95\% & 0,4 & 0,2 \\
LS IC 95\% & 0,9 & 0,5 \\
CV\% & 71,5 & 67,9 \\
\hline
\end{tabular}

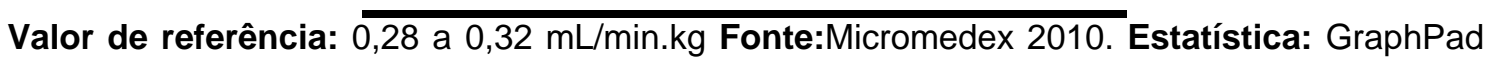
Instat 3.0 e GraphPad Prism 4 para estatística descritiva. Abreviaturas: FR: função renal; DP: desvio padrão da média; LI IC95\%: limite inferior do intervalo de confiança 95\%; LS IC95\%: limite superior do intervalo de confiança 95\%; Vmín: valor mínimo; Vmáx: valor máximo; CV: coeficiente de variação.

Conforme indicado na tabela 20, frente aos valores de referência, 0 volume aparente de distribuição se mostrou aumentado nos pacientes queimados

Tabela 20 - Volume aparente de distribuição de Sulfametoxazol, n=19

\begin{tabular}{lcc}
\hline Parâmetro & $\begin{array}{c}\text { FR normal } \\
(\mathbf{n}=13)\end{array}$ & $\begin{array}{c}\text { Diálise } \\
(\mathbf{n}=6)\end{array}$ \\
\hline Mediana & 0,41 & 0,66 \\
Média & 0,51 & 0,76 \\
DP & 0,41 & 0,58 \\
Vmín & 0,03 & 0,02 \\
Vmáx & 1,29 & 1,65 \\
LI IC 95\% & 0,30 & 0,29 \\
LS IC 95\% & 0,73 & 1,22 \\
CV\% & 76.1 & 76,4 \\
\hline
\end{tabular}

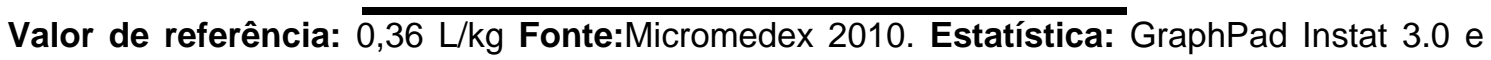
GraphPad Prism 4 para estatística descritiva. Abreviaturas: FRN: função renal normal; DP: desvio padrão da média; LI IC95\%: limite inferior do intervalo de confiança 95\%; LS IC95\%: limite superior do intervalo de confiança 95\%; Vmín: valor mínimo; Vmáx: valor máximo; CV\%: coeficiente de variação 
A farmacocinética da sulfametoxazol se mostrou alterada relativamente à depuração plasmática e ao volume aparente de distribuição aumentado nos pacientes queimados, independentemente da função renal. Adicionalmente, quando se compararam seguimentos de pacientes com insuficiência renal com aqueles de função renal preservada registrou-se prolongamento significativo da meia vida biológica $(p<0,05)$; permanecendo inalterados os demais parâmetros, tabela 21 e figura 28.

Tabela 21 - Farmacocinética do sulfametoxazol, n=19

\begin{tabular}{ccccc}
\hline Parâmetro & Unidade & $\begin{array}{c}\text { FRN } \\
(\mathbf{n = 1 3 )}\end{array}$ & $\begin{array}{c}\text { Diálise } \\
(\mathbf{n = 0 6})\end{array}$ & $\mathbf{P}$ \\
\hline $\mathrm{t}_{(1 / 2) \beta}$ & $($ hora $)$ & 8,5 & 24,8 & 0,0097 \\
$\mathrm{CL}_{\top}$ & $(\mathrm{mL} / \mathrm{min} . \mathrm{kg})$ & 0,5 & 0,4 & 0,1708 \\
$\mathrm{Vd}$ & $(\mathrm{L} / \mathrm{kg})$ & 0,41 & 0,66 & 0,4047 \\
\hline
\end{tabular}

Estatística: Teste de Mann Whitney, dados não pareados, medianas, $\mathrm{n}=19$, significância $(p<0,05)$ Abreviaturas: FRN: função renal normal; $P$ : probabilidade; $t_{(1 / 2) \beta}$ meia vida biológica; $\mathrm{CL}_{\mathrm{T}}$ depuração plasmática; $\mathrm{Vd}$ : volume aparente de distribuição

Evidenciou-se alta variabilidade na farmacocinética desse agente considerando-se os 19 seguimentos realizados nos oito pacientes queimados, fato que indicou a necessidade da terapia dose ajustada em 54\% dos seguimentos, mantendo-se, portanto em 46\% dos seguimentos a terapia empírica recomendada inicialmente. 

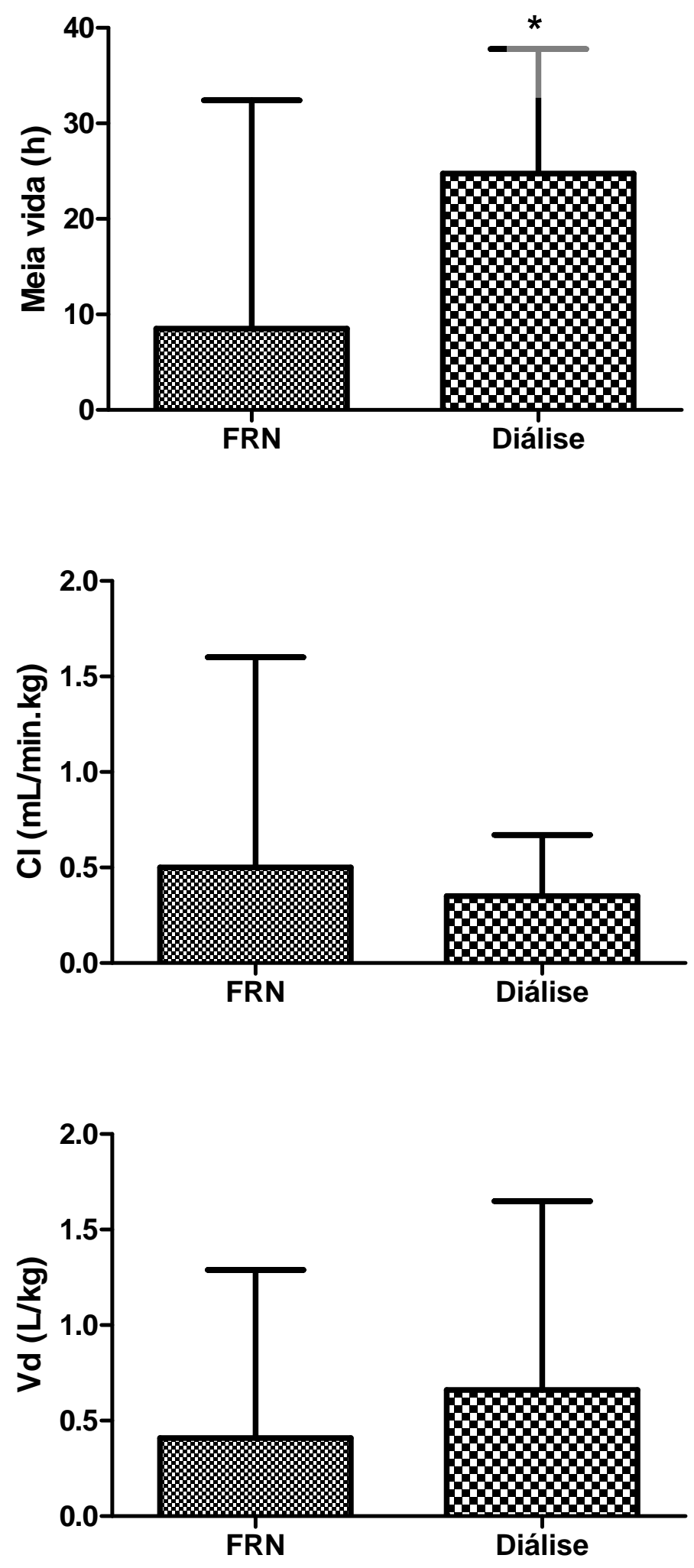

Figura 28: Comparação dos parâmetros farmacocinéticos do Sulfametoxazol para os pacientes com função renal normal e pacientes dialíticos (mediana; IC95\%) Estatística: Teste de Mann Whitney não paramétrico, dados não pareados,medianas * $p<0,05$ Abreviaturas: $F R N$ : função renal normal; $\mathrm{t}_{(1 / 2) \beta}$ meia vida biológica; $\mathrm{CL}_{\mathrm{T}}$ depuração plasmática; Vd: volume aparente de distribuição 
A atividade bactericida tempo-dependente do sulfametoxazol ainda não está bem estabelecida, sendo recomendado para esse agente a utilização de dois parâmetros importantes na predição da eficácia: $\mathrm{ASC}_{0-24}^{\mathrm{SS}} / \mathrm{CIM}$ e \%T>CIM, figura 29, obtidos a partir da curva de decaimento plasmático no decurso do tempo, com base na área sobre a curva ( $\mathrm{ASC}^{\mathrm{SS}}{ }_{0-24}$ ) e a razão com o CIM e a porcentagem de tempo $(\% \Delta \mathrm{T})$ em que a concentração do fármaco encontra-se acima do CIM.
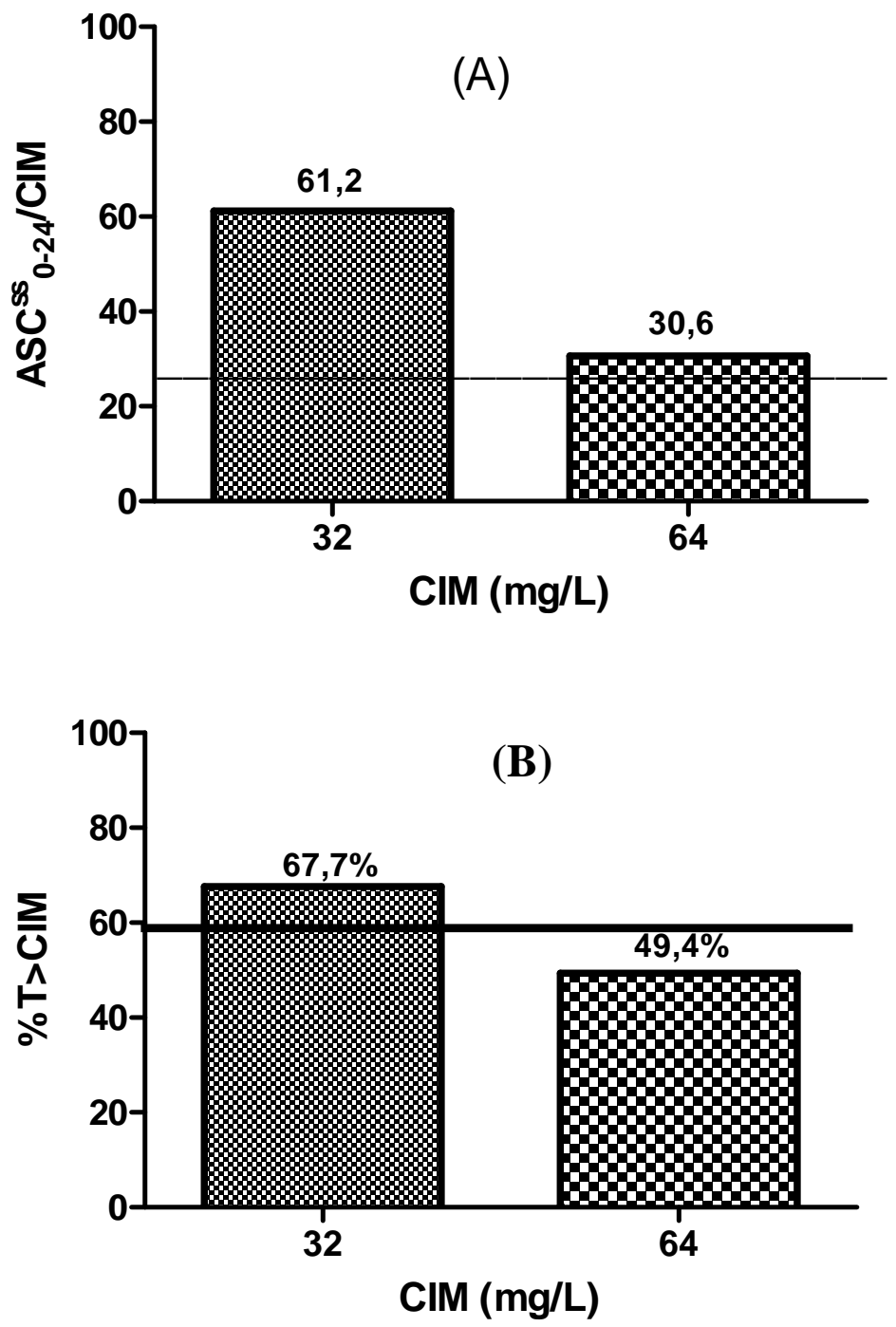

Figura 29 - Modelagem PK-PD para o sulfametoxazol - $(A) A S C_{0-24 h s}^{s s} / C I M$ e (B) $\% \mathrm{~T}>\mathrm{CIM}$ - em pacientes queimados. Valor de Referência: $\mathrm{ASC}^{\mathrm{sS}}{ }_{24} / \mathrm{CIM}>25$; \% $>\mathrm{CIM}=$ 60\% (CHENG et. al., 2009).Abreviaturas: ASC: área sobre a curva; CIM: concentração inibitória mínima, valor de referência 32mg/L (Staphylococcus aureous, Enterobacter ssp), 64mg/L (Klebsiella pneumoniae, Listeria monocytogem). Fonte: Eucast 2010. 
A modelagem PK-PD foi aplicada no presente estudo para a sulfametoxazol com base nos parâmetros de predição de eficácia (ASC/CIM> 25 e $\% \Delta \mathrm{T}>\mathrm{CIM}=60 \%$ ) que se mostraram acima da concentração inibitória mínima obtida na medida in vitro (CIM $32 \mathrm{mg} / \mathrm{L}$ ), figura 29, para 0 Staphylococcus aureous e Enterobacter ssp; se encontrando entretanto os parâmetros de predição abaixo dos valores recomendados e portanto permanecendo descoberto nas infecções por Klebsiella pneumoniae, Listeria monocytogem (CIM: 64mg/L). 


\subsection{VANCOMICINA}

No controle da sepse a vancomicina mostrou ser o antimicrobiano mais prescrito na UTI de queimados, em 31 pacientes totalizando 147 períodos de seguimento. Destes, 27 pacientes (112 seguimentos) apresentaram função renal normal e oito (35 seguimentos) evoluíram para insuficiência renal dialítica. A figura 30 ilustra que em $88 \%$ dos pacientes avaliados, a conduta clínica constou da substituição do regime de dose empírica em decorrência da farmacocinética alterada nos queimados.

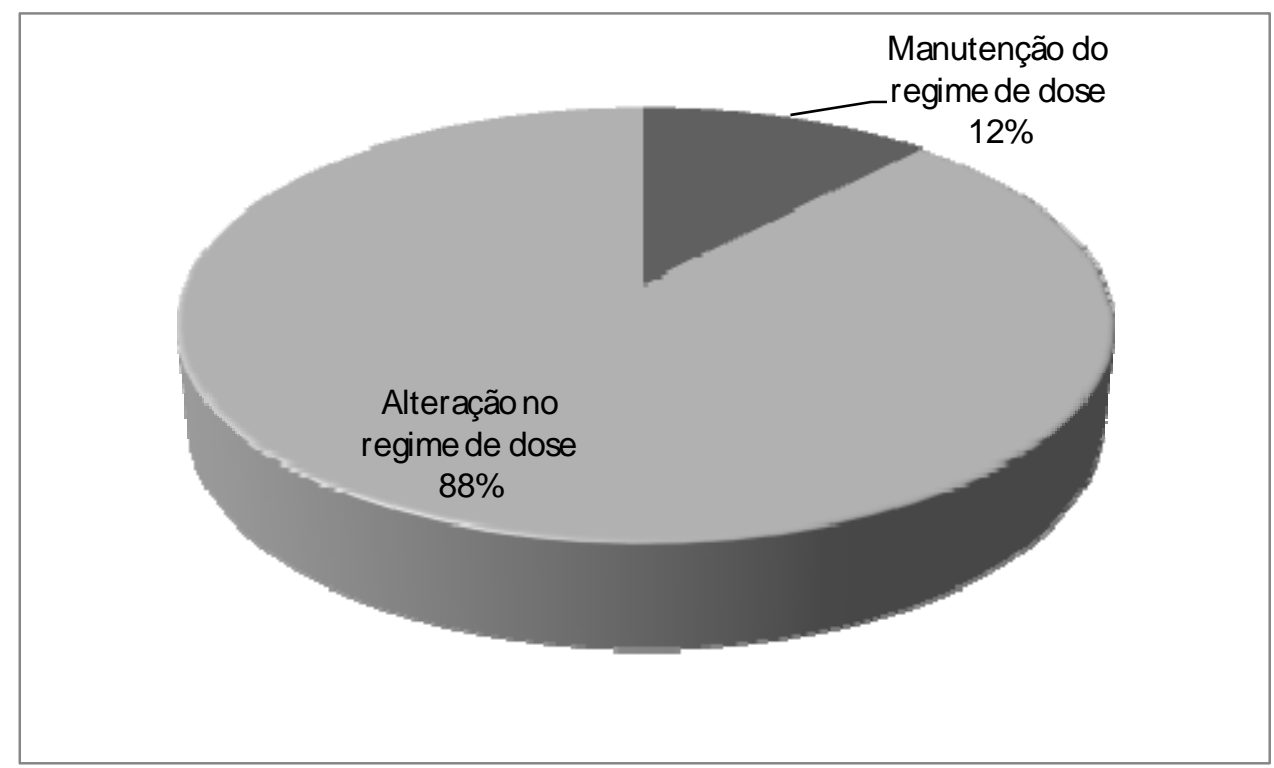

Figura 30. Necessidade de alteração do regime de dose empírica da Vancomicina para terapia dose ajustada num total de 147 seguimentos de 31 pacientes queimados com função renal preservada e disfunção renal dialítica.

Em 42\% dos seguimentos para os queimados da UTI, a dose empírica de $1 \mathrm{~g}$ de 12/12hs de vancomicina foi modificada para regime de 0,5g de 6/6hs, mantendo-se a dose diária de $2 g$ e optando-se pela redução do intervalo de dose. Esta conduta promoveu maior acúmulo do antimicrobiano administrado com manutenção de concentrações efetivas entre infusões consecutivas prescritas para as 24 horas (Figura 31 e 32).

Excepcionalmente, a conduta médica foi de aumentar a dose diária, pelo aumento da dose fracionada, mantendo-se o intervalo de 6 horas entre infusões consecutivas (Figura 32). 


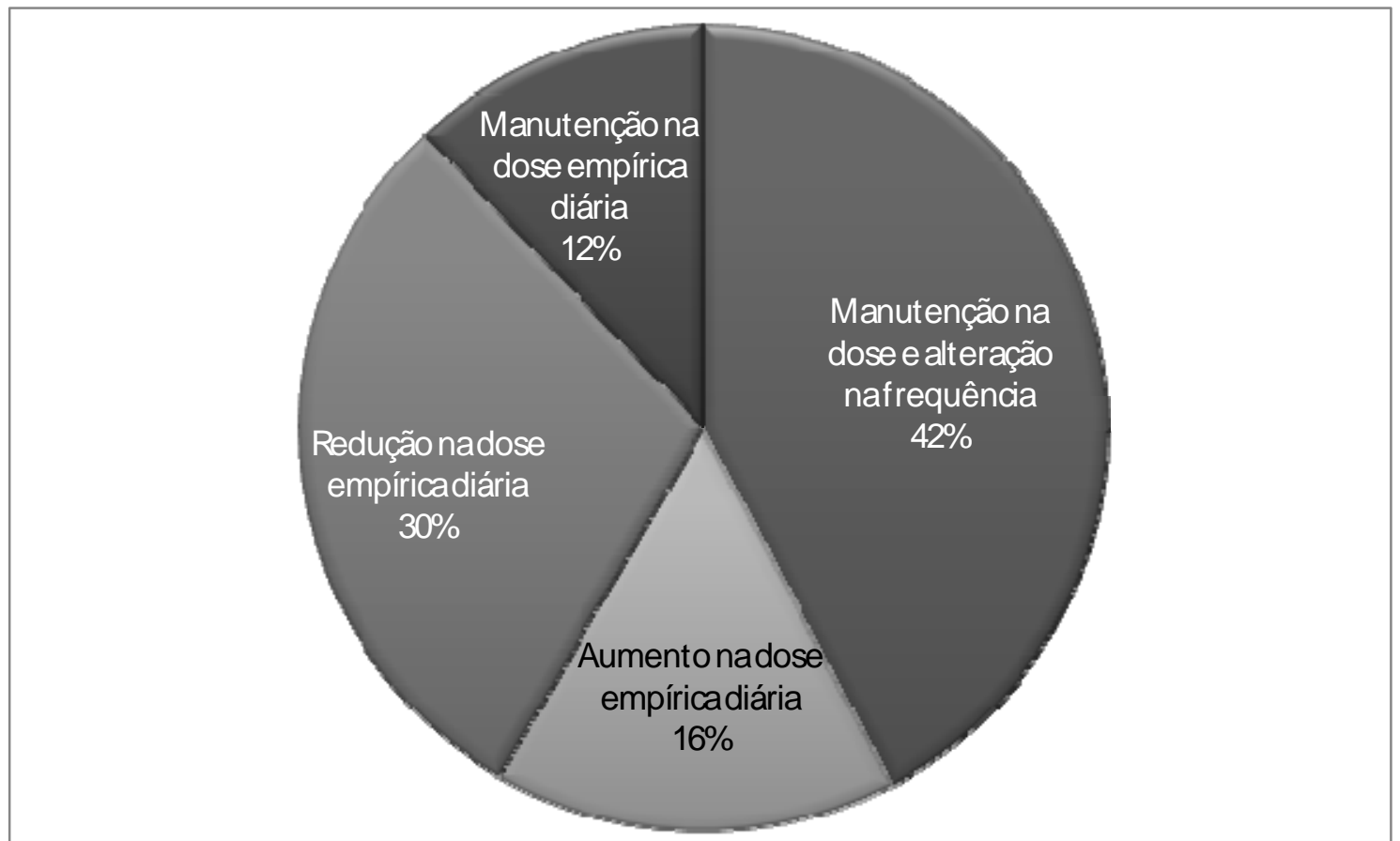

Figura 31. Alteração do regime de dose para individualização de terapia da Vancomicina num total de 147 seguimentos de 31 pacientes queimados

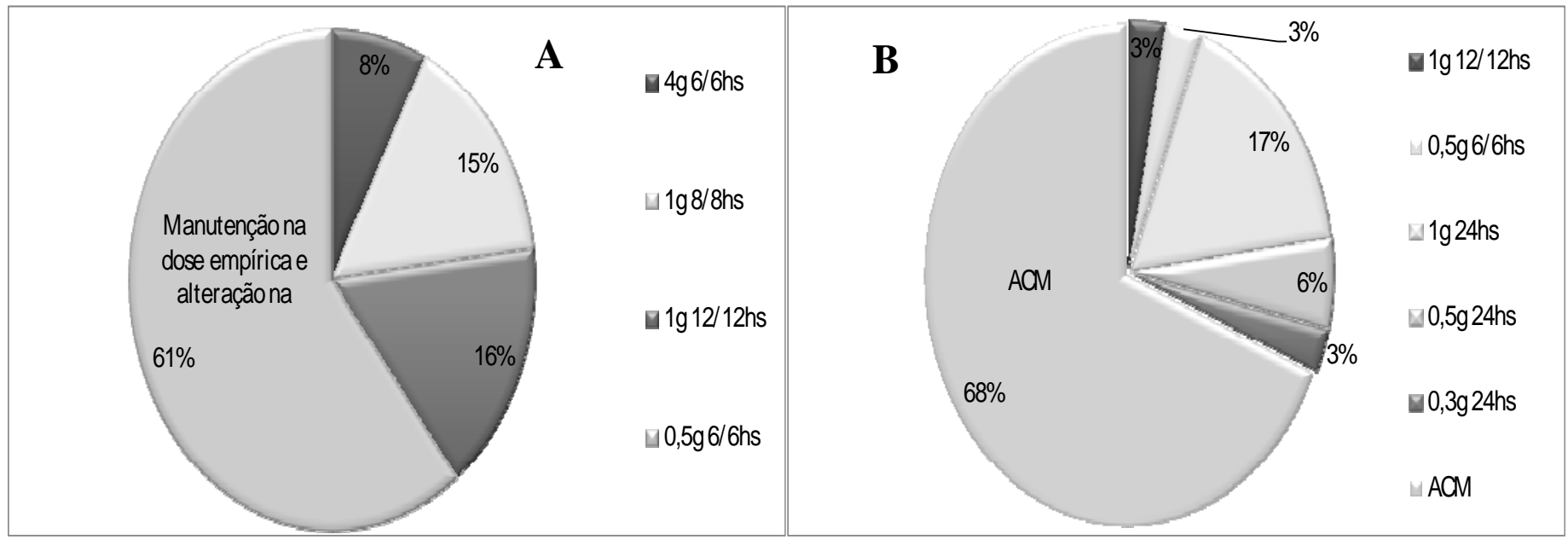

Figura 32 Alteração do regime de dose de Vancomicina em pacientes queimados, com função renal normal $(A)$ e insuficiência renal dialítica (B). ACM: a critério médico e administrelação com base no vale.

A caracterização de cada parâmetro cinético investigado nos seguimentos dos pacientes com base na função renal (normal e insuficiência renal dialítica) é apresentada nas tabelas 22 a 25.

Conforme indicado na tabela 22 e 25, frente aos valores de referência, a meia vida biológica se mostrou prolongada nos pacientes queimados dialíticos $(p<0,05)$. 
Tabela 22 - Meia vida biológica de Vancomicina, $\mathrm{n}=147$

\begin{tabular}{lcc}
\hline Parâmetro & $\begin{array}{c}\text { FR normal } \\
(\mathbf{n}=\mathbf{1 1 2})\end{array}$ & $\begin{array}{c}\text { Diálise } \\
(\mathbf{n}=\mathbf{3 5})\end{array}$ \\
\hline Mediana & 4,5 & 18,8 \\
Média & 6,6 & 21,8 \\
DP & 5,5 & 21,2 \\
Vmín & 1,2 & 6,2 \\
Vmáx & 30,5 & 96,8 \\
LI IC 95\% & 5,6 & 14,8 \\
LS IC 95\% & 7,6 & 28,8 \\
CV\% & 83,3 & 97,0
\end{tabular}

Valor de referência: 4 a 6 horas Fonte:Micromedex 2010 Estatística: GraphPad Instat 3.0 e GraphPad Prism 4 para estatística descritiva. Abreviaturas: FRN: função renal normal; DP: desvio padrão da média; LI IC95\%: limite inferior do intervalo de confiança 95\%; LS IC95\%: limite superior do intervalo de confiança 95\%; Vmín: valor mínimo; Vmáx: valor máximo; CV\%: coeficiente de variação

Conforme indicado na tabela 23 e 25, frente aos valores de referência, a depuração plasmática se mostrou acentuadamente reduzida nos queimados dialíticos $(p<0,05)$.

Tabela 23 - Depuração plasmática de Vancomicina, n=147

\begin{tabular}{lcc}
\hline Parâmetro & $\begin{array}{c}\text { FR normal } \\
(\mathbf{n}=\mathbf{1 1 2})\end{array}$ & $\begin{array}{c}\text { Diálise } \\
(\mathbf{n}=\mathbf{3 5})\end{array}$ \\
\hline Mediana & 1,8 & 0,3 \\
Média & 2,1 & 0,4 \\
DP & 1,4 & 0,4 \\
Vmín & 0,3 & 0,0 \\
Vmáx & 9,7 & 1,5 \\
LI IC 95\% & 1,8 & 0,3 \\
LS IC 95\% & 2,3 & 0,6 \\
CV\% & 68,9 & 93,8
\end{tabular}

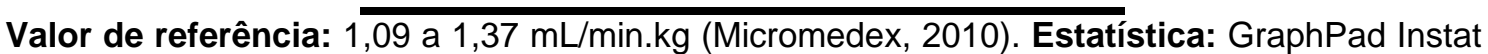
3.0 e GraphPad Prism 4 para estatística descritiva. Abreviaturas: FRN: função renal normal; DP: desvio padrão da média; LI IC95\%: limite inferior do intervalo de confiança 95\%; LS IC95\%: limite superior do intervalo de confiança 95\%; Vmín: valor mínimo; Vmáx: valor máximo; CV\%: coeficiente de variação

Conforme indicado na tabela 24 e 25, frente aos valores de referência, os valores obtidos para o volume de distribuição encontram-se dentro da faixa 
de referência tanto para o paciente com função renal normal quanto dialítico $(p>0,05)$.

Tabela 24 - Volume aparente de distribuição de Vancomicina, n= 147

\begin{tabular}{ccc}
\hline Parâmetro & $\begin{array}{c}\text { FR normal } \\
(\mathbf{n}=\mathbf{1 1 2})\end{array}$ & $\begin{array}{c}\text { Diálise } \\
(\mathbf{n}=\mathbf{3 5})\end{array}$ \\
\hline Mediana & 0,73 & 0,46 \\
Média & 1,05 & 0,82 \\
DP & 0,97 & 0,84 \\
Vmín & 0,03 & 0,08 \\
Vmáx & 4,81 & 2,56 \\
LI IC 95\% & 0,87 & 0,55 \\
LS IC 95\% & 1,23 & 1,10 \\
CV\% & 92,3 & 101,5
\end{tabular}

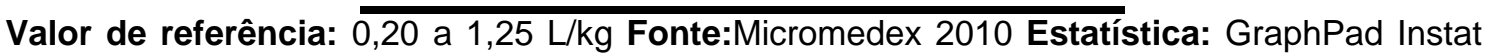
3.0 e GraphPad Prism 4 para estatística descritiva. Abreviaturas: FRN: função renal normal; DP: desvio padrão da média; LI IC95\%: limite inferior do intervalo de confiança 95\%; LS IC95\%: limite superior do intervalo de confiança 95\%; Vmín: valor mínimo; Vmáx: valor máximo; CV\%: coeficiente de variação

Tabela 25 - Farmacocinética vancomicina em queimados com sepse, $\mathrm{n}=147$

\begin{tabular}{ccccc}
\hline Parâmetro & Unidade & $\begin{array}{c}\text { FRN } \\
(\mathbf{n = 1 1 2})\end{array}$ & $\begin{array}{c}\text { Diálise } \\
(\mathbf{n}=\mathbf{3 5})\end{array}$ & $\mathbf{P}$ \\
\hline $\mathrm{t}_{(1 / 2) \beta}$ & (hora) & 4,5 & 18,8 & $<0,0001$ \\
$\mathrm{CL}_{T}$ & $(\mathrm{~mL} / \mathrm{min} . \mathrm{kg})$ & 1,8 & 0,3 & $<0,0001$ \\
$\mathrm{Vd}$ & $(\mathrm{L} / \mathrm{kg})$ & 0,76 & 0,43 & 0,1469 \\
\hline
\end{tabular}

Estatística: Teste de Mann Whitney, dados não pareados, medianas, $n=147$ seguimentos de 31 pacientes, significância $(p<0,05)$. Abreviaturas: FRN: função renal normal; $P$ : probabilidade; $\mathrm{t}_{(1 / 2) \beta}$ meia vida biológica; $\mathrm{CL}_{T}$ depuração plasmática; $V \mathrm{~d}$ : volume aparente de distribuição

Conforme descrito anteriormente para o imipenem, a alteração da farmacocinética da vancomicina no seguimento dos pacientes com insuficiência renal se mostrou evidente pelo prolongamento da meia vida biológica e redução da depuração plasmática. O volume de distribuição mostrou alta variabilidade em ambos os seguimentos de pacientes com FRN e com IR, portanto a aparente alteração desse parâmetro na IR não apresenta significância estatística. Os parâmetros farmacocinéticos estimados para os pacientes queimados nos seguimentos realizados, figura 33 . 

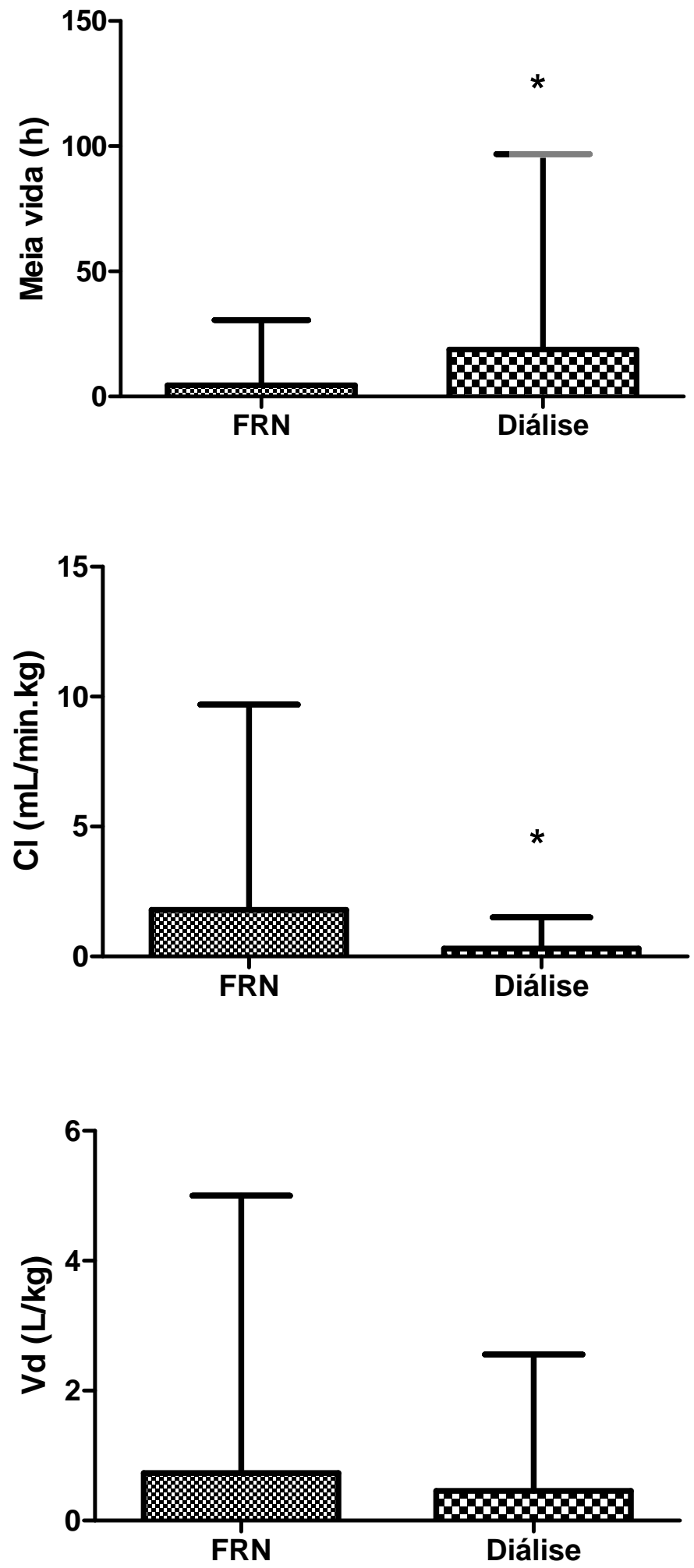

Figura 33: Comparação dos parâmetros farmacocinéticos da Vancomicina para os pacientes com função renal normal e pacientes dialíticos (mediana; IC95\%) Estatística: Teste de Mann Whitney não paramétrico, dados não pareados,medianas * $p<0,05$ Abreviaturas: $F R N$ : função renal normal; $\mathrm{t}_{(1 / 2) \beta}$ meia vida biológica; $\mathrm{CL}_{\mathrm{T}}$ depuração plasmática; Vd: volume aparente de distribuição 
Evidenciou-se alta variabilidade na farmacocinética do agente considerando-se os 147 seguimentos realizados nos 31 pacientes queimados, independentemente da função renal preservada $(n=112)$ ou não $(n=35)$, fato que indicou a necessidade da terapia dose ajustada devido à subterapia ou pelo aumento do acúmulo do antimicrobiano na falência renal. A faixa de concentração foi garantida pela terapia dose ajustada registrando-se manutenção da dose diária e redução do intervalo entre doses (40\%) ou ainda o aumento da dose diária (16\%) para os casos de função renal preservada; enquanto que a dose diária foi reduzida em todos os pacientes com a disfunção renal dialítica, representando $30 \%$ do total de seguimentos realizados nos pacientes queimados.

A atividade bactericida para a vancomicina depende do tempo e da concentração, sendo a razão $\mathrm{ASC}^{\mathrm{sS}}{ }_{0-24} / \mathrm{CIM}$ o melhor parâmetro de predição de eficácia. A modelagem PK-PD foi aplicada no presente estudo para a vancomicina conforme ilustrado na figura 34, com base na curva de decaimento plasmático no decurso do tempo, considerando-se a área sobre a curva ( $\mathrm{ASC}_{0-24}^{\mathrm{sS}}$ ) na razão com a concentração inibitória mínima (CIM).

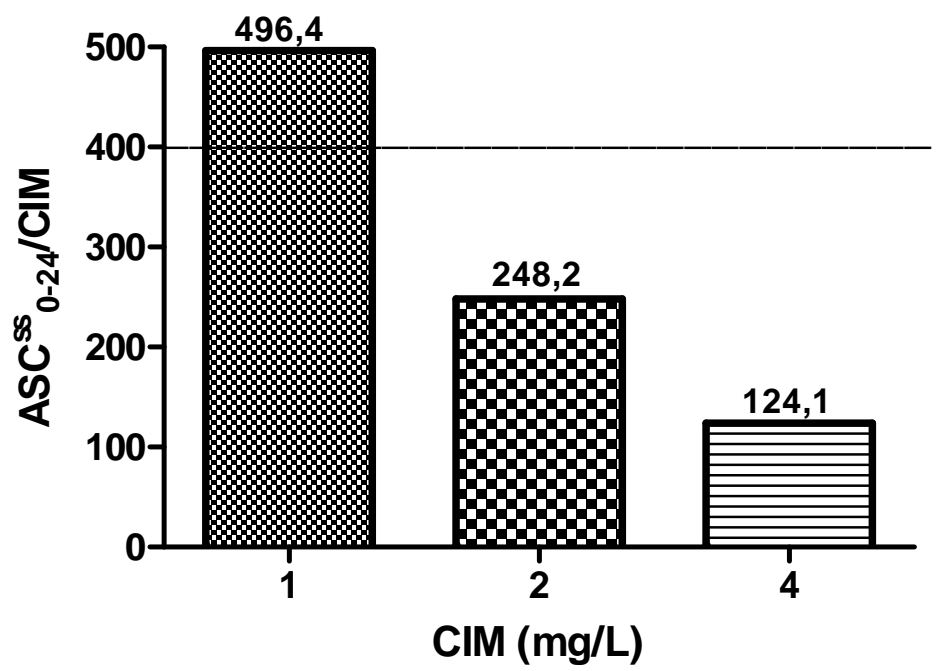

Figura 34: Modelagem PK-PD para a vancomicina $\left(\mathrm{ASC}^{\mathrm{sS}}{ }_{0-24 \mathrm{hs}} / \mathrm{CIM}\right)$ em pacientes queimados. Valor de Referência: $\mathrm{ASC}^{\mathrm{ss}}{ }_{0-24} / \mathrm{CIM}>400$ (MICROMEDEX, 2010; REVILLA et. al., 2010). Abreviaturas: ASC: área sobre a curva; CIM: concentração inibitória mínima, valor de referência 1mg/L (Streptococcus ssp ), 2mg/L (Staphylococcus aureous Meticilina Resistente, Clostridium difficile), 4mg/L (Enterococcus faecum e Enterococcus faecalis). Fonte: Eucast 2010. 
A aplicação da modelagem PK-PD indicou que os valores de referência para a predição de eficácia da vancomicina ( $\mathrm{ASC}^{\mathrm{sS}}{ }_{0-24} / \mathrm{CIM}>400$ ) foram atingidos nos seguimentos realizados considerando-se a concentração inibitória mínima de 1mg/L com cobertura apenas para as infecções causadas por Streptococcus ssp. Uma vez que para valores superiores como CIM de 2mg/L (Staphylococcus aureous Meticilina Resistente, Clostridium difficile) e 4mg/L (Enterococcus faecum e Enterococcus faecalis) os valores necessários para o parâmetro de predição não foram atingidos. 


\section{DISCUSSÃO}

As infecções hospitalares constituem atualmente, um grave problema de saúde pública mundial. Reporta-se hoje o surgimento de cepas resistentes aos vários agentes infecciosos, reduzindo-se a cada dia o arsenal terapêutico disponível para o tratamento da sepse e levando à necessidade de um enfoque farmacoterapêutico complexo para o tratamento e controle das infecções em pacientes queimados numa Unidade de Terapia Intensiva (ROBERTS \& LIPMAN, 2009).

A prescrição destes antimicrobianos visa garantir a eficácia terapêutica, considera-se crítica a decisão a ser tomada pelo médico intensivista, no sentido de manter ou não o regime posológico de determinado agente requerido no controle da infecção. Por outro lado, os resultados de vale referentes às concentrações plasmáticas atingidas pelo antimicrobiano imediatamente antes da dose subseqüente, não tem se mostrado índice de eficácia como se acreditava anteriormente (RYBAK, 2006). Assim, torna-se pouco efetivo o acompanhamento laboratorial realizado através do controle terapêutico apenas pela coleta e determinação da concentração plasmática de vale; o Clínico então se depara com uma situação desconfortante, pois, não dispõe de ferramentas suficientes para avaliar a efetividade do tratamento após prescrever determinado antimicrobiano.

Subseqüentemente se acreditou que a predição da eficácia poderia ser baseada na investigação da farmacocinética associada ao nível de vale, e que juntos forneceriam um índice definitivo para embasar a alteração de um regime posológico empírico. Infelizmente, isto não ocorreu devido à alta variabilidade farmacocinética intra e interindivíduos durante a internação do paciente queimado grave na UTI. Essa alta variabilidade na farmacocinética da vancomicina foi reportada anteriormente por Cameron e colaboradores (1998) em queimados após consecutivos procedimentos cirúrgicos e transfusões sanguíneas. Mais recentemente, Blanchet e colaboradores (2008) reforçaram os resultados obtidos por aqueles autores, justificando a alta variabilidade na farmacocinética de antimicrobianos como conseqüência do estado clínico do paciente com sepse, da extensão e da profundidade da lesão, 
do período decorrido desde o acidente, da administração de fármacos vasoativos, balanço hídrico, dentre outros.

Os dados obtidos pela realização do presente estudo com sete antimicrobianos e um antifúngico estão de acordo com os reportados anteriormente (GARRELTS \& PETERIE, 1988, WEINBRER, 1999; BLANCHET, 2008 RONG-HUA et al., 2009), uma vez que se registrou também alta variabilidade inter-indivíduos nos parâmetros a partir da investigação da farmacocinética justificada em parte pelo grande número de fatores dependentes do paciente queimado individual: superfície corpórea queimada (SCQ\%), alterações orgânicas, peso, idade, função renal e estados de doença prévia associada. Por outro lado, evidenciou-se alta variabilidade intra-indivídual da farmacocinética dos oito agentes terapêuticos no decurso da internação na Unidade de Terapia Intensiva (UTI), que dependeu da evolução do paciente na UTI, como por exemplo, da necessidade de fármacos vasoativos, da integridade da função renal, do número de cirurgias realizadas (limpeza, desbridamento e enxerto), da cicatrização da ferida, de infecções bacterianas e fúngicas. Portanto pela investigação de 32 pacientes queimados em 303 seguimentos, os resultados obtidos estão de acordo com aqueles reportados por Pea e colaboradores (2000).

No presente estudo, durante o período de internação e evolução clínica do queimado ocorreram alterações extensas demonstradas pela imprevisibilidade na farmacocinética de praticamente todos antimicrobianos investigados; conseqüentemente, em cada seguimento farmacoterapêutico realizado pela coleta de amostras sanguíneas, a variabilidade intra-individual excedeu aquela registrada interindivíduos. O fato reforça ainda mais a necessidade do ajuste de dose para a garantia da eficácia e controle das infecções, uma vez que a dose recomendada é adequada em determinado momento da internação tornando-se inadequada em outro (GARRELTS, 1988; WEINBRER, 1999; BLANCHET, 2008; ROBERTS \& LIPMAN, 2009; RONG-HUA, 2009).

A terapia antimicrobiana envolve uma série de agentes terapêuticos com características diversas relacionadas à molécula (estrutura, peso molecular, pK, hidrossolubilidade), à farmacocinética com relação à extensão e força de ligação as proteínas plasmáticas, volume aparente de distribuição, meia-vida 
biológica, depuração plasmática e fração da dose administrada sistemicamente que é excretada através dos rins, e à farmacodinâmica (WINTER, 2004).

Como os dados fornecidos através do monitoramento das concentrações plasmáticas associados apenas à farmacocinética não apresentam contribuição terapêutica apesar da efetividade do agente antimicrobiano, sugere-se que a modelagem PK-PD poderia fornecer um novo parâmetro na predição da eficácia vindo preencher a lacuna relacionada a falha terapêutica (FRIMODTMOLLER, 2002).

Assim, no presente estudo testaram-se os parâmetros de predição de eficácia recomendados para cada antimicrobiano de forma a justificar a atividade de determinado agente na dependência do tempo pós-dose e das concentrações (in vivo-in vitro) ou ainda de todos esses parâmetros; ou seja, a eficácia dependeria do tempo e das concentrações plasmáticas desse agente, considerando-se ainda a concentração inibitória mínima (CIM) da bactéria (EUCAST, 2010; MICROMEDEX, 2010).

A aplicação da modelagem PK-PD proposta por Chapuis e colaboradores (2010) para o cefepime nos pacientes do presente estudo indicou que o parâmetro de predição de eficácia (\% $\% \mathrm{~T}>\mathrm{CIM})$ se mostrou acima da concentração inibitória mínima obtida na medida in vitro (CIM variando de 1 a $8 \mathrm{mg} / \mathrm{L})$, figura 19, para a família Enterobacteriaceae (60-70\%T>CIM) e para o Staphylococcus aureus (40-50\%T>CIM) garantindo-se portanto a eficácia desse agente nos pacientes queimados durante os seguimentos realizados na UTI. Apesar da alta variabilidade na farmacocinética desse agente nos 10 seguimentos realizados nos pacientes queimados. Desta forma, considera-se que a modelagem PK-PD utilizando o parâmetro de predição de eficácia justifica plenamente a substituição da terapia empírica pela dose ajustada desse agente em cerca de $65 \%$ dos seguimentos realizados. Os resultados obtidos no estudo estão de acordo com os reportados anteriormente (AMBROSE et al, 2003, CHAPUIS et al, 2010, EUCAST 2010)

Com relação ao ciprofloxacino evidenciou-se alta variabilidade na farmacocinética durante os seis seguimentos realizados nos pacientes queimados. Tal fato pode ser justificado em decorrência das elevadas concentrações obtidas nos diversos seguimentos realizados para o paciente 
\#20 que apresentou no decurso do tratamento síndrome hemolítica e pancitopenia. Destaca-se ainda que a concentração plasmática máxima tolerada foi excedida para esse paciente no primeiro seguimento. A extensa alteração da farmacocinética registrada nos seguimentos pós-queimadura, com grande prejuízo na distribuição e na eliminação do ciprofloxacino, é decorrente da gravidade do quadro do paciente na fase hipermetabólica tardia. A aplicação da modelagem PK-PD proposta por Pea e colaboradores (2006) indicou que os valores de referência para os parâmetros de predição de eficácia do ciprofloxacino $\mathrm{ASC}^{\text {sS }}{ }_{0-24} / \mathrm{CIM}>125$ e $\mathrm{C}_{\text {max }}^{\text {sS }} / \mathrm{CIM}>10$ não foram atingidos em todos os seguimentos realizados no presente estudo considerando-se as bactérias gram negativas susceptíveis, CIM 0,5 mg/L. Portanto, a eficácia desse agente não foi garantida em 100\% dos seguimentos realizados no presente estudo indicando que o uso da ferramenta de PK-PD pode fornecer o suporte definitivo no ajuste de dose requerido para os pacientes queimados recebendo ciprofloxacino, conforme recomendado anteriormente (PEA et al, 2006; EUCAST, 2010).

Evidenciou-se ainda profunda alteração na farmacocinética do fluconazol pela investigação de 31 seguimentos realizados nos pacientes queimados, independentemente da função renal preservada ou na disfunção renal dialítica, fato que indicou a necessidade da terapia dose ajustada. O aumento da dose diária foi realizado em $32 \%$ dos seguimentos dos pacientes com função renal preservada, enquanto que a redução da dose diária de 400mg para 200mg 1x ao dia foi requerida em todos os seguimentos de pacientes queimados com função renal reduzida.

A atividade fungistática do agente depende do intervalo de tempo para manter a concentração que forneça área sob a curva integrada acima do valor recomendado, e a medida preditiva de eficácia é realizada através da razão $\mathrm{ASC}^{\mathrm{ss}}{ }_{0-24} / \mathrm{CIM}$ para o efeito pós-fluconazol contra a Candida ssp. Desta forma, a aplicação da modelagem PK-PD proposta por Pfaller e colaboradores (2006) no presente estudo indicou que os valores de referência para a predição de eficácia para esse agente $\left(\mathrm{ASC}^{\mathrm{Ss}}{ }_{0-24} / \mathrm{CIM}>25\right)$ foram atingidos somente em parte dos seguimentos realizados considerando-se Candida ssp, cepas sensíveis CIM 8 mg/L, estendendo-se ainda para os casos de Candida ssp. apresentando sensibilidade dose dependente para valores de CIM 8 e 16 mg/L, 
mas não para cepas apresentando CIM $32 \mathrm{mg} / \mathrm{L}$. Apesar das alterações farmacocinéticas registradas, a eficácia desse agente foi garantida para a maioria dos seguimentos realizados pelo uso da ferramenta de PK-PD no ajuste de dose requerido para os pacientes queimados recebendo o fluconazol conforme recomendado anteriormente (PFALLER et al, 2006: EUCAST, 2010; MICROMEDEX, 2010).

Considerando-se o imipenem, agente carbapenêmico de larga prescrição nas UTIs, o regime posológico recomendado foi alterado no presente estudo em cerca de $20 \%$ dos seguimentos contra a manutenção do regime nos demais de pacientes com função renal normal. Em contrapartida, o regime posológico foi reduzido em $68 \%$ dos seguimentos de pacientes com insuficiência renal dialítica. Evidenciou-se alteração na farmacocinética do imipenem na disfunção renal dialítica com evidente prolongamento da meia vida biológica e redução da depuração plasmática. Uma vez que a atividade antibacteriana tempo-dependente do imipenem é estimada através da razão $\% \Delta \mathrm{T}>\mathrm{CIM}$. A modelagem PK-PD foi aplicada no presente estudo com base na curva de decaimento plasmático do imipenem no decurso do tempo, considerando-se a porcentagem de tempo (\% $\% \mathrm{~T})$ em que a concentração do fármaco encontra-se acima do CIM. Devido ao imunocomprometimento desses pacientes, as concentrações de imipenem devem se manter em até $40 \%$ do tempo acima de CIM para a atividade bactericida. Registraram-se concentrações do imipenem acima de CIM para a grande maioria dos seguimentos realizados e para os diferentes microorganismos considerados. A atividade bacteriostática acima de 20\%T>CIM e a atividade bactericida acima de 40\%T>CIM foi reportada anteriormente (KAYS, 1999; BURGESS \& FREI, 2005; GEORGE et al, 2007; IKAWA, 2008; EUCAST, 2010) para concentração inibitória mínima, equivalente à 0,5mg/L (Escherichia coli), 1mg/L (Acinetobacter baumanni, Enterobacter aerogenes, Enterobacter cloacae, Klebsiella ssp) 4mg/L (Enterococcus faecalis, Enterococcus faecium, Morganella morganii). No presente estudo, o parâmetro PK-PD recomendado na predição de eficácia (\% $\% \mathrm{~T}>\mathrm{CIM})$ mostrou-se abaixo de $40 \%$, portanto sem efeito bactericida em 6/75 seguimentos, e inferior a 20\%, sem efeito bacteriostático em 2/75 seguimentos realizados. 
Alta variabilidade farmacocinética foi registrada também para a oxacilina e para a piperacilina principalmente com relação aos parâmetros meia vida biológica e volume aparente de distribuição. Adicionalmente, com relação à predição de eficácia, o intervalo de tempo em que a concentração plasmática do antimicrobiano permanece acima da concentração inibitória mínima (\% $\%$ T >CIM) mostrou ser o melhor parâmetro para a oxacilina e a piperacilina de ação tempo-dependente. A modelagem PK-PD referida por Kays e colaboradores (1999) foi aplicada no presente estudo para ambos agentes (oxacilina e piperacilina) nos seguimentos realizados, com base na curva de decaimento plasmático no decurso do tempo, considerando-se a porcentagem de tempo $(\% \Delta \mathrm{T})$ em que a concentração plasmática permanece acima do CIM.

A modelagem PK-PD foi aplicada no presente estudo para a oxacilina com base no parâmetro de predição de eficácia $\% \Delta \mathrm{T}>\mathrm{CIM}(50 \%$ para Staphylococcus aureus; e 70\% para os outros microorganismos). Os valores que se mostraram acima da concentração inibitória mínima obtida na medida in vitro (CIM $2 \mathrm{mg} / \mathrm{L})$, para todos os segmentos, exceto no $3^{\circ}$ segmento (\#20) onde a $\% \Delta \mathrm{T}>\mathrm{CIM}$ foi de 33,3\%, considerada portanto ineficaz. Desta forma, a modelagem PK-PD utilizando os parâmetros de predição de eficácia \% $\%$ T>CIM para a oxacilina justificou a substituição da terapia empírica pela dose ajustada desse agente com base no CIM do agente infeccioso (KAYS et al, 1999; EUCAST, 2010; MICROMEDEX, 2010).

Adicionalmente, para a piperacilina a modelagem PK-PD proposta pelos mesmos autores anteriores foi aplicada no presente estudo com base no parâmetro de predição de eficácia \% $\%$ T>CIM (50\% para Staphylococcus aureus; e 70\% para os outros microorganismos de acordo com Kays e colaboradores, 1999). Os valores que se mostraram acima da concentração inibitória mínima obtida na medida in vitro (CIM 2 e $8 \mathrm{mg} / \mathrm{L}$ ), para o Staphylococcus aureus, E.coli, Klebsiella ssp, Salmonella ssp, Serratia ssp. Por outro lado, os parâmetros de predição encontraram-se abaixo dos valores recomendados e portanto permanecendo descoberto nas infecções por Pseudomonas aeruginosa (CIM: 64mg/L), onde observou-se que em 6/10 segmentos o paciente encontrava-se descoberto. Desta forma, considera-se que a modelagem PK-PD utilizando os parâmetros de predição de eficácia 
$\% \Delta \mathrm{T}>\mathrm{CIM}$ para a piperacilina justificou a substituição da terapia empírica pela dose ajustada desse agente com base no CIM do agente infeccioso (KAYS et al, 1999; AMBROSE et al, 2003, EUCAST, 2010; MICROMEDEX, 2010).

A farmacocinética da sulfametoxazol se mostrou independentemente da função renal alterada relativamente à depuração plasmática e ao volume aparente de distribuição nos pacientes queimados. Adicionalmente, quando se compararam seguimentos de pacientes com insuficiência renal com aqueles de função renal preservada registrou-se prolongamento significativo da meia vida biológica, permanecendo inalterados os demais parâmetros. Registrou-se alta variabilidade na farmacocinética desse agente considerando-se os seguimentos realizados nos pacientes queimados, fato que indicou a necessidade da terapia dose ajustada em 54\% dos seguimentos farmacoterapêuticos, mantendo-se a terapia empírica recomendada inicialmente no restante dos seguimentos.

Apesar da atividade bactericida tempo-dependente do sulfametoxazol ainda não estar bem estabelecida, a modelagem PK-PD proposta por Cheng e colaboradores (2009) recomenda para esse agente a utilização de dois parâmetros como importantes na predição da eficácia: $\mathrm{ASC}^{\mathrm{sS}}{ }_{0-24} / \mathrm{CIM}$ e \% T>CIM, obtidos a partir da curva de decaimento plasmático no decurso do tempo, com base na área sobre a curva ( $\left.\mathrm{ASC}^{\mathrm{sS}}{ }_{0-24} / \mathrm{CIM}\right)$ e a razão com o CIM e a porcentagem de tempo $(\% \Delta T)$ em que a concentração do fármaco encontrase acima do CIM. A modelagem PK-PD foi aplicada para a sulfametoxazol no presente estudo com base nos parâmetros de predição de eficácia (ASC/CIM> 25 e \% $\% \mathrm{~T}>\mathrm{CIM}=60 \%$ ) que se mostraram acima da concentração inibitória mínima obtida na medida in vitro (CIM 32 mg/L), para o Staphylococcus aureus e Enterobacter ssp; se encontrando entretanto os parâmetros de predição abaixo dos valores recomendados, permanecendo o paciente descoberto no caso de infecções por Klebsiella pneumoniae, Listeria monocytogem (CIM: 64mg/L). Desta forma, considera-se que a modelagem PK-PD utilizando os parâmetros de predição de eficácia $\mathrm{ASC}^{\mathrm{Ss}}{ }_{0-24} / \mathrm{CIM}>25$ e $\% \Delta \mathrm{T}>\mathrm{CIM}=60$ para a sulfametoxazol justificou a substituição da terapia empírica pela dose ajustada desse agente com base no CIM do agente infeccioso (EUCAST, 2010; MICROMEDEX, 2010). 
Finalmente, a aplicação da modelagem PK-PD proposta por Revilla e colaboradores (2010) no presente estudo para a vancomicina, indicou que os valores de referência para a predição de eficácia da vancomicina $\left(\mathrm{ASC}_{0}^{\mathrm{SS}}\right.$ ${ }_{24} / \mathrm{CIM}>400$ ) foram atingidos nos seguimentos realizados para concentração inibitória mínima de 1mg/L com cobertura apenas das infecções causadas por Streptococcus ssp (EUCAST, 2010; REVILLA et al, 2010).

Uma vez que o parâmetro de predição de eficácia para esse antimicrobiano $\left(\mathrm{ASC}^{\mathrm{SS}}{ }_{0-24} / \mathrm{CIM}\right.$ ) foi equivalente à 248,2 para CIM 2mg/L e 124,1 para CIM de $4 \mathrm{mg} / \mathrm{L}$, os valores requeridos para cobertura contra Staphylococcus aureus Meticilina Resistente, Clostridium difficile (CIM: 2mg/L) e contra Enterococcus faecium e Enterococcus faecalis (CIM: 4mg/L) não foram atingidos, indica-se como definitiva a modelagem PK-PD para a garantia de eficácia e suporte no ajuste de dose de vancomicina.

A alta variabilidade da farmacocinética da vancomicina relacionada à instabilidade do paciente grave de longa permanência, ao grande número de procedimentos realizados na UTI, bem como as complicações da queimadura exige o uso da ferramenta de PK-PD com base no parâmetro de predição recomendado. Destaca-se que a eficácia da vancomicina não foi garantida apesar da terapia dose ajustada em $88 \%$ dos seguimentos realizados em 31 pacientes queimados.

Com base nos resultados obtidos no presente estudo principalmente com relação à vancomicina, sugere-se uma revisão dos valores de referência principalmente para a janela terapêutica no vale, uma vez que se prevêem a necessidade de se manter para esse agente concentração plasmática no intervalo de dose superior aquelas obtidas hoje de forma a atingir os valores recomendados para o parâmetro de predição de eficácia $\left(\mathrm{ASC}^{\mathrm{sS}}{ }_{0-24} / \mathrm{CIM}>400\right.$ ) considerando os agentes Staphylococcus aureus Meticilina Resistente, Clostridium difficile (CIM: 2mg/L) e Enterococcus faecium e Enterococcus faecalis (CIM: 4mg/L).

Desta forma, à partir da realização desse estudo, propõe-se o uso da ferramenta de PK-PD de rotina empregando os índices de predição de eficácia recentemente recomendados para os diferentes antimicrobianos tais como o intervalo de tempo em que a concentração plasmática permaneceu 
acima da concentração inibitória mínima (\% $\%$ T> CIM) para o cefepime, imipenem, oxacilina e piperacilina, $\mathrm{ASC}_{0-24}^{\mathrm{ss}} / \mathrm{CIM}+\mathrm{C}_{\max }^{\mathrm{ss}} / \mathrm{CIM}$ para 0 ciprofloxacino, $\mathrm{ASC}^{\mathrm{sS}}{ }_{0-24} / \mathrm{CIM}$ para o fluconazol e para a vancomicina e $\mathrm{ASC}_{0 \text { - }}^{\mathrm{ss}}$ ${ }_{24} / \mathrm{CIM}+\% \Delta \mathrm{T}>\mathrm{CIM}$ para a sulfametoxazol, considerando-se ainda os valores de referência recomendados para a atividade bacteriostática e bactericida.

Finalmente, acredita-se que o Médico Intensivista poderá dispor dessa promissora ferramenta na predição de eficácia antimicrobiana e controle das infecções nos pacientes queimados.

Considera-se ainda que o emprego dessa ferramenta nas populações de risco constituída por pacientes graves portadores de sepse ou reincidência dela, imunocomprometidos, ou de internação prolongada na UTI seja plenamente justificada pela imprevisibilidade da farmacocinética desses agentes e pelo crescimento da resistência bacteriana decorrente do aumento da concentração inibitória mínima requerida para a eficácia de antimicrobianos e antifúngicos. 


\section{CONCLUSÃO}

1. A farmacocinética dos oito agentes terapêuticos investigados se mostrou alterada em pacientes queimados.

2. Registrou-se alta variabilidade na farmacocinética de todos os agentes investigados, sendo que a variabilidade intra-individual excedeu a variabilidade inter-pacientes.

3. Evidenciou-se diferença significativa nos parâmetros farmacocinéticos do imipenem, sulfametoxazol e vancomicina nos seguimento de pacientes queimados com disfunção renal dialítica em comparação aos de função renal preservada.

4. A modelagem PK-PD baseada nos parâmetros in vivo-in vitro determinantes da predição de eficácia para os antimicrobianos mostrou-se ferramenta importante na garantia da eficácia antimicrobiana.

5. O uso da ferramenta de PK-PD empregando os índices de predição de eficácia pelas medidas in vivo - in vitro através do monitoramento plasmático dos antimicrobianos associado à concentração inibitória mínima do agente infeccioso será fundamental para o Médico Intensivista na tomada de decisão e alteração da prescrição de antimicrobianos com vistas à manutenção da eficácia, considerando-se a imprevisibilidade da farmacocinética desses agentes em pacientes queimados durante a permanência na UTI. 


\section{7-REFERÊNCIA BIBLIOGRÁFICA}

AMB - Associação Medica Brasileira e Conselho Federal de Medicina. Projeto Diretrizes: $\quad 2008 . \quad$ Queimaduras. Disponível em: http://www.projetodiretrizes.org.br, acessado em:25/07/2009.

AMB - Associação Medica Brasileira e Conselho Federal de Medicina. Projeto Diretrizes: Infecção Hospitalar. 2001. Disponível em: http://www.projetodiretrizes.org.br, acessado em:25/07/2009.

ABA - American Burn Association. Disponível em: http://www.ameriburn.org/resources_factsheet.php, acessado em: 25/07/2009.

AMBROSE PG, BHAVNANI SM, JONES RN. Pharmacokinetics-Pharmacodynamics of Cefepime and Piperacillin-Tazobactam against Escherichia coli and Klebsiella pneumoniae Strains Producing Extended-Spectrum _-Lactamases: Report from the ARREST Program. Antimicrobial Agents and Chemotherapy. v. 47, n. 5, p. 1643-1646, 2003

ANVISA - Agencia Nacional de Vigilancia Sanitaria. Curso Basico de controle de infecção Hospitalar, 2000

ASHP -American Society of Health-System Pharmacists. ASHP statement on the pharmacist's role in clinical pharmacokinetic monitoring. American Journal of Health-System Pharmacy; v.55, p.1726-7, 1998.

BANG LR, GANG RK, SANYAL SC, MOKADDAS E, EBRAHIM MK. Burn septicemia: an analysis of 79 patients. Burns, v.24, p.354-61, 1998.

BLANCHET B, JULLIEN V, VINSONNEAU C, TOD $M$. Influence of burns on pharmacokinetics and pharmacodynamics of drugs used in the care of burn patients. Clinical Pharmacokinetics. v.47, n.10, p.635-54, 2008.

BOUCHER BA, KUHL DA, HICKERSON WL. Pharmacokinetics of systemically administered antibiotics in patients with thermal injury. Clinical Infection Disease, v.14, p.458-63, 1992.

BRISKIER, A. Antimicrobial agents: antibacterials and antifungals. Ed. ASM Press, Washington DC, 2005.

BURGESS DS, FREI CR. Comparasion of $\beta$-lactam regimens for the treatment of Gram-negative pulmonary infections in the intensive care unit based on pharmacokinetics/pharmacodynamics. Journal of Antimicrobial Chemotherapy, v. 56, p. 893-898, 2005.

CAMERON DR, MULLER MJ, FAOAGALI J, Burn wound excision and massive blood transfusion did not affect perioperative vancomycin levels. Burns, v.24, p.475477, 1998.

CHAPUIS TM, GIANNONI E, MAJCHERCZYK PA, SCHALLER MD, BERGER MM, BOLAY S, DÉCOSTERD LA, BUGNON D, MOREILLON P. Prospective 
monitoring of cefepime in intensive care unit adult patients. Critical Care, v. 14, R51, 2010.

CHEATHAM SC, SHEA KM., HEALY DP, HUMPHREY ML, FLEMING MR, WACK MF, SMITH DW, SOWINSKI KM, KAYS MB. Steady-state pharmacokinetics and pharmacodynamics of cefepime administered by prolonged infusion in hospitalised patients. International Journal of Antimicrobial Agents., v.37, p.4650, 2011.

CHENG AC, MCBRYDE ES, WUTHIEKANUN V, CHIERAKUL W, AMORNCHAI P, DAY NPJ, WHITE NJ, PEACOCK S. Dosing Regimens of Cotrimoxazole (Trimethoprim-Sulfamethoxazole) for melioidosis. Antimicrobial Agents and Chemotherapy, v.53, n.10, p.4193-4199, 2009.

COCKCROFT DW, GAULT MH. Prediction of creatinine clearance from serum creatinine. Nephron, v.16, n.1, p.31-41, 1976.

DAILLY E, LE FLOCH R, DESLANDES G, PANNIER M, JOLLIET P. Influence of glomerular filtration rate on the clearance of vancomycin administered by continuous infusion in burn patients. Antimicrobial Agents, v. 31, p. 537-539, 2008.

DASGUPTA A. Introduction to therapeutic drug monitoring. In: Dasgupta A. Handbook of drug monitoring methods. Therapeutics and drugs of abuse. Humana Press, New Jersey,p.:1-39, 2008.

DEBRUYNE \& RYCKELYNECK. Clinical Pharmacokinetics of Fluconazol. Clinical Pharmacokinetics, n. 24, p.10-27, 1993.

DE SANTI, L. Phathophysiology and current management of burn injury. Advance Skin Wound Care. N.18 p.323-332, 2005.

DIPIRO JT, SPRUILL WJ, BLOUIN R.A, PRUEMER JM. Concept in clinical pharmacokinetics. American Society of Health-System Pharmacyst, 3rd ed., 2002

DOLTON M, XU H, CHEONG E, MAITZ P, KENNEDY P, GOTTLIEB T, BUONO E, MCLACHLAN A. Vancomycin pharmacokinetics in patients with severe burn injuries. Burns, v. 36, p.469-476, 2010.

EUCAST - European Committee of antimicrobial susceptibility testing. MIC distribution. Disponível em: http://www.eucast.org/mic distributions/ Acessado em: 20/09/2010.

FRIMODT-MOLLER N. How predictive is PK/PD for antibacterial agents? International Journal of Antimicrobial agents, v.19, p.333-339, 2002.

FRY DE. The importance of antibiotic pharmacokinetics in critical illness. Am J Surg; v.1, n.72(supl 6A), p.20S-5S. 1996.

GARRELTS JC, PETERIE JD. Altered vancomycin dose vs Serum concentration relationship in burn patients. Clinical Pharmacology Therapeutics, v.44, n.1, p.913, 1988. 
GEORGE G,. ZHANEL GG, WIEBE R, DILAY L, THOMSON K, RUBINSTEIN E, HOBAN DJ, NOREDDIN AM, KARLOWSKY JA. Comparative Review of the Carbapenems. Drugs. V. 67, n.(7), p.: 1027-1052, 2007

HCFMUSP. Guia de Utilização de Antimicrobianos e recomendações para a prevenção de infecções hospitalares, HCFMUSP, 2009-2011. Disponível em: www.hcnet.usp.br, acessado em 25/09/2010.

HIRAMATSU K. Vancomycin resistance in Staphylococci. Drug Resistance Updates;v.1, p.135-50, 1998.

IKAWA K, MORIKAWA N, IKEDA K, OHGE H, SUEDA T. Development of breakpoints of carbapenems for intraabdominal infections based on pharmacokinetics and pharmacodynamics in peritoneal fluid. Journal of Infection Chemotherapy, v. 14, p. 330-332, 2008.

KANG JS, LEE MH. Overview of Therapeutic Drug Monitoring The Korean Journal of Internal Medicine. V. 24, N. 1, 2009

KAYS MB. Comparison of Five $\beta$-lactam antibiotics against common nosocomial pathogens using the time above MIC at different creatinine clearances. Pharmacotherapy, v.19, n.12, 1999.

KECK M, HERNDON DH, KAMOLZ LP, Frey M, Jeschke MG. Phatophysiology of burns. Wien Med Wochenschr, v.159, n.13-14, p.327-336, 2009.

LAUNAY-VACHER V, IZZEDINE H, MERCADAL L, DERAY G. Clinical review: use of vancomycin in haemodialysis patients. Critical Care. v.6, n.4, p.313-6, 2002

LÓPEZ KJV, BERTOLUCI DF, VICENTE KM, DELL'AQUILLA AM, SANTOS SRCJ. Simultaneous determination of cefepime, vancomycin and imipenem in human plasma of burn patients by high-performance liquid chromatography. Journal of Chromatography B, v.860, p.241-245, 2007.

MICROMEDEX, Micromedex® Healthcare Series. Inc., Greenwood Village, Colorado, 2010

MURPHY JE, WARD ES, JOB ML. Implementing and maintaining a private pharmacokinetics practice. American Journal of Health-System Pharmacy, v.47, p.591-7. 1990

PEA F, PORRECA L, BARALDO M, FURLANUT M. High vancomycin dosage regimens required by intensive care unit patients cotreated with drugs to improve haemodynamics following cardiac surgical procedures. Journal of Antimicrobial Chemotherapy, v. 45, p. 329-335, 2000. 
PEA F, POZ D, VIALE P, PAVAN F, FURLANUT M. Wich reliable pharmacodynamic breakpoint should be advised for ciprofloxacin monotherapy in the hospital setting? A TDM-based retrospective perspective. Journal of Antimicrobial Chemotherapy, v.58, p. 380-386, 2006.

PFALLER MA, DIEKEMA DJ, SHEEHAN DJ. Interpretive breakpoints for Fluconazole and Candida Revised: a blueprint for the future of antifungal susceptibility testing. Clinical Microbiology Reviews, v.19, n.2, p.435-447, 2006.

REVILLA N, MARÍN-SUÁREZ A, PÉREZ MP, GONZÁLEZ FM, GATTA MMF. Vancomycin dosing assessment on intensive care unit patients based on a population pharmacokinetic/pharmacodynamic simulation. British Journal of Clinical Pharmacology, v.70, n.2, p.201-212, 2010.

ROBERTS JA, LIPMAN, J. Pharmacokinetic issues for antibiotics in the critically ill patient. Critical Care Med., vol.37, n.3, 840-851, 2009.

RONG-HUA Y, XIN-ZHOU R, RONG H, TAO Z. Pharmacokinetics of vancomycin and amikacin in the subeschar tissue fluid in patients with severe burn. Burns., v.35, p. 75-79, 2009.

RYBAK MJ. Pharmacodynamics: relation to antimicrobial resistance. The American Journal of Medicine, v.119, n.6A, p.S37-S44, 2006.

SANTOS SRCJ. Monitorização Terapêutica. In: Moreau RLM. Toxicologia Analítica. Rio de Janeiro: Guanabara Koogan, p.91-9, 2008.

SBRAFH - Sociedade Brasileira de Farmacêuticos Hospitalares. Padrões Mínimos para Farmácia Hospitalar, Goiânia, 2007.

SHERIDAN, RL. Burns. Critical Care Medicine, v.30, n.11, p.500-514, 2002.

WEINBREN MJ. Pharmacokinetics of antimibiotics in burn patients. Journal of Antimicrobial Chemotherapy, n.44, p.319-327, 1999.

WINTER, MICHAEL E. Basic Clinical Pharmacokinetics. 4th ed., Lippincott Williams \& Wilkins, 2004 


\section{UNIVERSIDADE DE SÃO PAULO \\ FACULDADE DE CIÊNCIAS FARMACÊUTICAS \\ Programa de Pós-Graduação em Fármacos e Medicamentos \\ Área de Produção e Controle}

\section{Desenvolvimento e Validação de Método Bioanalítico para quantificação de Antimicrobianos em Plasma através de Cromatografia Líquida de Alta Eficiência}




\section{LISTA DE ILUSTRAÇÕES}

Figura 1A - Perfil cromatográfico de ciprofloxacino, oxacilina, piperacilina e sulfametoxazol em plasma; corrida analítica de 35 minutos. (A): Plasma branco; (B) Concentração media de COP $(25 \mu \mathrm{g} / \mathrm{mL}$ para oxacilina e piperacilina, $2,5 \mu \mathrm{g} / \mathrm{mL}$ para ciprofloxacino e $40 \mu \mathrm{g} / \mathrm{mL}$ para sulfametoxazol); (C) Limite de deteç̧ão $(1 \mu \mathrm{g} / \mathrm{mL}$ para oxacilina e piperacilina, $0,2 \mu \mathrm{g} / \mathrm{mL}$ para ciprofloxacino e $0,78 \mu \mathrm{g} / \mathrm{mL}$ para sulfametoxazol); Tempo de retenção do ciprofloxacino 8,6min, piperacilina 10.4min, oxacilina 13,6min, sulfametoxazol 15,9 min e cetoconazol (padrão interno) 28,0min.

Figura 2A - Perfil cromatográfico de fluconazol em matriz biológica, tempo de corrida de 15 minutos. (A): Plasma branco; (B) CQM $(50,0 \mu \mathrm{g} / \mathrm{mL})(\mathrm{C})$ Limite de detecção $(0,4 \mu \mathrm{g} / \mathrm{mL})$. Tempo de retenção do fluconazol 6,2min e da carbamazepina (padrão interno) 7,2min.....

Figura 3A - Curva de calibração diária para determinação de ciprofloxacino plasmático através de CLAE. Plotaram-se as razões de área dos picos de ciprofloxacino e o cetoconazol (PI) versus as concentrações nos calibradores $(0,8-20 \mu \mathrm{g} / \mathrm{mL}) 20$

Figura 4A - Curva de calibração diária para determinação de fluconazol plasmático através de CLAE. Plotaram-se as razões de área dos picos de fluconazol e a carbamazepina $(\mathrm{Pi})$ versus as concentrações nos calibradores $(0,4-$ $100 \mu \mathrm{g} / \mathrm{mL}$ )

Figura 5A - Curva de calibração diária para determinação de oxacilina plasmático através de CLAE. Plotaram-se as razões de área dos picos de oxacilina e o cetoconazol $(\mathrm{Pi})$ versus as concentrações nos calibradores $(1,0-100 \mu \mathrm{g} / \mathrm{mL}) \ldots \mathbf{2 1}$

Figura 6A - Curva de calibração diária para determinação de piperacilina plasmático através de CLAE. Plotaram-se as razões de área dos picos de piperacilina e o cetoconazol (Pi) versus as concentrações nos calibradores $(3,0-100 \mu \mathrm{g} / \mathrm{mL}) .22$

Figura 7A - Curva de calibração diária para determinação de sulfametoxazol plasmático através de CLAE. Plotaram-se as razões de área dos picos de sulfametoxazol e o cetoconazol (Pi) versus as concentrações nos calibradores $(0,8-100 \mu \mathrm{g} / \mathrm{mL})$

Figura 8A - Perfil cromatográfico dos três agentes antimicrobianos em matrizes biológicas, tempo de corrida 30 min (A): Plasma branco com padrão interno (IS); (B) CQA; (C) CQB. Tempo de retenção (minutos) dos picos eluídos: 8,9 min (cefepime), 18,7 min (vancomicina), 21,7 min (imipenem), 26,5 min (padrão interno: cefuroxima).

Figura 9A - Curva de calibração diária para determinação do cefepime plasmático através de CLAE. Plotaram-se as razões de área dos picos de cefepime e a cefuroxima $(\mathrm{Pi})$ versus as concentrações do cefepime nos calibradores $(0,8-$ $200 \mu \mathrm{g} / \mathrm{mL})$

Figura 10A- Curva de calibração diária para determinação da vancomicina plasmática através de CLAE. Plotaram-se as razões de área dos picos de cefepime e a cefuroxima $(\mathrm{Pi})$ versus as concentrações do cefepime nos calibradores $(0,4-$ $100 \mu \mathrm{g} / \mathrm{mL})$

Curva de calibração diária para determinação do imipenem plasmático através de CLAE. Plotaram-se as razões de área dos picos de cefepime e a cefuroxima $(\mathrm{Pi})$ versus as concentrações do cefepime nos calibradores $(0,4-$ $100 \mu \mathrm{g} / \mathrm{mL})$ 


\section{LISTA DE TABELAS}

Tabela 1A- Concentrações dos calibradores para o teste de linearidade. 14

Tabela 3A- Limites de confiança para os métodos analíticos

Tabela 4A- Estudos de precisão e exatidão dos antimicrobianos investigados (Cefepime, Imipenem e Vancomicina)

\section{LISTA DE SIGLAS E ABREVIATURAS}

$\begin{array}{ll}\mu L & \text { Microlitros } \\ \text { CLAE } & \text { Cromatografia líquida de alta eficiência } \\ \text { CLAE-UV } & \text { Cromatografia Líquida de Alta Eficiência - Ultravioleta } \\ \text { CQ } & \text { Controle de Qualidade } \\ \text { CQA } & \text { Controle de qualidade alto } \\ \text { CQB } & \text { Controle de qualidade baixo } \\ \text { CQM } & \text { Controle de qualidade médio } \\ \text { CV\% } & \text { Coeficiente de Variação } \\ \text { DP } & \text { Desvio padrão } \\ \text { EDTA } & \text { Etilenodiaminotetracético sal sódico } \\ \text { G } & \text { Grama } \\ \text { H } & \text { Hora } \\ \text { IC95\% } & \text { Intervalo de Confiança 95\% } \\ \text { L } & \text { Litros } \\ \text { LD } & \text { Limite de detecção } \\ \text { LI IC95\% } & \text { Limite inferior do intervalo de confiança 95\% } \\ \text { LQ } & \text { Limite de quantificação } \\ \text { LS IC95\% } & \text { Limite superior do intervalo de confiança 95\% } \\ \text { M } & \text { Molar } \\ \text { m } & \text { Metro quadrado } \\ \text { mg } & \text { Miligrama } \\ \text { Min } & \text { Minutos } \\ \text { mL } & \text { Mililitro } \\ \text { mm } & \text { Milímetro } \\ \text { MOPS } & \text { Ácido 3-(N-morfolino)-propano-sulfônico } \\ \mathrm{N}_{2} & \text { Nitrogênio } \\ \text { NAP } & \text { Não aplicável } \\ \text { ND } & \text { Não detectado } \\ \text { nm } & \text { Nanômetro } \\ \text { P } & \text { Significância estatística } \\ \text { Pi } & \text { Padrão Interno } \\ \mathrm{r}^{2} & \text { Coeficiente de correlação linear } \\ \text { RA } & \text { Razão da área } \\ \text { Rpm } & \text { Rotações por minuto } \\ \text { UV } & \text { Ultravioleta } \\ \text { v/v } & \text { Volume por volume } \\ & \end{array}$




\section{SUMÁRIO}

1. INTRODUÇÃO

2. OBJETIVOS

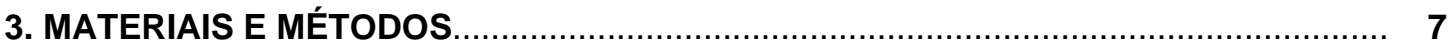

3.1. Padrões e Reagentes ....................................................................... $\quad 7$

3.2.- Preparo de padrões de referencia, calibradores e controles de qualidade $\mathbf{8}$

3.3.- Instrumentação analítica e condições cromatográficas ................... 9

3.4.- Procedimento de purificação da matriz biológica (plasma) ............. 9

4. RESULTADOS

3.5 -Validação do método analítico ………............................................. 11

4.1 Perfil Cromatográfico ................................................................. 18

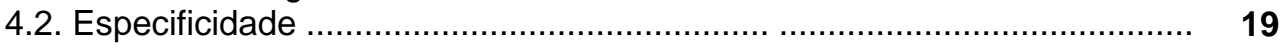

4.3. Limite de quantificação e limite de detecção ......................................... 19

4.4. Linearidade e curva de calibração ...................................................... 20

4.5. Precisão, exatidão e recuperação ....................................................... 23

4.6. Estabilidade dos antimicrobianos .................................................... $\quad 23$

4.7 Validação parcial de método bioanalítico para quantificação de Cefepime, Imipenem e Vancomicina. ..................................................................... 26

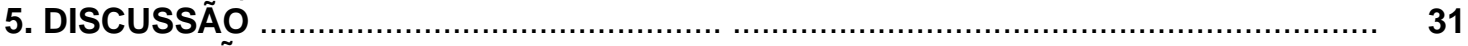

6. CONCLUSÃO

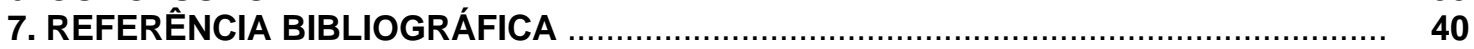




\section{INTRODUÇÃO}

A cromatografia líquida de alta eficiência (CLAE) é um método físico-químico que apresenta alta seletividade, precisão e exatidão além de manter a integridade da amostra no extrato da matriz biológica. Por outro lado, a sofisticação da instrumentação analítica, a complexidade de operacionalização, a exigência de analista treinado e utilização de softwares específicos podem ser consideradas como desvantagem de sua aplicação relativamente aos bioensaios e imunoensaios. Entretanto a falência terapêutica decorrente da utilização de imunoensaios ou de bioensaios não ocorre quando se determinam as concentrações plasmáticas de fármacos em geral por CLAE. É devido a esses fatores que o ajuste de dose pela alteração do regime posológico para os pacientes queimados é importante clinicamente, sendo fundamental no seguimento do tratamento.

A escolha do método cromatográfico é adequada se considerarmos a seletividade e a eficiência da técnica associadas ao sucesso terapêutico, redução do tempo de tratamento e alta precoce da UTI, com conseqüente redução de custo hospitalar.

A quantificação dos antimicrobianos na matriz biológica (plasma) foi realizada através da cromatografia líquida de alta eficiência CLAE-UVIVIS. Os métodos utilizados no presente trabalho foram validados e revalidados de acordo com a necessidade de cada análise. Assim, procedeu-se o desenvolvimento de novo método analítico para quantificação de sulfametoxazol e análise simultânea de ciprofloxacino, oxacilina e piperacilina em plasma (validação total) ou, adaptação e otimização de método desenvolvido anteriormente pelo grupo para quantificação de fluconazol em plasma (revalidação total, PEREZ 2007) e, finalmente validação parcial de método desenvolvido e validado anteriormente para quantificação simultânea de cefepime, imipenem e vancomicina em plasma (LOPEZ et al, 2007). Finalizada a validação, realizou-se a análise de oito analitos no plasma de 32 grandes queimados com base na curva de calibração diária (6-9 pontos) e três controles internos de qualidade (duplicatas). 


\section{OBJETIVO}

- Desenvolver, otimizar e validar método bioanalítico em cromatografia liquida de alta eficiência (CLAE-UV) para determinação de oito analitos (sete antimicrobianos e um antifúngico) utilizados no controle das infecções de pacientes grandes queimados internados na unidade de terapia intensiva (cefepime, ciprofloxacino, fluconazol, imipenem, oxacilina, piperacilina, sulfametoxazol e vancomicina) em plasma, com ênfase nos estudos de estabilidade de curta duração. 


\section{MATERIAIS E MÉTODOS}

\subsection{Padrões e Reagentes}

Foram utilizados os solventes, grau cromatográfico MERCK (Darmstadt, Alemanha), nos procedimentos de extração (precipitação das proteínas ou extração liquido-liquido) e na análise quantitativa do fármaco. A água ultrapura obtida através dos sistemas SIMPLICITY ${ }^{\circledR}$ e MILLIDI $^{\circledR}$, MILLIPORE (São Paulo, Brasil), foi utilizada na preparação da solução tampão para a fase móvel de cromatografia, na limpeza da tubulação e coluna analítica bem como na regeneração do cromatógrafo líquido. A fase móvel foi desgaseificada através do gás hélio, Hélio Premier-X50S, 99,99\% pureza, AIR PRODUCTS, (São Paulo, Brasil). Toda a vidraria, e demais materiais utilizados na análise do antibiótico e na cromatografia foi lavada previamente com ácido clorídrico 50\% seguindo o procedimento operacional padrão do Laboratório de Farmacologia Terapêutica, FCFUSP. O monitoramento do $\mathrm{pH}$ da fase móvel foi efetuado através de medidor de $\mathrm{pH}$ com eletrodo específico DM22, DIGIMED (São Paulo, Brasil).

Foram utilizados como referência os padrões secundários fornecidos pelas indústrias instaladas no país: cefepime (cloridrato) da BRISTOL-MEYERS SQUIBB DO BRASIL SIA, ciprofloxacino (cloridrato) da BAYER PHARMACEUTICALS DO BRASIL LTDA, fluconazol da PFIZER DO BRASIL LTDA, imipenem, da MERCK SHARP \& DOHME DO BRASIL LTDA, oxacilina (sal sódico) da BRISTOL-MEYERS SQUIBB DO BRASIL S/A, piperacilina (sal sódico) da WYETH S/A, sulfametoxazol, da ROCHE DO BRASIL SIA, e vancomicina (cloridrato), da ELI LILLY DO BRASIL LTDA, Os sais dos padrões de referência foram armazenados em recipiente com tampa, ao abrigo da luz e da umidade, em dessecador à temperatura ambiente, $21+/-1$ o $\quad$ C. Utilizou-se solução de ácido 3-Nmorfolinopropano sulfônico (MOPS) SIGMA (Steinheim, Alemanha) a 10\% $(\mathrm{p} / \mathrm{v})$ para os antimicrobianos (Cefepime, Imipenem, Meropenem, Vancomicina) que foi requerida na estabilização dos calibradores, aos 
controles internos e às amostras no momento da coleta de sangue dos pacientes e no procedimento de purificação da amostra de plasma, de acordo com o procedimento descrito abaixo.

\section{2.- Preparo de padrões de referencia, calibradores e controles de qualidade}

As soluções estoque foram preparadas pela pesagem de $5 \mathrm{mg}$ de cada padrão em balão volumétrico de $5 \mathrm{~mL}$, utilizando balança semi-micro analítica AX120, SHIMADZU (Kyoto, Japão), seguida de dissolução solvente adequado (água ou metanol), para obter uma concentração final de $1 \mathrm{mg} / \mathrm{mL}$.

A curva de calibração contendo os padrões em plasma foi preparada pela adição do volume apropriado de solução estoque de cada agente antimicrobiano em estudo ao plasma branco (testado e aprovado previamente) de forma a se obter os valores nominais na faixa de concentração desejada. Os controles internos de qualidade (CQs), alto (CQA), médio (CQM) e baixo (CQB) foram preparados através da diluição da solução estoque de cada antimicrobiano em plasma branco.

Para a quantificação de Cefepime, Imipenem e Vancomicina, alíquotas de $500 \mu \mathrm{L}$ dos padrões em plasma (calibradores), foram distribuídas para tubos de Eppendorf contendo $0,25 \mathrm{~mL}$ de solução estabilizante (MOPS 10\%) em caixas identificadas que foram armazenadas em congelador $\left(80^{\circ} \mathrm{C}\right.$, negativos) até o momento do ensaio.

Para os padrões internos utilizados em cada procedimento analítico preparou-se a solução padrão estoque $(1 \mathrm{mg} / \mathrm{mL})$ que foi distribuída para tubos de Eppendorf em alíquotas de 0,5mL/tubo e armazenadas em congelador REVCO, $80^{\circ} \mathrm{C}$, negativos (Asheville USA). O padrão de adição foi preparado diariamente, a partir da solução estoque de acordo com cada procedimento.

A solução de ácido 3-[N-morfolino] propano sulfônico 10\%, foi preparada pela dissolução de $1 \mathrm{~g}$ do MOPS com $10 \mathrm{~mL}$ de água ultrapura. 


\section{3.- Instrumentação analítica e condições cromatográficas}

Utilizou-se o cromatógrafo líquido SHIMADZU (Kyoto, Japão) constituído por bomba LC-10 AD VP, equipado com um controlador CBM 101 ou SCL-10AVP e programa Class VP, injetor automático SIL10A VP, detector SPD-10AVP, operando no ultravioleta no comprimento de onda $230 \mathrm{~nm}$. A integração da área dos picos dos antimicrobianos e do padrão interno foi realizada utilizando o programa Class VP, adicionalmente os picos foram monitorados em registrador-integrador Chromatopac CR-6A, Shimadzu (Kyoto, Japão).

Utilizou-se fase móvel binária preparada diariamente e desgaseificada com hélio por 3 minutos; efetuou-se o monitoramento do $\mathrm{pH}$ da fase móvel através de medidor de pH, DM22, DIGIMED (São Paulo, Brasil), com eletrodo específico e sensor de temperatura. Empregou-se ainda o sistema isocrático de eluição para os três métodos bioanalíticos propostos no estudo. Todas as análises foram realizadas a temperatura ambiente, $21+/-1{ }^{\circ} \mathrm{C}$ no Laboratório Analítico Instrumental.

\section{4.- Procedimento de purificação da matriz biológica (plasma)}

\section{A - Determinação simultânea de Cefepime, Imipenem e Vancomicina}

O método bioanalítico apresentado a seguir foi desenvolvido, validada e previamente publicada por Lopez e colaboradores (2007). Destaca-se que a quantificação dos fármacos exigiu volume reduzido da matriz biológica contendo a solução estabilizante MOPS na proporção de um volume de plasma/MOPS para três volumes de acetonitrila.

Em tubos tipo Eppendorf, foram adicionados $100 \mu \mathrm{L}$ de cefuroxima (Pi) na concentração de $40 \mu \mathrm{g} / \mathrm{mL}$ (diluído em água a partir da solução estoque), $100 \mu \mathrm{L}$ de MOPS e $200 \mu \mathrm{L}$ de matriz biológica contendo a solução estabilizante MOPS; a mistura foi agitada em vortex durante 10 segundos. A esses tubos Eppendorf foram adicionados $600 \mu \mathrm{L}$ de acetonitrila, seguida da homogeneização em vórtex durante 15 segundos, para precipitação 
homogênea das proteínas plasmáticas. Após agitação, as amostras foram centrifugadas a $7200 \mathrm{~g}$ a $4^{\circ} \mathrm{C}$ durante 20 minutos. Volumes de $400 \mu \mathrm{L}$ do sobrenadante foram aspirados e transferidos para tubos cônicos de $10 \mathrm{~mL}$ para evaporação à secura em banho-maria a $37^{\circ} \mathrm{C}$ sob fluxo de nitrogênio. Em seguida, o extrato seco foi dissolvido com $200 \mu \mathrm{L}$ da mistura de acetonitrila e água $(8: 2 \mathrm{v} / \mathrm{v})$ e volumes de $5 \mu \mathrm{L}$ foram injetados automaticamente no cromatógrafo líquido, SHIMADZU LC-10 AD VP (Kyoto, Japão); Coluna Supelcosil LC18 C18 (SUPELCO); Fase móvel tampão acetato $75 \mathrm{mM}, \mathrm{pH} 5,0$ e acetonitrila $(92: 8, \mathrm{v} / \mathrm{v})$; Fluxo: $0,8 \mathrm{~mL} / \mathrm{min}$, detector UV SPD-10AVP, $\lambda:$ 230nm; Autosampler SIL10A VP (Kyoto, Japão) e integração dos picos pelo programa Class VP. O tubo de Eppendorf contendo o material remanescente da precipitação foi descartado no lixo de resíduo biológico infectante para inativação.

\section{B - Determinação simultânea de Ciprofloxacino, Piperacilina, Oxacilina e Sulfametoxazol}

Em tubos tipo Eppendorf, foram adicionados $50 \mu \mathrm{L}$ de cetoconazol (Pi) na concentração de $100 \mu \mathrm{g} / \mathrm{mL}$ em metanol, a partir da solução estoque metanólica; após evaporação adicionaram-se $200 \mu \mathrm{L}$ de plasma e $600 \mu \mathrm{L}$ de acetonitrila, seguida da agitação em vórtex durante 15 segundos, para precipitação homogênea das proteínas plasmáticas. Os tubos foram centrifugados a $7200 \mathrm{~g} \mathrm{a} 4^{\circ} \mathrm{C}$ durante 20 minutos e volumes de $400 \mu \mathrm{L}$ do sobrenadante foram aspirados e transferidos para tubos cônicos de $10 \mathrm{~mL}$ para evaporação à secura em banho-maria a $37^{\circ} \mathrm{C}$ sob fluxo de nitrogênio. Em seguida, o extrato seco foi dissolvido com $200 \mu \mathrm{L}$ da mistura de acetonitrila e água $(8: 2 \mathrm{v} / \mathrm{v})$ e volumes de $5 \mu \mathrm{L}$ foram injetados automaticamente no cromatógrafo líquido (SHIMADZU LC-10 AD VP; Coluna Shimpack ${ }^{\mathrm{TM}}$ CLC-CN; Fase móvel tampão fosfato $10 \mathrm{mM}, \mathrm{pH}$ 4,0 e acetonitrila (68:32, v/v); Fluxo: 0,5mL/min. Detector UV SPD-10AVP, programa Class VP obedecendo à seguinte programação durante a corrida analítica: entre zero e 8,5 minutos $(280 \mathrm{~nm})$ entre 8,6 e 35 minutos (210nm). O tubo de Eppendorf contendo o material remanescente da 
precipitação foi descartado no lixo de resíduo biológico infectante para inativação.

\section{C - Determinação de Fluconazol}

Para esta determinação, utilizou-se extração simples líquido-líquido conforme descrito a seguir. Transferiu-se para tubo de extração: $50 \mu$ de Pi (carbamazepina $10 \mu \mathrm{g} / \mathrm{mL}$, previamente evaporada), $200 \mu \mathrm{L}$ de matriz biológica e $50 \mu \mathrm{L}$ de $\mathrm{NaOH}$ 1,25M para alcalinização. A mistura foi agitada em vortex por 15 segundos e adicionou-se $3 \mathrm{~mL}$ de diclorometano como solvente extrator. A mistura foi novamente agita em vortex por 1 minuto, seguida de centrifugação a $3000 \mathrm{~g}$ por 40 minutos a $4^{\circ} \mathrm{C}$. O sobrenadante foi aspirado e descartado e o tubo contendo a fase orgânica remanescente foi imerso em banho de nitrogênio líquido. A fase orgânica foi cuidadosamente transferida para tubos cônicos, e o solvente evaporado em banho-maria, sob corrente de nitrogênio a $37^{\circ} \mathrm{C}$. Em seguida, o extrato seco foi dissolvido com $200 \mu \mathrm{L}$ de fase móvel e volumes de $5 \mu \mathrm{L}$ foram injetados automaticamente no cromatógrafo líquido (SHIMADZU LC-10 AD VP; Coluna Shimpack ${ }^{\mathrm{TM}}$ CLC-CN; Fase água UP e acetonitrila (60:40, v/v); Fluxo: 0,5mL/min. Detector UV SPD-10AVP, $\lambda$ : 210nm; Autosampler SIL10A VP, e programa Class VP)

\section{5 - Validação do método analítico}

A validação dos métodos bioanalíticos desenvolvidos para quantificação de ciprofloxacino, oxacilina, piperacilina e sulfametoxazol, atendeu a recomendação da ANVISA /RE n`899 para métodos bioanalíticos (BRASIL, 2003) e pelo FDA/Americana (FDA, 2001) para métodos bioanalíticos. Efetuou-se apenas validação parcial para o método bioanalítico previamente desenvolvido e validado por Lopez e colaboradores (2007) para análise simultânea de cefepime, vancomicina e imipenem. Por outro lado, realizou-se a revalidação total do método bioanalítico proposto por Perez, (2007) para quantificação de fluconazol em plasma. 
Foram determinados os limites de confiança: linearidade, limites de sensibilidade e quantificação, precisão (coeficiente de variação) e exatidão (erro sistemático) intradia e interdias além de robustez e estudos de estabilidade de curta, média e longa duração. Complementarmente, investigou-se a estabilidade do tempo e condição de análise bem como a estabilidade das soluções padrão de referência dos antimicrobianos e dos padrões internos escolhidos.

Os resultados obtidos de acordo com cada método proposto foram expressos através de média, desvio padrão e coeficiente de variação.

\section{Especificidade}

Especificidade é a capacidade do método em diferenciar e quantificar o analito na presença de outros componentes da amostra.

Analisaram-se amostras da matriz biológica (plasma) obtidas de seis indivíduos, sendo quatro amostras normais, uma lipêmica e uma hemolisada, sob condições controladas referentes ao tempo, alimentação e outros fatores importantes para o estudo. Cada amostra de branco de plasma foi testada utilizando o procedimento e as condições cromatográficas propostas. Os resultados foram comparados aqueles obtidos com solução aquosa do analito, em concentração próxima ao LQ. Cada um dos analitos foi injetado separadamente para a determinação dos tempos de retenção individuais assegurando que as impurezas de um fármaco não interfiram na análise de outro.

Rejeitou-se qualquer amostra de plasma branco que evidenciou picos de componentes coeluídos com um dos analitos ou com o padrão interno. Caso uma ou mais das amostras analisadas apresentassem tal interferência, novas amostras de outros seis doadores (indivíduos sadios) foram testadas. Caso uma ou mais das amostras deste grupo apresentassem interferência significativa no tempo de retenção do fármaco, o método deveria ser modificado visando eliminação da interferência. Uma vez que isso não ocorreu, os métodos bioanalíticos propostos permaneceram sem alteração relativamente às condições de desenvolvimento e validação propostas. 


\section{Limite de Detecção e Quantificação}

Limite de detecção (LD) é a menor quantidade do analito presente em uma amostra que pode ser detectada, porém não necessariamente quantificada, sob as condições experimentais estabelecidas. Definido como 0,5 vezes o limite de quantificação.

Por outro lado, limite quantificação (LQ) representa a menor quantidade do analito em uma amostra que pode ser determinada com precisão e exatidão aceitáveis (<20\%) sob as condições experimentais estabelecidas.

Adicionalmente, a legislação relativa à validação de métodos bioanalíticos nacional e internacional preconiza que o sinal mensurado seja da ordem de três vezes e cinco vezes do ruído da linha de base para o LQ e o LD, respectivamente. Os limites de detecção e de quantificação foram determinados com base na análise de 10 réplicas.

\section{Linearidade}

É a capacidade de um método analítico demonstrar que os resultados obtidos são diretamente proporcionais à concentração do analito na amostra, dentro de um intervalo definido. Representa a faixa de concentração que evidencia boa correlação linear entre resposta mensurada (Y, a área do pico ou razão das áreas do fármaco e o padrão interno através do instrumento analítico), e as respectivas concentrações plasmáticas do fármaco inalterado ou biotransformado $(X)$. A equação da reta: $Y=a X+b$ deve evidenciar $\left(r^{2} \cong 1\right)$ boa correlação linear entre $Y$ e $X$, representando a curva de calibração construída diariamente, e o critério mínimo aceitável para o coeficiente de correlação deve ser igual ou superior a 0,99 .

A linearidade do método investigada pela adição de solução padrão de cada antimicrobiano $(1 \mathrm{mg} / \mathrm{mL})$ ao pool de plasma aprovado previamente. Preparou-se uma serie de diluições de forma a se obter as concentrações descritas na tabela 1. 
Tabela 1A-Concentração dos calibradores para teste de linearidade $(\mu \mathrm{g} / \mathrm{mL})$.

\begin{tabular}{c|ccccc}
\hline Calibrador & Ciprofloxacino & Fluconazol & Oxacilina & Piperacilina & Sulfametoxazol \\
\hline C1 & 20 & 100 & 100 & 100 & 100 \\
C2 & 16 & 50 & 80 & 80 & 50 \\
C3 & 10 & 25 & 50 & 50 & 25 \\
C4 & 5 & 12,5 & 25 & 25 & 12,5 \\
C5 & 2,5 & 6,25 & 12,5 & 12,5 & 6,25 \\
C6 & 1,2 & 3,125 & 6,0 & 6,0 & 3,125 \\
C7 & 0,6 & 1,56 & 3,0 & 3,0 & 1,56 \\
C8 & 0,2 & 0,78 & 1,0 & 1,0 & 0,78 \\
C9 & 0,1 & - & 0,5 & 0,5 & - \\
\hline
\end{tabular}

Abreviatura: C: calibrador do antimicrobiano em plasma

\section{Curva de calibração}

A curva de calibração foi preparada a partir de solução estoque $(1 \mathrm{mg} / \mathrm{mL})$ a alíquotas de plasma humano livre do fármaco (plasma branco) obtendo-se as concentrações descritas na tabela 1, que foram estocadas a $-80^{\circ} \mathrm{C}$ até o momento do ensaio. Os respectivos padrões internos foram preparados a partir das soluções estoque $(1 \mathrm{mg} / \mathrm{mL})$ distribuído em alíquotas e estocado a $-80^{\circ} \mathrm{C}$ até o ensaio.

Plotou-se o valor nominal para cada concentração plasmática de fármaco versus a respectiva razão da área do pico obtida do fármaco e seu padrão interno, obtendo-se o coeficiente de correlação linear $\left(r^{2}=0,99\right)$ e sua equação respectiva $(Y=a X+b)$. Ao menos cinco dos calibradores foram considerados para a construção diária da curva de calibração diária de forma a alcançar de $80 \%$ a $120 \%$ da concentração teórica do teste.

Os controles de qualidade internos (Tabela 2) foram preparados em duplicata e analisados durante cada corrida analítica para garantir a aceitação da mesma. Uma corrida foi aceita quando pelo menos quatro dos seis controles mostraram um desvio comparado com o seu valor nominal menor que $15 \%$. Uma vez aprovada, a curva de calibração foi utilizada para a quantificação de cada antimicrobiano nas amostras procedentes dos pacientes queimados investigado neste protocolo clínico. 
Tabela 2A - Concentrações dos controles de qualidade internos.

\begin{tabular}{c|ccccc}
\hline Calibrador & Ciprofloxacino & Fluconazol & Oxacilina & Piperacilina & Sulfametoxazol \\
\hline CQA & 15 & 80 & 75 & 75 & 80 \\
CQM & 8 & 40 & 40 & 40 & 40 \\
CQB & 0,4 & 2 & 2 & 2 & 4 \\
\hline
\end{tabular}

Abreviaturas: CQA: controle alto, CQM: controle médio; CQB: controle baixo.

\section{Exatidão}

A exatidão intradias é avaliada pelo desvio entre o valor real da concentração do fármaco na amostra e o valor obtido pelo método analítico na corrida do dia, enquanto que a exatidão interdias é avaliada pelo desvio entre o valor real da concentração do fármaco na amostra e o valor obtido pelo método analítico por três dias consecutivos.

A exatidão do método foi avaliada utilizando três concentrações (baixo, médio e alto) em seis replicatas, e o erro sistemático do ensaio foi determinado baseado na porcentagem de inexatidão e calculado de acordo com a equação abaixo:

$$
\text { Inexatidão } \%=\frac{\text { Valor obtido }- \text { Valor nominal }}{\text { Valor nominal }} \times 100
$$

O desvio não deve exceder 15\%, exceto para o limite de quantificação, para o qual se admite desvio igual ou inferior à $20 \%$.

\section{Precisão intra e interdia}

Precisão representa a reprodutibilidade dos resultados obtidos pela análise quantitativa de três concentrações (baixa, média e alta) em replicatas. A precisão intradia foi avaliada baseada em análises de duplicatas das três concentrações, enquanto que para a determinação da precisão interdias, análise de duplicatas de três concentrações foi realizada em três dias consecutivos totalizando dezoito ensaios para cada método validado. O 
resultado obtido foi expresso em coeficiente de variação (\%), não se admitindo valores superiores a 15\%, de acordo com a fórmula abaixo:

$$
\mathrm{CV} \%=\frac{\mathrm{DP} \times 100}{\mathrm{CMD}}
$$

Onde: DP é o desvio padrão e CMD a concentração média determinada.

\section{Estabilidade}

Para a determinação da estabilidade no plasma, menos de $15 \%$ de variação foi adotado como um critério aceitável para todas as concentrações estudadas. A análise consiste na avaliação da estabilidade. Os resultados obtidos foram expressos em percentagem do valor nominal.

- Ciclos de congelamento e descongelamento do analito em plasma: foram realizados com amostras em três concentrações analisadas em triplicata em três dias consecutivos para a realização dos ciclos 1,2 e 3 de congelamento e descongelamento. As amostras foram congeladas à $-20^{\circ} \mathrm{C}$ e mantidas por 24 horas, sendo então submetidas ao descongelamento à temperatura ambiente. Quando completamente descongeladas, as amostras foram novamente congeladas por 24 horas e assim sucessivamente, até completar os três ciclos. Os resultados foram comparados aqueles obtidos pela análise das amostras recémpreparadas.

- Pós-processamento: foi determinada a partir de amostras extraídas (no mínimo três concentrações em replicatas, $n=3$ ) e mantidas a temperatura ambiente na bandeja do autoinjetor, durante o tempo máximo no qual o extrato purificado da amostra poderá permanecer sob esta condição.

- Curta duração da matriz biológica: foi determinada em bancada para amostras de plasma em três concentrações que permaneceram à temperatura ambiente por 6 horas, sendo então submetidas à análise. 


\section{Validação parcial de método para quantificação de cefepime, imipenem e vancomicina}

De acordo com RE 899/03, os ensaios de validação parcial podem ser realizados através da determinação da exatidão e precisão intradia.

O critério mínimo aceitável do coeficiente de correlação $\left(r^{2}\right)$ foi de 0,99 para a curva de calibração e estudo da linearidade. A linearidade do método foi determinada utilizando nove concentrações, em triplicata, na faixa compreendida entre 0,8 a $200 \mu \mathrm{g} / \mathrm{mL}$ para o cefepime e 0,4 a $100 \mu \mathrm{g} / \mathrm{mL}$, para a vancomicina e o imipenem.

Paralelamente, os controles de qualidade internos (cefepime: 160, 80 e

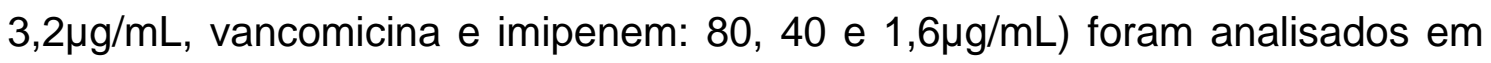
duplicata, durante cada corrida analítica para garantir a aceitação da mesma e determinação da precisão e exatidão intradia. 


\section{RESULTADOS}

\subsection{Perfil Cromatográfico}

A separação cromatográfica para a determinação dos analitos é ilustrada nas figuras $1 \mathrm{~A}$ e $2 \mathrm{~A}$, contendo os cromatogramas obtidos pela injeção de um extrato de branco de plasma adicionado do padrão interno, e de extrato de plasma adicionado dos analitos.
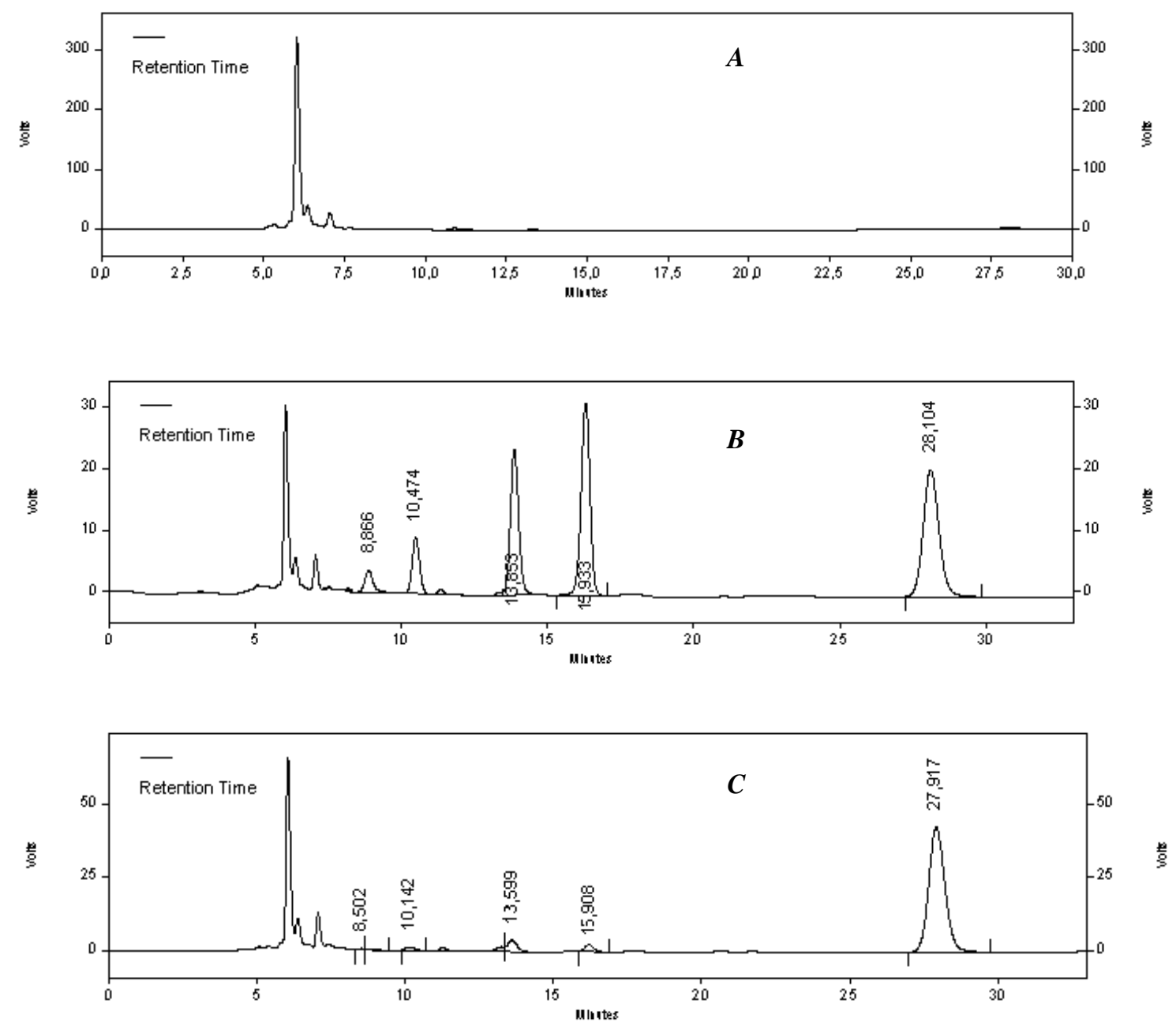

Figura 1A - Perfil cromatográfico de ciprofloxacino, oxacilina, piperacilina e sulfametoxazol em plasma; corrida analítica de 35 minutos. (A): Plasma branco; (B) Concentração media de COP $(25 \mu \mathrm{g} / \mathrm{mL}$ para oxacilina e piperacilina, $2,5 \mu \mathrm{g} / \mathrm{mL}$ para ciprofloxacino e $40 \mu \mathrm{g} / \mathrm{mL}$ para sulfametoxazol); (C) Limite de detecção $(1 \mu \mathrm{g} / \mathrm{mL}$ para oxacilina e piperacilina, $0,2 \mu \mathrm{g} / \mathrm{mL}$ para ciprofloxacino e $0,78 \mu \mathrm{g} / \mathrm{mL}$ para sulfametoxazol); Tempo de retenção do ciprofloxacino 8,6min, piperacilina $10.4 \mathrm{~min}$, oxacilina 13,6min, sulfametoxazol 15,9min e cetoconazol (padrão interno) 28,0min. 

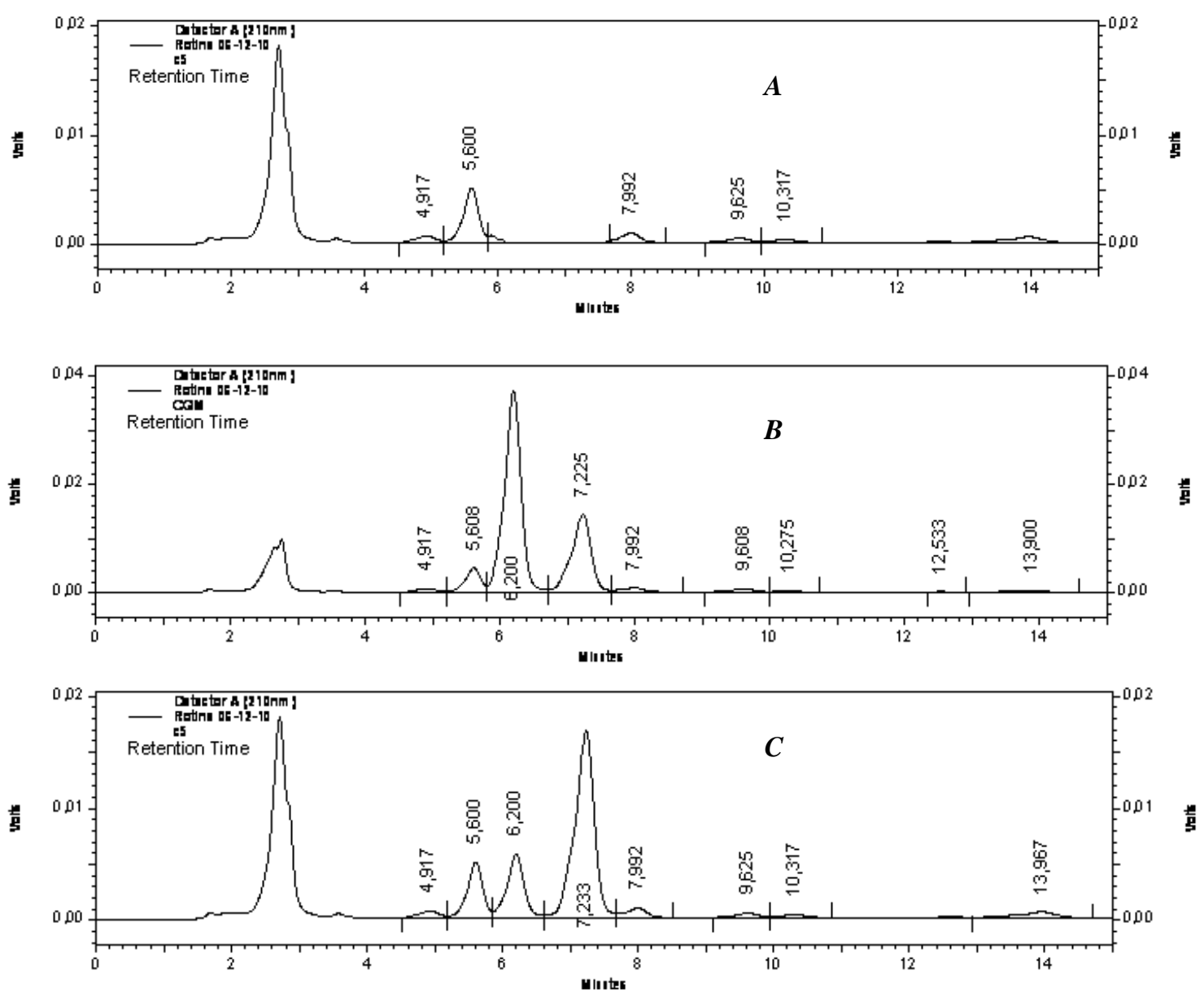

Figura 2A - Perfil cromatográfico de fluconazol em matriz biológica, tempo de corrida de 15 minutos. (A): Plasma branco; (B) CQM $(50,0 \mu \mathrm{g} / \mathrm{mL})$ (C) Limite de detecção $(0,4 \mu \mathrm{g} / \mathrm{mL})$. Tempo de retenção do fluconazol $6,2 \mathrm{~min}$ e da carbamazepina (padrão interno) $7,2 \mathrm{~min}$.

\subsection{Especificidade}

Não se registrou interferência dos componentes endógenos procedentes de plasma normal, lipêmico e hemolisado, que foram eluídos da coluna cromatográfica nos tempos e condições de análise. Os picos desses componentes eluídos na corrida analítica diferiram dos tempos de retenção dos antimicrobianos estudados e de seus respectivos padrões internos.

\subsection{Limite de quantificação e limite de deteç̧ão}

Os resultados obtidos para os limites de detecção (LD), coeficiente de variação, médias e desvio padrão encontram-se descritos na tabela 3. 


\subsection{Linearidade e curva de calibração}

Estabeleceu-se a correlação linear entre razões de área e as respectivas concentrações dos analitos. Evidenciou-se boa linearidade dos métodos bioanalíticos pela quantificação dos oito analitos no plasma. Os dados relativos à linearidade foram expressos para os oito analitos através da média do coeficiente de correlação linear $\left(r^{2}\right)$, intercepto, coeficiente angular da reta, e erro padrão da média (EPM), tabela 3 e ilustrados nas figuras 3A a 7A.

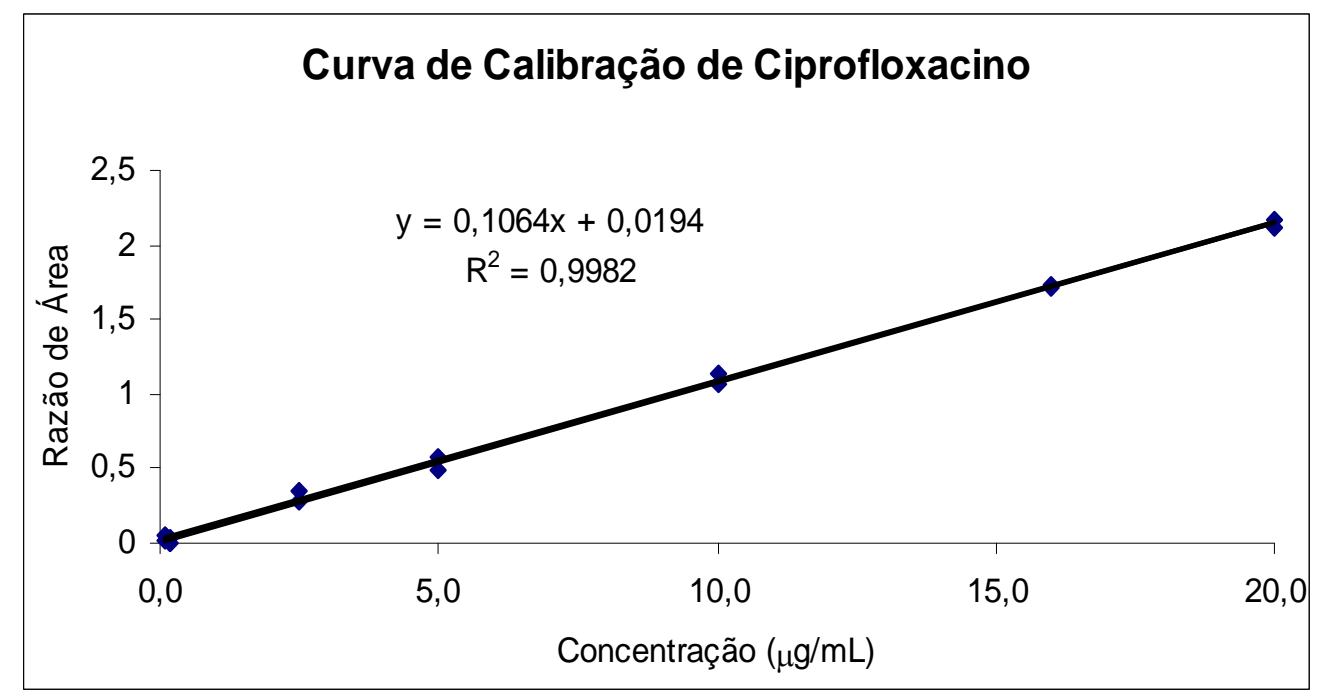

Figura 3A - Curva de calibração diária para determinação de ciprofloxacino plasmático através de CLAE. Plotaram-se as razões de área dos picos de ciprofloxacino e o cetoconazol $(\mathrm{Pi})$ versus as concentrações nos calibradores $(0,8-$ $20 \mu \mathrm{g} / \mathrm{mL})$ 


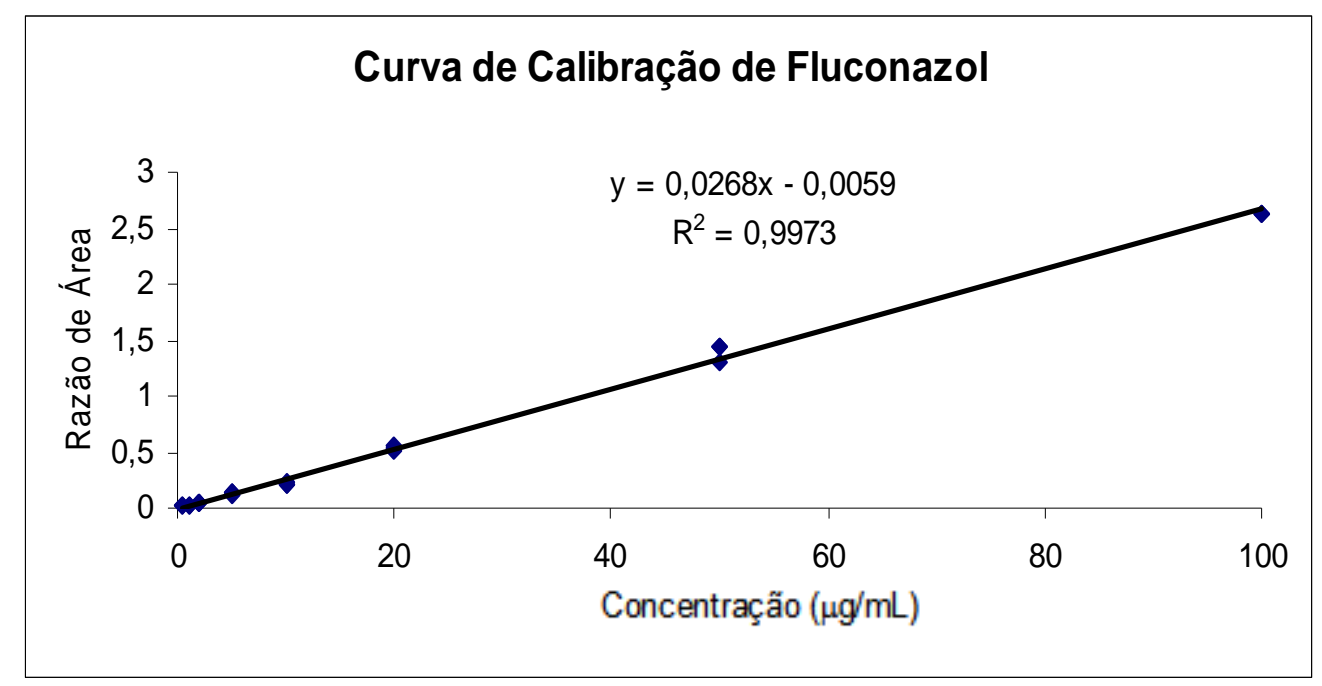

Figura 4A - Curva de calibração diária para determinação de fluconazol plasmático através de CLAE. Plotaram-se as razões de área dos picos de fluconazol e a carbamazepina $(\mathrm{Pi})$ versus as concentrações nos calibradores $(0,4-100 \mu \mathrm{g} / \mathrm{mL})$

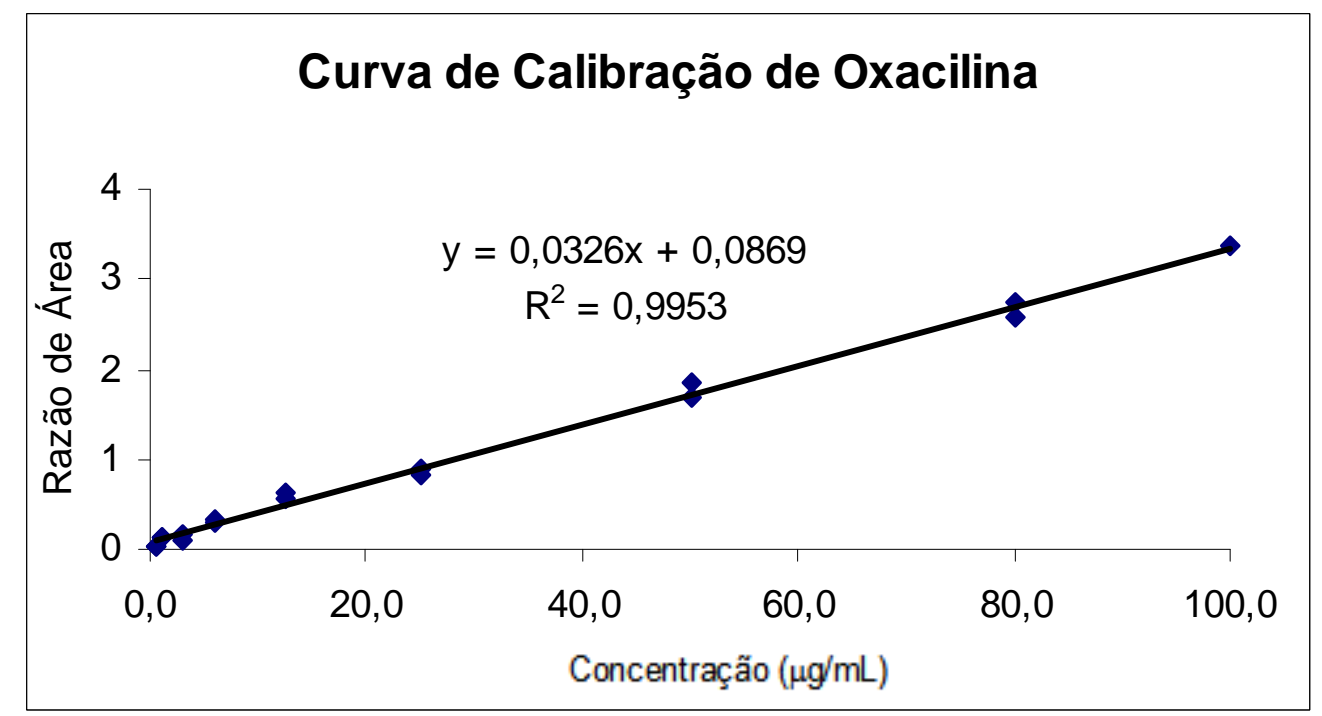

Figura 5A - Curva de calibração diária para determinação de oxacilina plasmático através de CLAE. Plotaram-se as razões de área dos picos de oxacilina e o cetoconazol $(\mathrm{Pi})$ versus as concentrações nos calibradores $(1,0-100 \mu \mathrm{g} / \mathrm{mL})$ 


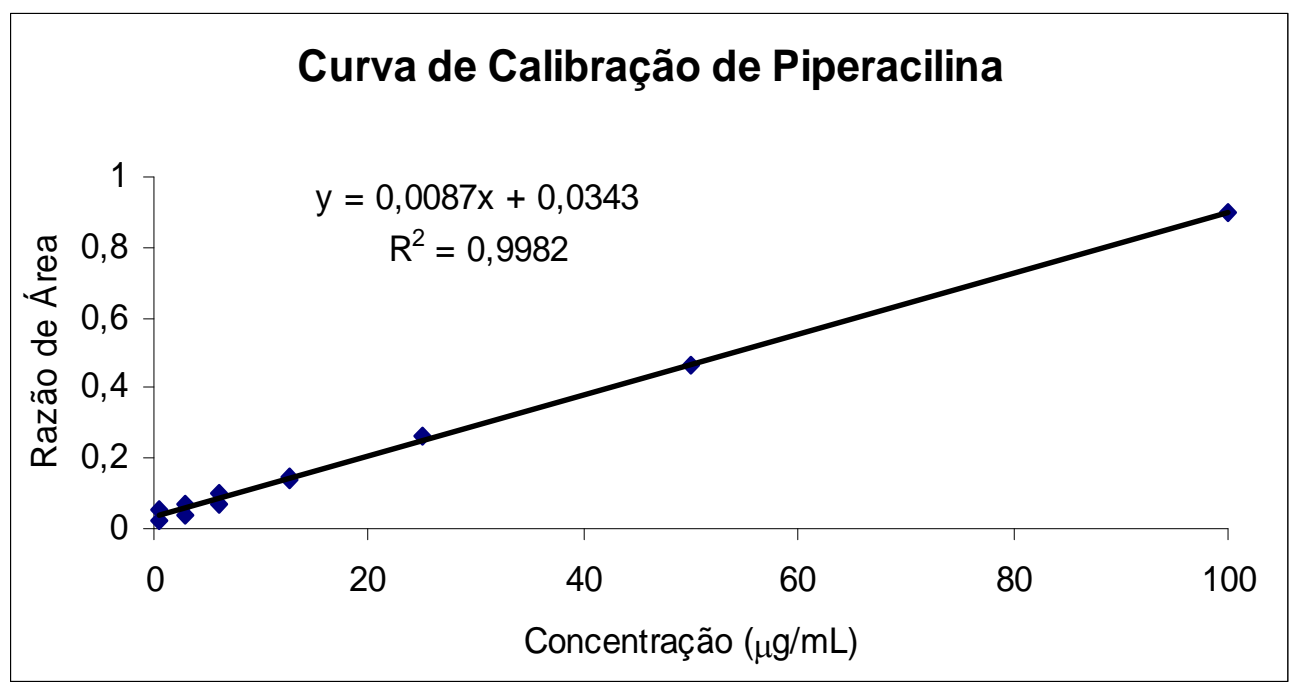

Figura 6A - Curva de calibração diária para determinação de piperacilina plasmático através de CLAE. Plotaram-se as razões de área dos picos de piperacilina e o cetoconazol $(\mathrm{Pi})$ versus as concentrações nos calibradores $(3,0-100 \mu \mathrm{g} / \mathrm{mL})$

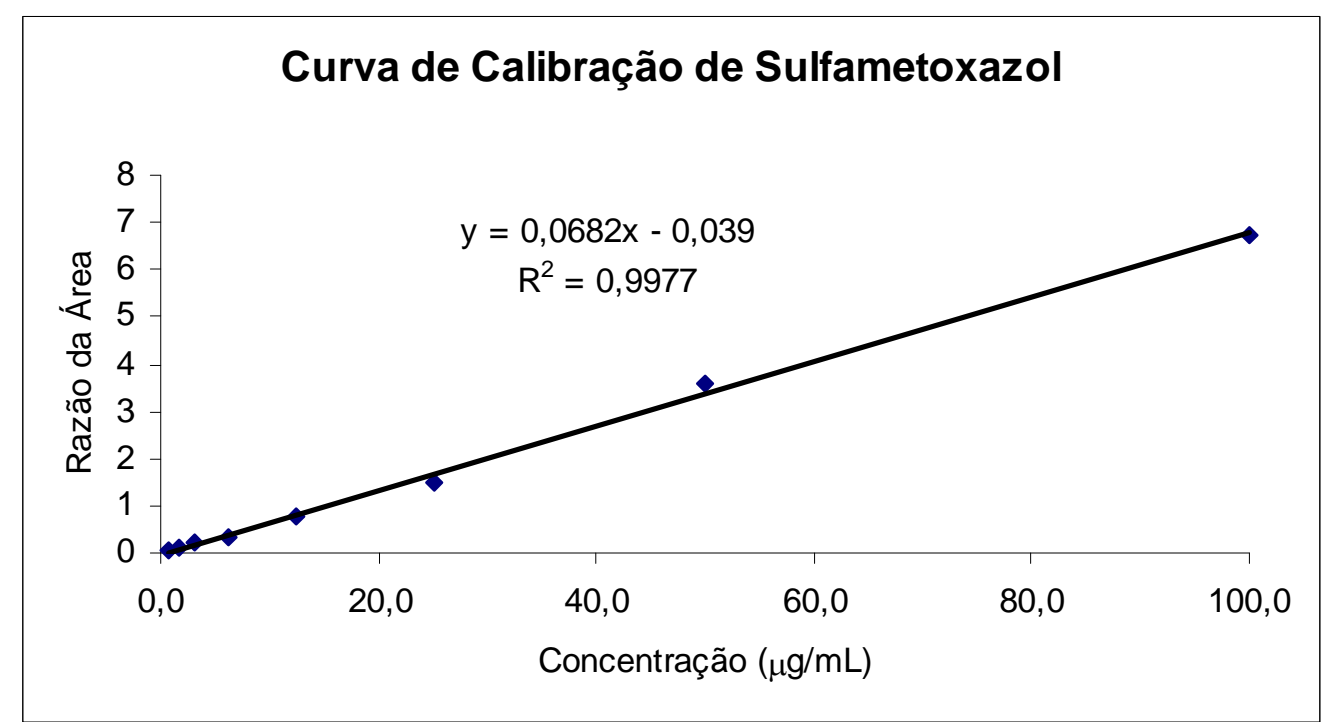

Figura 7A- Curva de calibração diária para determinação de sulfametoxazol plasmático através de CLAE. Plotaram-se as razões de área dos picos de sulfametoxazol e o cetoconazol $(\mathrm{Pi})$ versus as concentrações nos calibradores $(0,8$ $100 \mu \mathrm{g} / \mathrm{mL}$ ) 


\subsection{Precisão, exatidão e recuperação.}

Em relação aos estudos de precisão e exatidão intradia e interdias, os métodos apresentaram coeficientes de variação inferiores aos limites indicados na legislação (Tabela 03). A precisão do método analítico foi expressa através do coeficiente de variação percentual e a exatidão foi avaliada em função da "inexatidão percentual". Além disto, através da análise simultânea os métodos apresentaram boa recuperação relativa e absoluta para os analitos investigados.

\subsection{Estabilidade dos antimicrobianos}

Realizou-se o estudo de estabilidade apenas para os antimicrobianos que tiveram o método bioanalítico desenvolvido no presente estudo, ou seja, para os quais a estabilidade é ainda desconhecida.

Como critério da aceitação nos estudos de estabilidade dos antimicrobianos em plasma, adotou-se variação inferior a 15\% para todas as concentrações avaliadas. No estudo de estabilidade após ciclos de congelamento de descongelamento, verificou-se que os antimicrobianos se mantiveram estáveis por no mínimo três ciclos congelamento/ descongelamento, para três concentrações (alta, média e baixa) em triplicata com bom coeficiente de variação (Tabela 3). 
Tabela 3A- Limites de confiança para os métodos bioanalíticos validados

\begin{tabular}{|c|c|c|c|c|c|c|}
\hline Parâmetros & Unidade & Ciprofloxacino & Fluconazol & Oxacilina & Piperacilina & Sulfametoxazol \\
\hline Linearidade & $\mu \mathrm{g} / \mathrm{mL}$ & $0,2-20$ & $0,4-100,0$ & $1,0-100,0$ & $1,0-100,0$ & $0,8-100,0$ \\
\hline Coeficiente de regressão linear, $\left(r^{2}\right)$ & & 0,998 & 0,998 & 0,995 & 0,998 & 0,998 \\
\hline Intercepto - Média & & 0,0076 & 0,0146 & 0,0486 & 0,0175 & 0,0446 \\
\hline$(E P M)$ & & $(0,0084)$ & $(0,0183)$ & $(0,027)$ & $(0,0134)$ & $(0,0167)$ \\
\hline Coeficiente Angular - Média & & 0,0490 & 0,0273 & 0,0209 & 0,0050 & 0,0589 \\
\hline$(E P M)$ & & $(0,0414)$ & $(0,0004)$ & $(0,0085)$ & $(0,0026)$ & $(0,0237)$ \\
\hline Limite de detecção & $\mu \mathrm{g} / \mathrm{mL}$ & 0,1 & 0,2 & 0,5 & 0,5 & 0,4 \\
\hline - $\quad \mathrm{CV}$ & $\%$ & 9,9 & 2,67 & 8,3 & 6,3 & 9,3 \\
\hline - Média+DP & & $0,24 \pm 0,02$ & $0,20 \pm 0,01$ & $0,50 \pm 0,04$ & $0,52 \pm 0,03$ & $0,41 \pm 0,04$ \\
\hline Limite de quantificação & $\mu \mathrm{g} / \mathrm{mL}$ & 0,2 & 0,4 & 1,0 & 1,0 & 0,8 \\
\hline - $\quad \mathrm{CV}$ & $\%$ & 8,1 & 3,28 & 6,2 & 7,1 & 4,5 \\
\hline - Média+DP & & $0,31 \pm 0,02$ & $0,40 \pm 0,01$ & $1,07 \pm 0,07$ & $1,05 \pm 0,07$ & $0,73+0,03$ \\
\hline \multicolumn{7}{|l|}{ Precisão } \\
\hline - Interdias & média, DP & $6,48+3,03$ & $3,08+1,58$ & $7,10 \pm 6,02$ & $5,16 \pm 2,09$ & $6,23 \pm 2,74$ \\
\hline CQA & (CV\%) & 6,77 & 0,99 & 3,01 & 4,04 & 9,39 \\
\hline CQM & (CV\%) & 3,31 & 1,51 & 4,29 & 7,57 & 4,62 \\
\hline CQB & (CV\%) & 9,36 & 0,74 & 14,01 & 3,86 & 4,25 \\
\hline \multirow[t]{4}{*}{ - Intradia } & média, DP & $5,30 \pm 2,56$ & $1,08 \pm 0,39$ & $4,65 \pm 1,78$ & $7,79 \pm 4,43$ & $6,54 \pm 2,16$ \\
\hline & (CV\%) & 2,65 & 0,56 & 3,14 & 5,50 & 6,39 \\
\hline & (CV\%) & 7,76 & 2,27 & 4,19 & 12,90 & 8,77 \\
\hline & (CV\%) & 5,48 & 3,11 & 6,62 & 4,97 & 4,47 \\
\hline
\end{tabular}


APÊNDICE I - Desenvolvimento e Validação de Método Bioanalítico para quantificação de Antimicrobianos em Plasma 25

\begin{tabular}{|c|c|c|c|c|c|c|c|}
\hline \multirow[t]{4}{*}{ Erro sistemático (inexatidão) } & & média, DP & $2,37 \pm 6,02$ & $2,21 \pm 5,09$ & $3,08 \pm 8,47$ & $1,49 \pm 8,17$ & $0,93 \pm 5,52$ \\
\hline & CQA & (\%) & 1,83 & 1,01 & 8,16 & 1,74 & 0,93 \\
\hline & CQM & $(\%)$ & 4,67 & 1,70 & 7,82 & 5,99 & 3,39 \\
\hline & CQB & (\%) & 2,86 & 0,68 & 6,73 & 3,26 & 1,52 \\
\hline \multicolumn{8}{|l|}{ Ciclo de congelamento } \\
\hline \multirow{4}{*}{ - Ciclo 1} & & média, DP & $4,45 \pm 2,65$ & $0,06 \pm 0,12$ & $5,16 \pm 4,81$ & $7,13 \pm 7,67$ & $2,16 \pm 3,63$ \\
\hline & CQA & $(\mathrm{ES} \%)$ & 4,47 & 4,77 & 1,74 & 4,34 & 6,86 \\
\hline & CQM & $(E S \%)$ & 11,27 & 4,61 & 6,32 & 11,44 & 1,20 \\
\hline & CQB & $(E S \%)$ & 8,03 & 4,57 & 6,84 & 3,46 & 0,33 \\
\hline \multirow[t]{4}{*}{ - Ciclo 2} & & média, DP & $3,22 \pm 2,84$ & $1,65 \pm 2,58$ & $0,82 \pm 10,13$ & $3,49 \pm 6,99$ & $7,25 \pm 3,93$ \\
\hline & CQA & $(E S \%)$ & 7,39 & 6,62 & 3,41 & 8,07 & 11,36 \\
\hline & CQM & $(\mathrm{ES} \%)$ & 7,90 & 0,87 & 5,27 & 7,79 & 3,99 \\
\hline & CQB & $(\mathrm{ES} \%)$ & 4,42 & 4,41 & 4,74 & 2,42 & 6,39 \\
\hline \multirow[t]{4}{*}{ - Ciclo 3} & & média, DP & $6,34 \pm 0,62$ & $1,22 \pm 3,65$ & $3,77 \pm 9,05$ & $0,22 \pm 7,26$ & $10,10 \pm 3,79$ \\
\hline & CQA & (ES\%) & 1,92 & 6,31 & 8,89 & 4,77 & 6,47 \\
\hline & CQM & (ES\%) & 9,29 & 5,82 & 3,03 & 6,25 & 14,06 \\
\hline & CQB & (ES\%) & 8,54 & 2,94 & 2,80 & 1,31 & 9,77 \\
\hline
\end{tabular}

Abreviaturas - DP: desvio padrão da média; CV: coeficiente de variação; ES: erro sistemático 


\subsection{Validação parcial de método bioanalítico para quantificação de}

\section{Cefepime, Imipenem e Vancomicina.}

Conforme referido anteriormente, o método bioanalítico para quantificação simultânea de cefepime, imipenem e vancomicina foi desenvolvido e validado previamente por Lopez e colaboradores (2007) para aplicação no monitoramento das concentrações plasmáticas desses analitos em pacientes queimados. Desta forma no presente estudo, realizou-se a validação parcial dos três analitos em plasma.

O perfil cromatográfico dos três agentes antimicrobianos encontra-se ilustrado na figura $8 \mathrm{~A}$. 

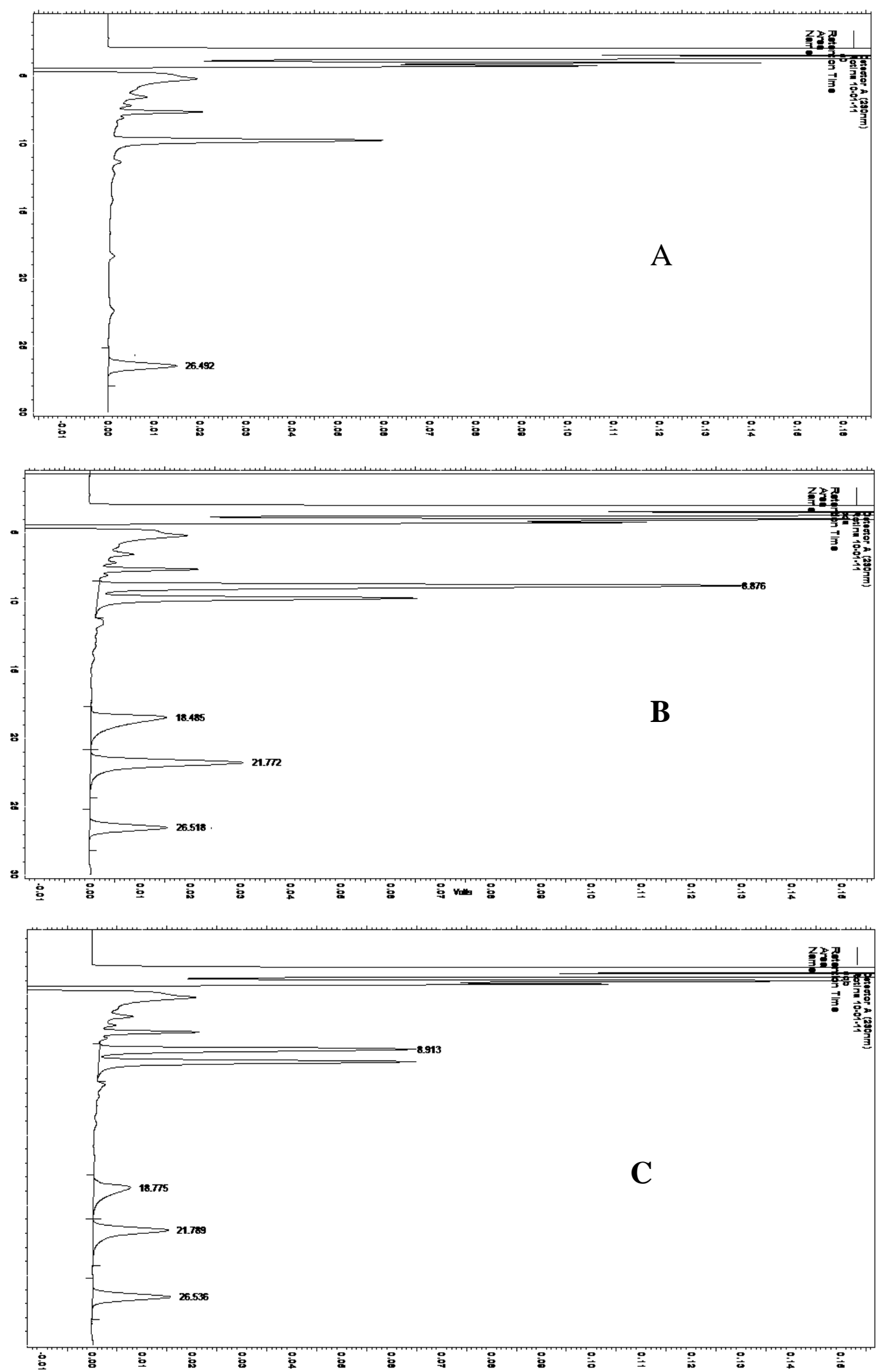

Figura 8A - Perfil cromatográfico dos três agentes antimicrobianos em matrizes biológicas, tempo de corrida 30 min (A): Plasma branco com padrão interno (IS); (B) CQA; (C) CQB. Tempo de retenção (minutos) dos picos eluídos: 8,9 min (cefepime), 18,7 min (vancomicina), 21,7 min (imipenem), 26,5 min (padrão interno: cefuroxima). 


\section{Curva de Calibração}

Evidenciou-se boa correlação linear entre razões de área e as respectivas concentrações dos analitos. A curva de calibração diária foi aceita a partir dos controles internos analisados em duplicata, com a rejeição de no máximo dois dos seis controles preparados, nunca sendo dois controles da mesma concentração (Figuras 9A a 11A).

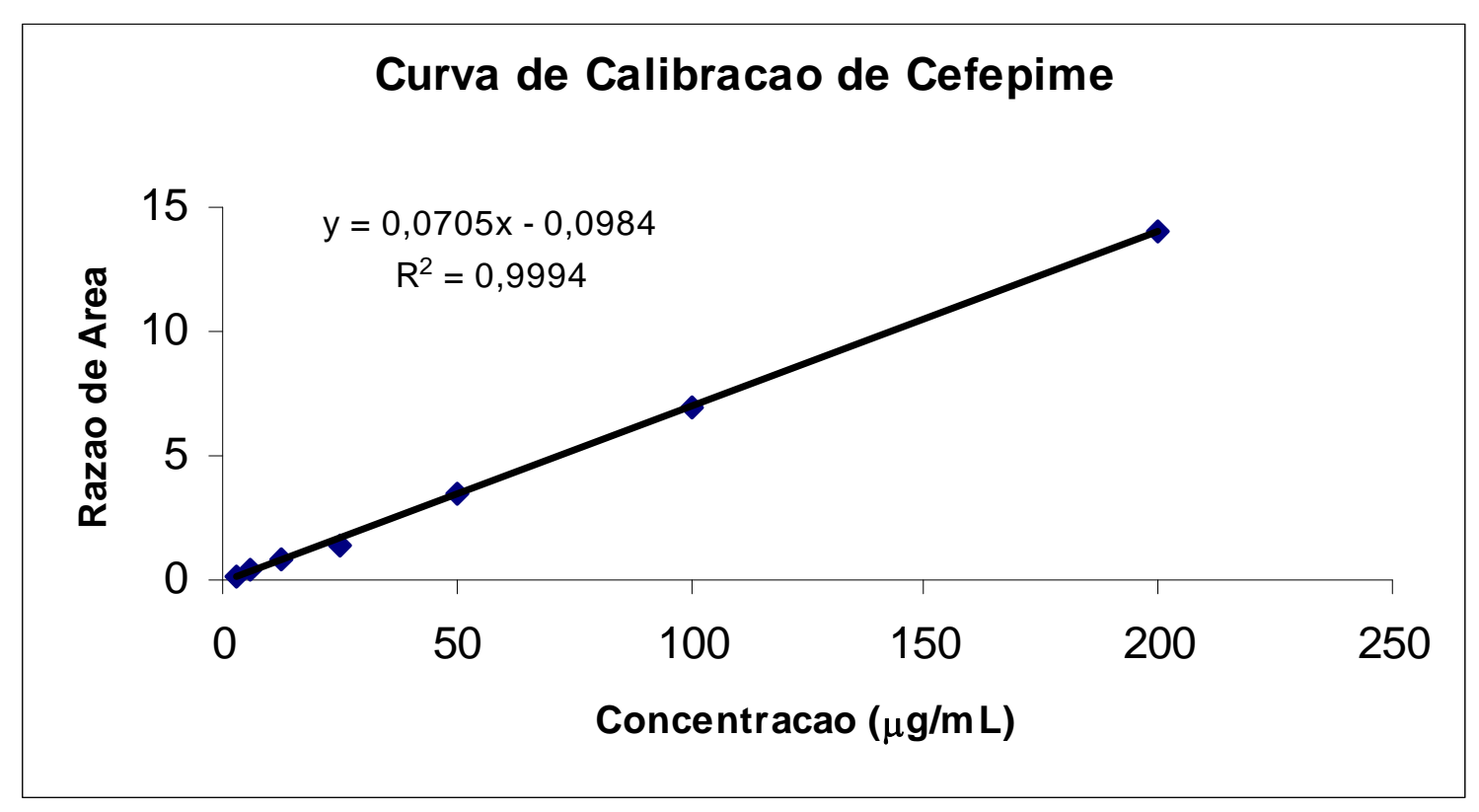

Figura 9A - Curva de calibração diária para determinação do cefepime plasmático através de CLAE. Plotaram-se as razões de área dos picos de cefepime e a cefuroxima $(\mathrm{Pi})$ versus as concentrações do cefepime nos calibradores $(0,8-200 \mu \mathrm{g} / \mathrm{mL})$ 


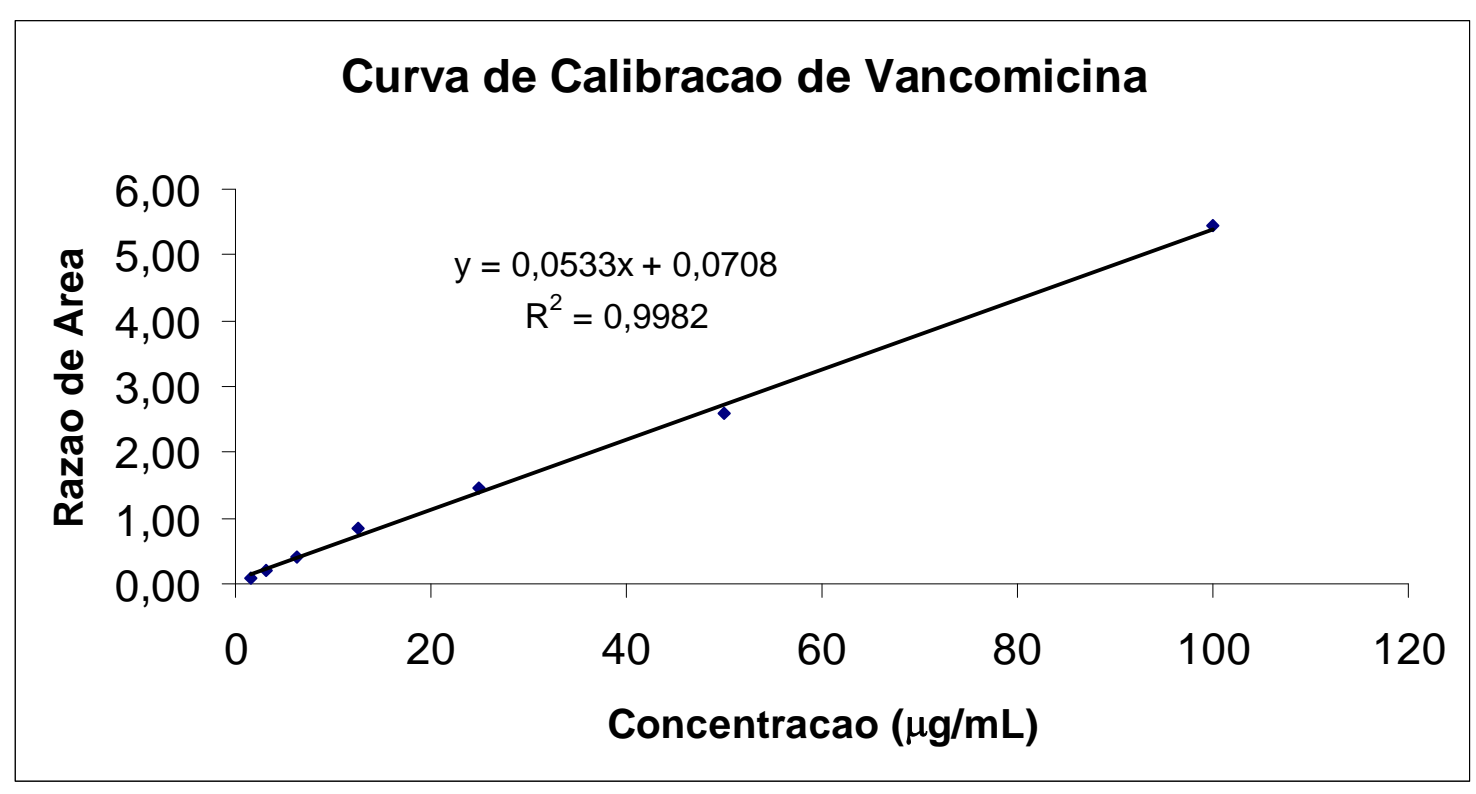

Figura 10A - Curva de calibração diária para determinação da vancomicina plasmática através de CLAE. Plotaram-se as razões de área dos picos de cefepime e a cefuroxima $(\mathrm{Pi})$ versus as concentrações do cefepime nos calibradores $(0,4-$ $100 \mu \mathrm{g} / \mathrm{mL})$

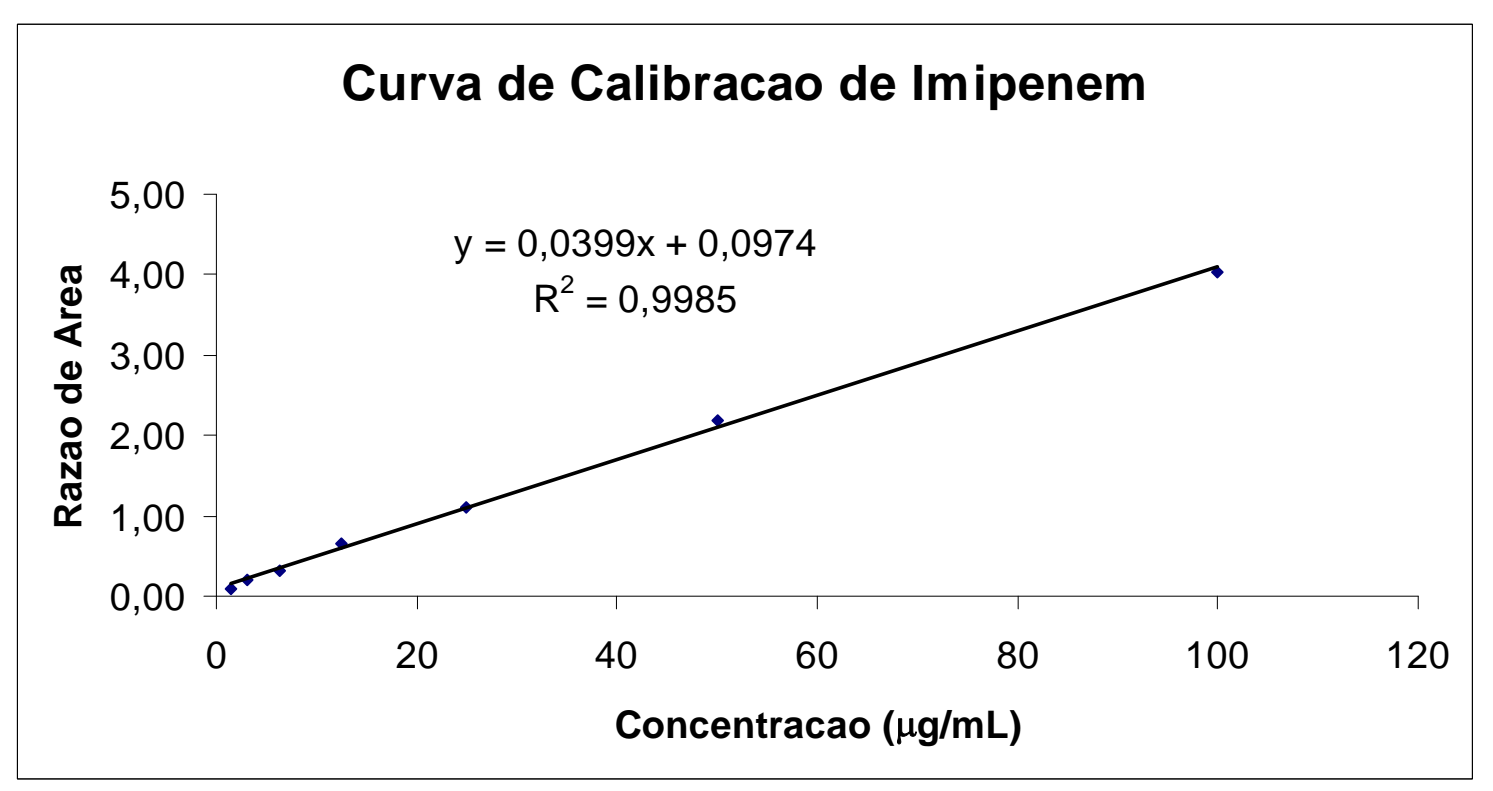

Figura 11A - Curva de calibração diária para determinação do imipenem plasmático através de CLAE. Plotaram-se as razões de área dos picos de cefepime e a cefuroxima $(\mathrm{Pi})$ versus as concentrações do cefepime nos calibradores $(0,4-100 \mu \mathrm{g} / \mathrm{mL})$ 


\section{Precisão e Exatidão Intradia}

Os resultados de precisão e exatidão dos antimicrobianos estão apresentados na tabela abaixo (Tabela 4). Os resultados foram expressos através da média de três replicatas no dia.

Tabela 4A- Estudos de precisão e exatidão dos antimicrobianos investigados (Cefepime, Imipenem e Vancomicina).

\begin{tabular}{|c|c|c|c|}
\hline FARMACO & $\begin{array}{c}\text { Concentração Nominal } \\
(\mu \mathrm{g} / \mathrm{mL})\end{array}$ & $\begin{array}{c}\text { Precisão (CV\%) } \\
\text { Intradia }\end{array}$ & $\begin{array}{c}\text { Inexatidão (\%) } \\
\text { Intradia }\end{array}$ \\
\hline Cefepime & $\begin{array}{c}160 \\
80 \\
3,2 \\
\text { Media } \pm D P\end{array}$ & $\begin{array}{c}0,33 \\
1,61 \\
0,81 \\
0,37 \pm 3,52\end{array}$ & $\begin{array}{c}5,10 \\
6,08 \\
0,48 \\
3,70 \pm 2,88\end{array}$ \\
\hline Vancomicina & $\begin{array}{c}80 \\
40 \\
1,6 \\
\text { Media } \pm D P\end{array}$ & $\begin{array}{c}4,81 \\
8,43 \\
1,35 \\
4,83+3,52\end{array}$ & $\begin{array}{c}5,07 \\
2,30 \\
8,38 \\
1,86+7,42\end{array}$ \\
\hline Imipenem & $\begin{array}{c}80 \\
40 \\
1,6 \\
\text { Media } \pm D P\end{array}$ & $\begin{array}{c}0,71 \\
4,20 \\
1,12 \\
2,31 \pm 1,93\end{array}$ & $\begin{array}{c}1,46 \\
3,18 \\
1,98 \\
2,20 \pm 2,05\end{array}$ \\
\hline
\end{tabular}

Abreviaturas: CV: coeficiente de variação; DP desvio padrão da média. 


\section{DISCUSSÃO}

De forma geral, realizou-se no presente estudo o desenvolvimento e revalidação de método analítico utilizando a cromatografia líquida de alta eficiência pela simplicidade, praticidade e relativo baixo custo com o objetivo de quantificar em "tempo real" sete antimicrobianos e um antifúngico (cefepime, ciprofloxacino, fluconazol, imipenem, oxacilina, piperacilina, sulfametoxazol e vancomicina) em plasma para a individualização da terapia antimicrobiana nos pacientes queimados.

A importância clínica da associação de pelo menos dois antimicrobianos visando aumentar seu espectro de ação já é largamente conhecida. Desta forma, a análise simultânea possibilita economia de tempo e redução de custos operacionais nos processos de purificação pela quantificação de diversos analitos numa mesma corrida analítica para o monitoramento plasmático desses antimicrobianos.

No presente estudo buscou-se a racionalização dos procedimentos analíticos pela quantificação simultânea de antimicrobianos em dois perfis cromatográficos independentes, a partir da precipitação de proteínas na obtenção de extrato purificado; assim os antimicrobianos cefepime, imipenem e vancomicina foram quantificados no perfil 1 , enquanto que o ciprofloxacino, piperacilina, oxacilina e sulfametoxazol foram determinados através do perfil 2 .

A purificação dos analitos no plasma foi racionalizada tomando-se por na base as características físico-químicas dos fármacos investigados (Anexo I); assim, optou-se pela precipitação de proteínas do plasma para os antimicrobianos hidrofílicos, enquanto que para o analito de maior lipofilicidade foi utilizada a extração líquido-líquido.

Além disto, com o objetivo de preservar o sistema cromatográfico, as análises foram processadas em baixo fluxo da fase móvel binária e força iônica reduzida pela utilização de meios tamponados de alta diluição. Além disso, utilizaram-se na injeção volumes reduzidos $(5 \mu \mathrm{L})$ de extrato purificado de forma aumentar a vida útil das colunas analíticas de fase reversa.

$\mathrm{Na}$ Clínica, a otimização da terapia antimicrobiana para o controle das infecções deve ser realizada com base nas concentrações plasmáticas dos 
analitos exigindo-se a coleta de diversas amostras sanguíneas dos pacientes queimados na UTI em cada seguimento farmacoterapêutico. Tal conduta na maioria das vezes requer coleta de número relativamente grande de amostras sangüíneas no decorrer dos diversos seguimentos durante a permanência do paciente queimado na UTI. Adicionalmente, esses pacientes apresentam área reduzida para a cateterização da veia, limitação da coleta de amostras sangüíneas e acesso venoso reduzido que prejudicam o seguimento do tratamento com esses antimicrobianos. Ressalta-se que para todos os métodos bioanalíticos validados exigiu-se volume reduzido de plasma $(0,2 \mathrm{~mL})$, sendo de grande importância essa conduta visto que o grande queimado será acompanhado por um período relativamente longo na UTI. Além disto, podemse registrar ainda problemas de restrição no volume de sangue a ser coletado em decorrência da perda de acesso venoso ou entupimento de cateter. Com base neste fato, reporta-se na literatura uma série de procedimentos que utilizam volume de plasma superior aquele requerido no ensaio de análise simultânea proposto no presente estudo (BURY et al, 1979; GOCHIN et al, 1981; BRISSON et al, 1982; WEBER et al, 1985; ASTBURY \& DIXON et al, 1987; STEUIJT \& SONNEVELD, 1987; MARUNAKA et al, 1988; AVGERINOS et al, 1991; GAUTIER et al, 1991; KROL et al, 1995; AUGEY et al, 1996; MAYA et al, 2001; IMRE et al, 2003; ARZUAGA et al, 2005; DENOOZ et al, 2008; WU et al, 2008; GIOVAMBERARDINO et al, 2009).

Os métodos bioanalíticos utilizados no presente estudo foram validados dentro das normas exigidas na RE 899/2003, mostrando-se adequados para a aplicação no monitoramento plasmático dos agentes anti-infecciosos investigados nos pacientes queimados.

A quantificação de cefepime, imipenem e vancomicina utilizou o método de análise simultânea descrito por Lopez e colaboradores (2007); portanto, o procedimento analítico foi validado parcialmente no presente estudo pela realização dos ensaios intradia de precisão e exatidão. Adicionalmente, o método desenvolvido por Perez (2007) para quantificação de antifúngicos em pacientes portadores de meningite criptocócica e doença de AIDS, foi revalidado mostrando-se adequado à quantificação de fluconazol no plasma de pacientes queimados (SANTOS et al, 2010). 
Uma vez que os procedimentos bioanalíticos de quantificação de cefepime, imipenem e vancomicina em plasma (perfil de análise simultânea), bem como o fluconazol plasmático descritos no presente estudo foram publicados anteriormente pelo mesmo grupo, essa discussão se restringirá à quantificação de ciprofloxacino, oxacilina, piperacilina e sulfametoxazol no plasma através de CLAE através da análise simultânea dos quatro analitos. A aplicação deste procedimento é de grande importância no controle das infecções causadas por germes menos agressivos para os pacientes queimados do que aqueles antimicrobianos utilizados no controle da sepse.

Uma série de métodos bioanalíticos foi reportada para análise isolada e quantificação de ciprofloxacino, piperacilina e sulfametoxazol em diversas matrizes biológicas de humanos (sangue, urina, bile e líquor) através de CLAEUV (BURY et al , 1979; GOCHIN et al , 1981; BRISSON et al , 1982; WEBER et al , 1983; ASTBURY et al, 1987; STEUIJT \& SONNEVELD et al , 1987; MARUNAKA et al , 1988; OCAMPO et al , 1989; AVGERINOS et al , 1991; GAUTIER et al , 1991; VREE et al , 1994; AUGEY et al, 1996; LIHL et al, 1996; KAMBERI et al , 1998;4 MAYA et al , 2001; AKAY et al, 2002; IMRE et al , 2003; ARZUAGA et al, 2005; GEIJLSWIJK et al , 2006; SAMANIDOU et al, 2006; AMINI \& AHMADIANI, 2007; XIA et al , 2007; YANG et al, 2007; DENOOZ et al , 2008; WU et al, 2008; GIOVAMBERARDI et al, 2009).

Ressalta-se ainda que nenhum procedimento foi reportado para quantificação da oxacilina em plasma, uma vez que as publicações encontradas descreveram a determinação isolada de resíduos do betalactâmico contidos nos derivados alimentares procedentes de animais (LIHL et al, 1996; LI et al, 2003; SAMANIDOU et al, 2006; YANG et al, 2007).

Portanto, em decorrência da ausência completa de publicações a respeito do assunto nos últimos 25 anos, considera-se como de contribuição, original e de grande importância a proposta do presente estudo relativa à quantificação simultânea desses quatro analitos em plasma.

A cromatografia líquida de alta eficiência com detector universal UV tem sido a técnica analítica viável e de custo relativo razoável para quantificação de antimicrobianos em matrizes biológicas. Desta forma, a literatura reporta a 
utilização de colunas analíticas de diversas procedências e diferentes recheios incluindo a fase reversa (C18), a cromatografia de pares iônicos (PIC) e fases móvel binária, terciária ou quaternária em sistemas de eluição isocrático ou em gradiente. A desvantagem na maioria dos trabalhos reside na necessidade de adicionar reagentes facilitadores à fase móvel tais como tetrametilamônio ou dimetilformamida, ou ácido acético, ou ainda trietilamina para melhoria na eluição dos picos (BURY et al, 1979; GOCHIN et al, 1981; VREE et al, 1994; AMINI \& AHMADIANI, 2007). Por outro lado, a literatura reporta que a cromatografia de pares iônicos (PIC) requer a adição de um agente específico à fase móvel como tetra-N-butilamônio, ácido ortofosfórico, ácido tricloroacético ou ainda o ácido acético que favorecerá a eluição dos analitos (MARUNAKA et al, 1988; GAUTIER et al, 1991; BA et al, 1998; KAMBERI et al, 1998; MAYA et al, 2001). No caso de antimicrobianos de baixo pKa como por exemplo o ciprofloxacino (Anexo I), o monitoramento do $\mathrm{pH}$ da fase móvel é fundamental na eluição em tempo adequado do pico do analito da coluna analítica; de forma geral, a adição de ácidos faz-se necessária (KROL et al, 1995). Por outro lado a adição de hidróxido de tetrametilamônio à fase móvel melhora a simetria do pico do ciprofloxacino (IMRE et al, 2003). Entretanto, a adição desses produtos a fase móvel representam obviamente custo adicional, além do aumento do número de variáveis a serem controladas para garantir a robustez do método empregado.

Em termos de encurtamento da corrida analítica pela redução do tempo de retenção do analito no extrato purificado, reportou-se ainda que a termostatização de coluna analítica em forno aquecido entre $35-40^{\circ} \mathrm{C}$ é um procedimento que proporciona agilização na análise cromatográfica (BRISSON et al, 1982; KROL et al, 1995; AUGEY et al, 1996; IMRE et al, 2003;Ll et al, 2003 XIA et al, 2007). Apesar da eluição do analito e demais componentes ser acelerada pelo aquecimento, considera-se também que a vida útil da coluna seja reduzida substancialmente com a temperatura levando ao comprometimento da seletividade, o quê representa uma desvantagem além de necessitar do módulo de forno acoplado ao sistema cromatográfico. 
O detector universal na região do ultravioleta tem sido o mais utilizado na análise por CLAE na quantificação de vários antimicrobianos (ciprofloxacino, oxacilina, piperacilina e sulfametoxazol) em matrizes biológicas. Empregaramse diferentes comprimentos de onda, uma vez que os antimicrobianos não foram quantificados em mistura nos métodos reportados anteriormente (BURY et al, 1979; GOCHIN et al, 1981;BRISSON et al, 1982; WEBER et al, 1983; ASTBURY \& DIXON , 1987; STEUIJT \& SONNEVELD et al, 1987; MARUNAKA et al, 1988; OCAMPO et al, 1989; AVGERINOS et al, 1991; GAUTIER et al, 1991; VREE et al, 1994; AUGEY et al, 1996; KAMBERI et al, 1998; MAYA et al, 2001; IMRE et al, 2003; ARZUAGA et al, 2005; GEIJLSWIJK et al, 2006; SAMANIDOU et al, 2006; AMINI \& AHMADIANI, 2007; XIA et al, 2007; YANG et al, 2007; DENOOZ et al, 2008; WU et al, 2008; GIOVAMBERARDINO et al, 2009).

Então a cromatografia líquida de alta eficiência foi escolhida no presente estudo para a quantificação em perfil de análise simultânea de quatro analitos (ciprofloxacino, oxacilina, piperacilina e sulfametoxazol) em extratos de plasma purificados. A utilização da coluna de fase reversa (CN) forneceu melhor resultado quando comparada a coluna C18 e os analitos e o padrão interno foram eluídos com fase móvel binária isocraticamente, conferindo simplicidade, redução de custos e robustez. O presente método permitiu a quantificação simultânea pela programação de alteração de comprimento de onda no detector ultravioleta durante a corrida analítica, garantindo alta sensibilidade e adequada linearidade ao método proposto conforme discutido na validação.

Previamente a quantificação dos analitos de interesse nesse estudo (ciprofloxacino, piperacilina, oxacilina e sulfametoxazol) pela cromatografia líquida, as matrizes biológicas (soro, plasma ou sangue total, urina, saliva, bile) requerem sempre um procedimento de purificação. A literatura reporta a obtenção dos extratos purificados para a grande maioria dos métodos de análise de ciprofloxacino em plasma através da precipitação de proteínas utilizando diferentes agentes tais como o ácido fosfórico (KROL et al, 1995), ácido acético (KAMBERI et al, 1998), ácido perclórico (MAYA et al, 2001; IMRE et al, 2003) ou ainda acetonitrila (WEBER et al, 1985; WU et al, 2008). Adicionalmente, registrou-se para a piperacilina e para o sulfametoxazol 
purificação através da precipitação de proteínas com metanol (ARZUAGA et al, 2005) ou acetonitrila (OCAMPO et al, 1989; GAUTIER et al, 1991; AUGEY et al, 1996; GIOVAMBERARDINO et al, 2009). Ressalta-se que no presente estudo a precipitação das proteínas com acetonitrila forneceu ótima recuperação para todos analitos em estudo.

Outro procedimento recomendado na purificação das matrizes biológicas de humanos é a extração de fase sólida reportada para o ciprofloxacino (VYBIRALOVA et al, 2005), e para a piperacilina (MARUNAKA et al, 1988; OCAMPO et al, 1989; GAUTIER et al, 1991; XIA et al, 2007; DENOOZ et al, 2008). No caso da oxacilina esse procedimento foi utilizado com a finalidade de determinar resíduos em produtos alimentícios derivados de animais (LIHL et al, 1996; SAMANIDOU et al, 2006; YANG et al, 2007). Em todas as situações a principal desvantagem deste procedimento de purificação é o alto custo dos cartuchos de fase sólida, o que limita sua utilização para o monitoramento plasmático desses antimicrobianos. Reporta-se adicionalmente que a capacidade desses cartuchos seja excedida para altas concentrações do analito no plasma, com redução substancial da recuperação, limite inferior de quantificação e redução da robustez em função da variabilidade nos cartuchos.

Com relação à validação é importante destacar a superioridade do método bioanalítico reportado no presente estudo, uma vez que para ciprofloxacino no plasma, registrou-se linearidade entre 0,2 e $20 \mu \mathrm{g} / \mathrm{mL}$ comparada a de até $6,0 \mu \mathrm{g} / \mathrm{mL}$ na determinação isolada desse agente plasma (KAMBERI et al, 1998; BA et al, 1998; MAYA et al, 2001; IMRE et al, 2003) que não contempla a janela terapêutica requerida no monitoramento plasmático, portanto, sendo inadequado para o seguimento farmacoterapêutico. Linearidade inadequada $(2-10 \mathrm{ng} / \mathrm{mL})$ também foi reportada por Weber e colaboradores (1985). Por outro lado a concentração plasmática máxima tolerada para o ciprofloxacino é de $10 \mu \mathrm{g} / \mathrm{mL}$; além disto, o limite de quantificação deve estar em consonância com a concentração plasmática do ciprofloxacino relacionada à janela terapêutica, uma vez se necessita quantificar valores inferiores a $0,2 \mu \mathrm{g} / \mathrm{mL}$ (MICROMEDEX, 2010). 
Adicionalmente, os poucos trabalhos disponíveis na literatura evidenciam linearidade inadequada para aplicação no monitoramento terapêutico, uma vez que a CIM para a oxacilina é de $3 \mu \mathrm{g} / \mathrm{mL}$ e doses de $5 \mathrm{~g}$ administradas por via intravenosa produzem pico de $43 \mu \mathrm{g} / \mathrm{mL}$ conforme reportado no Micromedex (2010). Conseqüentemente, o método de análise simultânea reportado no presente estudo evidenciou adequada linearidade para a oxacilina, numa faixa de concentração plasmática satisfatória (1 $100 \mu \mathrm{g} / \mathrm{mL}$ ) e adequada à realização do monitoramento plasmático.

Para a piperacilina em plasma, reporta-se uma série de métodos de análise isolada (ARZUAGA et al, 2005; AUGEY et al, 1996; BRISSON et al, 1982; GIOVAMBERARDINO et al, 2009; XIA et al,2007) com linearidade adequada na faixa compreendida entre 1-100 $\mu \mathrm{g} / \mathrm{mL}$. Ressalta-se a superioridade do método bioanalítico proposto no presente estudo pela análise em um perfil simultâneo de ciprofloxacino, oxacilina, piperacilina e sulfametoxazol numa mesma amostra de plasma o quê justifica considerável redução de tempo, custos laboratoriais e operacionais.

Com relação ao sulfametoxazol, os métodos reportados anteriormente descrevem limite inferior de quantificação de forma geral adequado ao monitoramento plasmático desse antimicrobiano no vale, entretanto não está contemplado o limite superior de quantificação de 80 até $100 \mu \mathrm{g} / \mathrm{mL}$, exigido no pico pela administração intravenosa de sulfametoxazol (BURY et al, 1979; GOCHIN et al, 1981; WEBER et al, 1983; ASTBURY \& DIXON, 1987; SONNEVELD et al, 1987; AVGERINOS et al, 1991; VREE et al, 1994; AKAY et al, 2002; AMINI \& AHMADIANI, 2007). No presente estudo está contemplada de forma satisfatória a linearidade requerida $(0,8-100 \mu \mathrm{g} / \mathrm{mL})$, bem como 0 limite de detecção equivalente a $0,4 \mu \mathrm{g} / \mathrm{mL}$ de forma a garantir 0 monitoramento plasmático do analito no intervalo de dose além do pico ao término da infusão e do vale, imediatamente antes da dose subsequente.

Com relação aos parâmetros de validação considerados no presente estudo, cumpre destacar que os dados obtidos evidenciaram linearidade, sensibilidade, recuperação, precisão e exatidão suficientes para a análise simultânea de ciprofloxacino, oxacilina, piperacilina e sulfametoxazol. 
Finalmente, os métodos bioanalíticos em CLAE-UV propostos no presente estudo mostraram-se superiores aos demais procedimentos reportados anteriormente, sendo os três métodos validados adequados ao monitoramento plasmático dos agentes anti-infecciosos de maior importância no controle das infecções de pacientes queimados na UTI. 


\section{CONCLUSÃO}

Os métodos bioanalíticos de análise simultânea de antimicrobianos utilizados contra as infecções causadas pelos germes agressivos da sepse (Perfil 1: cefepime, imipenem e vancomicina), contra as infecções causadas por germes menos agressivos e sensíveis ao ciprofloxacino, oxacilina, piperacilina e sulfametoxazol (Perfil 2), bem como o método de quantificação de fluconazol plasmático para o controle da infecção fúngica apresentam em comum simplicidade e fácil execução, linearidade, seletividade, sensibilidade e estabilidade adequadas, além de precisão e exatidão aceitáveis sendo portanto adequados ao monitoramento plasmático e estudo farmacocinético. 


\section{BIBLIOGRAFIA}

AKAY C, OZKAN SA. Simultaneous LC determination of trimethoprim and sulphamethoxazole in pharmaceutical formulations. Journal of Pharmaceutical and Biomedical Analysis, v.30, p.1207-1213, 2002.

AMINI H, AHMADIANI A. Rapid and simultaneous determination of sulfamethoxazole and trimethoprim in human plasma by high-performance liquid chromatography. Journal of Pharmaceutical and Biomedical Analysis, v.43, p.1146-1150, 2007.

ARZUAGA A, ISLA A, GASCÓN AR, MAYNAR J, MARTÍN A, SOLINÍS MA, TORAL D, PEDRAZ JL. Quantitation and stability of piperacillin and tazobactam in plasma and ultrafiltrate from patients undergoing continuous venovenous hemfiltration by HPLC. Biomedical Chromatography, v.19, p.570-578, 2005.

ASTBURY C, DIXON JS. Rapid method for the determination of either plasma sulphapyridine or sulphamethoxazole and their acetyl metabolites using highperformance liquid chromatography. Journal of Chromatography, v.414, p.223227, 1987.

AUGEY V, GROSSER PY, ALBERT G, AUDRAN M, BRESSOLLE F. Highperformance liquid chromatographic determination of tazobactam and piperacillin in human plasma and urine. Journal of Chromatography B, v.682, p.125-136, 1996.

AVGERINOS A, ATHANASIOU G, MALAMATARIS S. Rapid simultaneous determination of trimethoprim, sulphamethoxazole and acetylsulphamethoxazole in human plasma and urine by high-performance liquid chromatography. Journal of Pharmaceutical and Biomedical Analysis, v.9, n.5, p.507-510, 1991.

BA BB, DUCINT D, FOURTILLAN M, SAUX M. Fully automated high-performance liquid chromatography of ciprofloxacin with direct injection of plasma and MuellerHinton broth for pharmacokinetic/pharmacodynamic studies. Journal of Chromatography B, v.714, p.317-324, 1998.

BRASIL. Resolução n 899, de29 de maio de 2003. Diário Oficial da União, Brasília, 02 de junho de 2003. Seção 1. [A Agencia Nacional de Vigilância Sanitária aprova o Guia para validação de métodos analíticos e bioanaliticos. Disponível em: http://www.anvisa.gov.br/legis/resol/2003/re/899_03re.htm. Acessado em : 20/03/2008.

BRISSON AM, FOURTILLAN JB. High-performance liquid chromatographic determination of piperacillin in plasma. Antimicrobial Agents and Chemotherapy, v.21, n.4, p.664-665, 1982.

BURY RW, MASHFORD ML. Analysis of trimethoprim and sulphamethoxazole in human plasma by high-pressure liquid chromatography. Journal of Chromatography, v.163, p.114-117, 1979.

DENOOZ R, CHARLIER C. Simultaneous determination of five b-lactam antibiotics (cefepim, ceftazidim, cefuroxim, meropenem and piperacillin) in human plasma by high-performance liquid chromatography with ultraviolet detection. Journal of Chromatography B, v.864, p.161-167, 2008. 
FDA - Food and Drug Administration. Guidance for Industry: Bioanalytical Method Validation, U.S. Department of Health and Human Services, 2001.

GAUTIER V, DEMOTES-MAINARD F, FOUREAU M, VINÇON G. Micro-method for the determination of piperacillin in plasma by high-performance liquid chromatography. Journal of Pharmaceutical e Biomedical Analysis, v.9, n.2, p.183-186, 1991.

GEIJLSWIJK IM, VAN ZANTEN AR, VAN DER MEER YG. Reliable new highperformance liquid chromatographic method for the determination of ciprofloxacin in human serum. Ther Drug Monit. v.28, n.2, p.278-81. 2006

GIOVAMBERARDINO GD, FERRANNINI M, TESTORE GP, FEDERICI G, PASTORE A. High performance liquid chromatographic determination of plasma free and total tazobactam and piperacillin. Journal of Chromatography B, v.877, p.86-88, 2009.

GOCHIN R, KANFER I, HAIGH JM. Simultaneous determination of trimethoprim, sulphamethoxazole and N4-acetylsulphamethoxazole in serum and urine by highperformance liquid chromatography. Journal of Chromatography, v.223, p.139145, 1981.

IMRE S, DOGARU MT, VARI CE, MUNTEAN T, KELEMEN L. Validation of an HPLC method for the determination of ciprofloxacin in human plasma. Journal of Pharmaceutical and Biomedical Analysis, v.33, p.125-130, 2003.

KAMBERI $\mathrm{M}$, TSUTSUMI $\mathrm{K}$, KOTEGAWA $\mathrm{T}$, NAKAMURA $\mathrm{K}$, NAKANO $\mathrm{S}$. Determination of ciprofloxacin in plasma and urine by HPLC with ultraviolet detection. Clinical Chemistry, v.44, n.6, p.1251-1255, 1998.

KROL, GJ; BECK, GW; BENHAM, T. HPLC analysis of ciprofloxacin and ciprofloxacin metabolites in body fluids. Journal of Pharmaceutical and Biomedical Analysis, v.14, p.181-190, 1995.

LI F, QIAO M, GUO X. Specific determination of unbound oxacillin in protein solution with cefoperazone by high-performance frontal analysis with chemiluminescence detection. Biomedical Chromatography, v.17, p.53-57, 2003.

LIHL S, REHOREK A, PETZ M. High-performance liquid chromatographic determination of penicillins by means of automated solid-phase extraction and photochemical degradation with electrochemical detection. Journal of Chromatography A, v. 729, p. 229-235, 1996.

LÓPEZ KJV, BERTOLUCI DF, VICENTE KM, DELL'AQUILLA AM, SANTOS SRCJ. Simultaneous determination of cefepime, vancomycin and imipenem in human plasma of burn patients by high-performance liquid chromatography. Journal of Chromatography B, v.860, p.241-245, 2007. 
MARUNAKA T, MANIWA M, MATSUSHIMA E, MINAMI Y. High-performance liquid chromatographic determination of a new b-lactamase inhibitor and its metabolite in combination therapy with piperacillin in biological material. Journal of Chromatography, n.431, p.87-101, 1988.

MAYA, MT; GONÇALMES, NJ; SILVA, NB; MORAIS, JA. Simple high-performance liquid chromatographic assay for the determination of ciprofloxacin in humam plasma with ultravioleta detection. Journal of Chromatography B, v.755, p. 305309, 2001.

MICROMEDEX, Micromedex® Healthcare Series. Inc., Greenwood Village, Colorado, 2010

OCAMPO AP, HOYT KD, WADGAONKAR N, CARVER AH, PUBLISI CV. Determination of tazobactam and piperacillin in human plasma, serum, bile and urine by gradient elution reversed-phase high-performance liquid chromatography. Journal of Chromatography, v.496, p.167-179, 1989.

PEREZ, GS. Monitoramento de antifungicos em plasma e liquor de pacientes portadores de meningite criptococica e AIDS atraves de cromatografia liquida de alta eficientica - UVIVIS. Sao Paulo, 2007. 89p. (Dissertação de Mestrado Faculdade de Ciencias Farmaceuticas - USP).

SAMANIDOU VF, EVAGGELOPOULOU EN, PAPADOYANNIS IN. Development of a validated HPLC method for the determination of four penicillin antibiotics in pharmaceuticals and human biological fluids. Journal of Sep. Science, v.29, p. 1550-1560, 2006.

SANTOS, SRCJ; CAMPOS, EV; SANCHES C; GOMEZ DS; FERREIRA, MC. Fluconazole plasma concentration measurement by liquid chromatography for drug monitoring of burn patients. Clinics, v.65, n.2, p.237-43, 2010.

STEUIJT K, SONNEVELD P. Concurrent analysis of methotrexate, trimethoprim, sulphamethoxazole and their major metabolites in plasma by high-performance liquid chromatography. Journal of Chromatography, v.422, p.328-333, 1987.

VYBIRALOVA Z, NOBILIX M, ZOULOVA J, KVETINA J, PETR P. High-performance liquid chromatographic determination of ciprofloxacin in plasma samples. Journal of Pharmacy and Biomedical Analysis, v.37, n. 5, p. 851-858, 2005.

VREE TB, VAN DER VEN AJAM, VERWEY-VAN WISSEN CPWGM, Ewijk-Beneken Kolmer EWJ, Swolfs AEM, Galen PM, Amatdjais-Groenen H. Isolation, identification and determination of sulfamethoxazole and its known metabolites in human plasma and urine by high-performance liquid chromatography. Journal of Chromatography B, v.658, p.327-340, 1994.

WEBER, A; CHAFFIN, D; SMITH A; OPHEIM KE. Quantitation of ciprofloxacin in body fluids by high-pressures liquid chromatography. Antimicrobial Agents and Chemotherapy, v.27, n.4, p.531-534, 1985.

WU SS, CHEIN CY, WEN YH. Analysis of ciprofloxacin by a simple high-performance liquid chromatography method. Journal of Chromatographic Science, vol. 46, p. 490-495, 2008 
XIA C, XIONG Y, WANG G. An improved high-performance liquid chromatographic method with a solid-phase extraction for the determination of piperacillin and tazobactam: application to pharmacokinetic study of different dosage in Chinese healthy volunteers. Biomedical Chromatography, v.21, p.680-686, 2007.

YANG G, FENG S, LIU H, YIN J, ZHANG L, CAI L. On-line clean-up and screening of oxacillin and cloxacillin in human urine and plasma with a weak ion exchange monolithic column. Journal of Chromatography B, v.854, p.85-90, 2007. 


\section{Anexo I}

Propriedades moleculares e farmacocinéticas dos Antimicrobianos (MICROMEDEX, 2010; MERCK INDEX, 2006)

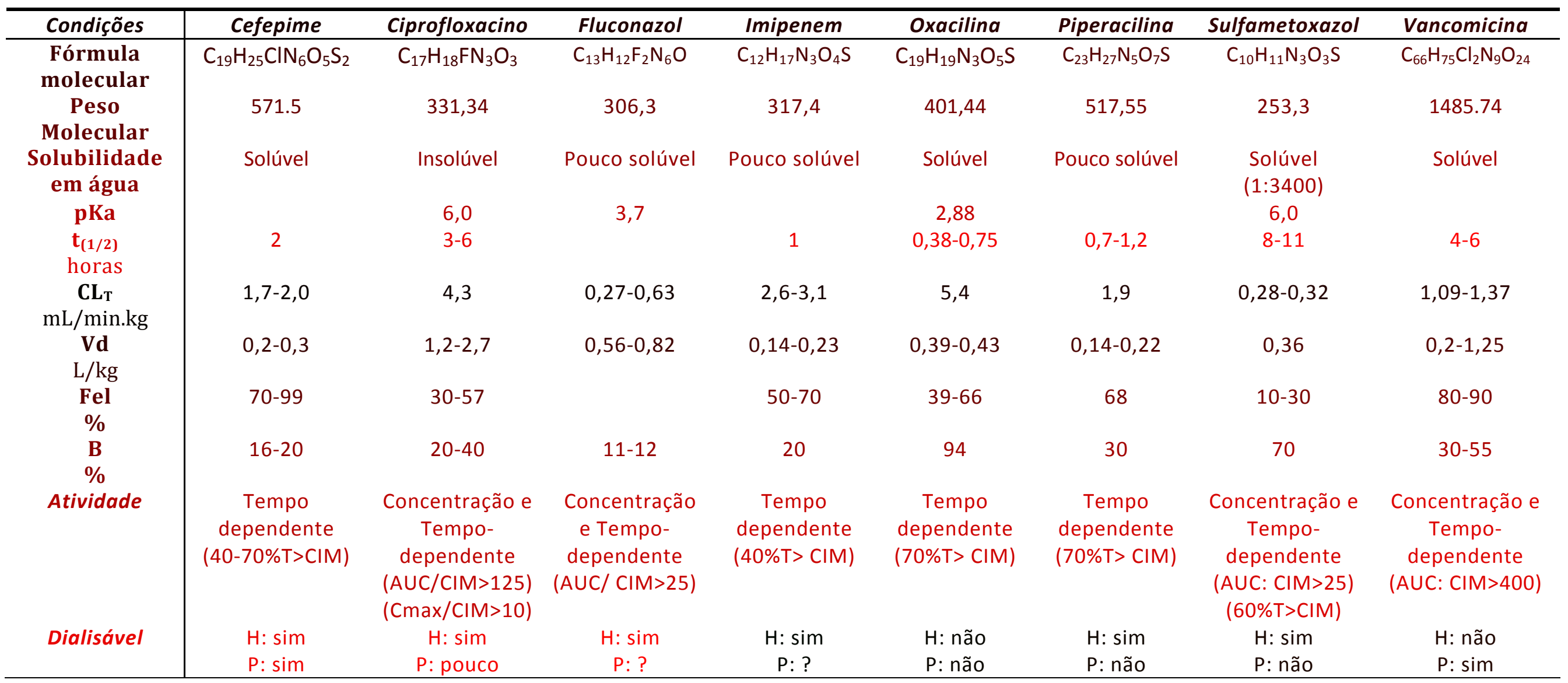

Abreviações: $t_{(1 / 2)}$ meia vida biológica, $\left(C L_{T}\right)$ depuração plasmática, $(V d)$ Volume de distribuição, Fel: fração da dose excretada pela urina, $B$ : ligação as proteínas plasmáticas, CEM: concentração eficaz mínima, CIM: concentração inibitória mínima, H: hemodiálise, P: diálise peritoneal 


\section{ANEXO II}

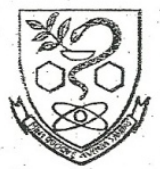

UNIVERSIDADE DE SÃO PAULO

FACULDADE DE CIÊNCIAS FARMACÊUTICAS

Comitê de Ética em Pesquisa

Ofício CEP/FCF/63/2010

São Paulo, 26 de abril de 2010.

IImo(a). Sr(a)

Cristina Sanches Giraud

Orientadora: Profa. Dra: Silvia Regina Cavani Jorge Santos

FBF

Senhor(a) Pesquisador(a)

O Comitê de Ética em Pesquisa da FCF/USP, em reunião realizada em 26 de abril de 2010, APROVOU o relatório parcial do projeto intitulado "Monitoramento terapêutico e modelagem farmacocinética de antimicrobianos em pacientes queímados. 'Follow up' da fase precoce e tardia na Unidade de Terapia Intensiva" (Protocolo CEP n 490) apresentado por Vossa Senhoria.

Atenciosamente,

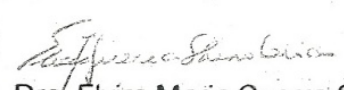

Profa. Dra. Elvira Maria Guerra Shinohara Coordenadora do Comitê de Ética em Pesquisa FCF/USP 
ANEXO III 


\section{APROVAÇÃO}

A Comissão de Ética para Análise de Projetos de Pesquisa CAPPesa da Diretoria Clínica do Hospital das Clínicas e da Faculdade de Medicina da Universidade de São Paulo, em sessão de 15/04/2009, AProvou O Protocolo de Pesquisa n 0069/09, intitulado: "MONITORAMENTO PLASMÁIICO DE ANTIMICROBIANOS EM PACIENTES QUEIMADOS" apresentado pelo Departamento de CIRURGIA, inclusive o Termo de Consentimento Livre e Esclarecido.

Cabe ao pesquisador elaborar e apresentar à CAPPesq, os relatórios parciais e final sobre a pesquisa (Resolução do Conselho Nacional de Saúde n'196, de 10/10/1996, inciso IX.2, letra "c"I.

Pesquisador (a) Responsável: Dr. David de Souza Gomez

Pesquisadores Executantes: Silvia Regina Cavani Jorge Santos, Cristina Sanches Giraud

CAPPesq, 16 de Abril de 2009

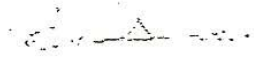

Prof. Dr. Eduardo Massad

Presidente da Comissāo de

Ética para Análise de Projetos

de Pesquisa

Comissāo de Ética para Análise de Projetos de Pesquisa do HCFMUSP e da FMUSP Diretoria Clínica do Hospital das Clinicas da Faculdade de Medicina da Universidade de São Paulo Rua Ovídio Pires de Campos,

225, $5^{\circ}$ andar - CEP 05403010 - São Paulo - SP Fone: 01130696442 Fax: 01130696492 e-mail: cappesq@hcnet.usp.br/ secretariacappesq2@hcnet.usp.br 


\title{
ANEXO IV
}

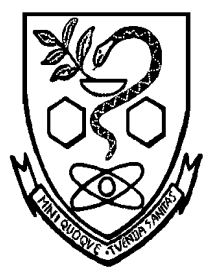

\author{
UNIVERSIDADE DE SÃO PAULO \\ FACULDADE DE CIÊNCIAS FARMACÊUTICAS \\ Av. Prof. Lineu Prestes, 580 - Bloco 13-B - $1^{\circ}$ piso \\ Cidade Universitária \\ 05508-900 - São Paulo - SP \\ Fone : (011) 818.2195 Fax: (011) 818. 2189
}

TERMO DE CONSENTIMENTO LIVRE E ESCLARECIDO

\section{I - DADOS DE IDENTIFICAÇÃO DO SUJEITO DA PESQUISA OU RESPONSÁVEL LEGAL}

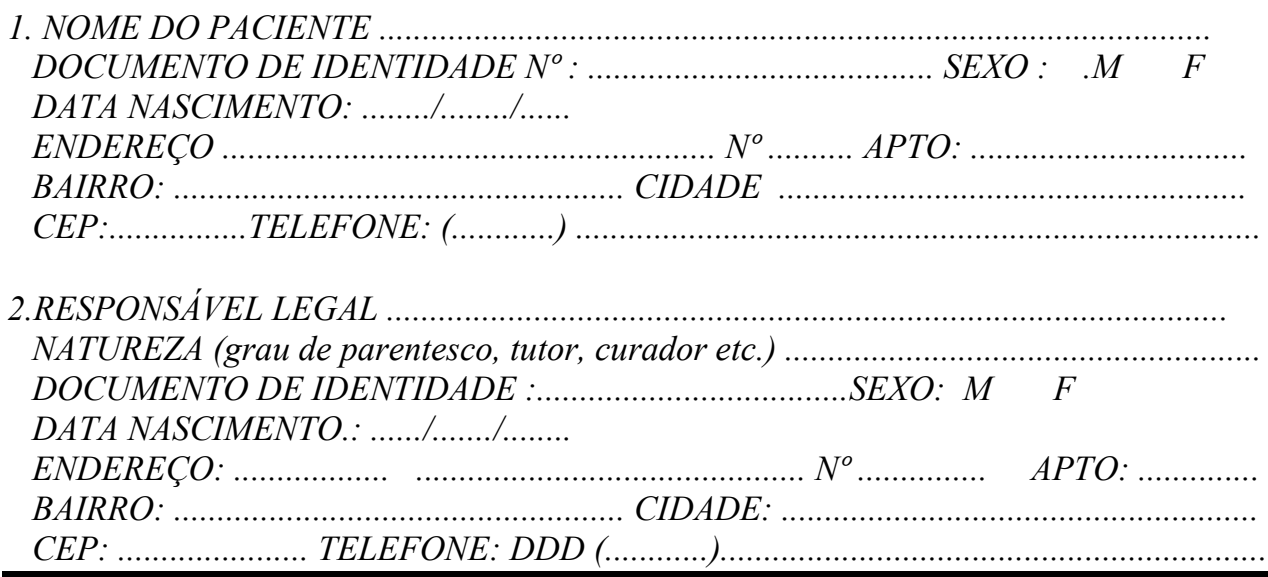

\section{II - DADOS SOBRE A PESQUISA CIENTÍFICA}

Estamos convidando o $\operatorname{Sr}($ a) a participar de um protocolo de pesquisa intitulado: $\underline{\text { Monitoramento }}$ Terapêutico e Modelagem Farmacocinética de Antimicrobianos em Pacientes Queimados. Follow up da fase precoce e tardia na Unidade de Terapia Intensiva.

O pesquisador responsável por este protocolo é a Sra. Cristina Sanches Giraud, também participarão deste estudo o Dr. David de Souza Gomes e o Dr. Edvaldo Vieira.

A pesquisa tem duração de um ano e apresenta risco mínimo à saúde.

1. Justificativa e os objetivos da pesquisa: Se o(a) senhor(a) apresentar sinais de infecção serão empregados antibióticos para o tratamento, isto é, medicações que visam tratar a infecção, conseqüente da lesão pela queimadura. Os antibióticos atualmente utilizados para esta finalidade são caspofungina, cefepime, ceftriaxona, ciprofloxacino, fluconazol, imipenem, linezolida, oxacilina, piperacilina/tazobactam, polimixina B ou E e vancomicina. O objetivo do presente estudo é avaliar se um destes antibióticos, na dose e forma utilizadas, atinge quantidades satisfatórias no sangue.

2. Procedimentos que serão utilizados: o senhor receberá o antibiótico nas doses e nos momentos normalmente utilizados pelos pacientes com infecção devido a queimaduras. Serão coletadas 6 amostras de sangue conforme segue: término da infusão (1 $1^{a}$ hora), $2^{a}, 3^{a}, 4^{a}, 6^{a}$ hora e imediatamente antes da dose subseqüente. Será coletado através de cateter venoso (dispositivo que substitui a picada) volume inferior a $15 \mathrm{~mL}$ de seu sangue para a dosagem do medicamento. No sangue será dosada a concentração do antibiótico utilizando método laboratorial específico.

3. Desconforto e riscos esperados: o risco a que o senhor será submetido é mínimo pois o procedimento é feito por profissionais altamente treinados, de forma estéril, com todo o material descartável. 
4. Benefícios que poderão ser obtidos: após os resultados de cada avaliação, caso seja necessário, serão realizados ajustes nas doses e intervalos de doses de antibióticos utilizados no tratamento de infecções em queimados. Este estudo deverá futuramente beneficiar muito outros pacientes queimados como o senhor.

5. Procedimentos alternativos que possam ser vantajosos para o indivíduo: neste caso, não há procedimentos alternativos, pois se trata de procedimento de escolha e o melhor para pacientes queimados com infecção, estes antibióticos, são os previstos no protocolo de tratamento de infecções com antimicrobianos em grandes queimados.

Além disto, garantimos que:

1. O Sr.(a) terá acesso, a qualquer tempo, às informações sobre procedimentos, riscos e beneficios relacionados à pesquisa, inclusive esclarecer eventuais dúvidas.

2. Liberdade de retirar seu consentimento a qualquer momento e de deixar de participar do estudo, sem que isto traga prejuizo à continuidade da assistência.

3. Terá a confidencialidade, sigilo e privacidade garantidos.

4. Disponibilidade de assistência na DIVISÃO DE CIRURGIA PLASTICA - HCFMUSP, por eventuais danos à saúde, decorrentes da pesquisa.

Em caso de intercorrências clínicas e reações adversas relacionadas ao estudo atual, entrar em contato com:

Cristina Sanches Giraud - Telefone (11) 3091-2189 ou (11) 7684-9233

Prof. Dr. David de Souza Gomez / Dr Edvaldo Vieira UTI Queimados

CIRURGIA PLASTICA - HCFMUSP - Fone (11) 3069-6470

\section{III - CONSENTIMENTO PÓS-ESCLARECIDO}

Declaro que, após convenientemente esclarecido pelo pesquisador e ter entendido o que me foi explicado, consinto em participar do presente Protocolo de Pesquisa

São Paulo, de de 200 .

Assinatura do sujeito da pesquisa ou responsável legal

Assinatura do pesquisador (carimbo ou nome Legível)

Para qualquer questão, dúvida, esclarecimento ou reclamação sobre aspectos éticos dessa pesquisa, favor entrar em contato com: Comitê de Ética em Pesquisas da Faculdade de Ciências Farmacêuticas da Universidade de São Paulo - Av Prof Lineu Prestes, 580 - Bloco 13A - Butantã - São Paulo - CEP 05508-900, Telefone 3091-3677 - e-mail: cepfcf@usp.br" 